APAE - 103

Copy No.

AEC Research and

Development Report

UC-81, Reactors - Power

(Special Distributión)

\title{
SUMMARY REPORT OF ANALYSIS OF PHYSICS MEASUREMENTS PERFORMED ON \\ SM-1 CORE I
}

Edited by :

L. Lois

S. Paluszkiewicz

B. E. Fried

R. 'H. Beam

L. Lois

Analysis by:

Approved by:

M. H. Dixon, Project Engineer

Issued: March 30, 1962

Contract No. AT(30-1)-2639

with U. S. Atomic Energy Commission

New York Operations Otfice

ALCO PRODUCTS, INC.

Nuclear Power Engineering Department

Post Office Box 414

Schenectady 1, N. Y. 


\section{ABSTRACT}

This report contains a comprehensive analysis of the nuclear characteristics of the SM-1 Core I. Comparison of analytical and experimental results for neutron ages and core reactivities of a variety of cases investigated shows that the MUFT III with P-1 slowing down approximation gives the best results.

At startup the core reactivity and rod bank worth under various operating conditions are investigated and compared to experiment. Core lifetime was calculated to be 16.8 MWYR compared to 16.4 MWYR experimental.

The temperature coefficient has been calculated and compared to experiment as function of burnup.

In Appendix A, flux distribution, temperature coefficient, effective delayed neutron fraction and core life are analyzed by Dr. R. L. Murray by one and two group modified theory and series expansion calculations.

\section{ACKNOWLEDGEMENT}

The analysis in this report was carried out under the direction of P.E. Bobe, who also prepared Appendix C. Dr. R. L. Murray, consultant, performed the calculations included in Appendix A. The assistance of J. G. Gallagher in editing this report is gratefully acknowledged. 


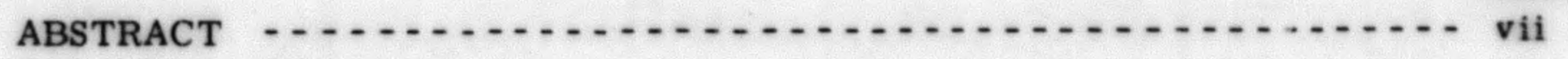

ACKNOWLEDGEMENT -

SUMMARY

INTRODUCTION

1.0 DESCRIPTION OF SM-1 CORE I 1 -

1.1 Reactor Characteristics

1.2 Source of Physics Measurements

1. 3 Dimensions and Material Content of SM-1 Core I

1.4 References

2. 0 CALCULATIONAL MODELS AND NUCLEAR DATA

2.1 Modified Two-Group Theory

2.1.1 Fast Group Constants

2.1.2 Thermal Properties .................... 2-2

2.1.2.1 Fixed Fuel Elements -........... 2-2

2.1.2.2 Control Rod Fuel Elements -......... 2-4

2.1.2.3 Neutron Temperature -........... 2-4

2.2 Core Geometry Considerations $2 . .62-6$

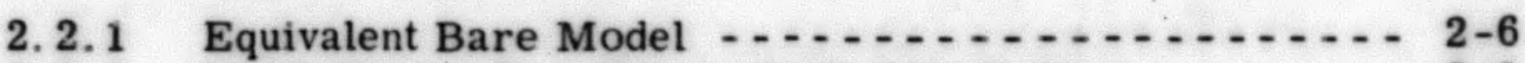

2.2.2 Multi-Region One-Dimensional Calculations ....... 2-8

2.2.2.1 VALPROD -................... 2-8

2.2.2.2 WINDOWSHADE -.............. 2-9

2. 2. 3 Analytical, Two-Region, Two-Group Calculations -... 2-9

2. 2.4 Multi-Region, Two-Dimensional Calculations ...... 2-9

2. 2.5 Multi-Region, One-Dimensional Depletion Calculations - 2-9

2. 3 Special Preparation IBM-650 Program

2.3.1 Program 50 (PROMPT - I) 


\section{TABLE OF CONTENTS (CONT'D)}

Page

2:4 Nuclear Data ..................... 2-10

2.4.1 MUFT-III Cross Section Files 2.......... 2-10

2.4.2 MUFT-V Cross Section Files -.......... 2-10

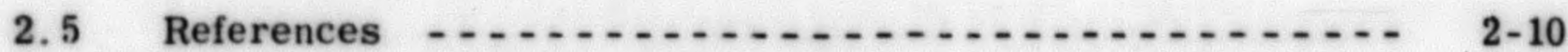

3. 0 REVIEW OF CALCULATIONAL MODELS $\ldots . . . . . . .1$

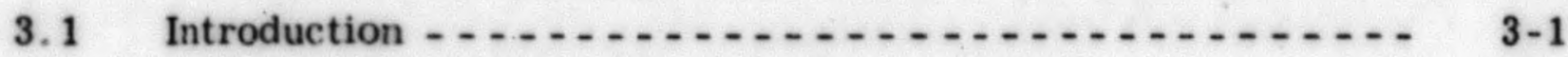

3. 2 Effect of Calculational Models on Neutron Age

3. 2.1 Systems Investigated

3.2.2 Calculational Approach _............. 3-2

3.2.3 Results (........... 3-2

3. 2.4 Conclusions

3. 3 Effect of Fast Group Calculational Model on Core Reactivity

3. 3.1 Cores Types Investigated

3.3.2 Results .............. 3-12

3.3. 3 Conciusions

3. 4 Effect of Fast Group Calculational Model on Fraction

of Thermal Fissions - . . . 3-23

3.4.1 Experimental Data ................ 3-23

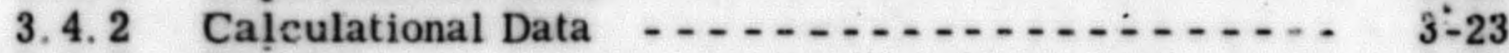

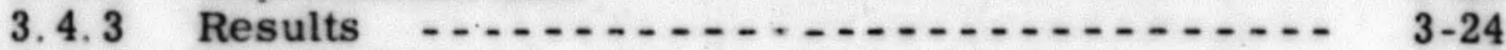

3.4.4 Conclusions -.................. 3-25

3. 5 Effect of Fast Calculations on Fast Flux Distributions _.

3.5.1 Experimental Data - . . 2. 3-25

3.5.2 Results ........

3.5.3 Conclusions

3. 6 Effect of Thermal Model on Reactivity of SM-1 Core I _.

3.6.1 Introduction -...

3.6.2 Results .........

3.6.3 Conclusions .......... 


\section{TABLE OF CONTENTS (CONT"D)}

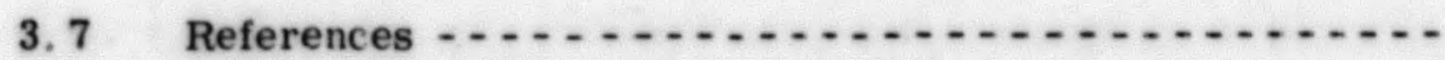

4. 0 CORE CHARACTERISTICS AT STARTUP

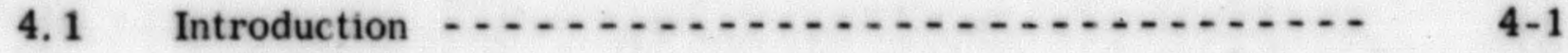

4.2 Core Reactivity

4. 2.1 Geometrical Models ................. 4-2
4.2.1.1 Two-Dimensional Model PDQ-....

4.2.1.2

One-Dimensional Model

4.2.1.3

VALPROD

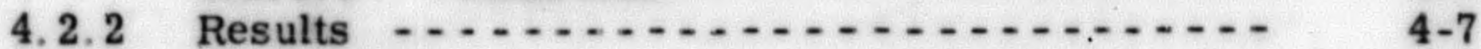

4.2.3 Conclusions (.................... 4-8

4. 3 Bank Position ...

4.3.1 Analytical Resuits ...... . . . 4-8

4.3.2 Conclusions (.................... 4-10

4. 4 Control Rod Worth in Poisoned Cores ... 4-10

4.4.1 Experimental Results (............... 4-10

4.4.2 Analytical Results .................. 4-13

4.4.3 Conclusions ....................... 4-14

45 Summary .................... 4-15

4. 6 References ... 4 4-15

5. 0 SM -1 CORE I BURNUP CALCULA TIONS

5.1 Review of Previous Calculations ......... 5-1

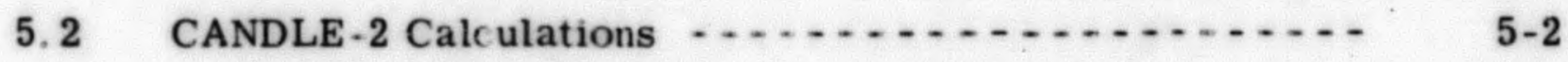

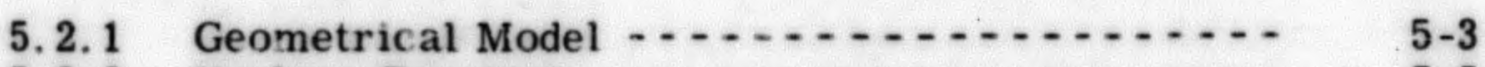

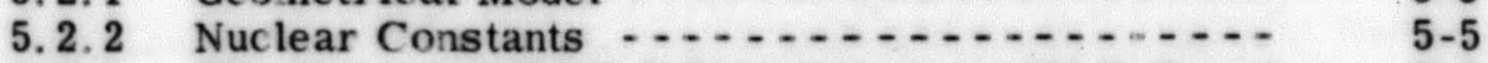

5.2.3 Results of CANDLE-2 Calculations on SM-1 Core I 5-6

5. 2.4 Core Life ....................... 5-6

5.2.5 Fuel and Boron Distribution as Function of Core

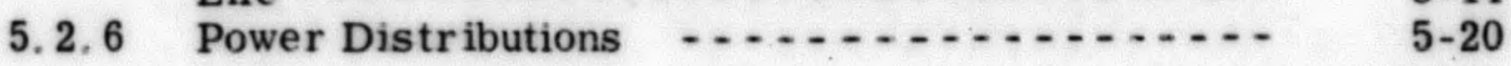




\section{TABLE OF CONTENTS (CON'T'D)}

Page

5. 2. 7 Change in 5 Rod Bank Worth

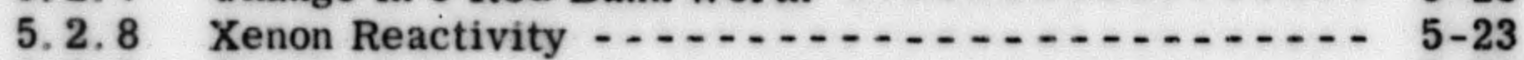

5.2.9 Conclusions.

5.3 Estimate of Core Changes at 10.5 MWYR of Core Life

5. 3.1 Buildup of U-236 in SM-1 Core I

5.3.2 Conclusions

5.4 Summary

5.5 References

6. 0 TEMPERATURE COEFFICIENT

6.1 Background $1 . .6-1$

6.2 Derivation of the Analytical Expression for

Temperature Coefficient

6. 3 Comparison at Calculated and Experimental

Temperature Coefficients

6. 4 Temperature Coefficient as a Function of Energy Release - - 6-7

6.5 Conclusions $5.6 .6-7$

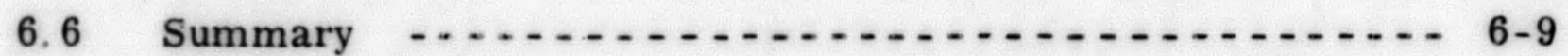

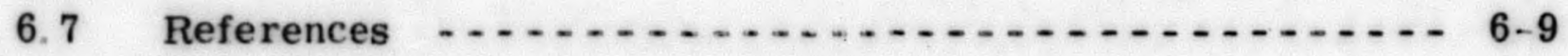

7. 0 CONCLUSIONS AND RECOMMENDATIONS

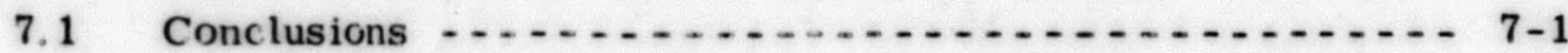

7.2 Recommendations 


\section{TABLE OF CONTENTS (CONT'D)}

APPENDIX A - Prediction of SM-1 Core I Burnup Characteristics

Using Series Technique

A. 1 Prediction of Core Life by Burnup Theory -

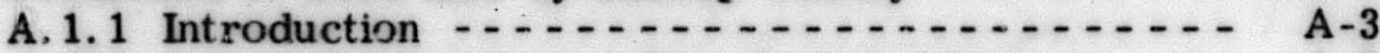

A. 1.2 Initial Criticality and Flux Distributions - - - - A-3

A. 1.3 Perturbation Theory - 3 .

A. 1.4 Burnup Theory

A. 1. 5 Reactivity Due to Rod Motion -....... A-10

A.1. 6 Calculation of System Group Constants--.--.- A-12

A. 1. 7 Region Group Constants -

A 1.8 Initial Criticality and Flux Calculations ....- A-15

A. 1.9 Summary ................... A-15

A. 2 Flux Distribution and Rod Bank Calculation - . . . . A-16

A. 2. 1 Rod Bank Position - ............ A-16

A. 2. 2 Variation of Core Reactivity with Fuel

Consumption - . . . A-21

A. 2. 3 Combined Bank and Burnout Reactivities -...- A-24

A. 2. 4 Summary .................. A-24

A. 3 Temperature Coefficient Analysis _. A-24

A. 3.1 Introduction $\ldots \ldots \ldots$ A-24

A. 3.2 Theory $\ldots . . .6$ A-27

A. 3. 3 Calculations -...

A. 3.4 Summary -...

A. 4 Steady State Xenon Poisoning

A. 4. 1 Introduction

A. 4.2 Analysis - .

A. 4. 3 Constants for $\mathrm{Xe}^{135}$ Calculations - . . - . . A -34

A. 4. 4 Combined Burnup, Fission Product and
Xe Reactivity

A. 4. 5 Summary

A. 5 Effective Delayed Neutron Fraction as a Function

of Bank Position .

A. 5.1 Introduction

A. 5.2 Critical Conditions $2 \ldots \ldots \ldots$ A -37

A. 5.3 Effective $\beta$ Analysis

A. 5. 4 Calculations -............. A-41

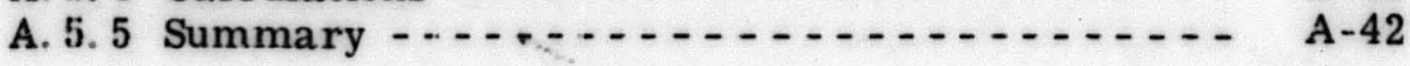




\section{TABLE OF CONTENTS (CONT'D)}

Page

APPENDIX B - CANDLE-2 Input for Axial SM-1 Core I - $440^{\circ}$ F- - - - B-1

APPENDIX C - Reference Parameters for SM-1 Core I - . . . . . - C-1

APPENDIX D - Discussion of Xe Cross Section and Non-Uniform Xe Factor .......... D-1

APPENDIX E - Nomenclature -

APPENDIX F - The MUFT-III Cross Section Files - .

xiv 


\section{LIST OF ILLUSTRATIONS}

2.1 Subdivision of a Fixed Fuel Element

2.2 Subdivision of a Control Rod Fuel Element

2.3 SM-1 Core I Layout

3.1 Energy Distribution of Fission Neutrons

3.2 Energy Spectrum From $\mathrm{Po}^{210}-\propto-\mathrm{Be}$ Neutron Source

3. 3 Fast Flux vs. Radial Position - SM-1 Core I, $68^{\circ} \mathrm{F}$

4.2 Rod C Integral Worth - SM-1 ZPE-2

5.2 Thermal Absorption Cross-Section of Fission Products in SM-1 at $440^{\circ} \mathrm{F}$ vs. Fuel Burnup

5. 3 SM-1 Core I Radial Burnup, $440^{\circ}$ F, Equilibrium Xenoi

5. 4 Radial Burnup SM-1 Core I, $440^{\circ} \mathrm{F}$, Equilibrium Xenon Normalized to Experimental Reactivity at 1.4 MWYR

5. 5 SM-1 Core I Control Rod Bank vs. MWYR $-440^{\circ} \mathrm{F}$, Equilibrium Xenon

5. 6 Excess Reactivity as a Function of Energy Release SM-1 Core I, $440^{\circ} \mathrm{F}$, Equilibrium Xenon

5. 7 SM-1 U-235 and B-10 Radial Burnup at 9.2 MWYR and 15. 7 MWYR - All Fixed Elements with $\sum_{a}$

5. 8 SM-1 Core I Axial Variation of Burnup Fraction of B-10 and U-235 at 9.2 and 15.7 MWYR

5.9 Measured Fuel Burnup in Element 45 of SM-1 Core I After 16.4 MWYR of Energy Release

5.10 Radial Power Distribution of Various Periods of Core Burnup in SM-1 Core I $-440^{\circ} \mathrm{F}$ 


\section{LIST OF ILLUSTRATIONS. (CONT" D)}

5.11 SM-1 Axial Power Distribution $-440^{\circ} \mathrm{F}$ Equilibrium Xenon

5.12 SN -1 Radial Power Distribution $-440^{\circ} \mathrm{F}$, Equilibrium Xenon - All Fixed Elements - $\Sigma_{\mathrm{a}}$

5.14 Transient Xenon Reactivity in SM-1 Core I at 12 MWYR

A. 10 Critical Bank Position During Core Life Equilibrium 


\section{LIST OF ILLUSTRATIONS (CONT"D)}

Figure

\section{Title}

Page
A. 11
Variation of $\left(\beta_{\mathrm{e}} / \beta\right)^{-1}$ and $\beta_{\mathrm{eff}}$ with Bank Position
A -43
D. 1
Effective Xe-135 Cross Section $\hat{\sigma}$ a vs. Effective Neutron Temperature $\mathrm{T}_{\mathrm{n}}{ }^{\circ} \mathrm{K}$
D-2
D. 2
Average Xe-135 Absorption vs. U-235/H Atom Ratio
D-3 


\section{LIST OF TABLES}

Table

Title

Page

1.1 Dimensions and Material Content of Core

3.1 Neutron Ages of Fission Neutrons in Pure Water Using Fast Files and Slowing-down Model

3.2 Effects of Fast Calculations on Fast Properties of Water Using Fission Neutrons, Fast.Files and Slowingdown Model

3. 3 Neutron Ages of Po-Be Neutrons in Iron-Water Mixtures Using Fast Files and Slowing-down Model

3. 4 Effects of Fast Calculations on Fast Properties of Iron-Water Mixtures Using Po-Be Neutrons

3. 5 Effects of Fast Calculations on Fast Properties of Iron-Water Mixtures Using Po-Be Neutrons

3. 6 Effects on Age of Eliminating Capture and Inelastic Cross Sections of Oxygen

3. 7 Atomic Number Densities (atoms $\left./ \mathrm{cm}^{3}\right) \times 10^{24}$ of Core Types - Investigated

3. 8 Reactivity Analys is of WAPD Homogeneous Critical Core No. 1 (\#15) - (No B-10 or Stainless Steel), $68^{\mathrm{O}} \mathrm{F}$

3. 9 Reactivity Analysis of WAPD Homogeneous Critical Core No, 2 (\#21) - (No B-10 or Stainless Steel), $68^{\mathrm{O}} \mathrm{F}$

3.10 Reactivity Analys is of ORNL Critica! Core No. 3 ("Light Loading") - (No. B-10), $68^{\circ} \mathrm{F}$

3.11 Reactivity Analys is of Spert-III Critical Water Height Core "A" (Core No. 4) - (No B-10), $80^{\circ} \mathrm{F}$

3.12 Excess Reactivity $(\% \rho)$ of Critical SM-1 Core I (Core 5) $68^{\circ} \mathrm{F}$, (10 Fixed Plus 7 Control Rod Fuel Elements 3-18

3.13 Excess Reactivity $(\%, \rho)$ of SM-1 Core I $3-18$ 


\section{LIST OF TABLES (CONT" D)}

Table

Title

Page

3.14 Reactivity Analys is of SM-1 Core I, $68^{\circ} \mathrm{F}$ (All 45

Fixed Fuel Elements

3.15 Reactivity Analysis of SM-2 Experimental Core (All 45 Fixed Elements with No B-10), 680F

3.16 Fraction of Thermal Fissions for the SM-1 ZPE Core I for Various Axial and Radial Positions

3.17 Comparison of Fraction of Thermal Fission, SM-1 Core I ZPE-2 (Clean), $68^{\circ} \mathrm{F}$

Fast and Thermal Constants and Reactivity $\rho$ for the SM-1

4. 1 Experimental Initial Five Rod Bank Positions and Excess Core Reactivities of the SM-1 Core I, 0 MWYR

Number Densities (Atoms/CC x 10-24) for SM-1 Core I $\left(\mathrm{T}=68^{\circ} \mathrm{F}\right)$

4. 3 Number Densities (Atoms/CC $\times 10^{-24}$ ) for SM-1 Core I $\left(\mathrm{T} \cdot 440^{\circ} \mathrm{F}\right)$

4.4 Reflector Savings and Bucklings for SM-1 Core I

4. 5 Fast Macroscopic Cross Sections for SM-1 Core I $\left(\mathrm{T}=68^{\circ} \mathrm{F}, \mathrm{E}_{\mathrm{n}}=0.0331 \mathrm{ev}\right)$

4. 6 Fast Macroscopic Cross Sections for SM-1 Core I $\left(\mathrm{T}=440^{\circ} \mathrm{F} \mathrm{E}_{\mathrm{n}}=0.0549 \mathrm{ev}\right)$

4. 7 Thermal Microscopic Cross Sections for Coolant Temperature, $68^{\circ} \mathrm{F}$ (Effective Neutron Temperature, $0.0331 \mathrm{ev}$ ) 4-5

4. 8 Thermal Microscopic Cross Sectionsfor Coolant Temperature, $440^{\circ} \mathrm{F}$ (Effective Neutron Temperatures, 0.0549 ev) 4-5

4. 9 Thermal Macroscopic Cross Sections for SM-1 Core I $\left(\mathrm{T}=68^{\mathrm{O}} \mathrm{F}, \mathrm{E}_{\mathrm{n}}=0.0331 \mathrm{ev}\right)$

4. 10 Thermal Macroscopic Cross Sections for SM-1 Core I $\left(\mathrm{T}=440^{\circ} \mathrm{F}, \mathrm{E}_{\mathrm{n}}=0.0549 \mathrm{ev}\right)$ 


\section{LIST OF TABLES (CONT'D)}

$\underline{\text { Table }}$

$\underline{\text { Title }}$

Page

4.11 Measured and Calculated Core Reactivity of SM-1 Core I ( O MWYR)

4.12 Core Reactivity of SM-1 Core I, 0 MWYR

4.13 SM-1 Core I Five and Seven Rod Bank Position for Various Core Conditions

4.13a

SM-1 Core I $\sum_{p}$ and $\sum_{\mathrm{a}}^{\text {sub }}$ for Various Conditions

4.14 Fast and Thermal Constants of Absorber Section 4-14

4.15 Integral Worth of Central Control Rod 4-14

5.1 Review of Burnup Calculations for SM-1 Core I 5-1

5.2 Advantages and Disadvantages of CANDLE-2 Compared with NUB-1

5.3 Equivalent Uniform Cross-Section for Control Rod Fuel Elements and Control Rod Absorbers

Number Densities for Regions of SM-1 Core I at $440^{\circ} \mathrm{F}$ (atoms $/ \mathrm{cm}^{3}$ )

5.5 Three Fast Group Data for CANDLE-2 Code, SM-1 Core I at $440^{\circ} \mathrm{F}$

5. 6 Thermal Microscopic Cross Sections

5. 7 Comparisons of Coalescing Schemes of CANDLE-2, MUFT-III P1-SG and MUFT-III P-1 Codes - SM-1 Core I at $440^{\circ} \mathrm{F}$ 5-12

5. 8 Results of Comparison of Coalescing Schemes for Pure Water Reflector Region, $440^{\circ} \mathrm{F}$

6.1 Comparison of Calculated and Experimental Temperature Coefficients

6. 2 Experimental and Calculated Temperature Coefficients for SM-1 Core I 


\section{LIST OF TABLES (CONT'D)}

Table

$\underline{\text { Title }}$

Page

B. 1 Alco Element Numbers for the CANDLE-2 IBM-704 Code

B-1

C. 1 Material and Geometrical Data for SM-1 Core Element

C-2

C. 2 Atomic Number Densities for SM-1 Core I Elements (0 MWYR, $1200 \mathrm{psia)}$

C. 3 Thermal Parameters for SM-1 Core I Elements (0 MWYR, 1200 psia)

C. 4 Fast Parameters of Cold Clean SM-1 Core I Elements (O N.WYR, T $\left.=68^{\circ} \mathrm{F}, 1200 \mathrm{psia}\right)\left(\mathrm{B}=0.0845 \mathrm{~cm}^{-1}\right) \quad \mathrm{C}-7$

C. 5 Fast Parameters of Hot Clean SM-1 Core I Elements (0 MWYR, T $\left.=440^{\circ} \mathrm{F}, 1200 \mathrm{psia}\right)\left(\mathrm{B}^{2}=.006594 \mathrm{~cm}^{-2}\right)$

C. 6 Xenon Parameters for SM-1 Core I, 0 MWYR $\left(\mathrm{T}=.440^{\circ} \mathrm{F}, \mathrm{E}_{\mathrm{n}}=0.0549 \mathrm{ev}\right)$ 
A reference calculational model for analysis of SM-1 Core I was developed by application of P-1 and P-1 S. G. slowing down models and MUFT-III and MUFT-V nuclear data to a wide variety of experiments. The analyses indicate P-1 slowing down model and MUFT-III nuclear data yielded the best agreement between calculated and measured reactivity. Calculations indicated that the P-1 MUFT-III model gave the best agreement with the measured neutron age in water. The thermal constants were calculated by use of cross sections evaluated to the effective temperature for the use of $\mathrm{P}_{3}$ theory. The reference model gave good agreement with the fraction of thermai fissions below cadmium cutoff and the worth of the central control rod in fully poisoned SM-1 cores.

Calculations performed using the reference model and one-and two- dimensional diffusion theory indicated good agreement between themselves and with experimental reactivity for SM-1 Core I at startup, $68^{\circ} \mathrm{F}$ and $440^{\circ} \mathrm{F}$. Application of one-dimensional Windowshade type calculations indicates that the reference model can predict startup bank positions within 1.4 inches.

The use of the CANDLE-2 depletion code indicated a core lifetime of 16. 8 MWYR compared with a measured value of 16.4 MWYR. Reasonable agreement was obtained with the burnup distribution of one element from SM-1 Core I. Good agreement was obtained with xenon steady state and transient reactivity.

A simplified model for calculation of the temperature coefficient was developed and applied to SM-1 Core I. Perturbation theory was utilized to predict core life, steady state, temperature coefficient and flux distribution. Good agreement was found in the case of core life prediction. Perturbation theory was utilized to predict an effective delayed neutron fraction of 0.0078 . 


\section{INTRODUCTION}

The analysis in this report was performed under Task 2 of the Program for Engineering Support and Development of Army PWR Power Plants. * The purpose of the study is to calculate the initial and burnup nuclear behavior of the SM-1 Core I and to compare to measurements. The results will be used to form a basis for improvement in prediction of reactor core performance and as a basis for the analysis of replacement cores.

SM-1 Core $I$ is one of the first power reactor cores and for that reason it has been the subject of a fairly comprehensive set of physics measurements to establish all important core physics characteristics during core burnout.

The results of these measurements are published in a companion report, APAE-96, "Summary of Physics Measurements on SM-1 Core 1." Part of this report is devoted to a review of the calculational models employed to predict the reactivity of the SM-1 Core I and various similar types of cores in order to select the most accurate model. The analysis employs modified two group theory. Fast constants are obtained using the MUFT Code and thermal constants obtained using $\mathrm{P}_{3}$ theory. The core nuclear characteristics are subsequently analyzed and compared to measured data at startup. The CANDLE-2 code was utilized to calculate the burnup behavior of the core. Certain special analytical investigations were performed by Dr. R. L. Murray, using perturbation techniques primarily.

It must be recognized that due to the time schedule much of the analysis presented in this report was performed simultaneously. This was a difficulty which could not have been avoided; however, whenever an analysis was performed using core nuclear parameters different from the "reference set" as given in Appendix C, attempts were made to determine the effects upon the calculated results.

* The Program plan was issued as AP Note-286, October 10, 1960. 


\section{0 DESCRIPTION OF SM-1 CORE I}

\subsection{REACTOR CHARACTERISTICS}

The SM-1 is a pressurized water reactor which generates about $1900 \mathrm{ekw}$ net of electricity from $10 \mathrm{tMW}$. (1)* SM-1 Core I employed fully enriched uranium as fuel in the form of $\mathrm{UO}_{2}$ dispersed in 0,030 in. thick stainless stee! fuel plates. Boron in the form of $\mathrm{B}_{4} \mathrm{C}$ is also incorporated in the fuel plates to act as a burnable poison. These fuel plates were assembled into elements by brazing. The core was composed of 38 fixed eiements and 7 control rod fuel elements of the follower type. The core contains $22.5 \mathrm{Kg}$ of U-235 and $1.57 \mathrm{gm}$ of B-10. The core is cooled by approximately $4000 \mathrm{gpm}$ of water at $1200 \mathrm{psi}$ pressure and a mean temperature of $440^{\circ} \mathrm{F}$.

Fig, 1.1 shows a photograph of a fixed element with the end box removed. Fig. 1.2 shows a control rod fuel element, absorber section and cap as well as the control rod tube. Thirty-eight fixed fuel elements and 7 control rod assemblies are assembled to form the reactor core as shown in Fig. 1.3. The core is approximately a 22 in. right cylinder. The core is surrounded by an essentially infinite water reflector in the radial direction and an axial reflector which consists of a mixture of stainless steel and water. The control rods are adjusted so that rods 1, 2, 3, 4, and C (see Fig. 1,3) are positioned as a bank while control rods A and B are essentially fully withdrawn. Neutrons were provided for initial startup by a 15 curie Po-Be source. After initial operation, startup neutrons are provided by $(\gamma, n)$ reactions on a 3 in, $x 3$ in, $x 0.5$ in. beryllium block attached to the core skirt.

\subsection{SOURCE OF PHYSICS MEASUREMENTS}

A report documenting all the physics measurements performed on SM-1 Core I has been issued as APAE-96, "Summary Report of Physics Measurements on SM-1 Core I." (2) This report includes measurements on SM-1 Core I and large number of measurements performed on SM-1 ZPE Core I at the Alco Critical Facility. That core was made to identical specifications as SM-1

Core $I$ and has been proven through measurements to be essentially identical.

\subsection{DIMENSIONS AND MATERIAL CONTENT OF SM-1 CORE I}

The most important dimensions and material content of SM-1 Core I are given in Table 1.1. A comprehensive list of material and geometrical data for SM-1 Core $I$ is given in Appendix C.

* References are in the last subsection of each main section of the report. 


\subsection{REFERENCES (1.0)}

1. Gallagher, J. G. "Summary of Reactor Design Information From Three-Years Operation of a Small PWR," IAEA, Vienna 1960 (also APAE Memo 273, September 9, 1960.

2. Weiss, S. H. , "Summary Report of Physics Measurements on SM-1 Core I," APAE-96, February 6, 1962. 
TABLE 1.1

\section{DIMENSIONS AND MATERIAL CONTENT OF CORE}

Dimensions of Core

\section{Active length \\ Equivalent diameter \\ Cell size}

Numberof Cells

Configuration

Fixed Element

$$
\begin{aligned}
& \text { Number } \\
& \text { Number of plates } \\
& \text { Plate dimension } \\
& \text { Weight of } \mathrm{U}^{235} \\
& \text { Weight of } \mathrm{U}^{0} \\
& \text { Weight of } \mathrm{B}_{1} 10 \\
& \text { Weight of } \mathrm{B}_{4} \mathrm{C}
\end{aligned}
$$

Control Rod Element

$$
\begin{aligned}
& \text { Number } \\
& \text { Number of plates } \\
& \text { Plate dimensions } \\
& \text { Weight of } \mathrm{U}^{235} \\
& \text { Weight of } \mathrm{U}_{2} \\
& \text { Weight of } \mathrm{B}_{10} \\
& \text { Weight of } \mathrm{B}_{4} \mathrm{C}
\end{aligned}
$$

Control Rod Absorber

Number of plates (box) Weight of $\mathrm{B}^{10}$

in.

gm

gm

$\mathrm{gm}$

gm

in.

in.

n.

45

$7 \times 7$ with corners missing

21. 75

22. 2

2. $9375 \times 2.9375$

\section{$0.030 \times 2.778 \times 2.3$}

515. 16

630.36

0. 3605

2. 626

2. 132 $\mathrm{gm}$

\section{7}

16

$0.030 \times 2.56 \times 23$

gm

gm

$\mathrm{gm}$

gm

417.76

512. 16

0. 2926

4

56. 4

22. 50

15. 75

208. 9

111. 08 


\section{0 CALCULATIONAL MODELS}

The calculational model employed in this report is two-group theory using fundamental nuclear data to determine group constants. The equations and codes used to determine group constants and to solve the diffusion equations are described in this section. The accuracy of the equations and codes is assessed in Section 3.0 by their application to a wide variety of experiments.

\subsection{TWO-GROUP THEORY ${ }^{(1)}$}

The SM-1 Core I has an initial loading of $22.5 \mathrm{~kg}$ of U-235 in. a $22.2 \mathrm{in}$. diameter cylinder of $21.75 \mathrm{in}$. height. This results in an average fuel concentration of $4.1 \times 10^{24}$ atoms $/ \mathrm{cm}^{3}$ of $\mathrm{U}-235$ and $\mathrm{H} / \mathrm{U}-235$ ratio of 107 (at $440^{\circ} \mathrm{F}$ ). As a result of this U-235 and $\mathrm{H}$ concentration it has an appreciable amount of resonance absorption and fission. The general two-group equations, including resonance fission and absorption are:

$$
\begin{aligned}
& D_{f} \nabla^{2} \emptyset_{f}(\bar{r})-\sum_{R} \emptyset_{f}(\bar{r})+S_{f}(\bar{r})=0 \\
& D \nabla^{2} \emptyset(\bar{r})-\sum_{a t h} \emptyset(\bar{r})+s_{t}(\bar{r})=0
\end{aligned}
$$

where the source terms are defined as,

$$
\begin{aligned}
& s_{\mathrm{f}}(\overline{\mathrm{r}})=\mathrm{K}_{\mathrm{th}} \sum \mathrm{a}_{\mathrm{th}} \emptyset(\overline{\mathrm{r}})+\mathrm{K}_{\mathrm{f}}(1-\mathrm{P}) \sum \mathrm{R}_{\mathrm{f}}(\overline{\mathrm{r}}) \\
& \mathrm{s}_{\mathrm{t}}(\overline{\mathrm{r}})=\mathrm{P} \sum \mathrm{R}_{\mathrm{f}}(\overline{\mathrm{r}})
\end{aligned}
$$

and the effective removal cross section, $\sum_{R^{\prime}}$ is given by,

$$
\sum R=D_{f} / \tau
$$

The remaining parameters are defined in Appendix E.

With the selection of this model for the treatment of SM-1 Core I it was first necessary to evaluate the effect of various calculational models for the fast and slow coefficients on the agreement of calculation and measurement: 


\subsection{Fast Group Constants}

The fast group constants $\tau, \mathrm{D}_{\mathrm{f}}, \mathrm{K}_{\mathrm{f}}$, and $\mathbf{P}$ are calculated employing the MUFT-III, IBM- 650 code $^{(2)},(3)$ which sulves the Fourier transform of the slowing down distribution from a point source. Two approximations $\mathbf{P}-1$ and P-1 S. G. were investigated.

Microscopic cross section data, atomic concentrations, and the total buckling are the only input required for the calculation. The 59 group cross sections and inelastic scattering matrices used in the MUFT-III calculations are shown in Appendix E.

In this report, the lower limits of the fast group are taken as $0.196 \mathrm{ev}$ at $68^{\circ} \mathrm{F}$ and $\left.0.248_{4}\right)^{\mathrm{v}}$ at $440^{\circ} \mathrm{F}$. The cutoff energy has been shown to have little effect on $k_{\text {eff }}$.

\subsubsection{Thermal Properties}

Intercell measurements made in the SM-1 critical experiment ${ }^{(5)}$ and the zero power experiment ZPE-1 ${ }^{(6)}$ indicate a significant variation of thermal flux within the fuel element cell. An accurate treatment of these flux variations is necessary if the thermal utilization is to be calculated accurately. The variation of innercell flux, both perpendicular and parallel to the fuel plates in the fixed elements, was calculated using a one velocity P-3 approximation to the Boltzmann equation. The determination of the velocity to be used is discussed in Section 2.1.2.3. The calculational procedure used was basically a superposition of two P-3 solutions to the one-dimensional single velocity transport equation. Murray provides a good description of the one-dimensional problem. (1) This theory has been programmed on the IBM- 650 machine for APPR- type fuel elements. (7) For the control rod fuel elements, a one-velocity P-3 calculation in cylindrical geometry was employed. This theory has also been programmed on the IBM- 650 for APPR-type control rod fuel elements. (8)

\subsubsection{Fixed Fuel Elements}

Figure 2.1 is a drawing of a typical SM-1 fixed fuel element. The following nomenclature is used for the various regions:

PLATE: This includes the meat and clad, but does not include the dead edges. Properties for this region are calculated as if the clad and meat are homogeneously mixed. The plate width is G.

CHANNEL: This includes material between the fuel plates. The width of this region is $G$, the same as for the fuel plates. Properties for this region are calculated on a homogenized basis.

ACTIVE: This is a mixed region consisting of the fuel plates and the channel. Its width is $\mathrm{G}$ and it is designated as region \#2. 


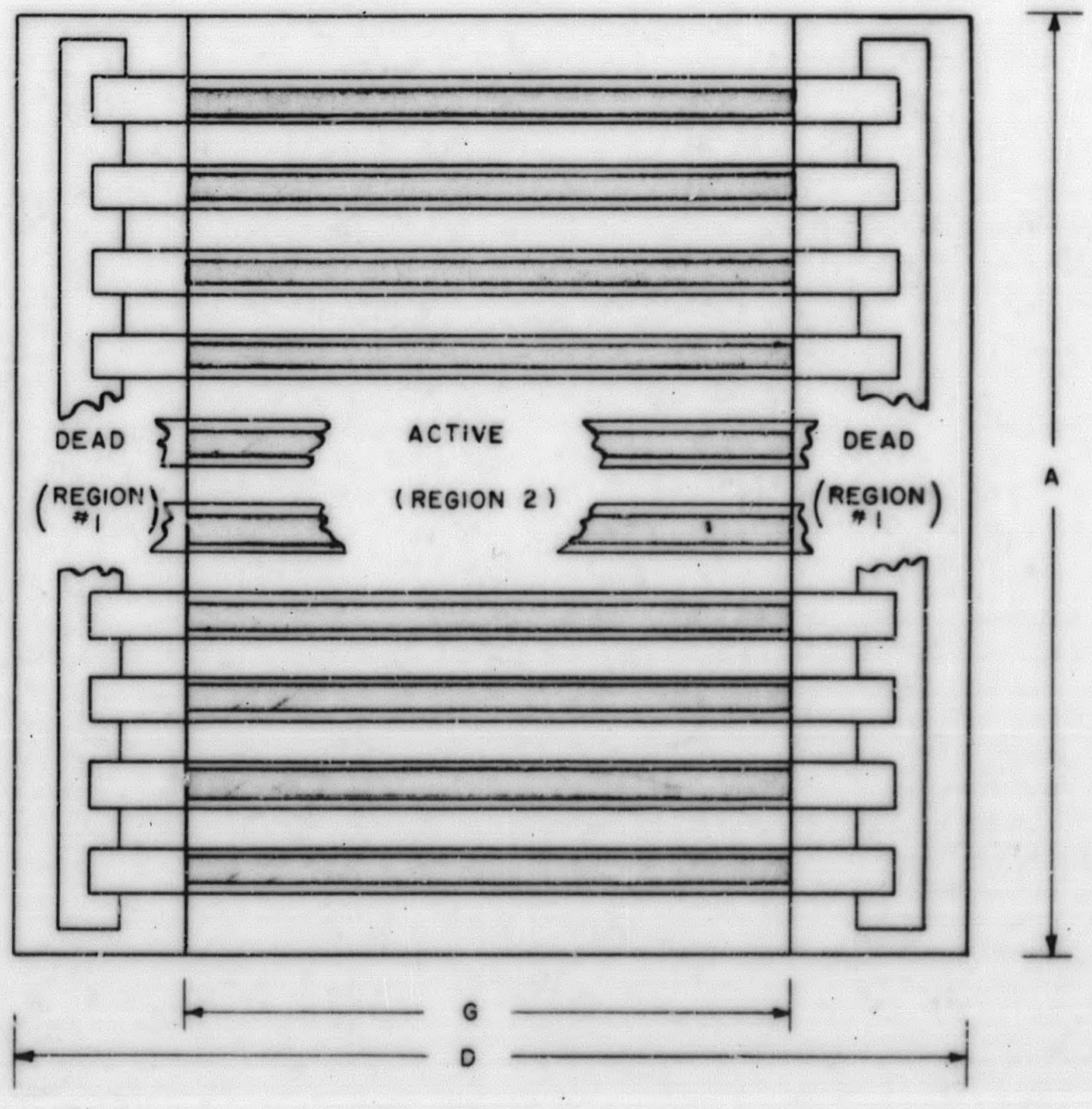

FIGURE. 2. 1

SUBDIVISION OF A

STATIONARY FUEL ELEMENT 
DEAD. This region includes the fuel plate dead edges, side plates, and all of the water in the element that is not in the channels. Its total width is D-G and it is referred to as region \#1, its properties are calculated as if all materials in the region are homogeneously distributed.

FUEL ELEMENT CELL: This includes all regions. It is made up of the active plus the dead regions.

The code ${ }^{(7)}$ first calculates the thermal flux distribution normal to the fuel plates. The flux is normalized to one in the active region. Average cross sections are calculated for the active region. Next the thermal flux distribution in the active and dead regions is calculated due to a uniform source of 1 neutron per $\mathrm{cm}^{3}$ in the dead region. Then the thermal flux distribution in the two regions is calculated due to a uniform source of 1 neutron per $\mathrm{cm}^{3}$ in the active region. The latter two solutions are weighted and superimposed to obtain the overall flux distribution parallel to the fuel plates. The relative source strength in each region is assumed proportional to the volume fraction of water. The relative flux is normalized to one in the entire cell. From the thermal fiux distribution normal and perpendicular to the fuel plates, the nuclear parameters for the whole fuel element cell are calculated.

\subsubsection{Control Rod Fuel Elements}

Figure 2.2 is a drawing of a typical SM-1 control rod fuel element. The nomenclature for the plate, channel, and active region (region \#5) is the same as for the fixed elements. Dead region \#3 includes the fuel plate dead edges, side plates, portions of the control rod basket, and portions of the water not contained in the channels. Its total width is D-G. Dead region \#4 includes portions of the control rod basket and water not contained in the channels. Its total is A-H. The element is cylindricalized into an active region surrounded by a dead region. The relative sources in the active and dead regions were assumed equal to the volume fraction of water in each region.

The code ${ }^{(8)}$ first calculates the thermal flux distribution normal to the fuel plates and normalizes it to one in the active region. Average cross sections are calculated for the active region. The properties of the dead region are calculated on a homogenized basis. The radial flux distribution throug, $n$ the active and dead regions are then calculated and normalized to one in the entire element. The nuclear parameters for the whole element are then calculated by flux weighting from the final thermal flux distribution.

\subsubsection{Neutron Temperature}

The absorption cross section of the SM-1 core is large compared to the scattering cross section.

$$
\left(\sum_{\mathrm{a}_{\text {th }}} / \Sigma_{\mathrm{s}}=0.13 \text { at } 440^{\circ} \mathrm{F}\right) .
$$

This is known to harden the spectrum, i.e. shift the spectrum to higher energies 


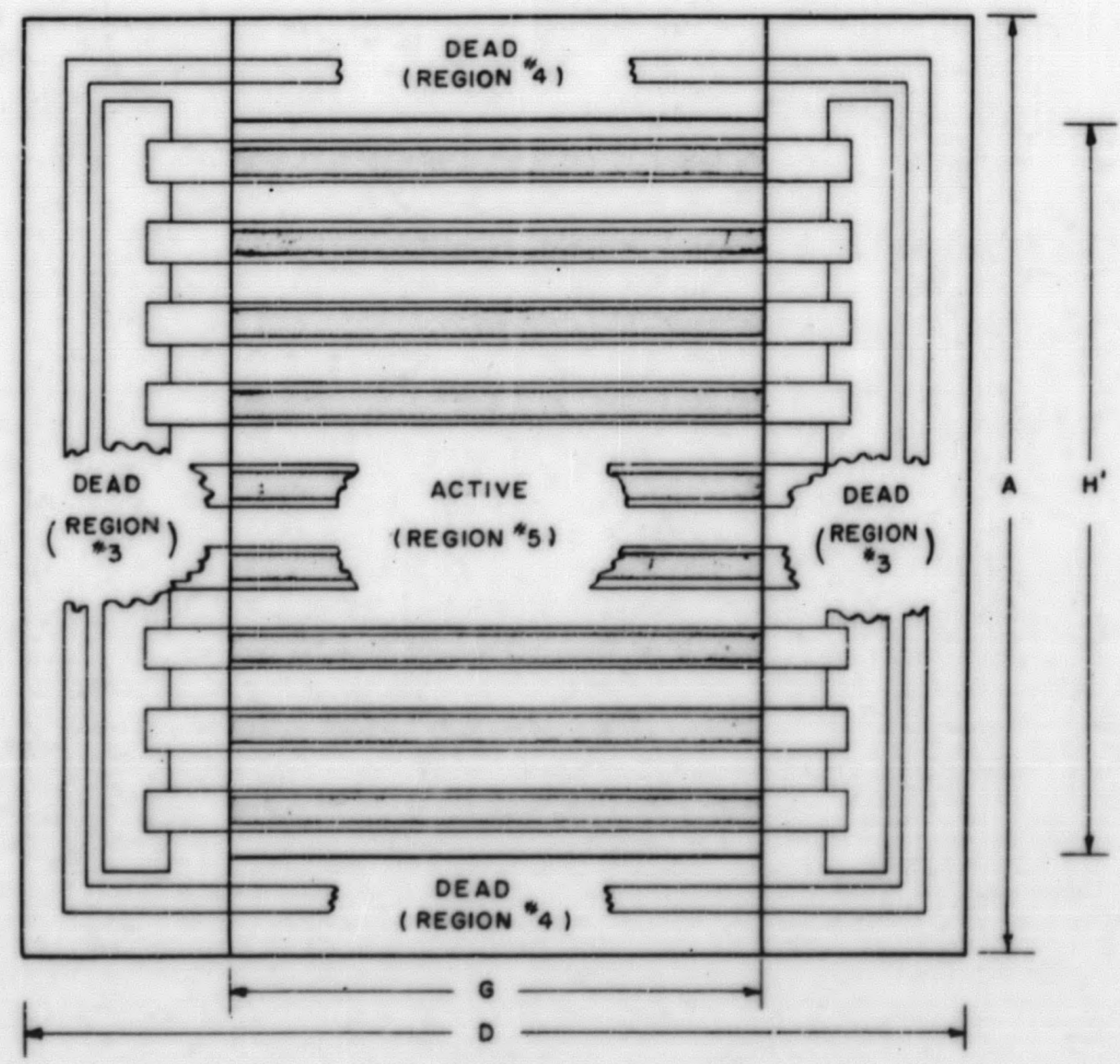

FIGURE 2. 2.

SUBDIVISION OF A CONTROL

ROD FUEL ELEMENT 
as a result of the preferential absorption of low energy neutrons. This problem has been treated by defining an effective neutron temperature which is higher than the physical temperature ${ }^{(9)}$ by an amount which depends on the ratio of absorption to scattering cross section in the assembly. The energy distribution of the thermal neutron flux was assumed to be a Maxwell-Boltzmann distribution about the effective neutron temperature.

The effective neutron temperature was calculated by the following equation,

$$
T_{n} / T_{0}=1+C \sum_{t_{h}} / \Sigma \sum_{s}
$$

where the parameters are defined in Appendix E.

\subsection{CORE GEOMETRY CONSIDERATIONS}

Figure 2. 3 presents the fixed and control rod fuel elements assembled in the SM-1 Core I. SM-1 Core I was operated with five of the rods positioned as a bank. A number of different approximations were applied to obtain a solution of the two-group equations.

\subsubsection{Equivalent Bare Model}

The solutions of the core equations, given in Section 2.1, may be found by proposing that each flux obeys the wave equation, i. e. :

$$
\begin{aligned}
& \nabla^{2} \emptyset_{\mathrm{f}}(\overline{\mathrm{r}})+\mathrm{B}^{2} \emptyset_{\mathrm{f}}(\overline{\mathrm{r}})=0 \\
& \nabla^{2} \emptyset(\overline{\mathrm{r}})+\mathrm{B}^{2} \emptyset(\overline{\mathrm{r}})=0
\end{aligned}
$$

where $\mathrm{B}^{2}$, the buckling, is assumed to be common to both fluxes. These equations may be substituted into (2.1) and (2.2) to yield two homogeneous equations. If these simultaneous equations in $\emptyset_{\mathrm{f}}$ and $\emptyset$ are to be solved, the determinant formed by the materials dependent coefficients must be zero. This implies that:

$$
\frac{\mathbf{K}_{\text {th }} \mathbf{P}}{\left(1+T \mathrm{~B}^{2}\right)\left(1+\mathrm{L}^{2} \mathrm{~B}^{2}\right)}+\frac{\mathbf{K}_{\mathrm{f}}(1-\mathbf{P})}{\left(1+\tau \mathrm{B}^{2}\right)}=1
$$

where the square of the diffusion length, $L^{2}$, is defined as:

$$
L^{2}=D / \sum a_{t h}
$$

This equation has been derived for a critical reactor. For a non-critical reactor, the multiplication factor for the system, $k_{\text {eff }}$, may be expressed in terms of the factors $V$ and $V_{c}$, the neutrons produced per fission and the 
(D)

LOG N CHAMBER
(ㄷ)

SAFETY CHAMBER 20

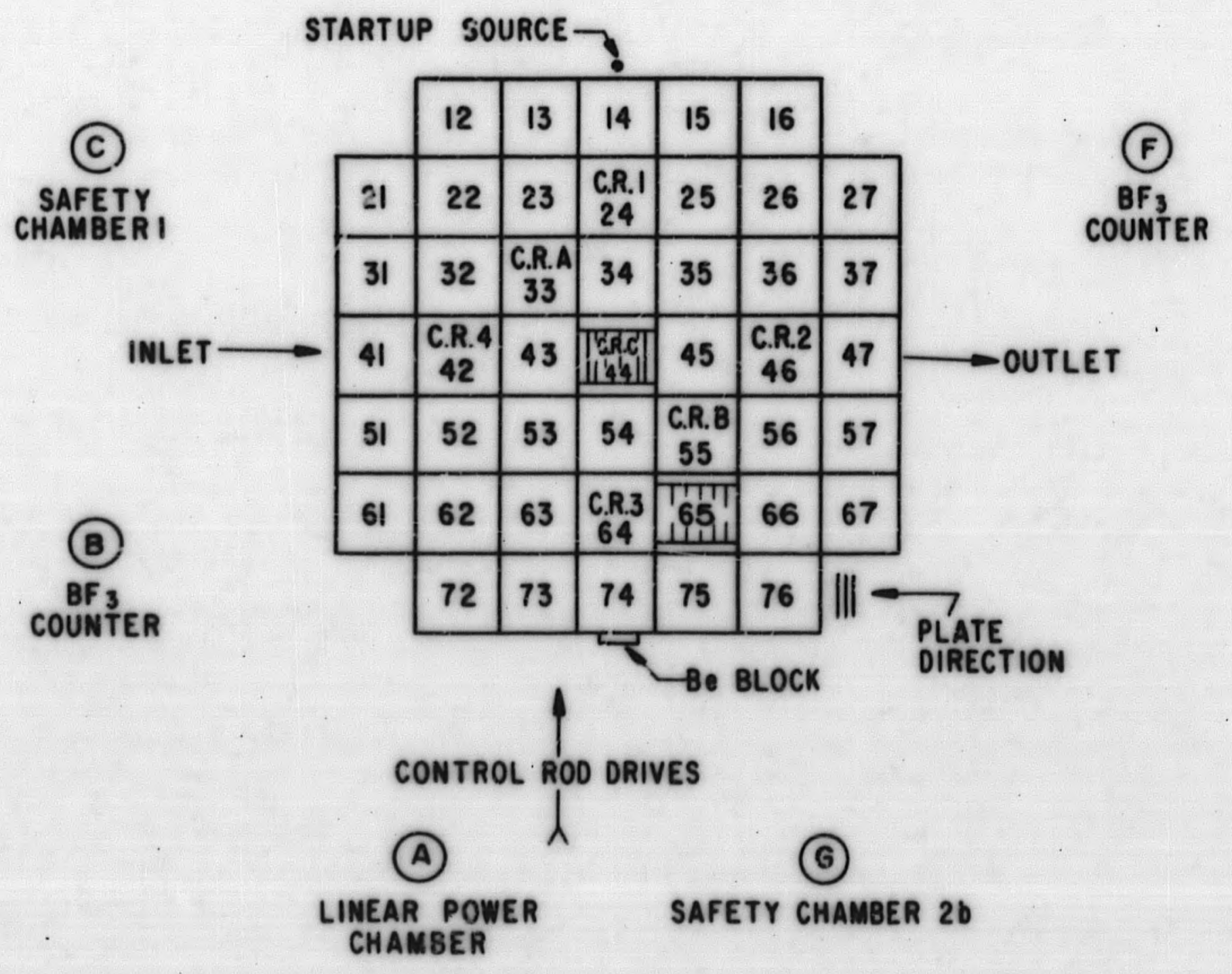

Figure 2.3 SM-1 Core Layout 
neutrons produced per fission required for criticality, respectively. Therefore:

$$
\mathrm{k}_{\text {eff }}=\frac{\nu}{\nu_{c}}=\frac{\mathbf{P K}_{\text {th }}}{\left(1+\tau B^{2}\right)\left(1+L^{2} B^{2}\right)}+\frac{K_{f}(1-P)}{\left(1+\tau B^{2}\right)}
$$

No distinction is made in this report between calculated static multiplication and measured dynamic multiplication. (20) The difference of static and dynamic multiplication has been found to be less than $1 \%$ in similar cores. $(21)$ The effect of a reflector may be included in the bare reactor calculation by modifying the definition of the buckling. For a finite cylindrical core:

$$
B^{2}=\left(\frac{\pi}{H+2 \cdot S_{z}}\right)^{2}+\left(\frac{2.405}{R+S_{r}}\right)^{2}
$$

where the parameters are defined in Appendix E. The change in reactivity of a core due to a change in $\mathrm{k}_{\text {eff }}$ from $\left(\mathrm{k}_{\mathrm{eff}}\right)_{1}$ to $\left(\mathrm{k}_{\mathrm{eff}}\right)_{2}$ is computed by:

$$
\Delta \rho=\frac{\left(\mathrm{k}_{\mathrm{eff}}\right)_{2}-\left(\mathrm{k}_{\mathrm{eff}}\right)_{1}}{\left(\mathrm{k}_{\text {eff }}\right)_{2}\left(\mathrm{k}_{\text {eff }}\right)_{1}}
$$

for a critical core $\rho=0$ and for change from critical

$$
\rho=\frac{k_{\text {eff }}^{-1}}{k_{\text {eff }}}
$$

\subsubsection{Multi-Region One-Dimensional Calculations}

For one dimensional radial calculations the core is approximated by an equivalent cylinder having a cross-sentional area equal to the cross-sectional area of the actual core array. The modifed two-group equations were employed to obtain the core reactivity and flux and power distributions. These one dimensional calculations were performed by use of VALPROD ${ }^{(10)}$ and WINDOWSHADE, (11) two IBM- 650 programs which are used to treat the radial and axial directions, respectively.

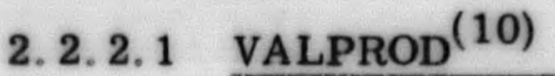

The VALPROD code for the IBM- 650 is used for the treatment of the radial direction where the height of the cylinder is accounted for by a perpendicular buckling. The code may also be used for axial calculations in which case the width or radius of the core is accounted for by a radial buckling. Input to the code includes group constants in each region, configuration of the core, and number of calculational points in each region. Output includes the flux distribution for each neutron group, the power distribution, and $\mathrm{k}_{\mathrm{eff}}$ of the core. 


\subsubsection{WINDOWSHADE ${ }^{(11)}$}

The WINDOWSHADE code is anine-region, two-group finite difference calculation in slab geometry for the IBM- 650 used to perform axial calculations. A perpendicular buckling must be specified as well as nuclear properties for each neutron group in each region. Also included is the addition of a uniform thermal poison to one section of the reactor to represent the effect of control rods. The program has two options: the placement of the control rod bank may be adjusted until criticality is obtained (the code may be made to iterate to $\mathrm{k}_{\text {eff }} \neq 1$ ) or the location of the bank may be specified and the code will calculate $\mathrm{k}_{\text {eff }}$. Output includes the flux distribution for each group, the power distribtition, the bank pasition, and the $\mathbf{k}_{\text {eff }}$ of the core.

\subsubsection{Analytical Two-Region, Two-Group Calculations}

An analytical solution of the two-group, two-region equations for a finite cylindrical core has been programmed for the IBM- 650. The FINK-1 Code(13) first solves the problem radially with an assumed axial savings and then axially with the computed radial savings. The process is repeated until satisfactory convergence is obtained.

\section{2,4 Multiregion, Two-Dimensional Calculations}

The PDQ, IBM- 704 code, (14), (15), (16) is a few-group, two dimensional, reactor design code. It finds a discrete numerical approximation to the fewgroup, time independent, neutron diffusion equations for a heterogeneous reactor in a two-dimensional bounded region. It solves for one to four lethargy groups, with variables either $\mathrm{x}-\mathrm{y}$, in rectangular co-ordinates, or $\mathrm{r}-\mathrm{z}$, in cylindrical coordinates. Input to the code includes nuclear parameters for each neutron group for each region, core configuration, and number of mesh points in each region. Output includes flux and power distributions and the $\mathrm{k}$ eff of the core. The code provides a much better estimate of the detailed power distribution within the core than can be obtained with the one-dimensional codes.

\section{2.5 Multiregion, One-Dimensional Depletion Calculation}

The CANDLE-2, IBM-704 code is a one-dimensional, few-group depletion code for rectangular, cylindrical, and spherical geometry. The following four type searches are provined as options: criticality buckling, criticality pcison, criticality boundary, and no criticality search. The output to the code includes geometry (mesh points and regions), isotopic number densities (constant distribution within a region), and number of time steps. The output provides group constants in each region at the initial time step, the eigenvalue and control parameters for each iteration, and the atomic density for each burnable element at each mesh point. 


\section{3 SPECIAL PREPARATION IBM-650 PROGRAM}

To facilitate the calculation of nuclear parameters for use in the various codes, a special rotitine was devised and programmed on the IBM-650.

\section{3. 1 Program 50 (PROMPT-I)}

Program 50 (PROMPT-I) prepares input for the MUFT-III and PlateType $\mathbf{P}_{3}$ codes for APPR-type fixed fuel elements. Input includes element and core geometry, material, and loading data. Temperature-dependent input data, including microscopic cross sections and densities, are obtained from specially prepared files. Output includes loading as a function of fuel burnup, weight and volume fractions, metal-water ratios, volumes, etc.

\subsection{NUCLEAR DATA}

\subsubsection{MUFT-Iil Cross Section Files}

The MUFT-III microscopic cross section files is listed in Appendix D. The cross sections have been obtained from reference (22). Modifications have been made and the number of groups increased to 59 so that the lowest energy is $0.196 \mathrm{ev}$.

\section{4. 2 MUFT-V Cross Section Files}

The MUFT-V microscopic cross section files have been obtained from reference (23). These have been modified for use in the MUFT-III.

\section{5 REFERENCES (2.0)}

1. Murray, R. L., "Nuclear Reactor Physics," Englewood Cliffs, New Jersey, Prentice-Hall, Inc., 1957.

2. Hellens, R. L. , "Multigroup Fourier Transform Calculation, Description of the MUFT-III Code," Westinghouse Atomic Power Division, WAPD-TM-4, July, 1956.

3. Rosen, S. S. , "Supplement to MUFT- III Code, Multigroup Fourier Transform Calculation," AP Note 90, Alco Products, Inc., December 6. 1957.

4. Byrne, B. J., "Analysis of Extended Zero Power Experiments on the Ar'my Package Power Reactor, ZPE-2," APAE No. 27, May 7, 1958.

5. Williams, D. V. P., "Army Package Power Reactor Critical Experiment," Oak Ridge National Laboratory, ORNL-2128, (1956). 
6. Noaks, J. W. , and Johnson, W. R., "Army Package Power Reactor Zerc Power Experiments, ZPE-1," APAE No. 8, February 8, 1957.

7. Byrne, B. J., and Caton, R. L., "Two-Dimensional P-3 Calculation for APPR-Type Fixed Fuel Elements," AP Note 96, Alco Products, Inc., February 14, 1958.

8. Bobe, P. E., and Oby, P. V., "Calculation of Thermal Properties of APPR-Type Control Fuel Elements, Program 54," AP Note 192, Alco Products, Inc., October 23, 1959.

9. Cohn, E. R. , "Survey of Neutron Thermalization Theories," Geneva Conference Paper P/611, Session 23A, August, 1955.

10. Oby, P. V., "Modified Two-Group Multiregion Calculation Using the VALPROD Code for the IBM-650," AP Note 24 (Revised), Aico Products, Inc., August 14, 1957.

11. Fairbanks, F.B., "Two-Group Multiregion Axial Windowshade Calculation on the IBM-650," APAE Memo 88, March 29, 1957.

12. Bohi, $\mathrm{H}$., et al, "P1MG - A One-Dimensional Multigroup $\mathrm{P}_{\mathbf{1}}$ Code for the IBM-704," WAPD-TM-135, July, 1959.

13. McElligott, P. E. "FINK-I A Two-Group, Two Region Calculation on the IBM-650, " APAE Memo 121, January 28, 1958.

14. Bilodeaux, G. G. , et al, "PDQ - An IBM- 704 Code to Solve the TwoDimensional, Few-Group Neutron Diffusion Equation, "Westinghouse Atomic Power Division, WAPD-TM-70, August, 1957.

15. Cadwell, W.R., "PD\&-2: A Two-Dimensional, Few-Group Diffusion Code," Bettis Technical Review, WAPD-BT-13, May, 1959.

16. Cadwell, W. R., "PDS-3, A Program for the Solution of the Neutron Diffusion Equations in Two-Dimensions on the IBM-704," WAPD-TM179; May, 1960.

17. Marlowe, O.J., and Ombrellaro, P.A. "CANDLE-A One-Dimensional Few-Group Depletion Code for the IBM-704, "WAPD-TM-53, May, 1957.

18. Marlowe, O.J., and Ombrellaro, P.A., "CANDLE-A One-Dimensional Few-Group Depletion Code for the IBM-704, Addendum 1, CANDLE-2," WAPD-TM- 53 Addendum 1, October, 1957.

19. Hughes, D. J. Carter, R. S., "Neutron Cross Section Angular Distribution," BNL-400, June, 1956. 
20. Gross, E. E., Marable, T. H., "Static and Dynamic Multiplication Factors and their Relation to the Inhour Equation," Nuc. Sc. and Eng., Vol. 7, No. 4, April, 1960.

21. Olsen, T. M., Welshans, L., "ANPP Code Development Program Pressurized Water Task Quarterly Progress Report Number Eight," MND-C2207, August, 1961.

22. Hellens, R. L., "Multigroup Fourier Transform Calcuiation Description of the MUFT-III Code," WAPD-TM-4, July 19, 1056.

23. Henry, A. F., "54 Group Library for P-1 Programs," WAPD-TM-224, April, 1960. 


\section{0 REVIEW OF THE CALCULATIONAL MOIJELS}

\subsection{INTRODUCTION}

The purpose of this analysis is to determine the accuracy of various calculational models and nuclear data described in Section 2.0 by comparing calculated and measured parameters for a wide range of reactor cores, and thereby select the best calculational model and nuclear data for analysis of SM-1 Core I.

The following core parameters were investigated, using various fast files (containing fast microscopic cross sections and slowing-down parameters) and slowing-down models: core reactivity, fast flux distribution, and fraction of thermal fissions. In order to provide a more fundamental check on the nuclear model and data, the neutron age from Po-Be and a fission source was calculated for both pure water and for iron water mixtures. This latter calculation is presented first.

\subsection{EFFECT OF CALCULATIONAL MODEL ON NEUTRON AGE}

The effects of the MUFT-III and MUFT-V fast files, and the P-1 and P-1 S. G. slowing-down models, on the calculated ages of fission and poloniumberyllium source neutrons in pure water and iron-water mixtures, were analyzed and compared to experiment.

\section{2. 1 Systems Investigated}

The following two systems were investigated to obtain the effects of the fast calculations on calculated ages:

1. Fission energy neutrons in pure water within a plant-source geometry, ${ }^{(1)}$

2. Polonium-beryllium energy neutrons in various iron-water mixtures within a plane-source geometry. (2)

In both systems the ages were measured up to the resonance energy of indium (1.46 ev).

Comparison of the calculated ages of fission neutrons in pure water and experimental results provides a test of the slowing-down approximation as applied to pure water. The Po-Be energy neutrons were investigated for metal-to-water ratios of $0.0,0.5,1.0,2.0$, and 3.0 in order to test the iron nuclear data. 


\section{2.2 Calculational Approach}

The MUFT-III code, with the MUFT-III and MUFT-V fast files, and P-1 and P-1 S. G. slowing-down models, was used to predict neutron ages and compare to experiment. Since the resonance energy of indium (1.46 ev) was used to measure ages in both systems, the MUFT-III and MUFT-V fast files were used with 51 lethary groups (corresponding to a lower energy cutoff of $1.44 \mathrm{ev}$ ). The input total buckling, $\mathrm{B}^{2}$, used was $10^{-6} \mathrm{~cm}^{-2}$, in order to simulate an infinite system as closely as possible. (This is the smallest buckling accepted by the MUFT-III code.)

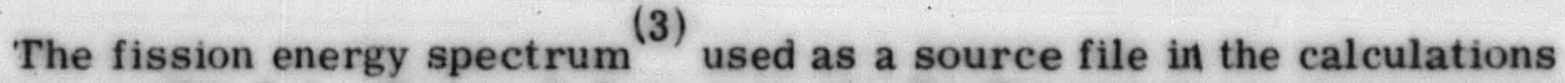
are given in Fig. 3.1. Figure 3.2 presents the Po-Be energy spectrum as used in the calculations. The spectrum was determined by ajeraging several spectra collected and reported in graphical form in reference. (2) Although there is a lack of similarity in the detailed structure of these curves, their overall shape and average energy compare favorably. It has been found that each particular spectrum provided a negligible effect on the calculated age. (2)

\subsection{Results}

Table 3.1 presents the experimental and calculated ages for fission neutrons in pure water, employing the MUFT-III and MUFT-V fast files, with the P-1 S. G. slowing-down models. The experimental age of $27.68+0.10 \mathrm{~cm}^{2}$ was obtained at the Argonne National Laboratory, $(1)$ and is reported to be the latest age determination. Previous published measurements have yielded ages of $30.5+1.5 \mathrm{~cm}^{2}(1)$

TABLE 3.1

NEUTRON AGES OF FISSION NEUTRONS IN PURE WATER USING FAST FII.ES AND SLOWING-DOWN MODEL

$\begin{array}{ccccc}\begin{array}{c}\text { Measured Age } \\ \left(\mathrm{cm}^{2}\right)\end{array} & \begin{array}{c}\text { MUFT-II, } \\ \text { P-1 }\end{array} & \begin{array}{c}\text { MUFT-II, } \\ \text { P-1 S. G. }\end{array} & \begin{array}{c}\text { MUFT-V, } \\ \text { P-1 }\end{array} & \begin{array}{c}\text { MUFT-V, } \\ \text { P-1 S. G. }\end{array} \\ 27.68 \pm 0.10 & 26.65 & 34.03 & 24.77 & 30.61\end{array}$

As is shown in Table 3.1 the calculated age of $26.65 \mathrm{~cm}^{2}$ of fission neutrons in pure water, based on the MUFT-III fast files and P-1 slowingdown model, provides the best prediction of the measured age of $27.68 \pm 0.10$ $\mathrm{cm}^{2}$. 


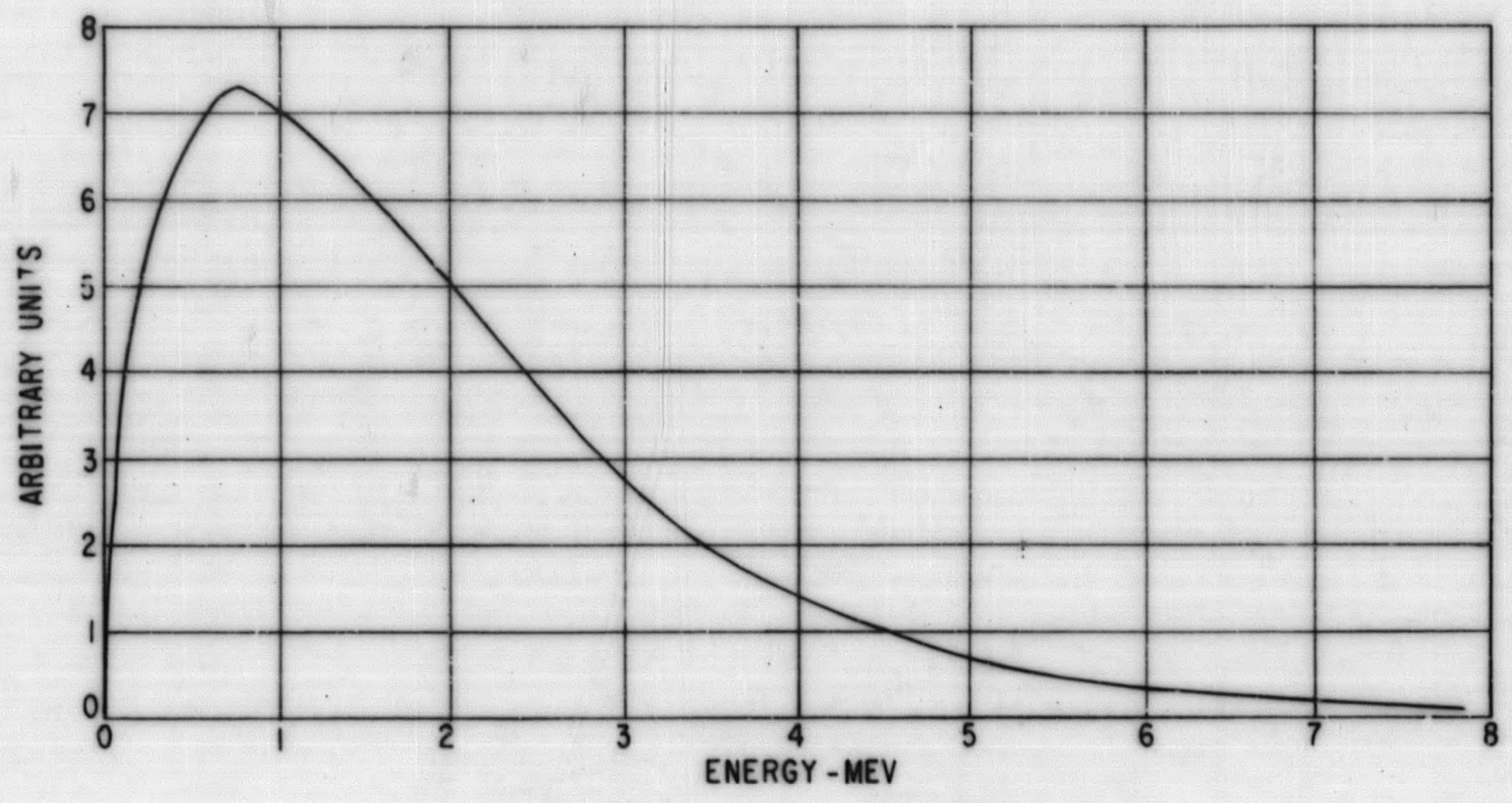

Figure 3.1 Energy Distribution of Fission Neutrons 


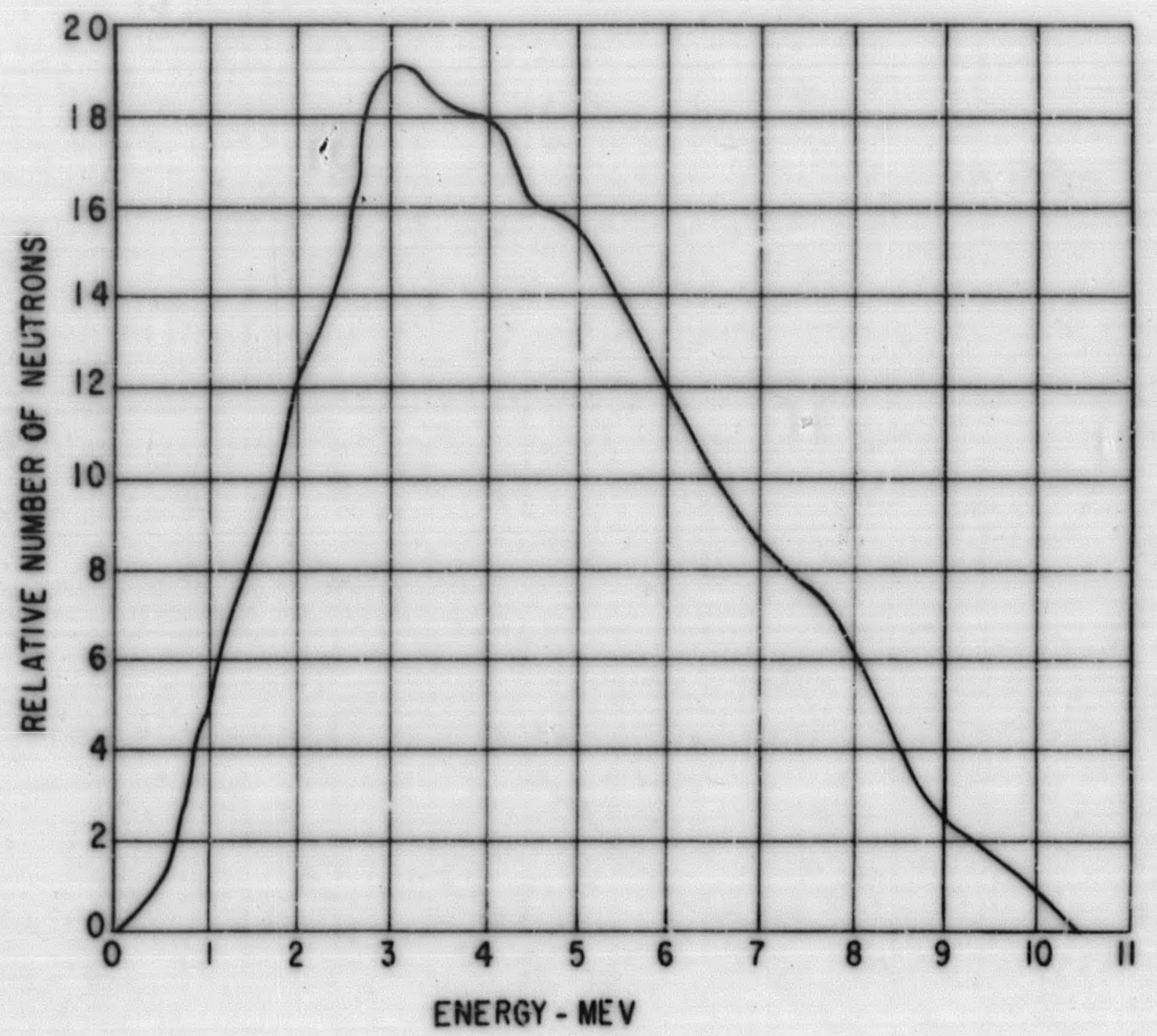

Figure 3.2. Energy Spectrum From $\mathrm{Po}^{210}-\propto$ - $-\mathrm{Be}$ Neutron Source 
Table 3.2 reporte the effects of the fast calculations on the fast nuclear parameters for pure v,ater with fission neutrons, using 51 lethargy groups (corresponding to a lower energy cutoff of $1.44 \mathrm{ev}$ ).

TABLE 3.2

EFFECTS OF FAST CALCULATIONS ON FAST PROPERTIES OF WATER USING FLSSION NEUTRONS (FAST FILES AND SLOWING-DOWN MODEL)

\begin{tabular}{|c|c|c|c|c|}
\hline $\begin{array}{l}\text { Npclear } \\
\text { Parameter }\end{array}$ & $\begin{array}{l}\text { MUFT-III, } \\
\text { P-1 }\end{array}$ & $\begin{array}{l}\text { MUFT-III, } \\
\text { P1-SG } \\
\end{array}$ & $\begin{array}{l}\text { MUFT-V, } \\
\text { P-1 }\end{array}$ & $\begin{array}{l}\text { MUFT-V, } \\
\text { P1-SG. }\end{array}$ \\
\hline$\sum_{a_{f}}\left(\mathrm{~cm}^{-1}\right)$ & 0.000517 & 0.000517 & 0.000726 & 0.000726 \\
\hline$\sum_{\mathrm{si}}\left(\mathrm{cm}^{-1}\right)^{*}$ & 0.050717 & 0.050717 & 0.050785 & 0.050785 \\
\hline$D_{f}(\mathrm{~cm})$ & 1. 365230 & 1. 743313 & 1. 276113 & 1. 576858 \\
\hline $\mathbf{P}$ & 0. 9899914 & 0.989914 & 0.985910 & 0.98591 \\
\hline
\end{tabular}

* Macroscopic slowing-down cross section from fast group, i. e., $\xi \sum \mathbf{s}^{\prime} \Delta U$

Table 3.3 presents the experimental and calculated ages for Pe-Be neutrons in various iron-water mixtures, and their dependence on the fast calculations. The experimental ages were obtained at the Bettis Atomic Power Division. (2) 
TABLE 3.3

NEUTRON A.GES OF YO-Be NEUTRONS IN IRCN-WATER MIXTURES (USING FAST FILES AND SLOWING-DOWN MODEL)

\begin{tabular}{|c|c|c|c|c|c|}
\hline $\begin{array}{l}\text { Metal/Water } \\
\text { Volume Ratio } \\
\end{array}$ & $\begin{array}{l}\text { Measured } \\
\text { Age }\left(\mathrm{cm}^{2}\right) \\
\end{array}$ & $\begin{array}{l}\text { MUFT-III: } \\
\text { P-1 } \\
\end{array}$ & $\begin{array}{c}\text { MUFT-III, } \\
\text { P1-SG. } \\
\end{array}$ & $\begin{array}{c}\text { MUFT-V, } \\
\text { P-1 }\end{array}$ & $\begin{array}{c}\text { MUFT-V, } \\
\text { P1-SG. }\end{array}$ \\
\hline 0.0 & $\begin{array}{l}55.4 \pm 1.7 \\
57.9 \pm 1.7\end{array}$ & 62.1 & 83.9 & 52.6 & 66.5 \\
\hline 0.5 & $56.2 \pm 2.2$ & 53.0 & 59.1 & 53.2 & 59.0 \\
\hline 1.0 & $58.8 \pm 1.8$ & 54.0 & 57.8 & 58.1 & 62.1 \\
\hline 2. 0 & $72.1 \pm 2.2$ & 60.4 & 63.0 & 69.6 & 72.6 \\
\hline 3.0 & $83.0+2.5$ & 67.4 & 69.5 & 81.1 & 83.7 \\
\hline
\end{tabular}

According to Table 3. 3, the MUFT-V fast fules with the P-1 slowing-down model affords the best comparison between calculated and measured ages of PoBe neutrons in iron-water mixtures.

TABLE 3.4 EFFECTS OF FAST CALCULATIONS ON FAST PROPERTIES OF IRON-WATER MIXTURES USING PO-Be NEUTRONS

$$
(\mathrm{M} / \mathrm{W}=0.0)
$$

\begin{tabular}{|c|c|c|c|c|}
\hline $\begin{array}{l}\text { Nuclear } \\
\text { Parameter } \\
\end{array}$ & $\begin{array}{l}\text { MUFT-III, } \\
\text { P-1 }\end{array}$ & $\begin{array}{c}\text { MUFT-III, } \\
\text { P1-SG } \\
\end{array}$ & $\begin{array}{l}\text { MUFT-V, } \\
\text { P-1 }\end{array}$ & $\begin{array}{c}\text { MUFT-V, } \\
\text { P1-SG }\end{array}$ \\
\hline$\sum_{a_{f}}\left(\mathrm{~cm}^{-1}\right)$ & 0.001954 & 0.001954 & 0.002376 & 0.002376 \\
\hline$\sum_{s}\left(\mathrm{em}^{-1}\right)$ & 0.034698 & 0.034698 & 0.035262 & 0.035262 \\
\hline $\mathrm{D}_{\mathrm{f}}(\mathrm{cm})$ & 2. 276717 & 3. 076325 & 1.980150 & 2. 500933 \\
\hline $\mathbf{P}$ & 0.946682 & 0.946683 & 0.936868 & 0.936869 \\
\hline
\end{tabular}

Table 3.4 and 3.5 ist the effects of the fast calculations on the fast properties for the metal/water volume ratios of 0.0 and 3.0;i.e., pure water and highly concentrated iron mixture, respectively, using Po-Be source neutrons.

3-6 
TABLE 3.5

EFFECTS OF FAST CALCULATIONS ON FAST PROPERTIES OF IRON-WATER MIXTURES USING PO-BE NEUTRONS

$$
(\mathrm{M} / \mathrm{w}=3.0)
$$

FAST FILES AND SLOWING-DOWN MODEL

\begin{tabular}{|c|c|c|c|c|}
\hline $\begin{array}{l}\text { Nuclear } \\
\text { Parameter }\end{array}$ & $\begin{array}{l}\text { MUFT-III, } \\
\text { p-1 } \\
\end{array}$ & $\begin{array}{l}\text { MUFT-III, } \\
\text { P1-SG. }\end{array}$ & $\begin{array}{l}\text { MUFT-V, } \\
\text { P-1 }\end{array}$ & $\begin{array}{c}\text { MUFT-V, } \\
\text { P1-SG }\end{array}$ \\
\hline$\sum_{a_{f}}\left(\mathrm{~cm}^{-1}\right)$ & 0.005900 & 0.005900 & 0.001855 & 0.001855 \\
\hline$\sum_{\mathrm{sl}}{ }^{*}\left(\mathrm{~cm}^{-1}\right)$ & 0.011949 & 0.011949 & 0.012718 & 0.012718 \\
\hline$D_{\mathrm{f}}(\mathrm{cm})$ & 1. 202927 & 1. 240689 & 1. 181425 & 1. 220028 \\
\hline $\mathbf{P}$ & 0.669467 & 0.669468 & 0.872718 & 0.872717 \\
\hline
\end{tabular}

A study has been performed ${ }^{(2)}$ to determine the effect of the rather uncertain capture and inelastic scattering cross sections of oxygen on the calculated age of fission neutrons in pure water. The results ${ }^{(2)}$ are listed in Table 3:6. The results for the $\mathbf{P}$ o- Be spectrum are also given.

TABLE 3. 6

EFFECT ON AGE OF ELIMINATING CAPTURE AND INELASTIC CROSS SECTIONS OF OXYGEN

\section{Condition of Oxygen}

All Cross Sections Used

$$
\begin{aligned}
& \sigma_{c}=0 \\
& \sigma_{\text {in }}=0 \\
& \sigma_{c}=\sigma_{\text {in }}=0
\end{aligned}
$$

\section{Fission Spectrum}

$25.9 \mathrm{~cm}^{2}$

27. 0

26. 1

27. 3
Po-Be Spectrum

$53.5 \mathrm{~cm}^{2}$

61.1

55.2

63. 6 
It can be seen in Table 3. 6 that the effect of suppressing the capture and inelastic cross sections of oxygen on the calculated age of fission neutrons is reasonaibly smali. The MUFT-III fast files do not consider inelastic scattering for oxygen and have a smaller effective oxygen capture cross section than the MUFT-V fast files (as can be seen from Table 3.6).

Table 3.2 indicates that the fast water capture cross section is greater for the MUFT-V fast files than for the MUFT-III files. However, according to Table 3. 6 eliminating the oxygen capture cross section considerably alters the calculated age of $\mathrm{Po}-\mathrm{Be}$ neutrons in pure water. The effect of neglecting oxygen inelastic scattering is relatively small. The strong sensitivity of the oxygen capture cross section on the calculated age of Po-Be neutrons in pure water is due to the rapid fall-off of the hydrogen capture cross section relative to that of oxygen at higher neut ron energies. According to Table 3. 3, the MUFT-III, P-1 fast model considerably overestimates the experimental age of Po-Be neutrons in pure water, whereas the MUF'T-V, P-1 fasi model slightly underestimates the experimental results. It is concluded that the oxygen capture cross section as used in the MUFT-III fast flles is too low for high neutron energies near $5 \mathrm{Mev}$ (average energy of Po-Be source spectrum). This does not affect the conclusion that the MUFT-III, P-1 fast model is best in predicting the age of fission neutrons in pure water, since for neutrons of $2 \mathrm{Mev}$ (average energy of fission source spectrum), eapture and inelastic scattering effects of oxygen were observed to have relatively small effect on the calculated age of fission neutrons in pure water, according to Table 3.6.

As seen in Table 3.5 the iron capture cross section as used in the MUFT-III fast files is considerably greater than that for the MUFT-V fast files, at high energies near $5 \mathrm{Mev}$. According to Table 3.3 the calculated age of Po-Be neut rons for $M / W=3,0$, based on the MUFT-III, P-1 fast model, considerably underestimates the measured result, where as the age based on the MUF'T-V, P-1 fast model is in excellent agreement with experiment. Indeed, this comparison is the same for the low metal-to-water volume rates; i. e., $0.5,1.0$, and 2. 0 where the concentration of iron in the mixtures is relatively small. Therefore, it is concluded that the iron capture cross section, as used in the MUFT-III fast files, is definitely too large at high energies near $5 \mathrm{Mev}$. However, this does not imply that the MUFT-III iron fast file is inaccurate at lower energies below $2 \mathrm{Mev}_{\text {, at }}$ which it is necessary to properly describe the fast absorption and slowing-down properties for reactors.

\subsection{Conclusions}

From the investigation of the effect of calculational model on neutron age from fission and Po-Be sources the following conclusions can be drawn.

1. The P-1 model employing MUFT-III nuclear data file (Appendix F) gives the best calculated fission age in water. 
2. The P-1 model employing MUFT-V nuclear data file gives the best calculated $\mathrm{Po}-\mathrm{Be}$ ages in water and iron-water mixtures.

3. The MUFT-III iron data need revision at energies greater than 2 Mev to improve agreement with Po-Be ages.

\section{3 EFFECT OF FAST GROUP CALCULATIONAL MODEL ON CORE REACTIVITY}

The reactivity of a number of cores has been calculated using the P-1 and P1-SG. slowing-down models and MUFT-III and MUFT-V nuclear data.

The core types chosen for investigation provide a wide variety of test cores, since they range from cores consisting of only uranium and water, to cores containing uranium, water, stainless steel and boron. The cores calculated vary from those containing little or no reactivity to those containing as much as 30 dollars with the rods out. The critical cores provide the cleanest comparison of calculated to experimertal reactivities since there are uncertainties when dealing with cores with large excess reactivity. These uncertainties are the method of measurement, the effective delayed neutron fraction $\beta$ eff as a function of control rod position, and the equation used to convert experimental reactivities obtained in dollars to reactivities $(\rho)$.

In this report the experimental excess reactivities, expressed in dollars are converted to reactivities $(D)$ using the relation, $(4)$

$$
\begin{aligned}
& \rho=1-e^{-1} \text { ex } \beta_{\text {eff }} \\
& \text { where, } P \text { = reactivity } \\
& I_{\text {ex }} \quad \text { excess reactivity (dollars) } \\
& \beta_{\text {eff }}=\text { effective delayed neutron fraction }
\end{aligned}
$$

Previous analyses of the SM- 1 Core 1 have been based on a value for the effective delayed neut ron fraction, $\beta$ eff, of 0,0073 . Measurements performed upon the SPERT-III(5) and BSR-II(6) cores, indicate a value of 0.0078 for $\beta_{\text {eff }}$. In addition, $\beta_{\text {eff }}$ has been calculated for SM-1 to be 0.0078 by R. L. Murray (See Appendix A) using modified one-group theory and $\beta=0.0065$. Therefore, the value of 0.0078 will be adopted for the effective delayed neutron fraction, Nefi, throughout this repoit. 


\subsubsection{Core Types Investigated}

The following core types were analyzed to obtain the reactivity effect of the MUFT-III and MUFT-V fast files, with the P-1 and P1-SG. slowing-down models:

1,2. WAPD homogeneous critical cores with no B-10 or stainless steel, $68^{\circ} \mathrm{F},(\% \cap \cong 0)(7)$

3. ORNL critical core ("light loading") with no B- $10,68^{\circ} \mathrm{F}$, $(\% \cong 0)(8)$

4. SPERT-III critical water height core ("A") with no B-10, $80^{\circ} \mathrm{F}$ $(\%,) \cong 0)(5)$

5. SM-1 Core I ( 10 fixed plus 7 control fuel elements) with "as fabricated" B-10 loading, $68^{\circ} \mathrm{F},\left(\% \curlywedge^{\circ} \cong 0\right)^{(9)}$

6. SM-1 Core I (15 fixed plus 1 control fuel element) with 'as fabricated" B-10 loading, $68^{\circ} \mathrm{F},\left(\% D^{\prime} \cong 0\right)(10)$

7. SM-1 Core I critical water height core ( 38 fixed plus 7 control fuel elements) with "as fabricated" B-10 loading, $68^{\circ} \mathrm{F}(\% \rho \cong 0)^{(11)}$

8. SM-1 Core I (38 fixed plus 7 control fuel elements, poisoned with boron-stainless steel strips) with "as fabricated" B-10 loading, $68^{\circ} \mathrm{F},(\% \circ \cong 0)(11)$

9. SM-1 Core I (38 fixed plus 7 control fuel elements, poisoned with stainless steel strips) with "as fabricated" B- 10 loading, $68^{\circ} \mathrm{F}$, $(\%) 0)^{(11)}$

10, 11. SM-1 Core I ( 38 fixed plus 7 control fuel elements) with "as fabricated" B-10 loadings, $68^{\circ} \mathrm{F}$ and $440^{\circ} \mathrm{F},\left(\% \rho^{>>0}\right)(12),(13),(14)$

12. SM-1 Core I (all 45 fixed fuel elements) with "as fabricated" B-10 loading, $68^{\circ} \mathrm{F},(\% \bigcirc>0)(10)$

13. SM-2 experimental core (all 45 fixed fuel elements) with no B-10 loading, $68^{\circ} \mathrm{F},(\%>>0)(15)$

The first two cores are aqueous homogeneous solutions employing fully enriched uranium. All the rest of the cores are fuily enriched uranium, stainless steel, water-moderated cores, with the SM-1 type cores containing boron as a burnable poison.

Table 3.7 lists the atomic number densities of the various cores investigated. U-238 was included in the MUFT-V files but not in the MUFT-III files. The reactivity effect of $U-238$ is approximately $0.25 \%, \rho$ for these cores. 


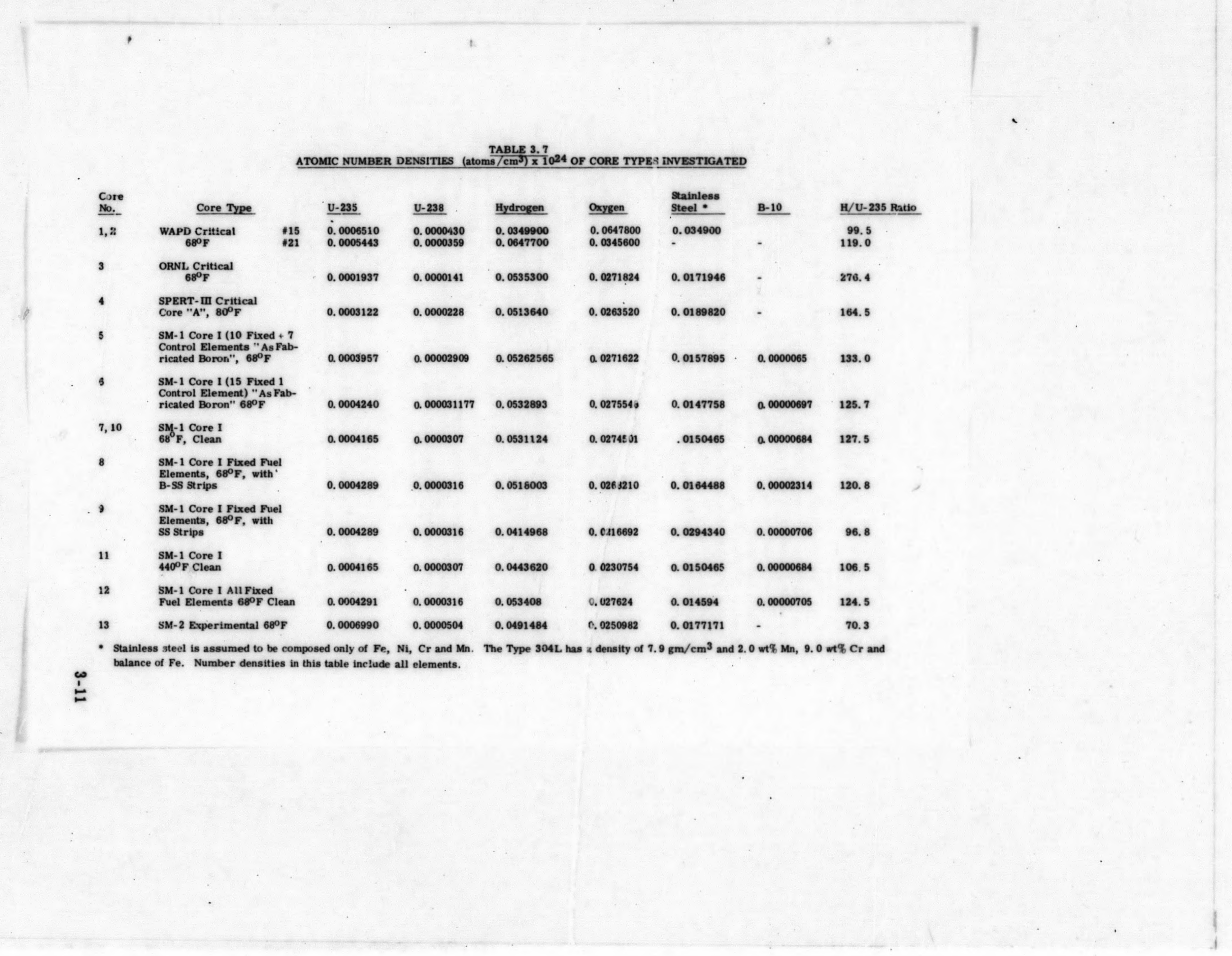




\subsubsection{Results}

\section{Cores No. 1 and 2}

The reactivity of Cores No. 1 and 2(homogeneous cores No. 15 and 21, respectively) were calculated using an equivalent bare model. The measured reactivity was reported to be $0.0+0.6 \%$ and $0.0+0.2 \% \rho$ for the critical cores No. 15 and 21 , respectively. Tables $3 . \overline{8}$ and 3.9 contain the group constants and reactivity calculated by several different slowing down models and nuclear data files. The results indicate that the P-1 slowing down model employing MUFT-III data file yields the closest agreement to measured reactivities. It is of interest to note that the calculated reactivities for both cores are within experimental error.

\section{Core No. 3}

As part of the ORNL critical experiment program for the APPR-1, an experiment was assembled with no reactivity containing fully enriched uranium stainless steel and light water in the SM-1 Core I configuration. The critical experiment employed uranium metal foils stainless steel clad fuel plates. In order to determine the most accurate thermal group constants P-5 theory has previously been applied. The measured reactivity of the critical core was reported to be $0.0 \pm 0.5 \% \rho$. The reactivity was calculated using the equivalent bare model and several slowing down models and nuclear data files. The results are given in Table 3. 10. The table shows that the MUFT-III P-1 files give the most accurate reactivity. The calculated reactivity for this slowing down model and nuclear data are within experimental error.

\section{Core No. 4}

The SPERT-III core employs fuel elements of stainless steel $\mathrm{UO}_{2}$ dispersion As part of the initial experiments on this program several clean cores were assembled. One of these was known as SPERT-III critical water height core "A". No estimate of the experimental uncertainty in measured reactivity was available. The calculated reactivity using the equivalent bare model in several slowing down models and nuclear data files is shown in Table 3.11. 
TABLE 3.8

REACTIVITY ANALYSIS OF WAPD HOMOGENEOUS CRITICAL CORE NO.1 (स15) (NO B-10 OR STAINLESS STEEL), $68^{\circ} \mathrm{F}$

\section{FAST FILES AND SLOWING-DOWN MODEL}

\begin{tabular}{|c|c|c|c|c|}
\hline $\begin{array}{l}\text { Nuclear } \\
\text { Parameter }\end{array}$ & $\begin{array}{l}\text { MUFT-III, } \\
\text { P-1 } \\
\end{array}$ & $\begin{array}{l}\text { MUFT-III, } \\
\text { P1-SG } \\
\end{array}$ & $\begin{array}{l}\text { MUFT-V, } \\
\text { P-1 }\end{array}$ & $\begin{array}{l}\text { MUFT-V, } \\
\text { P1-SG } \\
\end{array}$ \\
\hline $\mathbf{P}$ & 0. 756463 & 0. 759281 & & \\
\hline$T\left(\mathrm{~cm}^{2}\right)$ & 29.356796 & 32.430402 & & \\
\hline$v \sum_{\mathrm{f}_{\mathrm{f}}}\left(\mathrm{cm}^{-1}\right)$ & 0.018394 & 0.019177 & & \\
\hline$\sum_{a_{f}}\left(\mathrm{~cm}^{-1}\right)$ & 0.010615 & 0.010984 & & \\
\hline $\mathbf{K}_{\mathrm{f}}=\nu \sum_{\mathrm{f}_{\mathrm{f}}} / \sum_{\mathrm{a}_{\mathrm{f}}}$ & 1. 732802 & 1. 745843 & & \\
\hline $\mathbf{K}_{\mathrm{th}}=\nu \sum_{\mathbf{f}_{\mathrm{th}}} / \sum_{\mathrm{a}_{\mathrm{th}}}$ & 1. 980030 & 1. 980030 & Not & Not \\
\hline $\mathrm{L}^{2}\left(\mathrm{~cm}^{2}\right)$ & 0.426740 & 0.426740 & Performed & Performed \\
\hline $\mathrm{B}^{2}\left(\mathrm{~cm}^{-2}\right)$ & 0.030320 & 0.030320 & & \\
\hline$\% \rho$ (Equivalent Bare) & 0.56 & -4.14 & & \\
\hline$\% \rho$ (Measured) & $0.0 \pm 0.6$ & $0.0 \pm 0.6$ & & \\
\hline
\end{tabular}


TABLE 3.9

REACTIVITY ANALYSIS OF WAPD HOMOGENEOUS CRITICAL CORE No. 2 (\#21) (NO B-10 OR STAINLESS STEEL), 680F

FAST FILES AND SLOWING-DOWN MODEL

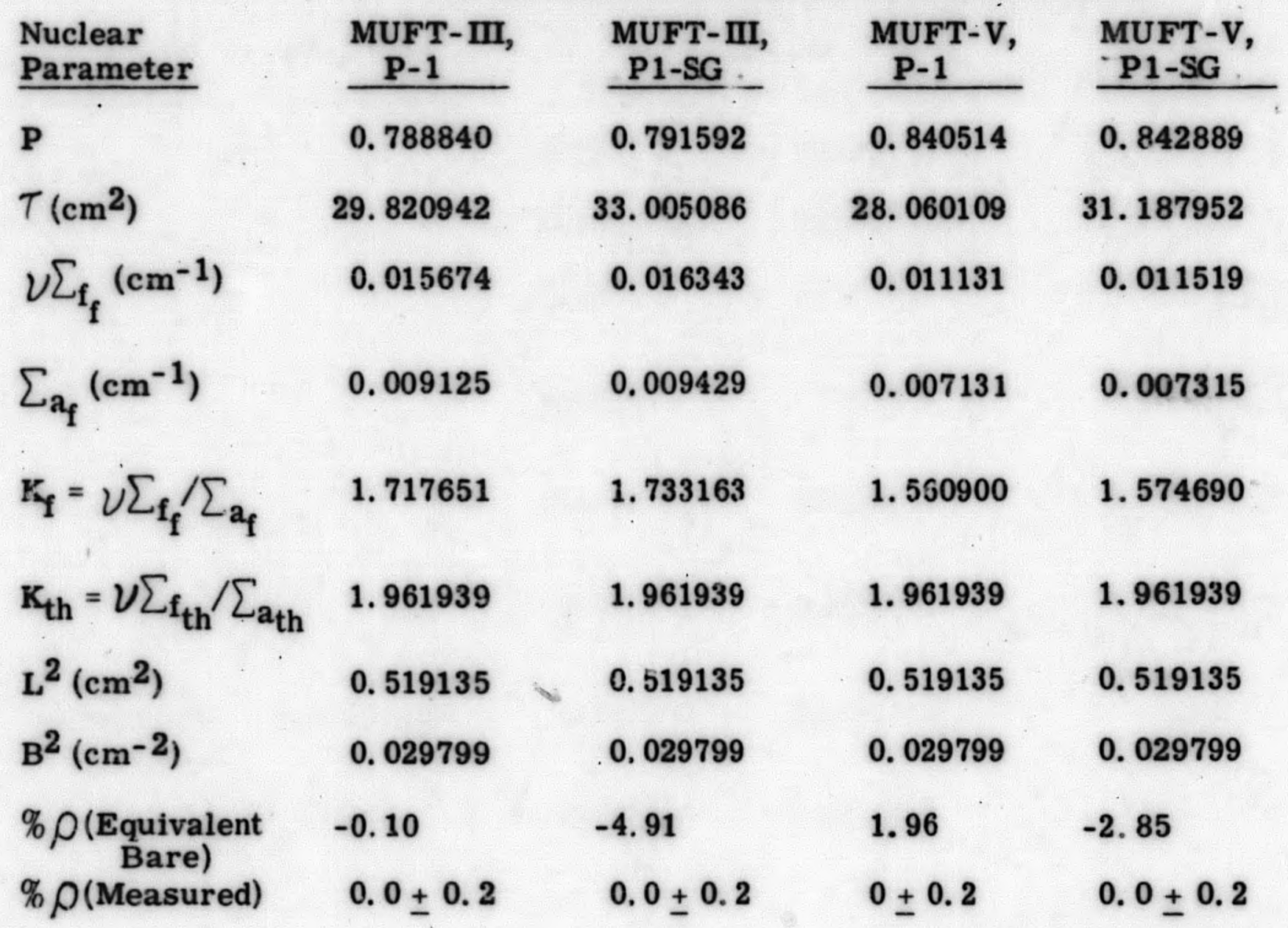


TABLE 3.10

REACTIVITY ANALYSIS OF ORNL CRITICAL CORE NO. 3

("LIGHT LOADING") (NO B-10), 680F

FAST FILES AND SLOWING-DOWN MODEL

\begin{tabular}{|c|c|c|c|c|}
\hline $\begin{array}{l}\text { Nuclear } \\
\text { Parameter }\end{array}$ & $\begin{array}{l}\text { MUFT-III, } \\
\text { P-1 }\end{array}$ & $\begin{array}{l}\text { MUFT-III, } \\
=\text { P1-SG } \\
\end{array}$ & $\begin{array}{c}\text { MUFT-V, } \\
\text { P-1 } \\
\end{array}$ & $\begin{array}{l}\text { MUFT-V, } \\
\text { P1-SG } \\
\end{array}$ \\
\hline $\mathbf{P}$ & 0.844098 & 0.844858 & 0.905917 & 0.906291 \\
\hline$\tau\left(\mathrm{cm}^{2}\right)$ & 29. 712738 & 33. 492978 & 27. 709370 & 31.139038 \\
\hline$\nu \sum_{\mathbf{f}_{\mathbf{f}}}\left(\mathrm{cm}^{-1}\right)$ & 0.006327 & 0.006382 & 0.004439 & 0.004470 \\
\hline$\sum_{a_{f}}\left(\mathrm{~cm}^{-1}\right)$ & 0.006279 & 0.006305 & 0.003868 & 0.003883 \\
\hline $\mathbf{K}_{\mathrm{f}}=v \sum_{\mathrm{f}_{\mathrm{f}}} / \sum_{\mathrm{a}_{\mathrm{f}}}$ & 1. 007645 & 1. 012213 & 1. 147688 & 1.150989 \\
\hline $\mathbf{K}_{\mathrm{th}}=v \sum_{\mathrm{f}_{\mathrm{th}}} / \sum_{\mathrm{ath}_{\mathrm{th}}} *$ & 1.253974 & 1. 253974 & 1. 253974 & 1.253974 \\
\hline$L^{2}\left(\mathrm{~cm}^{2}\right) *$ & 1. 102640 & 1.102640 & 1.102640 & 1.102640 \\
\hline $\mathrm{B}^{2}\left(\mathrm{~cm}^{-2}\right)$ & 0.007154 & 0.007154 & 0.007154 & 0.007154 \\
\hline $\begin{array}{c}\% \rho(\text { Equivalent } \\
\text { Bare })\end{array}$ & -0.44 & 2. 60 & 2.88 & 0.90 \\
\hline$\% \rho$ (Measured) & $0.0 \pm 0.5 \%$ & $0.0 \pm 0.5 \%$ & $0.0 \pm 0.5 \%$ & $0.0 \pm 0.5 \%$ \\
\hline
\end{tabular}

* Obtained by $\mathbf{P}_{5}$ theory. (8) 
TABLE 3.11

REACTIVITY ANALYSIS OF SPERT-III CRITICAL WATER HEIGHT CORE "A" (CORE NO.4) (NO B-10), 800 F

FAST FILES AND SLOWING-DOWN MODEL

\begin{tabular}{|c|c|c|c|c|}
\hline $\begin{array}{l}\text { Nuclear } \\
\text { Parameter }\end{array}$ & $\begin{array}{l}\text { MUFT-III, } \\
\text { P-1 }\end{array}$ & $\begin{array}{c}\text { MUFT-III, } \\
\text { P1-SG }\end{array}$ & $\begin{array}{c}\text { MUFT-V, } \\
\text { P-1 }\end{array}$ & $\begin{array}{l}\text { MUFT-V, } \\
\text { P1-SG }\end{array}$ \\
\hline $\mathbf{P}$ & 0. 784109 & 0.785388 & 0.864791 & 0.865403 \\
\hline$T\left(\mathrm{~cm}^{2}\right)$ & 31.478520 & 34.785106 & 29.354799 & 32.426552 \\
\hline$V \sum_{\mathrm{f}_{\mathrm{f}}}\left(\mathrm{cm}^{-1}\right)$ & 0.009673 & 0.009813 & 0.006927 & 0.007004 \\
\hline$\sum_{a_{f}}\left(\mathrm{~cm}^{-1}\right)$ & 0.008260 & 0.008336 & 0.005266 & 0.005312 \\
\hline $\mathbf{K}_{\mathbf{f}}=v \sum_{\mathbf{f}_{\mathbf{f}}} / \Sigma$ & 1. 171059 & 1.177090 & 1.315241 & 1.318649 \\
\hline $\mathbf{K}_{\text {th }}=U \sum_{\mathbf{f}_{\text {th }}} / \Sigma$ & 1. 494952 & 1.494952 & 1. 494952 & 1.494952 \\
\hline $\mathrm{L}^{2}\left(\mathrm{~cm}^{2}\right)$ & 0.739830 & 0.739830 & 0. 739830 & 0.73 .9830 \\
\hline $\mathrm{B}^{2}\left(\mathrm{~cm}^{-2}\right)$ & 0.012766 & 0.012766 & 0.012766 & 0.012766 \\
\hline \multicolumn{2}{|c|}{$\% \rho$ (Equivalent Bare)0. 86} & -2.00 & 5. 75 . & 3.10 \\
\hline$\% \rho$ (Measu & 0 & $\sim 0$ & $\sim 0$ & -0 \\
\hline
\end{tabular}


The initial critical configuration of SM-1 ZPE Core I consisted of 10 fixed elements plus $\mathbf{7}$ control rod elements. The core which obtained criticality was 6 control rod fuel elements fully inserted into the core in the central control rod fuel element inserted 17 in. Measured calibrations of the central control rod in the $\mathbf{4 5}$ and 21 element core (see Fig. 2. 3) were used to estimate the worth of the central rod in a 17 element core by extrapolation. The worth of the central rod in the 17 element core from 17 to 22 in.withdrawal was estimated to be 113 cents or $0.93 \% \rho$. The experimental uncertainty is probably large due to the method used for obtaining the rod worth. The reactivity was calculated using the PDQ code in $x, y$ geometry. The control rod elements were represented explicitly in the calculation. Table 3.12 lists the reactivity for this core. The MUFT-III P-1 S. G. nuclear data and model yield the closest agreement to experiment.

\section{Core No. 6}

In a special experiment using SM-1 ZPE Core I fuel elements, the critical core was assembled employing 16 fixed elements plus one control rod fuel element. Criticality was obtained with the control rod withdrawal of 7.92 in. Boron stainless steel strips were added uniformly and the control rod was calibrated. The measured excess reactivity was 317 cents \pm 15 cents or approximately $2.42+0.1 \%$. The results of $\operatorname{PDQ}(x, y)$ calculations are given in Table 3,13. In this configuration the P-1 S. G. model using MUFT-III data yielded closest agreement to experiment. In this as well as in the previous case the smallness of the core may be the cause of the discrepancies between experimental and calculated results.

\section{Core No. 7}

In the course of the SM-1 zero power experiments the full 45 element core consisting of $\mathbf{3 8}$ fixed elements plus $\mathbf{7}$ control rod fuel elements was brought critical on water height. The axial buckling determined from previous analysis was utilized. A PDQ $(x, y)$ calculation was employed to determine core reactivity. The results are shown in Table 3.13. It is of interest to note that in this case, the P-1 slowing down model employing the MUFT-III nuclear data yielded best agreement with experiment. 
TABLE 3.12

EXCESS REACTIVITY (\% $\%$ ) OF CRITICAL SM-1 CORE I (CORE 5) $68^{\circ} \mathrm{F}$

(10 FIXED PLUS 7 CONTROL ROD FUEL ELEMENTS

FAST FILES AND SLOWING DOWN MODEL

\begin{tabular}{|c|c|c|c|c|}
\hline $\begin{array}{l}\text { Measured } \\
\text { Reactivity }(\%, 0)\end{array}$ & $\begin{array}{l}\text { MUFT-III, } \\
\text { P-1 }\end{array}$ & $\begin{array}{l}\text { MUFT-III, } \\
\text { P-1 S. G. }\end{array}$ & $\begin{array}{c}\text { MUFT-V, } \\
\text { P-1 }\end{array}$ & $\begin{array}{l}\text { MUFT-V, } \\
\text { P-1. S. G. }\end{array}$ \\
\hline .93 & 3.00 & -.09 & Not I & med \\
\hline
\end{tabular}

TABLE 3.13

EXCESS REACTIVITY $(\% \rho)$ OF SM-1 CORE I

\begin{tabular}{|c|c|c|c|c|c|c|c|c|c|}
\hline \multirow[b]{3}{*}{$\begin{array}{l}\text { Core } \\
\text { No. }\end{array}$} & \multicolumn{4}{|c|}{ Core Conditions } & \multicolumn{5}{|c|}{ Reactivity } \\
\hline & \multirow[b]{2}{*}{$\begin{array}{l}\text { Fixed } \\
\text { Elements }\end{array}$} & \multirow[b]{2}{*}{$\begin{array}{l}\text { Control } \\
\text { Elements } \\
\end{array}$} & \multirow{2}{*}{$\begin{array}{c}\text { Total No. } \\
\text { of } \\
\text { Elements }\end{array}$} & \multirow{2}{*}{$\begin{array}{l}\text { Core } \\
\text { Temp. } \\
\text { o }_{F}\end{array}$} & \multirow{2}{*}{ Measured } & \multicolumn{4}{|c|}{ Fast Files and Slowing Down Approximation } \\
\hline & & & & & & $\begin{array}{c}\text { MUFT-III } \\
\text { P-1 }\end{array}$ & $\begin{array}{l}\text { MUFT-III, } \\
\text { P-1 S. G. }\end{array}$ & $\begin{array}{c}\text { MUFT-V, } \\
\text { P-1 }\end{array}$ & $\begin{array}{l}\text { MUFT-V, } \\
\text { P-1 S. G. }\end{array}$ \\
\hline 5 & 10 & 7 & 17 & 68 & .93 & 3.00 & -.09 & - & - \\
\hline 6 & 15 & 1 & 16 & 68 & 2. 42 & 5.76 & 2. 76 & - & - \\
\hline $7+$ & 38 & 7 & 45 & 68 & 0 & .01 & -3.22 & - & - \\
\hline 8 & $38^{* *}$ & $7 * *$ & 45 & 68 & .18 & 1.53 & -.56 & - & - \\
\hline 9 & $38^{* *}$ & $7^{* *}$ & 45 & 68 & .17 & 1.37 & -.25 & - & - \\
\hline 10 & 38 & 7 & 45 & 68 & 16.95 & 16. 67 & 15.00 & 19.13 & 17.69 \\
\hline 11 & 38 & 7 & 45 & 440 & 12.10 & 12. $87^{*}$ & $10.87^{*}$ & 16.00 & 14.00 \\
\hline
\end{tabular}

* Based on 58 fast Lethargy groups (corresponding to a lower energy cut-off of . $248 \mathrm{ev}$ ).

** Poisoned with Boron-Stainless Steel strips.

+ Critical water height core. 


\section{Core No. 8}

In the zero power experiments the SM-1 ZPE Core I was fully poisoned with boron stainless steel strips inserted in the water channels in order to completely remove the control rod bank. Six of the control rods were withdrawn $20.5 \mathrm{in}$. while the central rod was withdrawn 17. 7 inches. The excess reactivity of the core was estimated to be 25 cents or $0.18 \% \rho$. Table 3.13 indicates that the calculated reactivity using the P-1 S. G. slowing down model and MUFT-III nuclear data resulted in the best agreement with experiment. However it must be pointed out that the boron content of the stainless steel strips is not accurately known.

\section{Core No. 9}

In the zero power experiment the SM-1 ZPE Core I was completely poisoned with stainless steel strips inserted in the water channels. Six of the control rods were withdrawn $20.5 \mathrm{in}$. while the central rod was withdrawn 18.3 inches. The excess reactivity of the core was determined as 21 cents or $0.17 \% \rho$. Table 3.13 indicates that P-1 S. G. slowing down model using the MUFT-III nuclear data yielded the best agreement with experiment. From Table 3.7 one can see that this case is an extreme as far as the stainless steel content is concerned.

\section{Cores No. 10 and 11}

The reactivity of SM-1 Core I at both $68^{\circ}$ (Core No. 10) and $440^{\circ}$ (Core No.11) was estimated using the 5 rod calibration as reported in reference (16). This calibration curve is a result of many different measurements under a varicty of conditions and is believed to be the best estimate of 5 rod bank calibration. The measured reactivity in dollars was converted to reactivity in percent using the formula beta effective discussed in the previous section. The uncertainty in the integral bank worth is estimated to be one dollar or $0.7 \% \rho$. Table 3.13 indicates that the P-1 slowing down model using the MUFT-III nuclear data gives calculated reactivities within experimental error. 


\section{Core No. 12}

The reactivity of SM-1 Core I in the rods out condition with the control rod fuel elements replaced by 7 fixed elements was estimated based on limited experimental data. As reported in reference (16) the substitution of fixed fuel elements for all 7 of the control rod fuel elements results in an increase in core reactivity of 3.15 dollars. The measured substitution effect ( 3.15 dollars) plus the measured excess reactivity from rod calibrations (23.8 dollars) yields an estimated excess reactivity of the SM-1 Core I with 45 fixed elements of 26.95 dollars or $18.93 \% \rho$. The reactivity of this configuration was calculated using the PDQ code in $x, y$ geometry. The results are shown in Table 3.14 and indicate that the P-1 slowing down model using MUFT-III nuclear data yields the best agreement with the experimental reactivity determined by the recipe previously described.

\section{Core No. 13}

In the SM-2 critical experiments a core was assembled with no burnable poison and the reactivity of the core in the rods out conditions estimated from control rod bank calibrations. The effect of replacing the 7 control rod fuel elements by fixed elements was also estimated. The experimental reactivity for this core (45 fixed elements) was estimated to be $30.6 \pm 0.43$ dollars or $26 \% \rho$. Table 3.15 gives the results of calculated reactivities using the equivalent bare model. The comparison with experiment indicated the P-1 slowing down model using MUFT-III nuclear data yield the best agreement with experiments.

\subsubsection{Conclusions}

Based on the results presented in the previous section the following conclusions are drawn relative to the accuracy of various nuclear models and nuclear data for calculation of fast loop constants for use in two group theory.

1. In $\mathbf{1 3}$ cores calculated the P-1 slowing down model using MUFT-III nuclear data yielded standard deviation of measured and calculated reactivities of $0.91 \% \rho$.

2. In 13 cores the P-1 S. G. slowing down model using MUFT-III nuclear data yielded standard deviation of measured and calculated reactivities of $1.31 \% p$.

3. For 6 experiments calculated using P-1 slowing down model and MUFT-V nuclear data, the calculated reactivities were on the average 3. $3 \% \rho$ higher than measured. 
TABLE 3.14

REACTIVITY ANALYSIS OF SM- 1 CORE I, $68^{\circ} \mathrm{F}$

(ALL 45 FLXED FUEL ELEMENTS)

FAST FILES AND SLOWING-DOWN MODEL

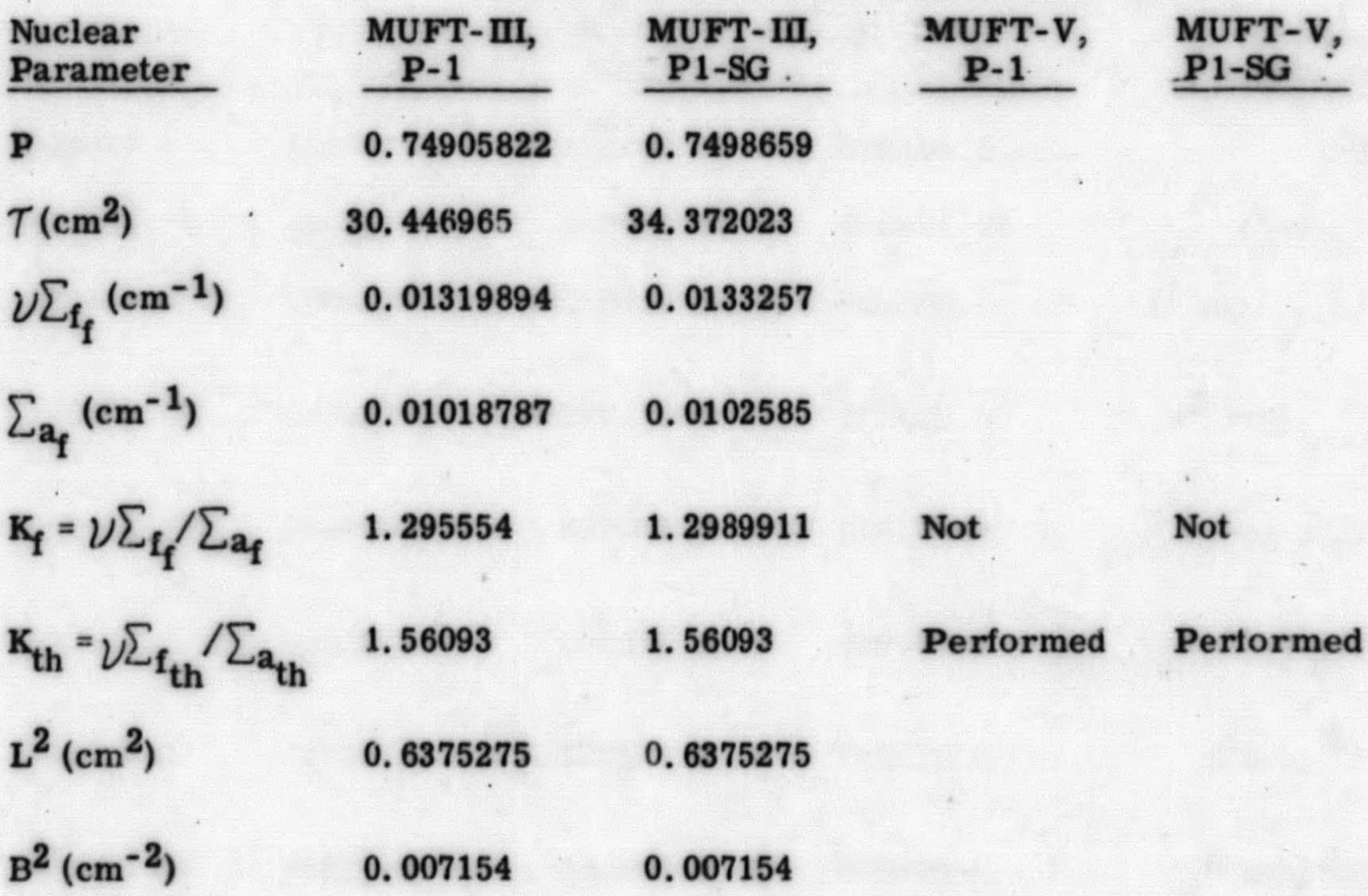

$\% \rho$ (Equivalent Bare) 18. 21

16. 39

$\% \rho$ (PDQ) $\quad 18.26$

$\% \rho$ (measured)* $\quad 18.93 \quad 18.93$

* Overall measured substitution reactivity effect for 7 elements was obtained by individual element measurements. 
TABLE 3.15

REACTIVITY ANALYSIS OF SM-2 EXPERIMENTAL CORE

(ALL 45 FIXED ELEMENTS WITH NO B-10), 680 F

FAST FILES AND SLOWING-DOWN MODEL

\begin{tabular}{|c|c|c|c|c|}
\hline $\begin{array}{l}\text { Nuclear } \\
\text { Parameter }\end{array}$ & $\begin{array}{c}\text { MUFT-III, } \\
\text { P-1 } \\
\end{array}$ & $\begin{array}{l}\text { MUFT-III, } \\
\text { P1-SG. }\end{array}$ & $\begin{array}{l}\text { MUFT-V, } \\
\text { P-1 }\end{array}$ & $\begin{array}{l}\text { MUFT-V, } \\
\text { P1-SG }\end{array}$ \\
\hline $\mathbf{p}$ & 0.646630 & 0.647411 & 0.750529 & 0.750986 \\
\hline$\tau\left(\mathrm{cm}^{2}\right)$ & 32.176362 & 35. 886659 & 30.232861 & 33.683175 \\
\hline$V \sum_{f_{f}}\left(\mathrm{~cm}^{-1}\right)$ & 0.020218 & 0.013872 & 0.014935 & 0.015038 \\
\hline$\sum_{a_{f}}\left(\mathrm{~cm}^{-1}\right)$ & 0.013773 & 0.013872 & 0.009849 & 0.009911 \\
\hline $\mathbf{K}_{\mathrm{f}}=v \sum_{\mathbf{f}_{\mathrm{f}}} / \sum_{\mathrm{a}_{\mathrm{f}}}$ & 1. 467913 & 1. 470408 & 1. 516400 & 1. 517380 \\
\hline $\mathbf{k}_{\mathrm{th}}=\nu \sum_{\mathbf{f}_{\mathrm{th}}} / \sum_{\mathbf{a}_{\mathrm{th}}}$ & 1. 775900 & 1. 775900 & 1. 775900 & 1. 775900 \\
\hline $\mathrm{L}^{2}\left(\mathrm{~cm}^{2}\right)$ & 0.472351 & 0.472351 & 0.472351 & 0.472351 \\
\hline $\mathrm{B}^{2}\left(\mathrm{~cm}^{-2}\right)$ & 0.006956 & 0.006956 & 0.006956 & 0.006956 \\
\hline$\% \rho$ (Equivalent Bare & 26.42 & 24.92 & 29. 09 & 27. 70 \\
\hline$\% \rho$ (Measured) & 26.00 & $\sim 26.00$ & $\sim 26.00$ & $\sim 26.00$ \\
\hline
\end{tabular}


4. There are some inconsistencies in comparison of various nuclear models and data with certain of the experiments; in particular, the minimum size SM-1 ZPE Core I experiments, and the fully poisoned ZPE experiments. The cause of this may be due to the very small size of the cores in the first case and the possible inaccuracies of material content of the fully poisoned cores.

\section{4 EFFECT OF FAST GROUP CALCULATIONAL MODEL ON FRACTION OF THERMAL FISSIONS}

The effect of the fast calculation model on the fraction of thermal fissions was calculated and compared to experiment. The analysis was performed for the SM-1 Core I at $68^{\circ} \mathrm{F}$.

\subsubsection{Experimental Data}

The experimental determination of the fraction of thermal fissions, $\Psi$, was based upon the irradiation of bare and cadmium covered uranium foils. The measurements were performed in the SM-1 ZPE Core I (17) which employs a core which is a duplicate of SM-1 Core I. The initial 5 rod actual bank position was 3.7 in. withdrawn from the bottom of the active core which indicates $18.3 \mathrm{in}$. of the core was rodded. The experimental method is described in reference (9). The effective cutoff energy for the 0.020 in. cadmium covers used in the measurements is $0.414 \mathrm{ev}$. (18) Bare and cadmium covered uranium foils were irradiated in several fuel element cells at 9 in. elevation. The results are shown in Table 3.16.

TABLE 3.16

FRACTION OF THERMAL FISSIONS FOR THE SM-1 ZPE CORE I FOR VARIOUS AXIAL AND RADIAL POSITIONS

Radial Position from Center of Core (Inches)

0

5.9

4.2

4.2
Axial Position from Bottom of Core (Inches)
Fraction of Thermal Fission
9.0
.801
.840
.802
.825

Table 3.16 indicates that the average fraction of thermal fissions below $0.414 \mathrm{ev}$ is $0.82 \pm 0.02$ for SM-1 ZPE Core I at $680 \mathrm{~F}$. 


\subsubsection{Calculational Approach}

The following definition of $\Psi_{\text {was }}$ used

$$
\Psi=\frac{1}{\mathbf{k}_{\text {eff }}} \frac{\mathbf{K}_{t h} \mathbf{P}}{\left(1+\tau \mathbf{B}^{2}\right)\left(1+L^{2} \mathbf{B}^{2}\right)}
$$

Where $\mathbf{k}_{e f f}$ is given by equation (2.10), and the remaining parameters are defined in Appendix E.

The effective cutoff energy of $0.414 \mathrm{ev}$ corresponds to the use of 56 fast groups with a lower cutoff of $0.400 \mathrm{ev}$.

\subsection{Results}

Table 3.17 presents the measured and calculated values of the fraction of thermal fission, $\Psi$, for the clean SM-1 Core I ZPE-2, at $68^{\circ} \mathrm{F}$, using various fast files and number of fast groups, with the P-1 slowing-down model.

TABLE 3.17

COMPARISON OF FRACTION OF THERMAL FISSION, SM-1 CORE I ZPE-2 (CLEAN), 680

\begin{tabular}{|c|c|c|c|c|}
\hline $\begin{array}{l}\text { Calculational } \\
\text { Method } \\
\end{array}$ & $\begin{array}{l}\text { Number of } \\
\text { Fast Groups }\end{array}$ & $\begin{array}{l}\text { Lower Cutoff } \\
\text { Energy (ev) }\end{array}$ & Calculated & Measured \\
\hline MUFT-V, P-1 & 54 & 0.625 & 0.85 & $0.82 \pm 0.02$ \\
\hline MUFT-III, P-1 & 54 & 0.625 & 0.85 & $0.82 \pm 0.02$ \\
\hline MUFT-III, P-1 & 56 & 0.400 & 0.83 & $0.82 \pm 0.02$ \\
\hline MUFT-III, P-1 & 59 & 0.196 & 0.78 & $0.82+0.02$ \\
\hline
\end{tabular}

According to Table 3. 17, the calculated fraction of thermal fission, $\Psi$ as obtained by the 56 fast group, MUFT-III fast files (approximately corresponding to the effective cadmium cutoff energy of $0.414 \mathrm{ev}$ ), using the P-1 slowing-down model, agrees well with the measured value. The calculated values for $\Psi$, as obtained by the MUFT-III and MUFT-V fast files, using 54 fast groups (corresponding to a lower cutoff energy of $0.625 \mathrm{ev}$ ), are identical. It is not possible to decide whether the MUFT-III or MUFT-V fast files are more accurate in pre-

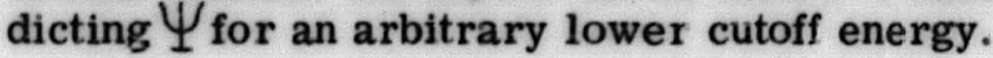




\subsubsection{Conclusions}

Using MUFT-III nuclear data and the P-1 slowing down model the predicted fraction of thermal fission was found to be in very good agreement with experiment. At the center of the fuel elements, the calculated and measured values are within experimental error.

\section{5 EFFECT OF FAST CALCULATIONS ON FAST FLUX DISTRIBUTIONS}

An analysis was performed to obtain the effect of the fast group constants on the fast flux distributions for the reference SM-1 Core I (38 fixed plus 7 control rod fuel elements), at $68^{\circ} \mathrm{F}$. The measurements were performed for the clean SM-1 ZPE Core. (9) The measurements were limited to the center positions of one row of elements in the unrodded region of the core. The analytical flux distributions were compared to experiment.

\subsubsection{Experimental Data}

The experimental determination of the fast flux distributions was based upon the irradiation of bare and cadmium covered gold foils in the clean SM-1 ZPE Core $(9)$ at $68^{\circ} \mathrm{F}$. The initial five rod bank position was $3.7 \mathrm{in}$. withdrawn from the bottom of the active core. The bare gold foils provided an indication of the total flux, whereas the cadmium covered gold foil readings yielded the fast flux above $0.414 \mathrm{ev}$ (effective cutoff energy of 0.020 in. cadmium).

A radial traverse through the center of elements $44,45,46$ and 47 at 2.5 in. axially was made with bare and cadmium covered gold foils.

\subsubsection{Results}

Figure 3. 3 presents measured and calculated fast radial flux distributions, for SM-1 Core I ZPE- 1 , at $68^{\circ} \mathrm{F}$. The calculated fluxes as based on the MUFTIII and MUFT-V fast files, with the P-1 slowing-down model, were found to be undistinguishable. A one-dimensional two region calculation was performed with VALPROD.

\subsubsection{Conclusions}

1. The difference in calculated radial fast flux distribution using P-1 MUFT-III and MUFT-V was undistinguishable for SM-1 Core I.

2. The calcuiated radial fast flux distribution is in good agreement with the fast flux as measured with cadmium covered gold foils. 
ڤ்

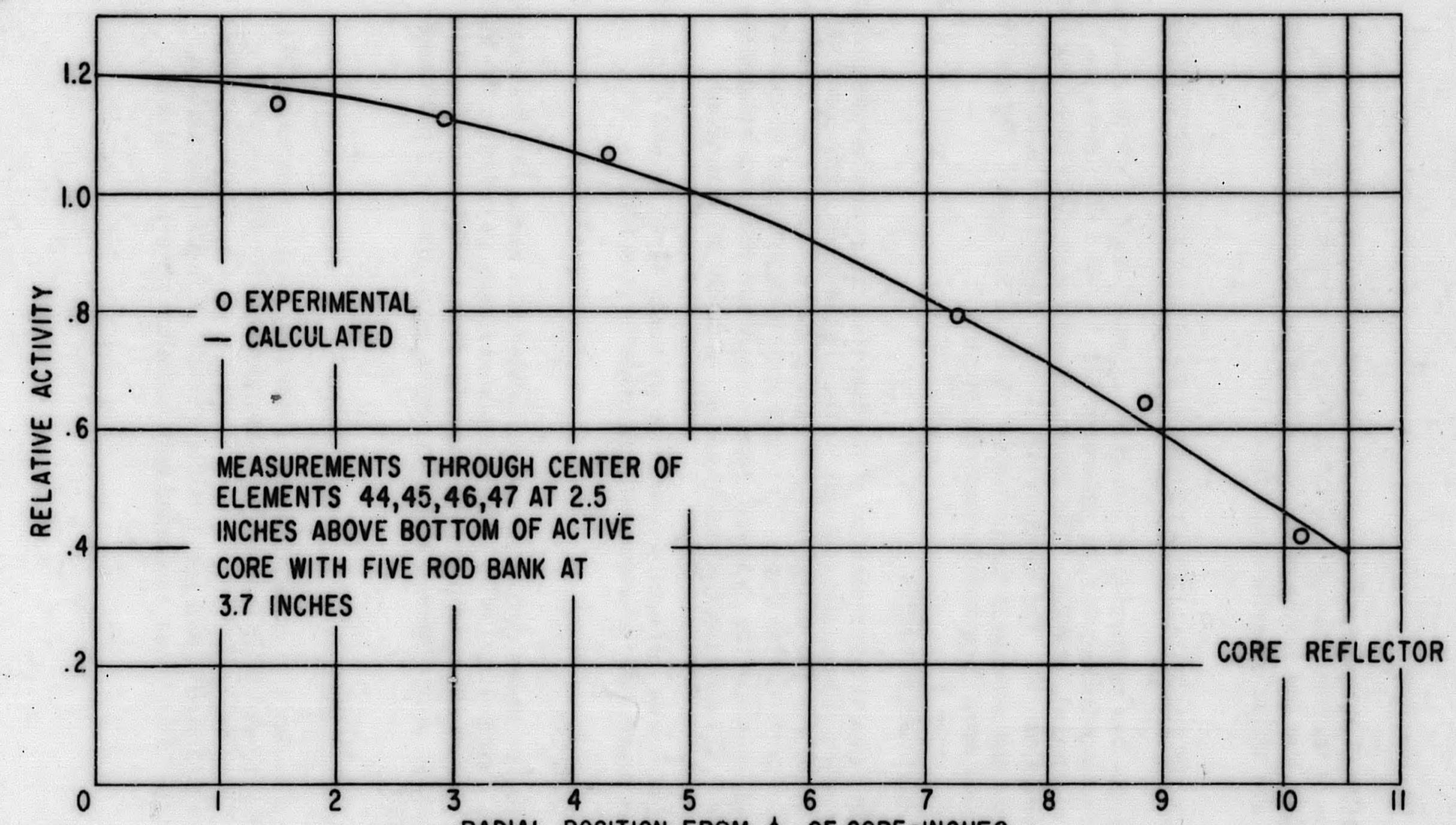

Figure 3.3 Fast Flux vs. Radial Position - SM-1 Core 1, $68^{\circ} \mathrm{F}$ 


\section{6 EFFECT OF THERMAL MODEL ON REACTIVITY OF SM-1 CORE I}

\subsection{Introduction}

The thermal model currently employed by Alco to calculate thermal flux distribution is based on the one velocity, $\mathbf{P}_{3}$ spherical harmonics approximation to the tiansport equation. Hardened, Maxwellian averaged cross sections are employed. The thermal neutron energy spectrum is assumed independent of position and is taken to be that for an infinite homogeneous mixture of the materials comprising the core.

Flux disadvantage factors are obtained from the calculated thermal flux distribution and are used to obtain effective nuclear constants for an infinite array of fuel element cells. $K_{\text {th }}{ }^{*}, D$ and $L^{2}$ for the cell are computed in this manner. (19)

Only one direct comparison between measured and calculated (i. e., by the hardened Maxwellian, $\mathbf{P}_{3}$ scheme) microscopic intraplate flux distribution has been performed. This comparison was made with data obtained during zero power experiments on the SM-1 Core I mockup (core spectral hardening index, $\beta \gamma^{* *}$, equal to 0.35 at room temperature) and yielded reasonable agreement between the calculated and experimental flux distributions. (20)

Measured and calculated gross intracell power distributions for the SM-1 have been compared. However, the results of this comparison are not a direct measure of the validity of the thermal model since the thermal constants used in the calculation (as computed by the hardened Maxwellian, $\mathrm{P}_{3}$ scheme) are subsequently used in a diffusion theory calculation which determined the gross intracell power distribution.

The rods-out excess reactivity of the SM-1 Core $I$ is computed for an all fixed element core based on Wigner-Wilkins averaged thermal cross sections and compared to the excess reactivity computed using hardened Maxwellian averaged cross sections. The same fast model (MUFT-III, P-1) is used for both cases.

* $\mathbf{K}_{\mathrm{th}}=\frac{\nu \sum \mathrm{f}_{\mathrm{th}}}{\sum_{\mathrm{ath}}}$ where $\nu, \sum_{\mathrm{f}_{\text {th }}}, \sum_{\mathrm{a}_{\mathrm{th}}}$ are defined in Appendix E.

** $\beta \gamma_{\text {is defined as }} \sum_{\mathrm{a}}\left(\mathrm{KT}_{\mathrm{m}}\right) / \xi \sum \mathrm{s} \cdot \sum_{\mathrm{ath}_{\mathrm{th}}}$ and $\sum_{\mathrm{s}}$ are defined in Appendix $\mathbf{E}$. 


\subsection{Results}

The thermai multiplication constant, $\mathrm{K}_{\mathrm{th}}$, for the rods-out SM-1 Core I was computed with Wigner-Wilkins averaged thermal cross sections and compared to $\mathrm{K}_{\mathrm{th}}$ calculated with Maxwellian averaged thermal cross sections. The cutoff energy of the Wigner-Wilkins distribution was $10 \mathrm{KT}_{\mathrm{m}}$ while the Maxwellian distribution was assumed to extend to infinity. The values of the fast and thermal constants used in the calculation are given in Table 3.18. The equivalent bare model was used.

TABLE 3.18

FAST AND THERMAL CONSTANTS AND REACTIVITY $C_{\text {FOR THE SM-1 }}$

Method of

Obtaining

Thermal

Constants

$\mathbf{K}_{\text {th }}$

$L^{2} \quad B^{2}$

$\tau \quad \mathbf{K}_{\mathrm{f}}$

P* $\% \rho$

Hardened

1. 56093

$6375 \quad .007154$

30.45

1. 29555

$74906 \quad 18.21$

Maxwellian

Wigner-

Wilkins

Averaged

$1.55777 \quad .6796 \quad 007154 \quad 30.45$

$1.29555 \quad .74906$

18. 06

* The fast constants were obtained from MUFT-III using the P-1 slowing down approximation.

\subsection{Conclusions}

1. Use of Wigner-Wilkins averaging of thermal constants for calculation of thermal group constants lowers reactivity of SM-1 Core I by about $0.2 \%$.

2. Core reactivities are not known for SM-1 Core I to sufficient accuracy to be used as a criteria for thermal selection.

3. Insufficient thermal flux distributions and no thermal spectra are available to serve as a test of calculational model.

\subsection{Summary}

In this section we have investigated the accuracy of various models and files in predicting nuclear constants and reactivity of various assemblies. MUFT-III files and P-1 slowing down model gave the best results for reactivity, thermal fission fraction and fast flux. 
In the following section this will be applied in the investigation of the characteristics of SM-1 Core I at startup.

\section{7 REFERENCES (3.0)}

1. Doerner, R. C., et al, "Age of Fission Energy Neutrons to Indium Resonance in Water," Nuclear Sc. \& Engr., Vol.9 No. 2, P. 221, February 1961.

2. Reier, M. , "The Age of Polonium-Beryliium and Polonium-Boron Neutrons in Various Metal-Water Mixtures; A Comparison Between Theory and Experiment," A/CONF. 15/P/635, June 1958.

3. Mills, C. B., "The General Methods of Reactor Analysis used by the ANP Physics Group," ORNL-1493, September 22; 1953. (Secret)

4. MacKay, S. D., et al, "SM-1 (APPR-1), Research and Development Program, Interim Report on Core Measurements, Task No. VII, APAE Memo No. 178, March 1, 1959.

5. Forbes, S. G. , et al, "Quarterly Technical Report, SPERT Project," IDO-16584, April 12, 1960.

6. Blizard, E. P., "Neutron Physics Division Annual Progress Report for Period ending September 1, 1960," ORNL-3016, December 17, 1960.

7. Rutledge, G. P. and Kantorczyk, P. A., "Nuclear Analysis of Thermal Reflected Cylindrical Homogeneous Critical Assemblies," WAPD-TM244, November, 1960.

8. Williamson, T. G. "Analysis of the ORNL Experiments for APPR-1 Using Improved Techniques," AP Note 118 Alco Products, Inc., November 14, 1958.

9. Noaks, J. W. and Johnson, W. R. , "Army Package Power Reactor Zero Power Experiments (ZPE-1)," APAE-8, February 8, 1957.

10. Giesler, H. W., "Additional Measurements on the Army Package Power Reactor Zero Power Experiments, ZPE-1 and ZPE-2," APAE Memo 115, November 15, 1957.

11. MacKay, S. D., et al, "Extended Zero Power Experiments on the Army Package Power Reactor, ZPE-2, "APAE No. 21, November 15, 1957.

12. Paluszkiewicz, S., "Analysis of Zero Power Experiments on SM-1 Core II and SM-1A Core I, " APAE No. 71, October 5, 1960. 
13. Rosen, S. S., "Hazards Summary Report for the Army Package Power Reactor SM-1, Task XVI," APAE No. 2, Revision 1, May, 1960.

14. O'Brien, J. F., et al, "A Boron Determination for the APPR-1," MND-E-1718-1, May 25, 1959.

15. Bobe, P. E., et al, "Interim Report of Nuclear Analysis Performed on SM-2 Core and Vessel, September 1, 1958 to December 31, 1959," APAE No. 65, May 27, 1960.

16. Weiss, S. H., "Summary Report of Physics Measurements on SM-1 Core $I_{2}$ " APAE-96, February 6, 1962.

17. Mackay, J.D., et al, "Extended Zero Power Experiments on the APPR-ZPE-2," APAE-21, November 15, 1957.

18. Dayton, T. E. and Pettus, W. J., "Effective Cadium Cut Off Energy," Nucleonics, Vol. 15 No. 12 p. 86, December 1957.

19. Byrne, B. J., Caton, R. L., "Two-Dimensional P-3 Calculation for APPR-'Type Fixed Fuel Elements,". AP Note 96, Alco Products, Inc., February 14, 1958.

20. Caton, R. L., Byrne, B. J., "Two Dimensional $\mathbf{P}_{3}$ Calcuiation for APPR-Type Fixed Fuel Elements," AP Note 96, Alco Products, Inc., February 141958.

21. Hellens, R. H., et al, "Multigroup Fourier Transform Calculation Description of MUFT-III Code," WAPD-TM-4, Juiy 1956.

22. Rosen, S. S. , 'Supplement to MUFT-III Code Muitigroup Fourier Transform Calculations," AP Note-90, Alco Products, Inc., December 6, 1957.

23. Paluszkiewicz, S. "Nuciear Analysis of Various SPERT-III Critical Experiments," APAE Memo No. 279, April 27, 1961.

24. Henry, A. F., "54 Group Library for P-1 Programs," WAPD-TM-224, April, 1960.

25. Byrne, B. J., and Oby, P. V., "Anaiysis of Extended Zero Power Experiments on the Army Package Power Reactor, ZPE-2," APAE No. 27, May $7,1958$.

26. Noaks, J. W., "SM-2 Critical Experiments, CE-1," APAE No. 54, November $30,1959$. 
27. Williams, D., "Army Package Power Reactor Critical Experiment," ORNL-2128, August 8, 1956.

28. Spano, A.H., "Experimental and Analytical Studies of Clean Criticai Stainless Steel Cores," IDO-16691, June 16, 1961. 


\section{0 CORE CHARACTERISTICS AT STARTUP}

\subsection{INTRODUCTION}

Using the nuclear model (P-1) and nuclear data (MUFT-III) selected in Section 3. 0, a number of important SM-1 Core I characteristics were calculated and compared to experiment. These are as follows:

Core Reactivity at $68^{\circ} \mathrm{F}$

Core Reactivity at $440^{\circ} \mathrm{F}$

Core Reactivity at $440^{\circ} \mathrm{F}$ equilibrium Xe

Bank Position at $68^{\circ} \mathrm{F}$

Bank Position at $440^{\circ} \mathrm{F}$

Bank Position at $440^{\circ} \mathrm{F}$ equilibrium Xe

Central control rod worth in poisoned core, $68^{\circ} \mathrm{F}$

\section{2 CORE REACTIVITY}

The reactivity of SM-1 Core I at $68^{\circ} \mathrm{F}, 440^{\circ} \mathrm{F}$ and $440^{\circ} \mathrm{F}$ equilibrium Xe was obtained from 5 rod critical positions and a 5 rod bank calibration curve. The positions and curves are given in reference (1) for SM-1 Core I at startup.

Table 4.1 presents this experimental data.

\section{TABLE 4.1}

EXPERIMENTAL INITIAL FIVE ROD BANK POSITIONS AND EXCESS

CORE REACTIVITIES OF THE SM-1 CORE I. 0 MWYR

\section{Operating}

Condition

$68^{\circ} \mathrm{F}$ (no xenon)

$440^{\circ} \mathrm{F}$ (no xenon)

$440^{\circ} \mathrm{F}$ (eq. xenon)
Initial 5 Rod

Bank Position (in.)

3. 7

6. 7

8. 3

\section{Excess Core} Reactivity (\$)

23. 80

16. 50

12. 90
Excess Core Reactivity $(\% \rho)$
16. 95

12. 10

9. 55 


\section{2. 1. Geometrical Models}

The reactivity of the SM-1 Core I for the various core operating conditions was calculated by both one-and two-dimensional models.

\subsubsection{Two-Dimensional Model PDQ $(x, y)$}

The reactivity of the SM-1 Core I at $68^{\circ} \mathrm{F}$ (clean) and $440^{\circ} \mathrm{F}$ (clean) were calculated using the PDQ $(x, y)$ code. The fixed and control rod fuel elements were broken down into active and dead regions according to Fig. 2.1 and 2.2 respectively. Tables 4.2 and 4.3 present the region isotopic number densities of the SM-1 Core I at $68^{\circ} \mathrm{F}$ and $440^{\circ} \mathrm{F}$ (clean) respectively.

Fast nuclear constants, required as input to the PDQ code, were calculated by the MUFT-III code, employing MUFT-III fast files with the P-1 slowing-down model. The MUFT-III code requires the total core buckling, $\mathrm{B}^{2}$, as an input parameter. The buckling was calculated employing. Eq. (2.11). Reflector savings was calculated from the fast flux distributions obtained from cadmium covered gold foil measurements at $68^{\circ} \mathrm{F}$. The savings was also determined by the FINK-I, IBM-650 machine code, which employs the equivalent bare model at $68^{\circ} \mathrm{F}$ and $440^{\circ} \mathrm{F}$. The difference between the calculated and measured savings at $68^{\circ} \mathrm{F}$ was used as a correction to the hot, calculated savings to obtain the "measured" savings at $440^{\circ} \mathrm{F}$. Table 4.4 presents the reflector savings and bucklings for the SM-1 Core $I$ at $68^{\circ} \mathrm{F}$ and $440^{\circ} \mathrm{F}$. The axial bucklings, $\mathrm{B}_{\mathrm{Z}}{ }^{2}$, that are listed, were used as input parameters to the PDQ $(x, y)$ calculations.

Tables 4. 5 and 4. 6 present the fast macroscopic cross sections for the various regions as used in the $\mathrm{PDQ}(\mathrm{x}, \mathrm{y})$ code, at $68^{\circ} \mathrm{F}$ and $440^{\circ} \mathrm{F}$ (clean), respectively. The cold $\left(68^{\circ} \mathrm{F}\right)$ calculations were based on 59 fast lethargy groups (lower energy cutoff of $0.196 \mathrm{ev}$ ), whereas the hot $\left(440^{\circ} \mathrm{F}\right)$ calculations were based on 58 fast groups $(0.248 \mathrm{ev})$.

The thermal macroscopic cross sections were calculated using an IBM-650, two-dimensional P-3 superposition code written for the APPR type fuel cell geometry. Input parameters to the code were based upon Maxwell-Boltzmann averaged microscopic cross sections evaluated at hardened neutron temperatures according to Eq. (2.6). Effective neutron temperatures of $0.0331 \mathrm{ev}$ and $0.0549 \mathrm{ev}$, corresponding to coolant temperatures at $68^{\circ} \mathrm{F}$ and $440^{\circ} \mathrm{F}$ respectively, were determined by this relation. Microscopic thermal neutron cross section were evaluated (2) at these effective temperatures and are tabulated in Tables 4.7 and 4.8 for coolant temperatures of $68^{\circ} \mathrm{F}$ and $440^{\circ} \mathrm{F}$ respectively.

Tables 4.9 and 4.10 present the thermal macroscopic cross sections as obtained by the P-3 code for the various regions as seen by the PDQ $(x, y)$ code, at $68^{\circ} \mathrm{F}$ and $440^{\circ} \mathrm{F}$, respectively. Slowing-down sources, required as input to the P-3 code, were taken to be the volume fractions of water in any region. 


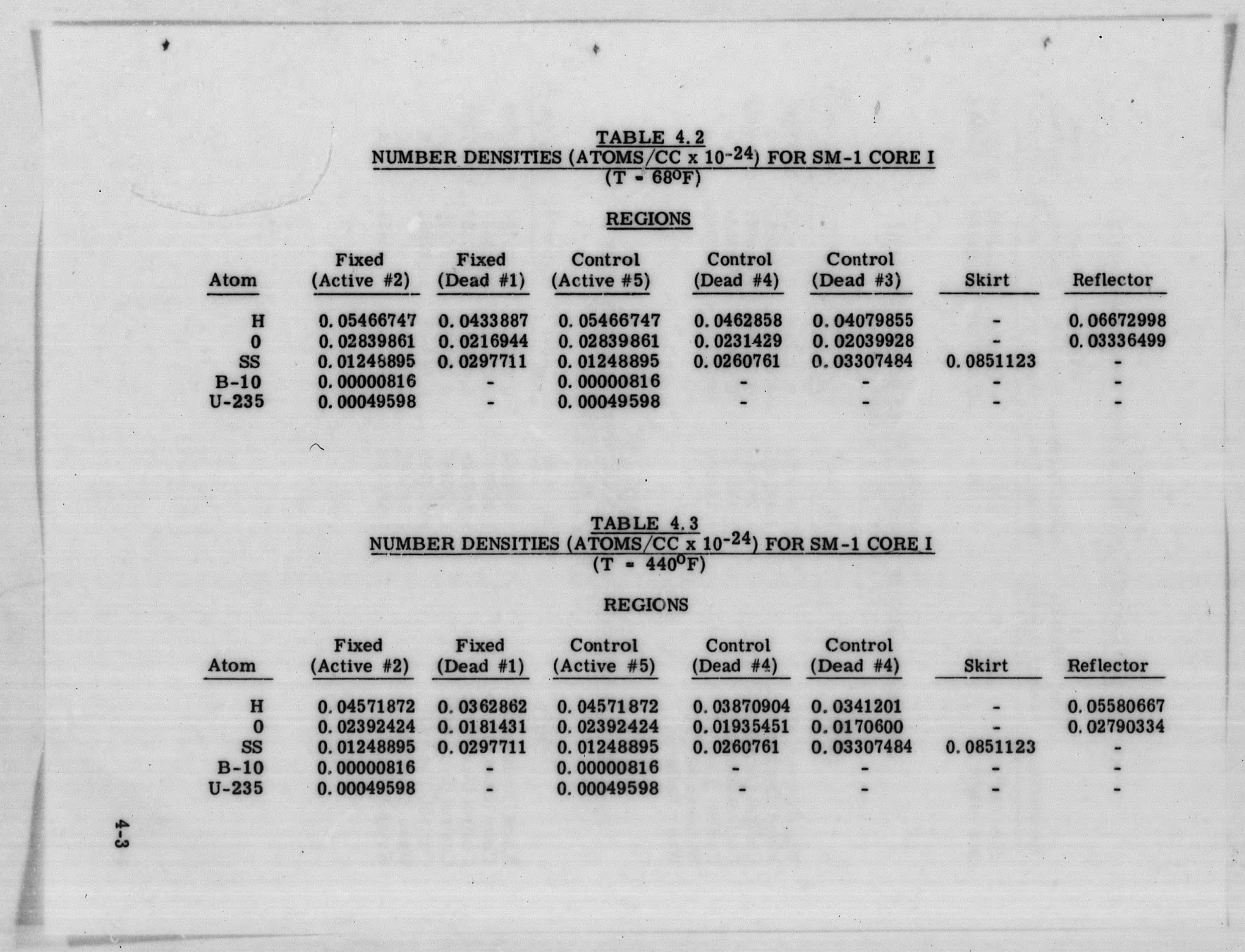


TABLE 4.4

REFLECTOR SAVINGS AND BUCKLINGS FOR SM-1 CORE I

Axial Axial Total

Axial Reflector Radial Reflector Buckling Buckling

Temperature Savings, $\mathrm{S}_{\mathbf{z}}(\mathrm{cm})$

Cold $\left(68^{\circ} \mathrm{F}\right)$

Hot $\left(440^{\circ} \mathrm{F}\right)$

5. 11

6. 10

6. 18

7. 80

0.002259

0.002129

0. 004895

ค. 004465

\subsection{4}

0.006594

TABLE 4.5

FAST MACROSCOPIC CROSS SECTIONS FOR SM-1 CORE I $\left(\mathrm{T}=68^{\circ} \mathrm{F}, \mathrm{E}_{\mathrm{n}}=0.0331 \mathrm{ev}\right)$

\begin{tabular}{|c|c|c|c|c|}
\hline Region & $\mathrm{D}_{\mathrm{f}}(\mathrm{cr}$ & $\sum_{\mathrm{af}}\left(\mathrm{cm}^{-1}\right)$ & $\sum_{\mathrm{sl}}\left(\mathrm{cm}^{-1}\right)$ & $\sum_{\mathrm{ff}}\left(\mathrm{cm}^{-1}\right)$ \\
\hline \multirow{7}{*}{$\begin{array}{l}\text { Fixed (Active \#2) } \\
\text { Fixed (Dead \#1) } \\
\text { Control (Active \#5) } \\
\text { Control (Dead \#4) } \\
\text { Control (Dead \#3) } \\
\text { Stainless Stl. Skirt } \\
\text { Water Reflector }\end{array}$} & 1. 249010 & 0.010989 & 0.030652 & 0.015080 \\
\hline & 1. 161803 & 0.004505 & 0.029212 & \\
\hline & 1. 249010 & 0.010989 & 0.030652 & 0.015080 \\
\hline & 1. 174127 & 0.004029 & 0.031347 & 0 \\
\hline & 1. 151920 & 0.004927 & 0.027290 & 0 \\
\hline & & & & \\
\hline & & & & \\
\hline \multicolumn{5}{|c|}{ TABLE 4.6} \\
\hline \multicolumn{5}{|c|}{$\begin{array}{l}\text { FAST MACROSCOPIC CROSS SECTIONS FOR SM-1 CORE I } \\
\qquad\left(T=440^{\circ} \mathrm{F}_{1} \mathrm{E}_{\mathrm{n}}=0.0549 \mathrm{ev}\right)\end{array}$} \\
\hline Region & $\underline{D_{\mathrm{f}}(\mathrm{cm})}$ & $\sum_{\mathrm{af}}\left(\mathrm{cm}^{-1}\right)$ & $\sum_{\mathrm{sl}}\left(\mathrm{cm}^{-1}\right)$ & $V \sum_{\mathrm{ff}}\left(\mathrm{cm}^{-1}\right)$ \\
\hline Fixed (Active \#2) & 1. 441284 & 0.010016 & 0.025256 & 0.013702 \\
\hline Fixed (Dead \#1) & 1. 296577 & 0.004233 & 0.024447 & 0 \\
\hline Control (Active \#5) & 1. 441284 & 0.010016 & 0.025256 & 0.013702 \\
\hline Control (Dead \#4) & 1. 320149 & 0.003773 & 0.026239 & 0 \\
\hline Control (Dead \#3) & 1. 277278 & 0.004643 & 0.022832 & 0 \\
\hline Stain. Stl. Skirt & 1. 513043 & 0.008133 & 0 & 0 \\
\hline Water Reflector & 1. 561416 & 0.000499 & 0.038424 & 0 \\
\hline
\end{tabular}


TABLE 4.7

THERMAL MICROSCOPIC CROSS SECTIONS FOR COOLANT TEMPERATURE, $68^{\circ} \mathrm{F}$ (EFFECTIVE NEUTRON TEMPERATURE, $0.0331 \mathrm{ev}$ )

\begin{tabular}{|c|c|c|c|c|}
\hline Nuclide & $\overline{\sigma_{s}}$ & ${\overline{\sigma_{a}}}_{a}$ & $\bar{\sigma}_{\mathrm{tr}}$ & $\nu \bar{\sigma}_{f}$ \\
\hline U-235 & 9.0 & 512. 6564 & 521.630 & 1065.1394 \\
\hline $\mathrm{U}-238$ & 9.0 & 2. 118036 & 11. 093 & - \\
\hline $\mathbf{H}$ & 34. 32 & 0.254164 & 27.170 & - \\
\hline 0 & 3. 9 & 0 & 3. 7375 & \\
\hline B-10* & 4,4 & 2932.4980 & 2936.6051 & - \\
\hline SS & 10.44 & 2. 270275 & 12. 586 & - \\
\hline
\end{tabular}

TABLE 4.8

THERMAL MICROSCOPIC CROSS SECTIONS FOR COOLANT TEM PERATURE, $440^{\circ} \mathrm{F}$ (EFFECTIVE NEUTRON TEMPERATURE, $0.0549 \mathrm{ev}$ )

\begin{tabular}{|c|c|c|c|c|}
\hline Nuclide & $\bar{\sigma}_{s}$ & $\bar{\sigma}_{\mathrm{a}}$ & $\bar{\sigma}_{\mathrm{tr}}$ & $v \bar{\gamma}_{f}$ \\
\hline U-235 & 9.0 & 385.5384 & 394.512 & 801. 0342' \\
\hline U-238 & 9.0 & 1. 644605 & 10.620 & - \\
\hline H & 28. 97 & 0.197353 & 20.65 & - \\
\hline 0 & 3. 9 & 0 & 3. 7375 & - \\
\hline B-10* & 4. 4 & 2277.0146 & 2281.1217 & - \\
\hline SS & 10.44 & 1. 762814 & 12.078 & - \\
\hline
\end{tabular}

* Based upon $19.8 \mathrm{a} / \mathrm{o}$ of $\mathrm{B}-10$ in natural boron. 
TABLE 4.9 THERMAL MACROSCOPIC CROSS SECTIONS FOR SM-1 CORE I $\left(\mathrm{T}=68^{\circ} \mathrm{F}, \mathrm{E}_{\mathrm{n}}=0.0331 \mathrm{ev}\right)$

\begin{tabular}{|c|c|c|c|}
\hline Region & $\mathrm{D}_{\text {th }}(\mathrm{cm})$ & $\sum_{a t h}\left(\mathrm{~cm}^{-1}\right)$ & $\nu \sum_{\mathrm{fth}}\left(\mathrm{cm}^{-1}\right)$ \\
\hline Fixed (Active \#2) & 0. 164460 & 0.305872 & 0.502897 \\
\hline Fixed (Dead \#1) & 0.203917 & 0.078616 & 0 \\
\hline Control (Active \#5) & 0.164460 & 0.305872 & 0.502897 \\
\hline Control (Dead \#4) & 0.199329 & 0.070964 & 0 \\
\hline Control (Dead \#3) & 0.208201 & 0.085458 & 0 \\
\hline Stainless Steel Skirt & 0.311171 & 0. 193228 & 0 \\
\hline Water Reflector & 0.172020 & 0.016960 & 0 \\
\hline
\end{tabular}

TABLE 4.10

THERMAL MACROSCOPIC CROSS SECTIONS FOR SM-1 CORE I $\left(\mathrm{T}=440^{\circ} \mathrm{F}, \mathrm{E}_{\mathrm{n}}=0.0549 \mathrm{ev}\right)$

$\underline{\text { Region }} \quad \underline{\mathrm{D}_{\mathrm{th}}(\mathrm{cm})} \quad \underline{\sum_{\mathrm{a}_{\mathrm{th}}}\left(\mathrm{cm}^{-1}\right)} \quad \underline{V \sum_{\mathrm{f}_{\mathrm{th}}}\left(\mathrm{cm}^{-1}\right)}$

\section{Fixed (Active \#2)}

Fixed (Dead \#1)

Control (Active \#5)

Control (Dead \#4)

Control (Dead \#3)

Stainless Steel Skirt

Water Reflector
0.240550
0.283279
0.240550
0.280908
0.285432
0. 324259
0. $26524 €$

0. 234431

0. 059642

0. 234431

0. 053607

0. 065038

0. 150037

0. 011014
0.386374

0

0. 386374

0
0
0
0




\section{2.1.2 One Dimensional Models (VALPROD and WINDOWSHADE)}

The reactivity of the SM-1 Core I was calculated by two one-dimensional models. The VALPROD code was used to calculate a slab configuration in which the fixed elements were homogenized. The transverse buckling in the VALPROD code was taken as

$$
B_{L}^{2}=B_{z}^{2}+B_{y}^{2}=B_{z}^{2}+\frac{B_{y}^{2}}{2}=.004707
$$

\section{2.1.3 VALPROD and WINDOWSHADE}

In addition to the detailed reactivity analysis afforded by the two-dirnensional PDQ $(x, y)$ code, the excess reactivity of the SM-1 Core I at $68^{\circ} \mathrm{F}$, clean, was calculated by the one-dimensional VALPROD and WINDOWSHADE IBM-650 codes. A slab VALPROD case was run for a completely homogenized core. The effect of the control rod elements has been accounted for by the addition of a thermal absorption cross section $\sum_{\mathrm{a}}{ }^{\text {sub }}$ derived as it is described in Section 5.2.1 of this report. For a $2.4 \% \rho$ measured reactivity change for the substitution of seven control rod elements with fixed elements, $\sum_{\mathrm{a}}$ sub was found to be $0.008416 \mathrm{~cm}^{-1}$ and added to $\sum \mathrm{a}$ of the core. The $68^{\circ} \mathrm{F}$ homogenized and fast constants for the fixed element can be found in Appendix C. The WINDOWSHADE code was used to calculate the reactivity of the core, using bucklings to account for the $x$ and $y$ dimensions.

\section{2.2 Results}

The results of the two-dimensional and one-dimensional reactivity calculations for SM-1 Core I rods out is given in Table 4.11.

TABLE 4.11

MEASURED AND CALCULATED REACTIVITY OF SM-1 CORE I

(0 MWYR)

\section{Condition Measured Two-Dimensional}

$\begin{array}{lr}68^{\circ} \mathrm{F} & 16.35 \\ 440^{\circ} \mathrm{F} & 12.10 \\ 440^{\circ} \mathrm{F} \text { Eq. Xenon } & 9.55\end{array}$

16. 67

12. 87
One-Dimensional VALPROD WINDOWSHADE

16. 80

17. 04

12. 88

10. 56 
It is seen that there is very good agreement between the one-dimensional. and two-dimensional reactivity calculations. It is not known how much of this agreement may be due to an error in the treatment of the control rod substitution effect.

It is noted that the hot to cold reactivity is $3.8 \% \rho$ calculated (two- dimensional) and $4.85 \% \rho$ measured.

\section{2.3 Conclusions}

1. The two-dimensional calculations, using the model from Section 3. 0 , yield hot and cold reactivities within $0.8 \% \rho$.

2. The cold to hot reactivity is underestimated by $1 \% \rho$ using two dimensional calculation.

3. There is little difference between one-and two-dimensional calculations of reactivity provided the control rod element substitution effect is properly chosen.

\section{3 BANK POSITIONS}

A comparison of calculated and melasured initial bank positions (five and seven rods) was performed for several core operating conditions at the start of iife.

The analytical results' were determined by the WINDOWSHADE code.

\subsubsection{Analytical Results}

Axial WINDOWSHADE calculations were performed to predict critical bank conditions for the SM-1 Co:re I at various initial operating conditions. The reference analytical model was used, employing modified two-group theory.

sub The equivalent bare model, as given by Eq. (2. 7), was used to calculate $\sum a$ and $\sum_{p}$, thermal absnrption cross sections used to represent the effects of the control rod fuel elements and control rods respectively. The substitution cross section, $\sum$ sub, was added to $\sum_{\text {ath, }}$, the therinal absorption cross section, uniformly throughout the core. The thermal poison cross section, $\sum \mathbf{p}$, was added to $\sum \mathbf{a}_{\text {th }}$ uniformly throughout the rodded region located at the top of the core.

The calculated bank positions were obtained by forcing the WINDOWSHADE code to iterate to a bank position corresponding to $\mathrm{k}_{\text {eff }}-1$ i $\neq \Delta \mathbf{k}^{\prime}$ eff, where $\Delta \mathbf{k}^{\prime}$ eff, is the difference between the excess core reactivities in terms of $k_{e f f}$, as obtained by experiment and the WINDOWSHADE code (rod bank fully withdrawn), called a "model" correction. Table 4.12 presents the excess reactivity, in terms of $\mathrm{K}_{\mathrm{eff}}$, of the SM-1 core under various operating conditions, as tbtained by measurement and the WINDOWSHADE code, with the corresponding values of $\Delta \mathrm{k}^{\prime}$ eff - 
TABLE 4.12

CORE REACTIVITY OF SM-1 CORE I, O MWYR

\begin{tabular}{|c|c|c|c|}
\hline $\begin{array}{l}\text { Core } \\
\text { Condition }\end{array}$ & $\begin{array}{l}\text { Measured } \\
\left.\text { Reactivity ( } \mathrm{k}_{\text {eff }}\right)\end{array}$ & $\begin{array}{l}\text { Calculated } \\
\text { Reactivity }\left(\mathrm{k}_{\text {teff }}\right)\end{array}$ & $\begin{array}{l}\Delta \mathbf{k}^{\prime} \text { eft } \\
\text { (Cale. -Exp. ) }\end{array}$ \\
\hline $\begin{array}{l}68^{\circ} \mathrm{F} \text {, clean } \\
440^{\circ} \mathrm{F} \text {, clean } \\
440^{\circ} \mathrm{F} \text {, eq. xe. }\end{array}$ & $\begin{array}{l}1.2034 \\
1.1377 \\
1.1056\end{array}$ & $\begin{array}{l}1.2054 \\
1.1478 \\
1.1181\end{array}$ & $\begin{array}{l}+0.0020 \\
+0.0101 \\
+0.0125\end{array}$ \\
\hline
\end{tabular}

Table 4.13 presents the comparison of initial bank positipns between measurements and analysis for the SM-1 Core I under various operating conditions at the start of life.

Table 4. 13a presents the values of $\sum_{p}$ and $\sum_{a}$ sub for a five and a seven rod bani for various core conditions.

TABLE 4.13

SM-1 CORE I FIVE AND SEVEN ROD BANK POSITION

FOR VARIOUS CORE CONDITIONS

Rod Bank Position (Inches From Bottom Of Core)

Calculated $\quad \begin{gathered}\text { Difference between } \\ \text { Measured and Calculated }\end{gathered}$

$\begin{array}{llll}\text { Core Conditions Measured } & \begin{array}{l}\text { No Model } \\ \text { Correction }\end{array} \text { Correction } & \begin{array}{l}\text { Wath Model No Model } \\ \text { Correction }\end{array} \text { With Model } \\ \text { Correction }\end{array}$

Five Rods

$68^{\circ} \mathrm{F}$, clean

3. 7

3. 0

3. 6

.7

1

Seven Rod

$68^{\circ} \mathrm{F}$, clean

5. 3

4. 6

4. 9

.7

.4

Five Rods

$440^{\circ} \mathrm{F}$, clean

6. 7

5. 2

6. 8

1. 5

$-1$

Five Rods

$440^{\circ} \mathrm{F}$, Eq. Xe.

8. 3

6. 9

8. 0

1. 4

.3 
TABLE 4.13a

SM-1 CORE I $\sum_{p}$ AND $\sum_{a}^{\text {sub }}$ FOR VARIOUS CONDITIONS

Bank Type, Core Conditions

Five Rodis

$68^{\circ} \mathrm{F}$

Five Rods

$440^{\circ} \mathrm{F}$

Seven Rods

$68^{\circ} \mathrm{F}$

$$
\sum_{p}\left(\mathrm{~cm}^{-1}\right)
$$

.088969

.078180
.058969

.078180

$\sum_{\mathrm{a}}^{\text {sub }}\left(\mathrm{cm}^{-1}\right)$

.008416

As seen in Table 4.13, the calculated bank positions are observed to be in good agreement with the measured positions, on the basis that the excess core reactivities as calculated by the WINDOWSHADE code were corrected to the measured reactivities.

\section{3. 2 Conclusions}

1. The five rod bank position can be predicted within $1.4 \mathrm{in}$. without any model correction and 0.3 in. using a model correction on core reactivity.

2. The use of a homogeneous $\sum_{p}$ for rods and $\sum_{a}$ sub in a one-dimensional axial calculation can give reasonable agreement with experiment.

\section{4 CENTRAL ROD WORTH IN POISONED CORES}

The integral worth of the central control rod alone was determied experimentally in two ways (3): one, by poisoning the core, using boron stainless steel strips, and the other, employing pure stainless steel strips. The worth of the central rod was determined analytically by use of the VALPROD, IEM-650 machine code, and compared to measurement.

\section{4.1 Experimental Results}

The calibration of the central control rod, using boron-stainless steel and pure stainless steel strips to poison the core, was measured during the SM-1 ZPE-2 critical experiments $(3)$ at the Alco Products Critical Facility. Fig. 4.1 presents the results of the calibration. All control rods, except for the central rod, were fully withdrawn while the calibration was performed. 


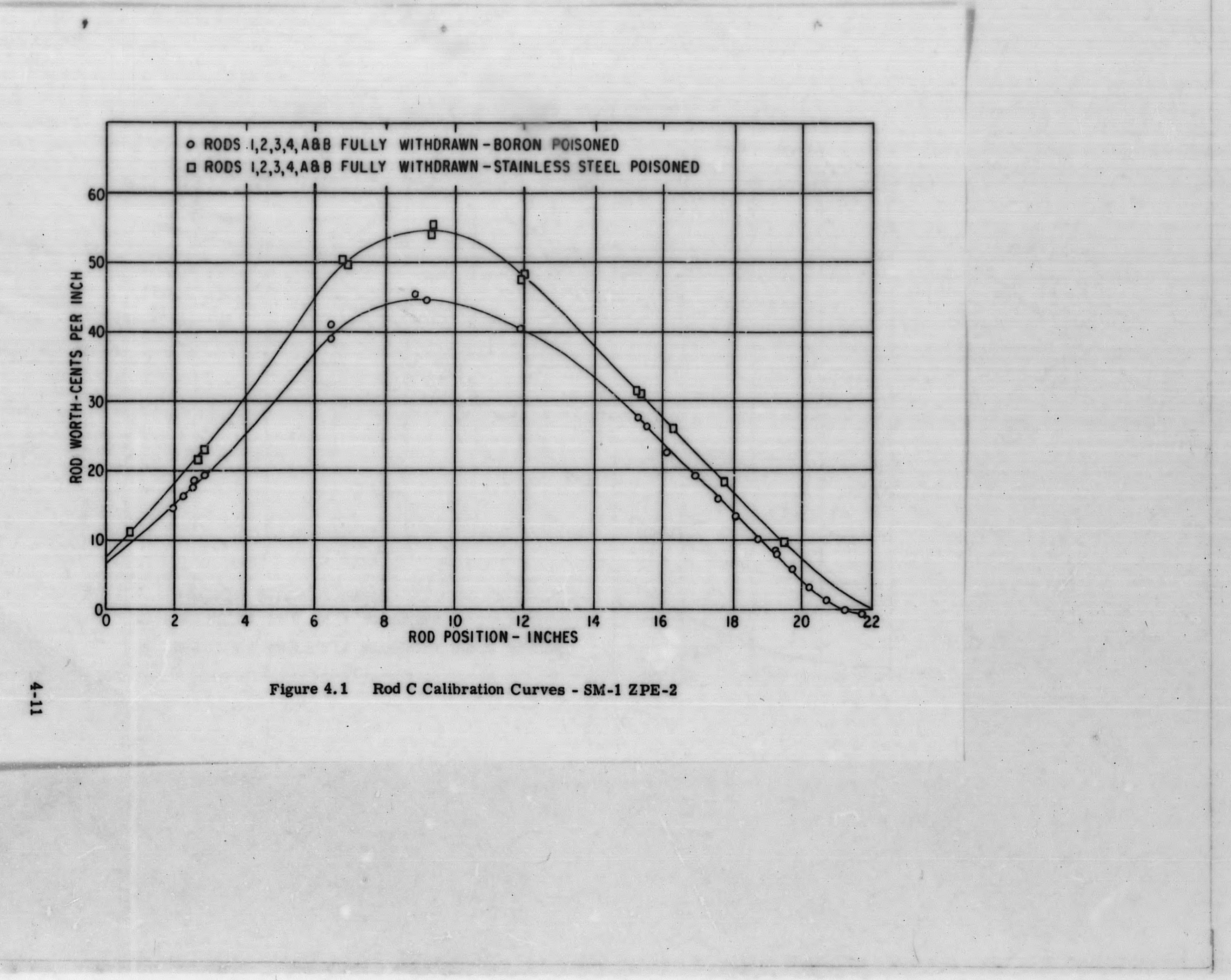




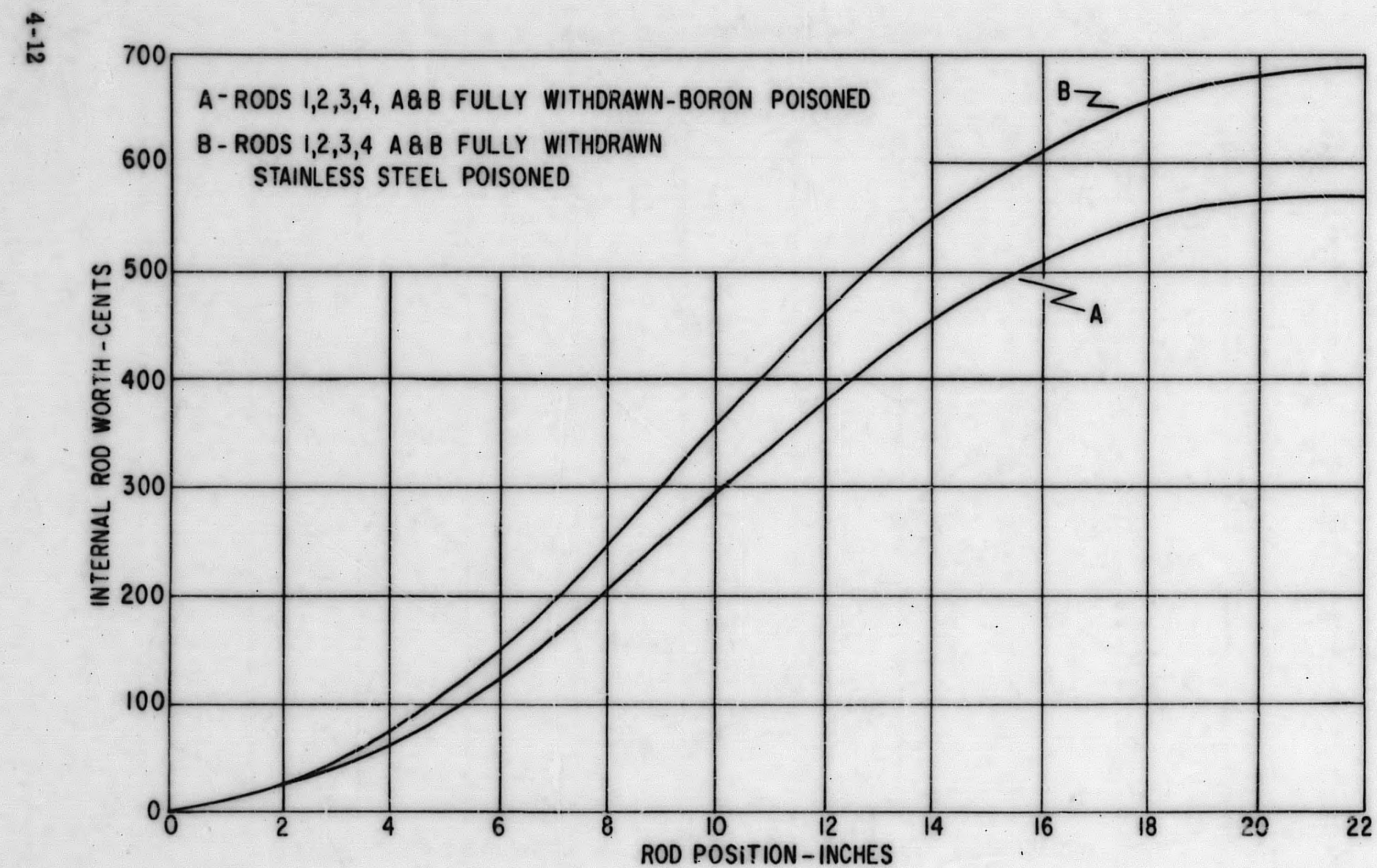

Figure 4.2 Rod C Integral Worth - SM-1 ZPE-2 
The integral worth of the central rod obtained from the calibration curves in Fig. 4. 2 indicates that the control rod is worth approximately one dollar greater for the stainless steel poisoned core than for the boron-stainless steel poisoned core.

\section{4.2 Analytical Results}

VALPROD calculations were performed for the following two configurations: one containing all poisoned fixed fuel elements, and the other with a control rod substituted for the central poisoned fuel element. The reactivity results of these calculations yield the worth of the central rod relative to a poisoned fixed fuel element. The measurements yielded the worth of the central rod relative to a clean control rod fuel element. Therefore, the worths of the central rod, as obtained by experiment and analytically, are not directly comparable. However, the analysis will indicate the dependence of rod worth on the type of poisoning . employed, which can be directly compared to experiment.

Fig. 4.3 presents the cylindrical representation of the core containing a central control rod, as seen by the VALPROD code.

\section{FIGURE 4.3}

SM-1 CORE I AS SEEN BY VALPROD CODE

(CENTRAL CONTROL ROD PLUS 44 FIXED FUEL ELEMENTS)

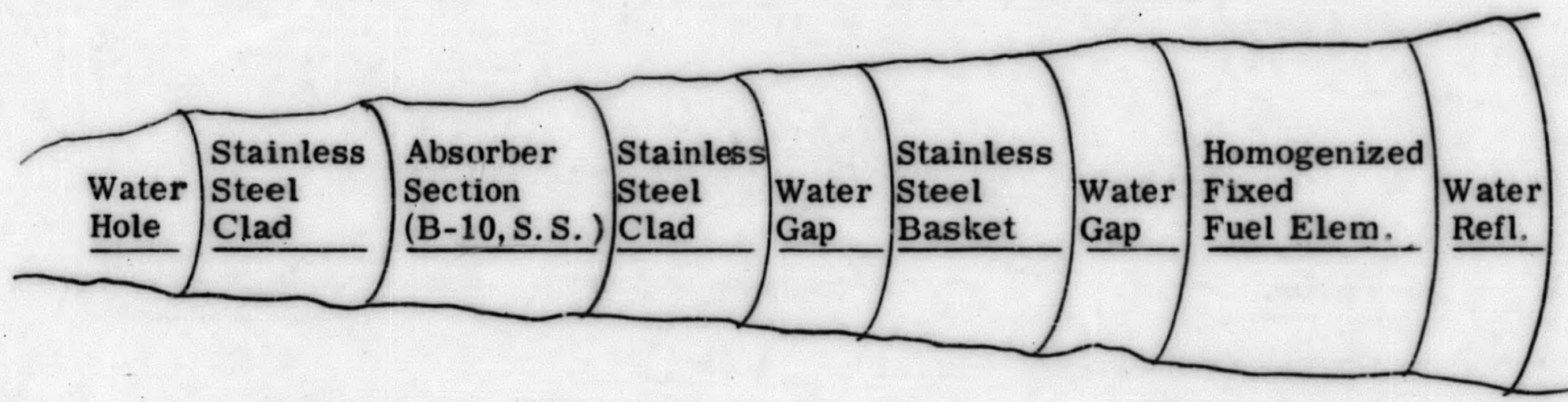

The area was conserved in all regions except for the absorber section where, instead, the thickness was conserved in order to maintain the thermally black absorption properties of the region. 
The absorber section, consisting of a homogeneous mixture of Boron-10 and stainless steel, was treated as a thermally black region with resonance absorption included. The thermal properties were represented by "effective" diffusion theory constants obtained from blackness theory $(4),(5)$ Resonance absorption was calculated, using the same basic theory, (4) except that the absorption was treated as gray in this case. Table 4.14 presents the fast and thermal constants of the absorber section, as used for the VALPROD code.

TABLE 4.14

FAST AND THERMAL CONSTANTS OF ABSORBER SECTION

$\begin{array}{cll}\text { Constant } & \text { Fast } & \text { Thermal } \\ \mathrm{D}(\mathrm{cm}) & 1.520834^{*} & 0.000651 \\ \sum_{\mathrm{a}}\left(\mathrm{cm}^{-1}\right) & 0.33 & 8.572055\end{array}$

* Diffusion constant for pure stainless steel.

Table 4.15 presents the results of the worth of the central control rod, as obtained by measurement and the VALPROD calculations. The calculated worths were obtained from the difference in reactivities $(\% \rho)$ of the rodded and unrodded cores.

TABLE 4.15

INTEGRAL WORTH OF CENTRAL CONTROL ROD

Poison

Boron-Stainless Steel

Stainless Steel
Measured $(\% \rho)$

4. 32

5.07
Calculated $(\% \rho)$

4. 80

5. 34

\section{4.3 Conclusion}

1. The worth of a central control rod can be accurately calculated, using P-1 slowing down model, MUFT-III nuclear data and absorber properties from blackness theory. 


\subsection{SUMMARY}

In the present section the application of one-and two-dimensional calculations at startup has predicted reactivity of SM-1 Core I within $0.8 \% \rho$. The cold to hot change in reactivity is underestimated by $1 \% \rho$.

Use has been made of substitution poison cross section to represent the control rod bank and it has been found that the control rod bank position can be predicted within $0.4 \mathrm{in}$. at $68^{\circ} \mathrm{F}$ and $440^{\circ} \mathrm{F}$.

In the following section reactivity and control rod bank will be investigated as a function of core burnup. In addition the spatial dependence of power, material concentration and the effect of xenon, samarium and fission products in reactivity will be sought.

\section{6 REFERENCES (4.0)}

1. Weiss, S. H., "Summary Report of Physics Measurements on SM-1 Core I," APAE-96, February 6, 1962.

2. Hughes, D. J., et al, "Neutron Cross Sections," Brookhaven National Laboratory, BNL-325, second edition, July 1, 1953.

3. Mackay, S. D. , et al, "Extended Zero Power Experiments on the APPR-ZPE-2," APAE No. 21, November 15, 1957.

4. Henry, A. F., "Theoretical Method for Determining the Worth of Control Rods," WAPD-218, August 1959.

5. Fried, B. E., Alford, M. R. , and Oggerino, J. P., "Flux and Power Distributions for the SM-2 References and Critical Experimental Cores, " APAE Memo No. 286, June 30, 1961.

6. Noaks, J.W., and Johnson, W. R., "Army Package Power Reactor Zero Power Experiments (ZPE-1)," APAE-8, February 8, 1957.

7. Noaks, J.W., et al, "SM-2 Critical Experiments, CE-1", APAE No. 54, November 30, 1959.

8. McCool, W.J. et al, "Extended SM-2 Critical Experiments, CE-2", APAE No. 54, Supplement 1, June 30, 1961.

9. Raby, T. M., et al, "PM-2A Core I Zero Power Experiment," APAE No. 75, October 21, 1960. 


\section{0 SM-1 CORE I BURNUP CALCULATIONS}

This section presents the results of the SM-1 Core I burnup analysis. A review of previous calculations of SM-1 Core 1 lifetime is also presented. The new calculations were performed by the use of the CANDLE-2 IBM-704 code, described in Section 2. 0, Reference (1), and the results were compared with measured data in order to determine the accuracy of the calculational model.

\subsection{REVIEW OF PREVIOUS CALCULATIONS}

The review of previous burnup calculations for SM-1 can be divided into four distinct periods. These are: (1) calculations performed in the conceptual design stage by Oak Ridge National Laboratory; (2) calculations performed by Alco Products during and following the flexible critical experiments performed at Oak Ridge National Laboratory; (3) calculations performed by Alco Products following the zero power experiment on SM-1 Core I and initial startup of the SM-1 at Fort Belvoir; (4) calculations performed after burnout of the SM-1 Core I at Fort Belvoir.

The calculations reported in this work fall into the latter category. Inchided in the second category of calculations must be those performed by the Walter Kidde Nuclear Laboratories as a subcontractor to Alco Products. These calculations were performed independent of those at Alco but did make use of the results of the ORNL flexible critical experiments. Most of the calculations performed have employed two-group theory with provisions for resonance absorption and fission of U-235. In the conceptual design stage, ORNL performed certain check calculations using multigroup theory. It is realized that in the course of the transition from the conceptual design to the final design of SM-1, there were certain structural changes to the core. However, these did not account for a significant change in metal-to-water ratio.

TABLE 5.1 REVIEW OF BURNUP CALCULATIONS FOR SM-1 CORE I

\begin{tabular}{|c|c|c|c|c|c|c|}
\hline Period & Reference & Date of Issue & $\begin{array}{c}\mathrm{Kg} \\
\mathrm{U}-235 \\
\end{array}$ & $\begin{array}{l}\text { Grams } \\
\text { B-10 }\end{array}$ & $\begin{array}{l}\text { Core Life, } \\
\text { MWYR }\end{array}$ & $\begin{array}{l}\text { Predicted } \\
\Delta K \text { Increase } \\
\text { In Core Life }\end{array}$ \\
\hline (1) & ORNL-1613 & June 1955 & 17. 7 & 34.0 & 15 & 0.07 \\
\hline (2) & APAE- 7 & May 1956 & 22. 5 & 21.1 & 15 & 0.02 \\
\hline (2) & WKNL-57 & March 1956 & 22.5 & $\begin{array}{l}(24.9 \\
(31.0\end{array}$ & 9. 4 & 0.03 \\
\hline (3) & APAE-32 & July 1958 & 22. 5 & 19.5 & 16. 4 & 0 \\
\hline
\end{tabular}


Flexible critical experiments were performed from September 1955 to February 1956. Once flexible critical experiments information was available (Fall 1955) the predictions of APAE-7(2) of the loadings of fuel and boron were markedly improved over those of the conceptual design. The calculations performed in ORNL-1613(3) and APAE-7 were limited to uniform burnout. All other calculations included the effect of non-uniform fuel and burnable poison burnout with core life. It is noted that the initial design reactivity of the SM-1 was increased during the course of the core development. This was due to a concern of overpoisoning the core with boron. This eliminated to a large extent the expected increase in core reactivity with core burnout. It is of particular interest that the calculations of core burnout performed after initial startup of SM-1 predicted the core life to be 16.2 MWYR. These calculations were performed using the NUB-1 code (4) which employs group constants obtained from MUFT-III (P1-SG) and from plate P-3 theory.

\subsection{CANDLE-2 CALCULATIONS}

The calculations of SM-1 Core I burnout reported herein involved the use of the CANDLE-2 IBM-704 code. This code is a one-dimensional few group depletion code as described in Section 2. 0 . Some of the advantages and disadvantages of CANDLE-2 code compared with NUB-1 code used in Reference (4) are given in Table 5. 2.

TABLE 5.2

ADVANTAGES AND DISADVANTAGES OF CANDLE-2

COMPARED WITH NUB-1

\section{ADVANTAGES}

1. Computing time reduced by a factor varying from 10 to 100 .

2. Option of using 2 or 4 energy groups.

3. Calculation of new flux and power distributions at each time step.

4. Pointwise variation of flux, power and material composition in core.

5. Automatic calculation of transient xenon.

\section{DISADVANTAGES}

1. Fast and thermal microscopic cross sections cannot vary with burnup.

2. The self-shielding factor for the thermal group does not vary accurately with burnup.

3. The coalescing scheme for three groups to one fast group is not directly equivalent to the results of the MUFT-III code.

4. The ${ }^{\sum} \alpha^{\text {sub }}$ for control rod fuel elements cannot vary with burnup. 
A review of the advantages and disadvantages of the CANDLE-2 code compared with the NUB code indicates it is superior in treating spatial variations but inferior in calculating group constants. Since the CANDLE-2 code is faster and performs a multistep burnup automatically with the detailed spatial treatment,it was chosen as the basis for the SM-1 Core I burnout calculations reported in the following section.

\section{2.1 Geometrical Model}

CANDLE-2 is a one-dimensional code which leads to a number of severe problems when applied to SM-1 Core I. A review of Fig. 1. 3 in Section 1. 0 indicates that SM-1 Core I is highly heterogeneous. The rodded region of the core consists of 5 massive hollow absorbers in a region of $\mathbf{3 8}$ fixed fuel elements and 2 control rod fuel elements. In the unrodded region of the core the composition is 38 fixed elements and 7 control rod elements. In addition to the normal complications of the moving control rod bank, the control rods employed in SM-1 introduce the added complication of moving fuel into the unrodded region as the bank is withdrawn.

The core in the unrodded region is represented by fixed element properties on which is superimposed a uniform thermal absorption cross section to account for the control rod fuel elements.

The magnitude of this cross section, referred to as the control rod substitution cross section, $\sum_{\mathrm{a}}^{\text {sub }}$, is found using an estimated reactivity effect of replacing seven fixed elements by seven control rod fuel elements and the equivalent bare reactivity equation in the following manner:

$$
K_{\text {eff }} \text { can be expressed as } k_{e f f}=\frac{p K_{t h}}{\left(1+L^{2} B^{2}\right)\left(1+\tau B^{2}\right)}+\frac{(1-p) K_{f}}{\left(1+\tau B^{2}\right)}
$$

and, since only the $\mathrm{K}_{\text {th }}$ term will change, we put $\mathbf{k}_{\text {eff }}=\mathrm{K}_{\text {th }} \mathrm{H}+\mathrm{J}$, where:

$$
K_{t h}=\frac{\nu \sum_{f_{t h}}^{F \cdot E . *}}{\sum_{a_{t h}}^{F . E .}} \quad, H=\frac{p}{\left(1+L^{2} B^{2}\right)\left(1+T B^{2}\right)}, J=\frac{(1-p) K_{f}}{\left(1+T B^{2}\right.}
$$

Then the measured reactivity difference between 7 fixed and 7 control rod fuel elements is subtracted from the cold clean reactivity giving:

$$
\mathbf{k}_{\text {eff }}^{\prime}=\mathbf{k}_{\text {th }}^{\prime} \mathbf{H}+\mathrm{J} \text { but now } K_{\text {th }}^{\prime}=\frac{\nu \sum_{f_{\text {th }}}^{F . ~ E . ~}}{\sum_{\text {ath }}^{\text {F. E. }}+\sum_{a}^{\text {sub }}} \text { which yields } \sum_{a}^{\text {sub }}
$$

* The superscript F. E. stands for fixed elements. 
the only unknown parameter. To obtain $\sum_{\mathrm{a}}^{\mathrm{sub}}$ at operating temperature, i. e. $440^{\circ} \mathrm{F}$, it was assumed that $\sum_{\mathrm{a}}^{\mathrm{sub}}$ varies with temperature in the same manner as the U-235 microscopic absorption cross section does, since $\sum_{a}^{25}$ accounts for most of the thermal absorptions.

TABLE 5.3

EQUIVALENT UNIFORM CROSSSECTION FOR CONTROL ROD FUEL ELEMENTS AND CONTROL ROD ABSORBERS

\begin{tabular}{|l|c|c|}
\hline Cross-Section & $\underline{68^{\circ} \mathrm{F}}$ & $\underline{440^{\circ} \mathrm{F}}$ \\
\hline$\sum_{\mathrm{a}}^{\text {sub }}$ & .007846 & .006131 \\
\hline$\sum_{\mathrm{p}}^{\text {rods }}$ & .088239 & .07754 \\
\hline
\end{tabular}

The core in the rodded region is represented by fixed element properties on which is superimposed a thermal absorption cross section $\sum^{\text {rods }}$ to account for the 5 absorbers and the $\sum_{\mathrm{a}}$ sub to account for the presence of the control rod elements. This therma absorption cross section is known as the control rod absorption cross section and is calculated in a similar fashion as $\sum_{\mathrm{a}}^{\mathrm{sub}}$ above:

$$
\begin{aligned}
& k_{\text {eff }} \text { (rods out) }=\frac{1}{1-\rho_{F}^{\prime} . E .}=K_{\text {th }} H+J k_{\text {eff }}(\text { rods in })=\frac{1}{1-\rho^{\pi}}=K_{t h} H+J \\
& \mathrm{~K}_{\mathrm{th}}=\frac{\sum_{\mathrm{th}}}{\sum_{\mathrm{a}}^{\mathrm{F} . \mathrm{E}}+\sum_{\mathrm{a}}^{\mathrm{sub}}+\sum_{\mathrm{p}}^{\mathrm{rods}}} \text { at } 68^{\circ} \mathrm{F} \text { it was found that }
\end{aligned}
$$

$k_{\text {eff }}($ rods out $)=1.1566 \mathrm{k}_{\text {eff }}($ rods in $)=.93950 \sum_{p}^{\text {rods }}=.088239 \mathrm{~cm}^{-1}$

The cold to hot change in bank worth was callculated by solving the multigroup diffusion problem (VALPROD) for a core with a central rod (water, absorber shell, core and water regions). The VALPROD's were run hot and cold with and without the centerline rod inserted. An equivalent $\sum_{p}^{\text {rod }}$ was calculated for the center rod at the two temperatures. The ratio of $\sum_{p}^{r o d}$ at $68^{\circ} \mathrm{F}$ to that at $440^{\circ} \mathrm{F}$ was 1.138 and assumed to be the same for the ${ }_{5}$ rod bank. The equivalent thermal cross sections used to approximate control rod fuel elements are summarized in Table 5.3. Due to code limitations the uniform cross sections given in Table 5.3 were taken to be invariant with core burnup.

The core is then reduced to a four region configuration as shown in Fig. 5.1. 
RADIAL CALCULATION

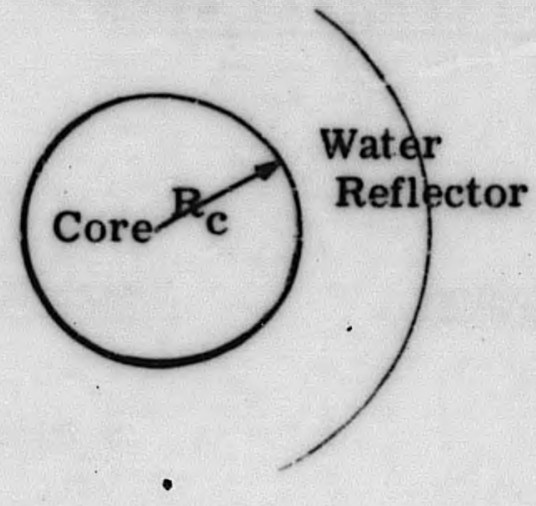

AXIAL CALCULATION

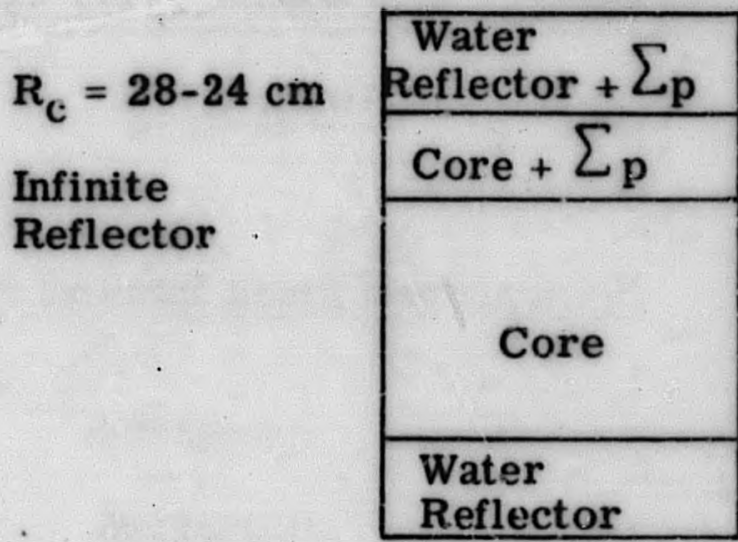

Core Height $55.245 \mathrm{~cm}$

Reflector (top, bottom) $28 \mathrm{~cm}$ each

Figure 5. 1. Geometrical Models for CANDLE-2 Calculations

\section{2. 2 Nuclear Constants}

The nuclear data required to perform CANDLE-2 calculations are the concentrations of various isotopes in the core and few-group microscopic cross sections. As discussed in Section 2. 0 CANDLE-2 calculates group constants from stored microscopic data. Table 5.4 lists the number densities of the el ements in the various regions of the SM-1 Core I. The water number densities are employed in the reflector regions. The number densities reported in Table 5.4 vary very slightly from the reference set as given in Appendix C. This latter set is based on slightly better estimates of the material content of the SM-1 Core I. Check calculations indicated that the difference in number densities yielded a negligible effect on core reactivity.

Table 5.5 lists the three group fast cross section library used in the CANDLE-2 code. Table 5. 6 lists the thermal microscopic cross section used in CANDLE-2. Table 5.7 shows the results of a comparison of the coalescing schemes of CANDLE-2 with MUFT-III P1-SG and P-1 calculations and equivalent bare core $k_{\text {eff }}$ for CANDLE-2, MUFT-III P1-SG and MUFT-III P-1 with $\mathbf{P}_{3}$ thermal model.

Table 5.8 shows the results of comparison of coalescing schemes for CANDLE-2, MUFT-III P1 - SG, and MUFT-III P-1 for the water reflector region. 
TABLE 5.4

NUMBER DENSITIES FOR REGIONS OF SM-1 CORE I AT $440^{\circ} \mathrm{F}$

(Atoms $/ \mathrm{cm}^{3}$ )

Element

Homogenized Fixed Element Region

0. 0443984

0.0231195

0. 0148188

Stainless Steel

Natural Boron

Uranium-235

0.000035602

0.00042863

Water Region

0.0559414

0.0279707

Note: To convert BNAT to B-10, multiply former by 0.198 . The number density of boron in the SM-1 Core I reflects a $22.4 \%$ fabrication loss.

\section{2. 3 Results of CANDLE-2 Calculations on SM-1 Core I}

CANDLE-2 code calculates a detailed point by point variation in flux, power and material composition, which provides information for comparison with experiment.

\subsection{Core Life}

The SM-1 Core I was first burned up using radial geometry. The calculated variation in $\rho$ from CANDLE-2 with equilibrium xenon at $440^{\circ} \mathrm{F}$ is shown in Fig. 5. 3 along with the results of a uniform burnup calculation normallized to the CANDLE-2 reactivity at the start of life. The normalization was necessary due to different reactivities at the start of life which resulted from differences in constants between CANDLE-2 and MUFT-III P1-SG as shown in Table 5. 7. MUFT-III P1-SG , was used for the uniform burnup calculation. It is noted that CANDLE-2 calculations yield core reactivity at 1.4 MWYR with equilibrium xenon of 8.9 percent. This compares with the measured reactivity of 9.2 percent. The CANDLE-2 radial burnout has been adjusted to a reactivity of 9.2 percent at $1.4 \mathrm{MWYR}$ to correspond to experiment. The results are shown in Fig. 5.4. The indicated core life is 18.4 MWYR for the nonuniform radial burnup. 


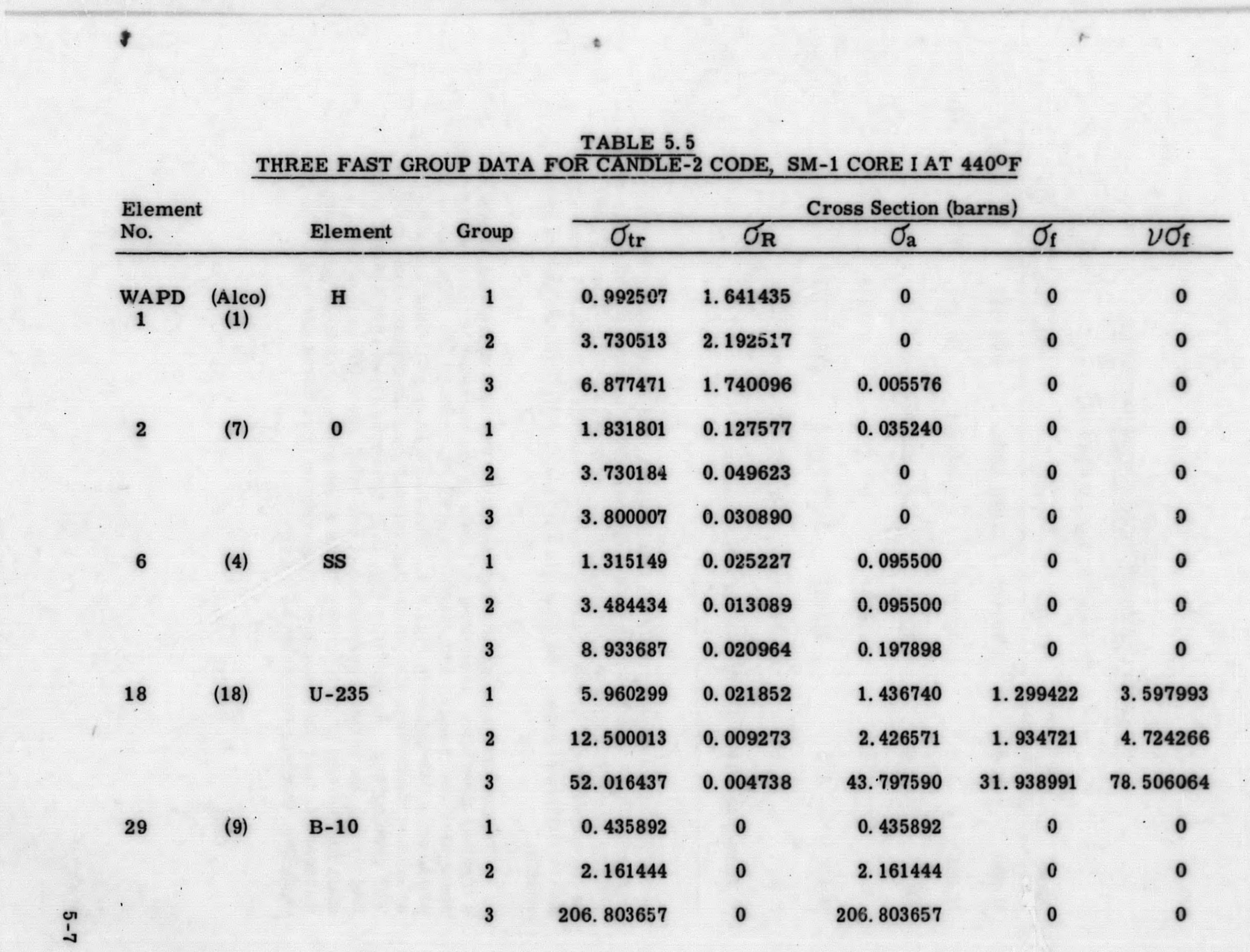


TABLE 5.6

THERMAL MICROSCOPIC CROSS SECTIONS

$$
\left(\mathrm{T}=440^{\circ} \mathrm{F} ; \mathrm{E}_{\mathrm{N}}=0.0549 \mathrm{ev}\right)
$$

\begin{tabular}{cccccc} 
Atom & $\bar{\sigma}_{\mathrm{s}}$ & $(1-\bar{\mu})$ & $\bar{\sigma}_{\mathrm{a}}$ & $\bar{\sigma}_{\mathrm{tr}}$ & $\overline{\nu \sigma}_{\mathrm{f}}$ \\
\hline $\mathrm{U}-235$ & 9.0 & 0.997165 & 385.5384 & 394.512 & 801.0342 \\
$\mathrm{U}-238$ & 9.0 & 0.997201 & 1.644605 & 10.620 & - \\
$\mathrm{H}$ & 28.97 & 0.7059 & 0.197353 & 20.65 & - \\
O & 3.9 & 0.958334 & 0 & 3.7375 & - \\
B-10* & 4.4 & 0.933441 & 2277.0146 & 2281.1217 & - \\
S.S. & 10.44 & 0.988 & 1.762814 & 12.078 & -
\end{tabular}

* Based upon $19.8 \mathrm{a} / \mathrm{o}$ of B-10 in natural boron.

The effect of using the P-1 slowing down model rather than P1-SG * on core reactivity, and hence on core life, has been investigated. The core reactivity was calculated on a uniform basis using MUFT-III P-1 and P1-SG group constants. The reactivity difference is shown in Table 5.7 along with the experimental value. As shown in Table 5. 7, MUFT-III, P-1 gives better results.

Fission product absorption excluding Xe was also expressed simply as a thermal absorption cross-section. Data on the variation of the fission product absorption was found in ANL-5800(5) and KAPL-2000-12. (6) This data is reproduced in this report in Fig. 5.2. The curve from ANL-5800 was used to determine the average fission product microscopic absorption cross-section with core burnup. As shown in Fig. 5.2, the curve rises very sharply at 5\% fuel burnup due to the accumulation of Sm-149. The slope is then fairly constant for the rest of core burnup. This slope corresponds to a fission product microscopic thermal absorption cross-section of 11 barns per fraction U-235 depletion, this was calculated as follows:

$$
\sum_{a_{f p}}=\bar{B} N_{U-235}^{O} \sigma_{a_{f p}}
$$




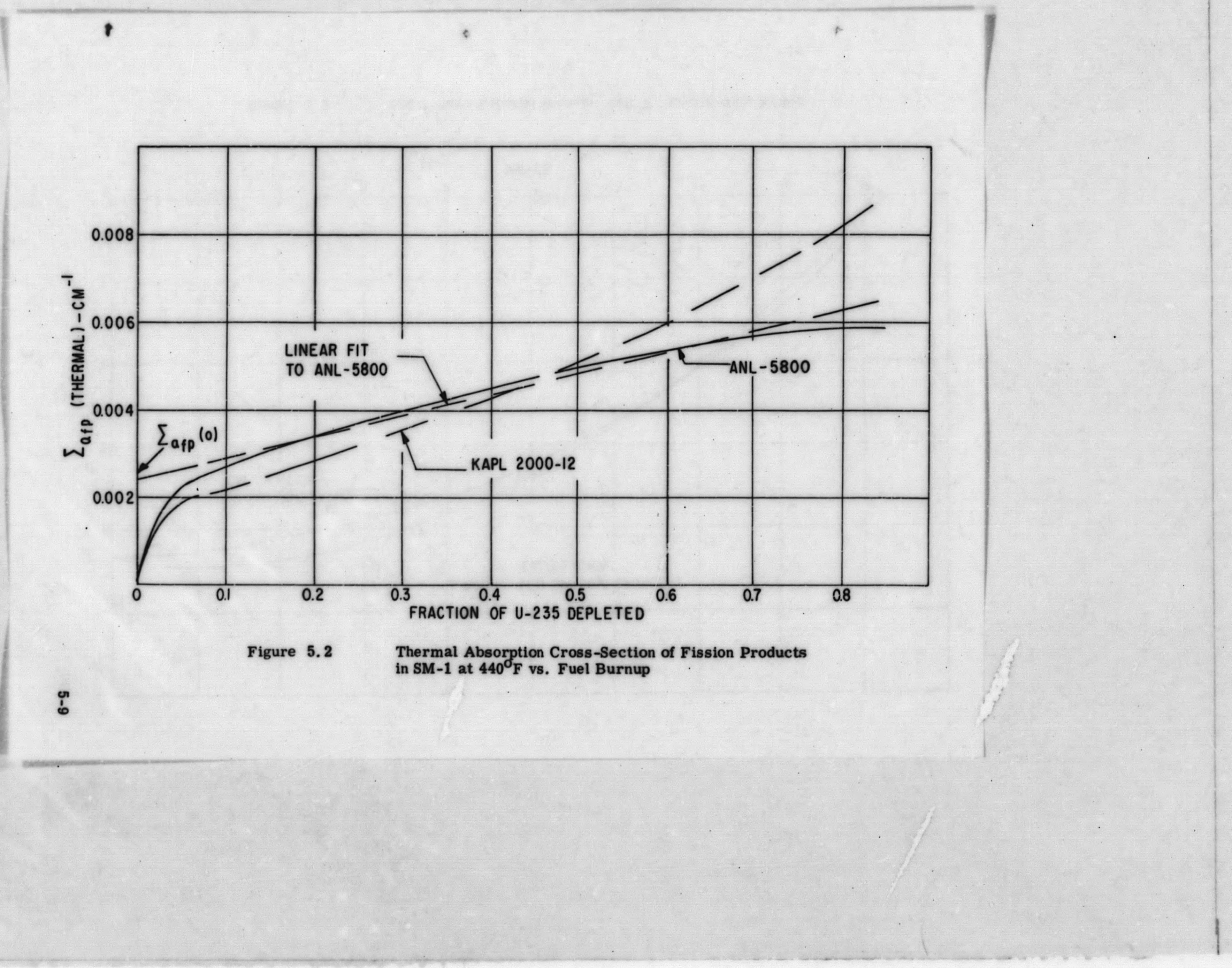




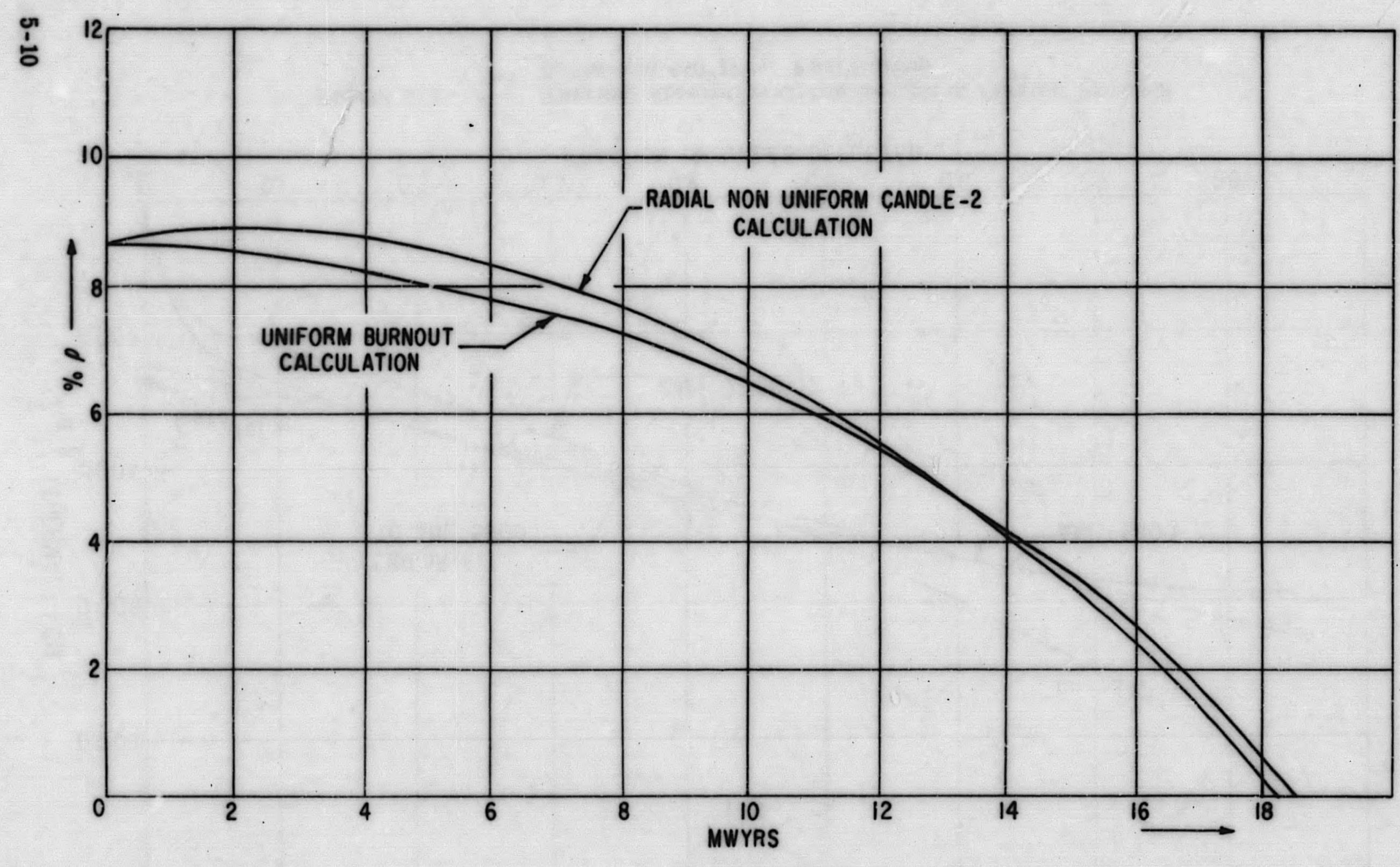

Figure 5.3 SM-1 Core I Radial Burnup, $440^{\circ} \mathrm{F}$, Equilibrium Xenon

1 


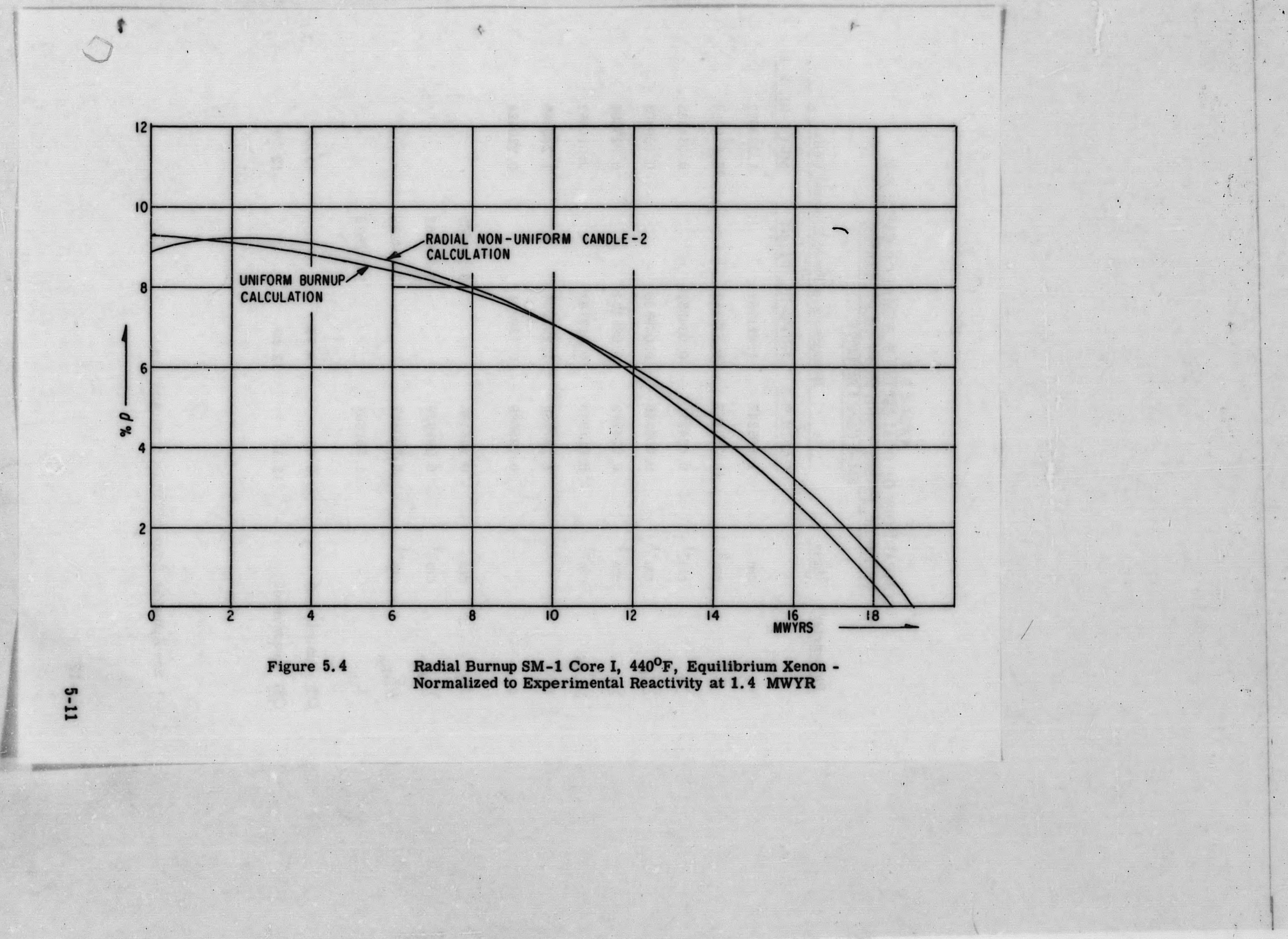


TABLE 5.7

COMPARISONS OF COALESCING SCHEMES OF CANDLE-2, MUFT-III P1-SG, AND MUFT-III P-1 CODES

SM-1 Core I At $4400 \mathrm{~F}$

\section{Parameter* Units}

CANDLE-2 MUFT-III, P1-SG

1. 605247

46. 867157

0.034251

0.009279

0.024972

0.011949

1. 287746

1. 292004

0. 729089

0.245496

0.206539

0.320447

1. 551508

0. 730201

0.247063

0. 206452

$\mathrm{cm}^{-1}$

-

$\mathrm{K}_{\text {th }}$

0.324239

1. 570528

P\% (calculated)

8. 63

9. 79

$\rho \%$ (measured)

12. 10

12. 10

MUFT-III, P-1

1. 334972

38. 826884

0. 034383

0. 009303

0.025080

0. 011992

1. 289046

0. 729426

* See Appendix E for definition of parameters. 
TABLE 5.8

RESULTS OF COMPARISON OF COALESCING SCHEMES

FOR PURE WATER REFLECTOR REGION- $440^{\circ} \mathrm{F}$

\begin{tabular}{|c|c|c|c|c|}
\hline Parameter* & $\underline{\text { Units }}$ & CANDLE-2 & MUFT-III, P1-SG & MUF'T-III, P-1 \\
\hline$D_{f}$ & $\mathrm{~cm}$ & 1. 554893 & 1. 899871 & 1. 56416 \\
\hline$\tau$ & $\mathrm{cm}^{2}$ & 41. 472660 & 47. 830185 & 40.115196 \\
\hline$\Sigma_{T_{f}}$ & $\mathrm{~cm}^{-1}$ & 0.0004200 & 0.000457 & 0.000499 \\
\hline$\sum_{a_{f}}$ & $\mathrm{~cm}^{-1}$ & 0.0004200 & 0.000457 & 0.000499 \\
\hline$\sum_{\mathrm{s} 1}$ & $\mathrm{~cm}^{-1}$ & 0. 0370716 & 0.039264 & 0.038424 \\
\hline$v \sum_{\mathrm{f}_{\mathrm{f}}}$ & $\mathrm{cm}^{-1}$ & 0 & 0 & 0 \\
\hline$K_{f}$ & . & 0 & 0 & 0 \\
\hline $\mathrm{p}$ & - & 0.988798 & 0.988490 & 0.987177 \\
\hline$D_{\text {th }}$ & $\mathrm{cm}$ & 0.265809 & 0.265809 & 0.265809 \\
\hline$\sum_{a_{t h}}$ & $\mathrm{~cm}^{-1}$ & 0.011014 & 0.011014 & 0.011014 \\
\hline$v \sum_{\mathbf{f}_{\mathrm{th}}}$ & $\mathrm{cm}^{-1}$ & 0 & 0 & 0 \\
\hline $\mathrm{K}_{\text {th }}$ & - & 0 & 0 & 0 \\
\hline
\end{tabular}

* See Appendix $\mathrm{E}$ for definition of parameters.

The equation of the linear portion of the curve is:

$$
\sum_{a_{f p}}=m \bar{B}+\sum_{a_{f p}} \text { (o) }
$$

$\sum_{\mathrm{a}_{\mathrm{fp}}}$ (o) was used as a contant term which was added to the core thermal macroscopic absorption cross-section. By moving the origin up to $\sum_{\mathrm{afp}}(\mathrm{o})$, the linear equation then reduced to:

$$
\sum_{a_{f p}}=m \cdot \bar{B}=\bar{B} N_{U-235}^{o} \sigma_{a_{f p}} \text { or } \sigma_{a_{f p}}=\frac{m}{N_{U-235}^{\circ}}
$$


For the SM-1 core at $440^{\circ} \mathrm{F}$,

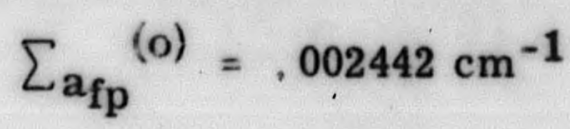

$$
\sigma_{\mathrm{a}_{\mathrm{fp}}}=\frac{.0047}{.0004286 \times 10^{24}}=11 \text { barns per fraction U-235 depletion. }
$$

The thermal absorption cross section $\sum_{\mathrm{a}}^{\mathrm{Xe}}$ which accounts for the reactivity effect of xenon, is calculated as follows:

$$
\Sigma_{\mathrm{a}}^{\mathrm{Xe}}=\frac{\alpha \mathrm{x}\left(\mathrm{Y}_{\mathrm{I}}+\mathrm{Y}_{\mathrm{Xe}}\right) \sigma_{\mathrm{a}}^{-\mathrm{Xe}} \cdot\left(\frac{{ }^{\prime} \mathrm{P}_{\mathrm{Mw}}}{\mathrm{V}}\right)}{\lambda_{\mathrm{Xe}_{\mathrm{e}}}+\sigma_{\mathrm{a}}^{-\sigma_{\mathrm{e}}}\left(\frac{\beta \sigma \mathbf{P}_{\mathrm{Mw}}}{\mathrm{V}}\right)\left[\frac{1}{\left(1-\beta^{\prime} \sum_{\mathrm{fth}}\right.}\right]}
$$

where $x=(1-\beta)+\beta g^{\prime}(B)$ and the remaining parameters are given in Appendix E. At start of life and $440^{\circ} \mathrm{F}, \sum_{\mathrm{a}}$ was found to be $0.006975 \mathrm{~cm}^{-1}$. The values of the parameters used are listed in Appendix C.

Figure 5. 5 shows the calculated variation of control rod bank position as obtained from the axial CANDLE-2 calculation. With the effect of the nonuniform radial burnout included. Also shown are the experimental measurements of bank withdrawal versus energy release. Figure 5. 6 shows the results of CANDLE-2 including the radial non-uniform burnup correiation normalized to the measured reactivity at 1.4 MWYR. It is seen that the CANDLE-2 axial burnout calculation gives very good prediction of bank position variation with energy release but overestimates the core life by approximately 0.5 MWYR*.

\section{2. 5 Fuel and Boron Distribution as Function of Core Life}

Pointwise distribution of uranium and boron were obtained from the axial and radial CANDLE-2 calculations. Figure 5.7 indicates the radial variation of U-235 and B-10 burnups at two different megawatt years. At 16. 8 MWYR, the average $\mathrm{U}-235$ burnup is $37.4 \%$ compared to an average $\mathrm{B}-10$ burnup of $93 \%$.

Figure 5. 8 shows the axial distribution of U-235 and B-10 burnup at two different energy releases. Only preliminary results of hot cell examinations of SM-1 Core I elements are available for comparison with these calculated U-235 burnups. At the end of SM-1 Core I life,16.4 MWYR, two elements were sent for hot cell examination. Figure 5.9 shows a comparison of the axial burnout distribution of U-235 in element 79 with that obtained by ORNL. This element was located in position 45 of SM-1 Core I for 16. 4 MWYR. The measured burnout corresponds to the average burnout across the width of the fuel plate

* At 10.5 MWYR two new elements were added; it has been calculated that the lifetime is increased by 0.3 MWYR. This correction is shown in Fig. 5.6. 


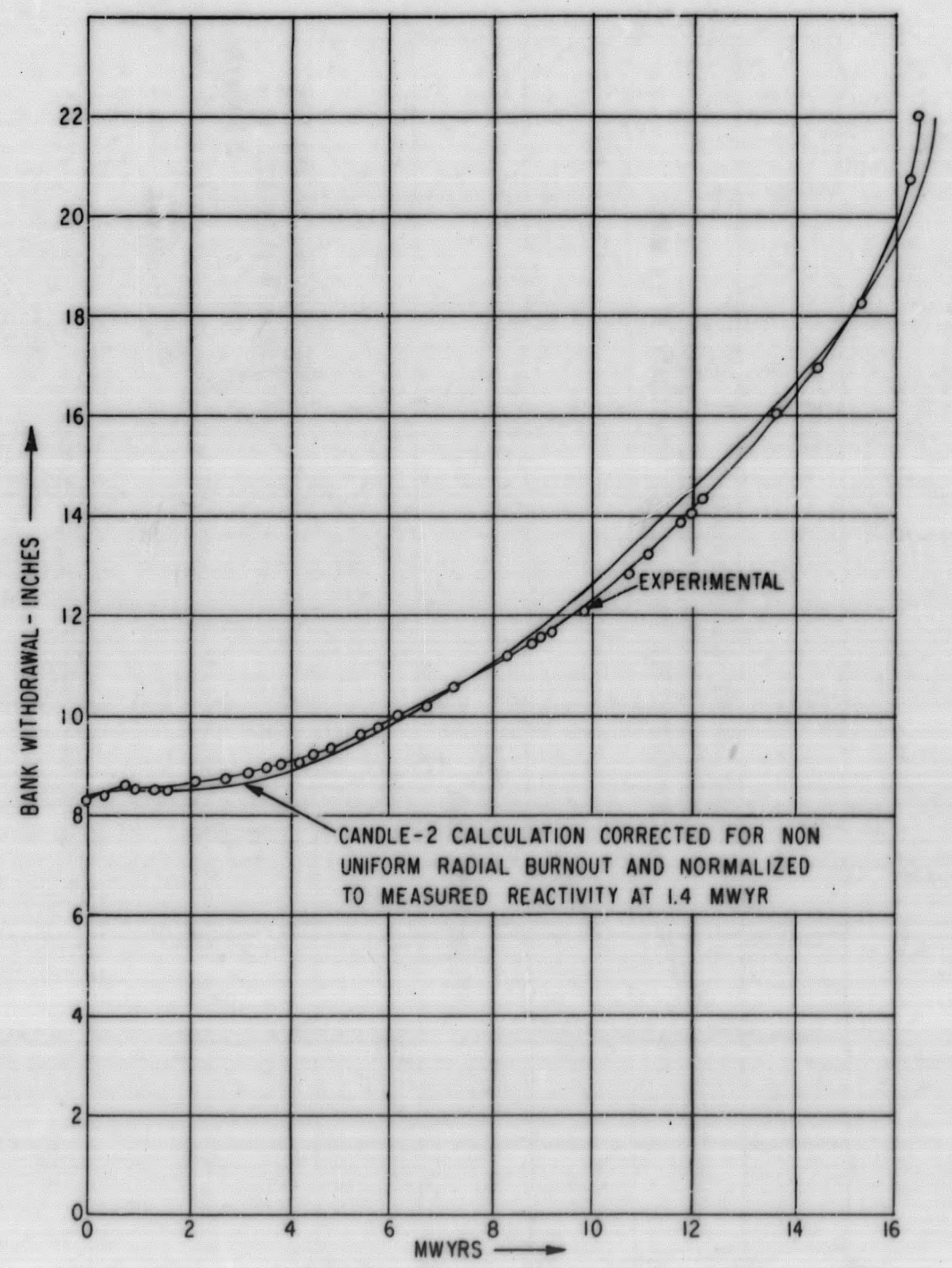

Figure 5.5 SM-1 Core I Control Rod Bank vs. MWYR $-440^{\circ} \mathrm{F}$, Equilibrium Xenon 
菅

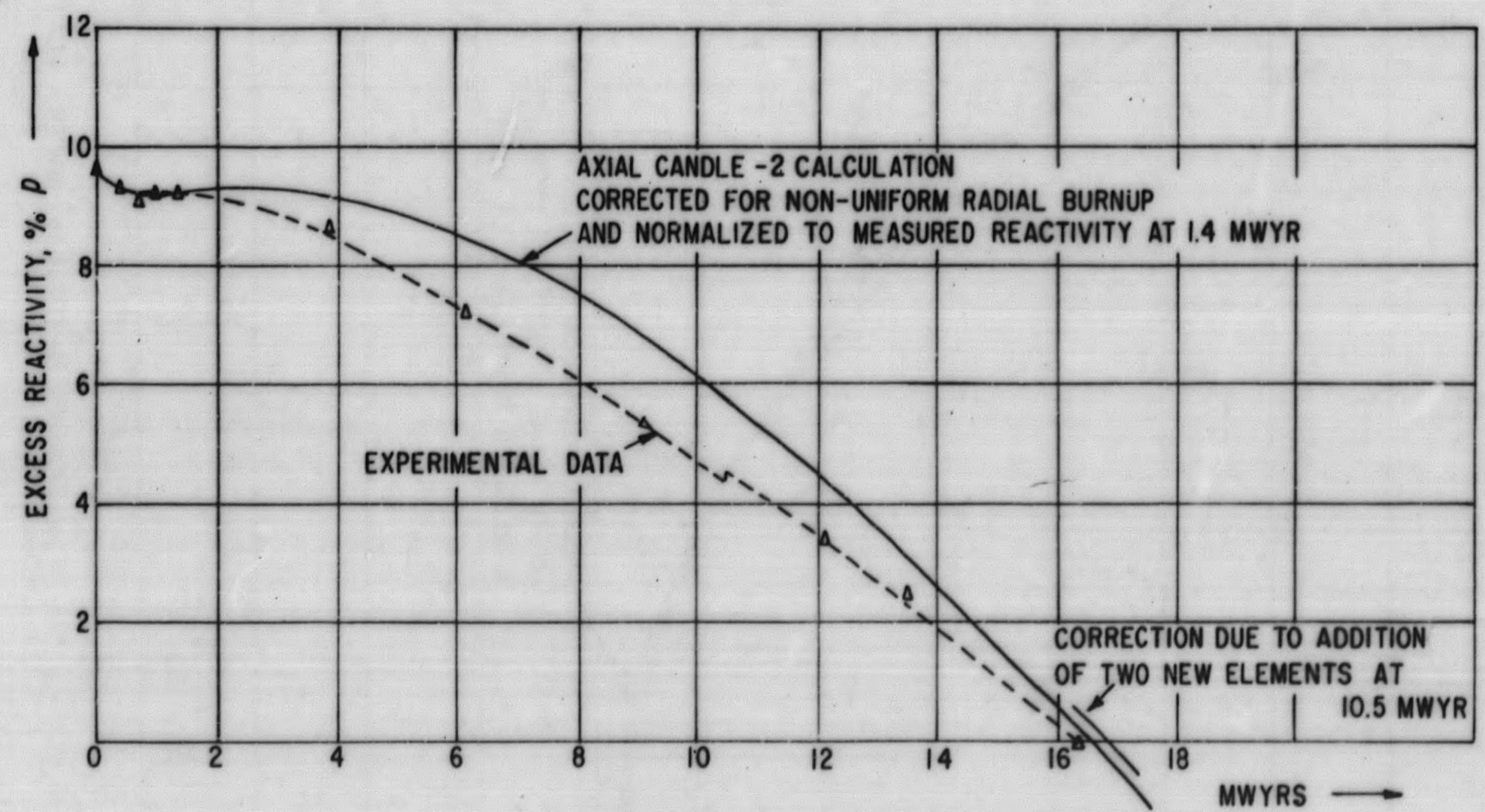

Figure 5.6 Excess Reactivity as a Function of Energy Release SM-1 Core I, $440^{\circ} \mathrm{F}$, Equilibrium Xenon 


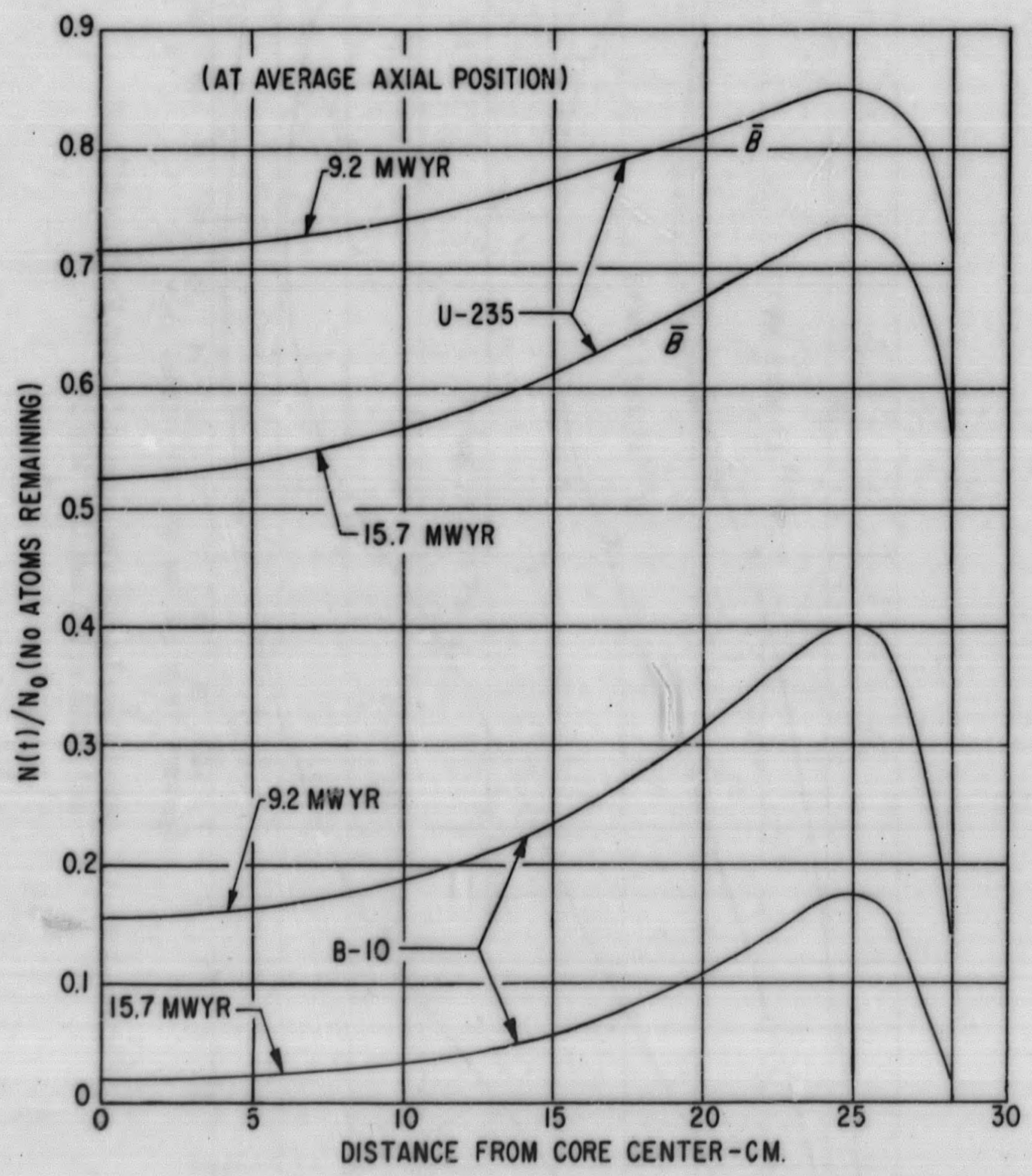

Figure 5.7

SM-1 U-235 and B-10 Radial Burnup at 9.2 MWYR and 15. 7 MWYR - All Fixed Elements with $\sum_{\text {a }}$ 
密

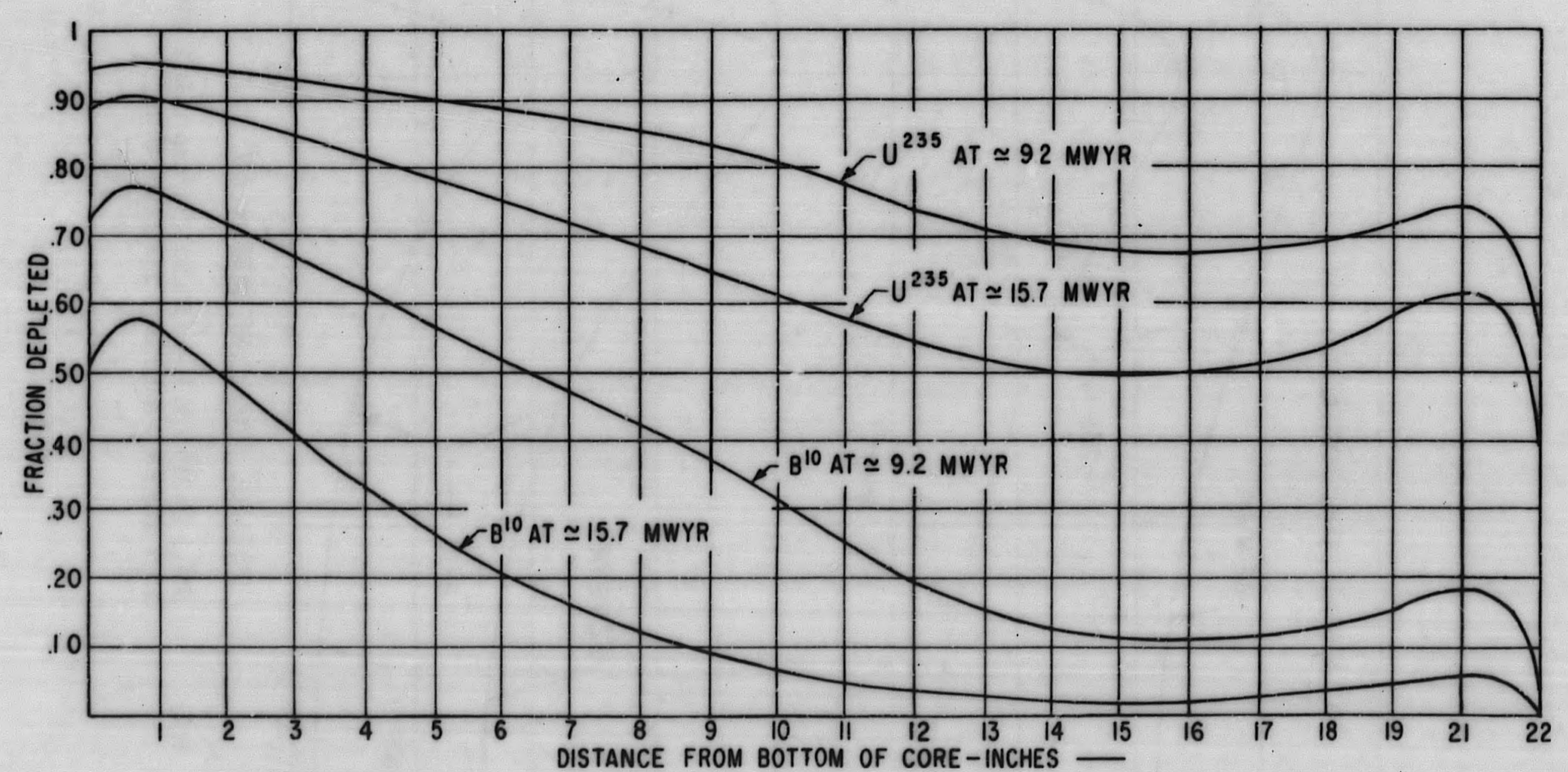

Figure 5.8 SM-1 Core I Axial Variation of Burnup Fraction of B-10 and $\mathrm{U}-235$ at 9.2 and 15.7 MWYR 


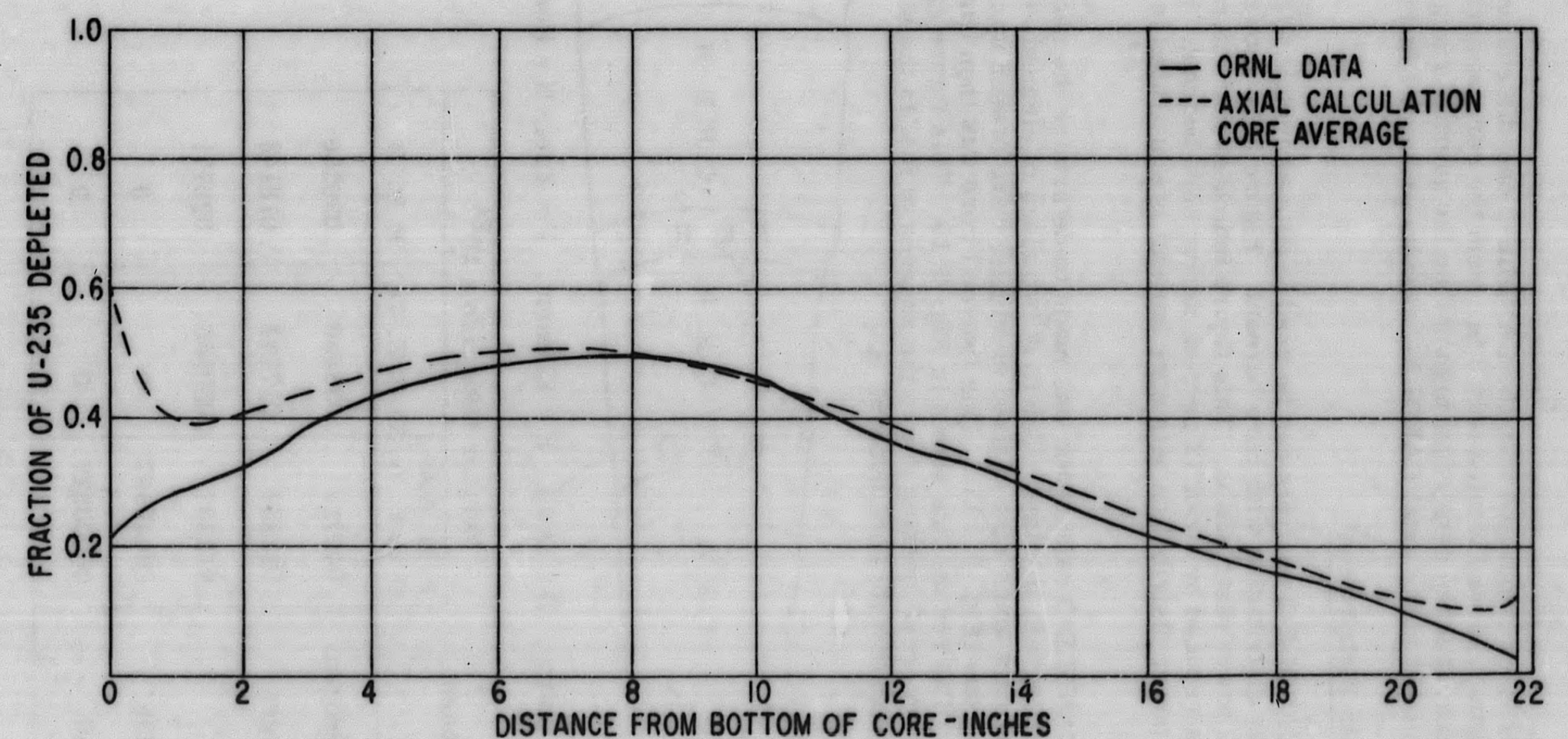

Figure 5.9 Measured Fuel Burnup in Element 45 of SM-1 Core I After 16.4 MWYR of Energy Release

$\frac{n}{4}$ 
and therefore affords a comparison with the CANDLE-2 one-dimensional results. It is noted that element $\mathbf{4 5}$ was located only 3 in. from the core centerline and hence it should have a buinup 24 percent higher than the average radial burnup which is that ealculated in the axial CANDLE-2 results presented in Fig. 5.9.

\section{2. 6 Power Distribution}

Results of CANDLE-2 analysis can be used to gain an insight to the variation of gross power distribution with core burnout. Figure 5.10 shows the variation in radial power distribution. This figure indicates that the radial max-to-average is reduced by about 12 percent during core burnout. The variation in axial power distribution with core burnout is illustrated in Fig. 5. 11.

A detailed CANDLE-2 calculation was made to determine the decrease in local power peaking with lifetime. The first two rings of elements (central control rod fuel element and a ring of fixed elements) were broken up into active and dead regions (Fig. 5.10A). This two-cell core was then burned out using CANDLE-2. The results are shown in Fig. 5.10. This figure clearly illustrates how the intercell peaking due to the absence of fuel in the side plate region rapidly decreases with core burnout.

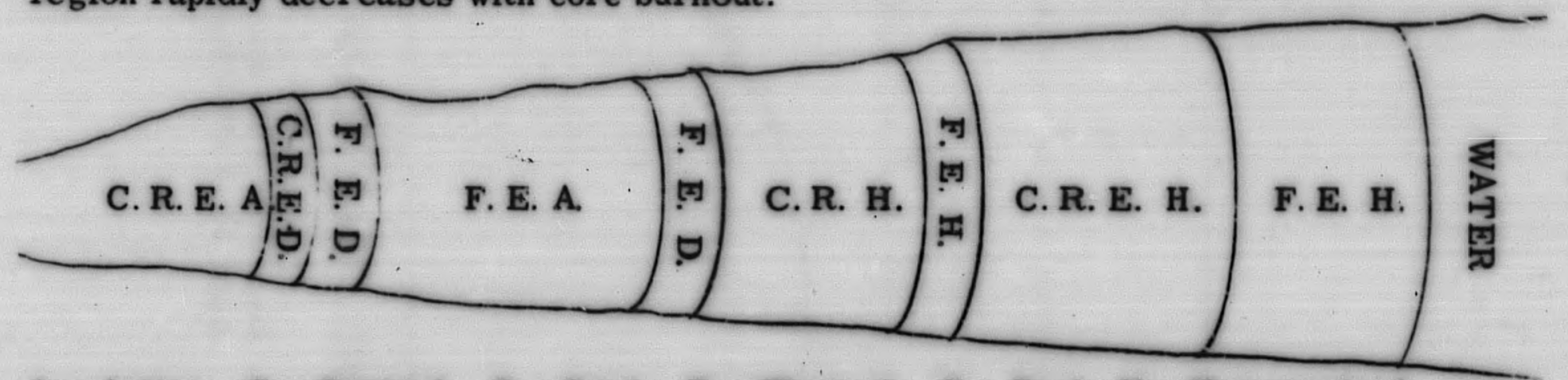

$\mathbf{A}=$ Active,$\quad \mathbf{C}=$ Control,$\quad \mathbf{D}=$ Dead, $\mathbf{E}=$ Element, $\mathbf{F}=$ Fuel, $\mathbf{H}=$ Homogenized

\begin{tabular}{|l|c|c|c|}
\hline \multirow{2}{*}{ Element } & \multicolumn{3}{|c|}{ Number Densities $\times 10^{24}$} \\
\cline { 2 - 4 } & $\begin{array}{c}\text { F. E. A.\& } \\
\text { C. R. E. A. }\end{array}$ & C. R. E. D. & F. E. D. \\
\hline Hydrogen & .045719 & .035489 & .036286 \\
Oxygen & .023924 & 017744 & .018143 \\
S. S. & .012487 & .030986 & .029771 \\
U-235 & .00049597 & 0 & 0 \\
B-10 & .00000827 & 0 & 0 \\
\hline
\end{tabular}

Figure 5. 10A. 


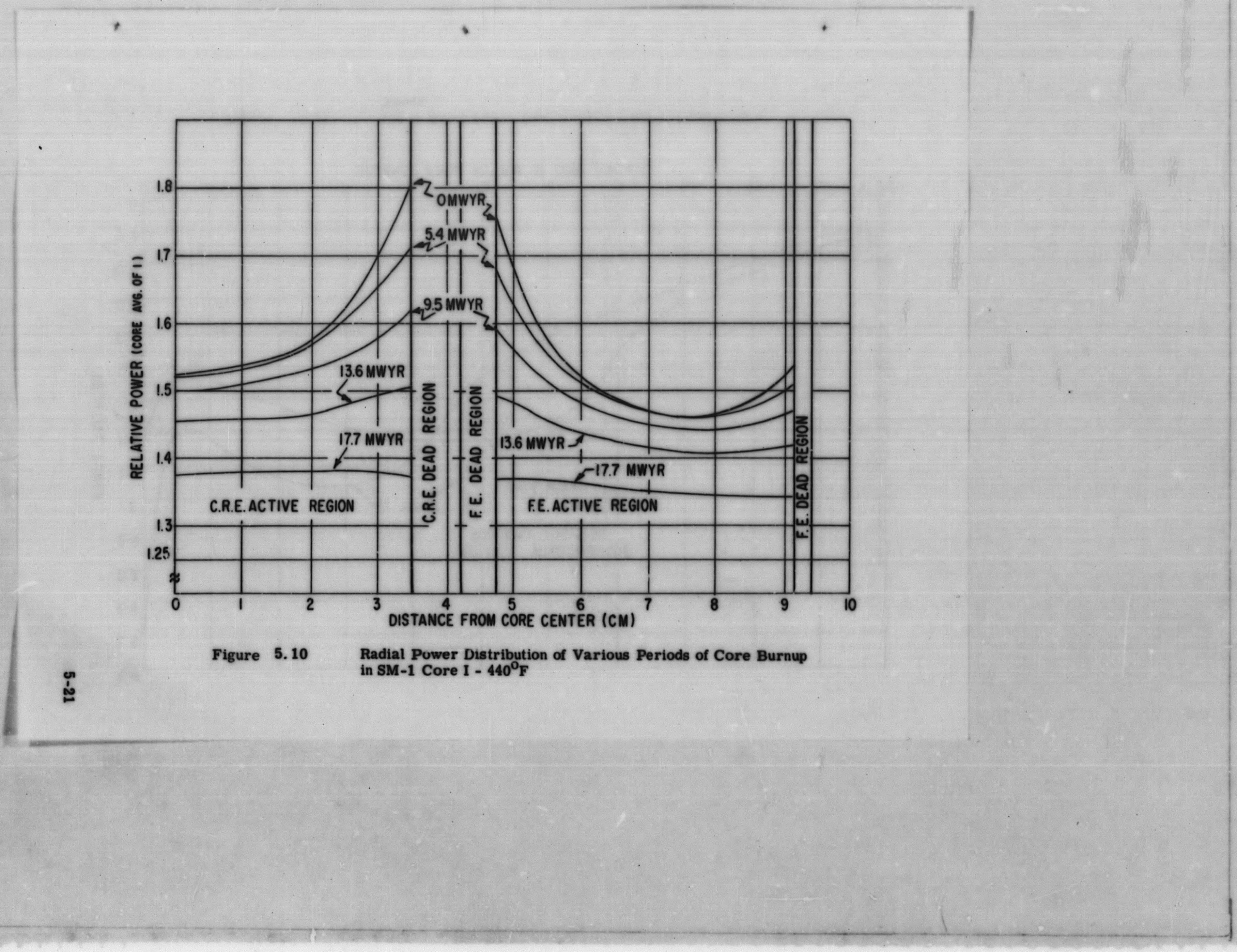


ì

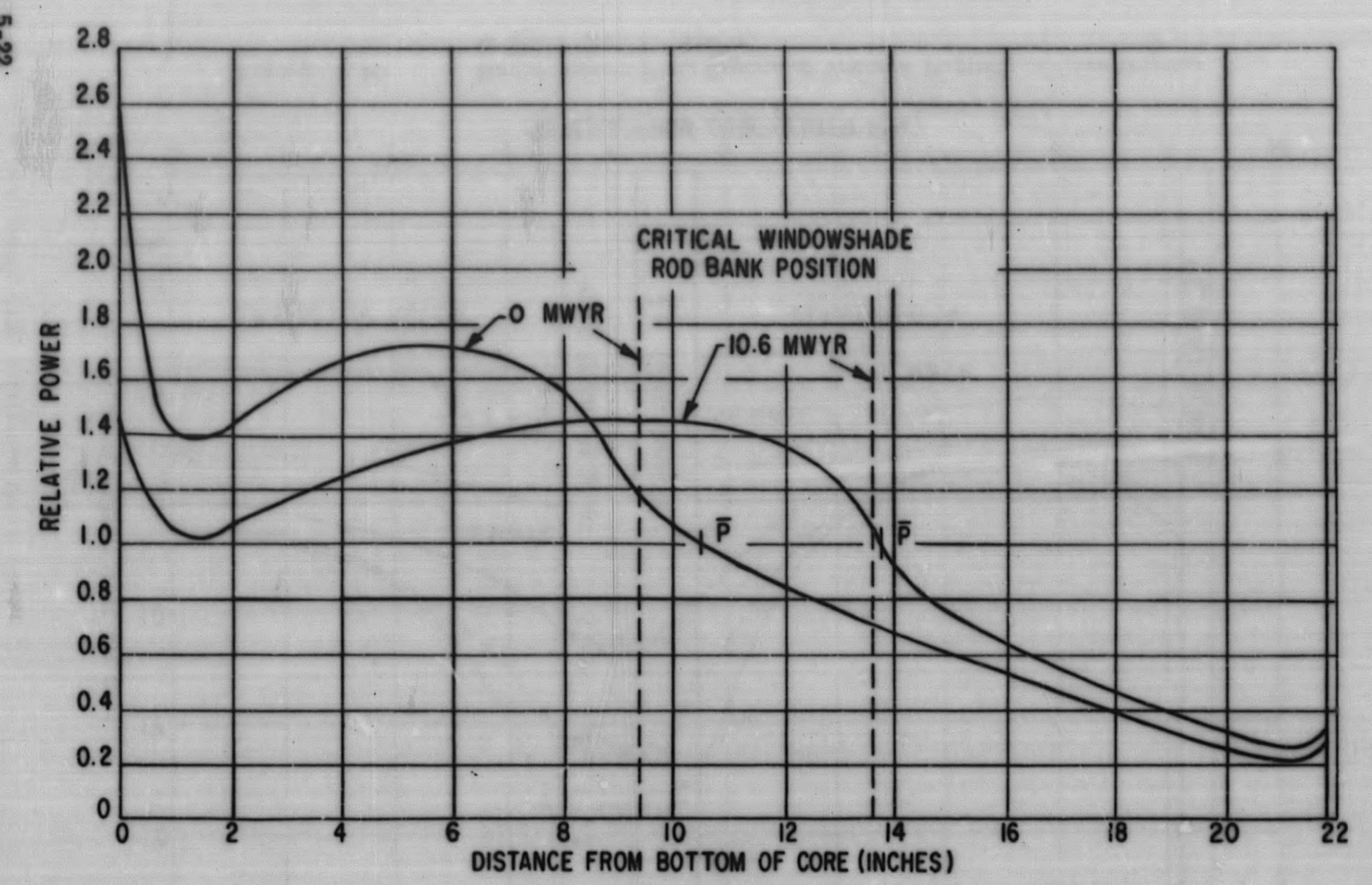
Figure 5.11 $\begin{aligned} & \text { SM-1 Axial Power Distribution }-440^{\circ} \text { F Equilibrium } \\ & \text { Xenon }\end{aligned}$ 
Figure 5. 12 illustrates the overall radial power distribution for 0 MWYR. It is seen that power interface and center peaks are reduced.

\section{2. 7 Change in 5 Rod Bank Worth}

The measurements $(1)$ made on the SM-1 Core I 5 rod bank worth indicated an increase in worth with core life. In order to determine if CANDLE-2 would predict this increase in rod worth, an analytical calculation of rod worth was carried out for the core at 12 MWYR energy release. In order to obtain a complete rod bank worth curve, material compositions of various regions of axial CANDLE-2 calculations at 12 MWYR were used. These compositions were averaged over six axial core regions. The rod poison $\sum$ rods cross section (Table 5. 3) was assumed to remain constant with core bufnout. A series of axial VALPROD calculations were run with the $\sum_{\mathrm{p}}$ rods moved into the core on 2-in. intervals. The resulting reactivity was converted into rod bank worths and plotted in Fig. 5.13. Also shown in Fig. 5.13 is the calculated rod worth curve for 0 MWYR. The experimental curves for 0 and 12 MWYR are also shown.

\section{2. 8 Xenon Reactivity}

The reactivity associated with equilibrium and maximum xenon was calculated using CANDLE-2 over the lifetime of SM-1 Core I. In addition, a detailed study of a xenon transient of 12 MWYR was performed. In these calculations, a xenon thermal microscopic abisorption cross section of 2.0 2. $6 \times 10^{6}$ barns was used. In addition, a non-uniform special distribution factor, $\alpha=1.134$, for xenon was used. Figure 5.14 shows the calculated and measured variation in reactivity of transient xenon with time after reactor shoutdown. The calculations are presented for two values of average xenon microscopic cross section. The sensitivity of the reactivity on Xe cross section is illustrated in this figure. The analysis of this problem in Appendix $D$ indicates that a cross section in the range of 2.34 to $2.60 \times 106$ barns is the best value.

The CANDLE-2 code was used to compute the equilibrium and maximum $\mathrm{Xe}$ reactivity as a function of core energy release. A xe-135 cross section of $2.6 \times 10^{6}$ barns and a distribution factor of $\alpha=1$ was used in this calculation. Figure 5.15 shows the calculated and measured xenon reactivities as a function of core energy release.

\section{2.9 Conclusions}

1. The application of CANDLE-2 in the radial and axial directions in the SM-1 Core I gave a core life of 16. 3 MWYR compared to 16. 4 MWYR experimental.

2. The spatial change of fuel due to burnup can be predicted with reasonable accuracy.

3. Equilibrium and maximum xenon reactivity were found to have been predicted very accurately using CANDL,E-2 code. 


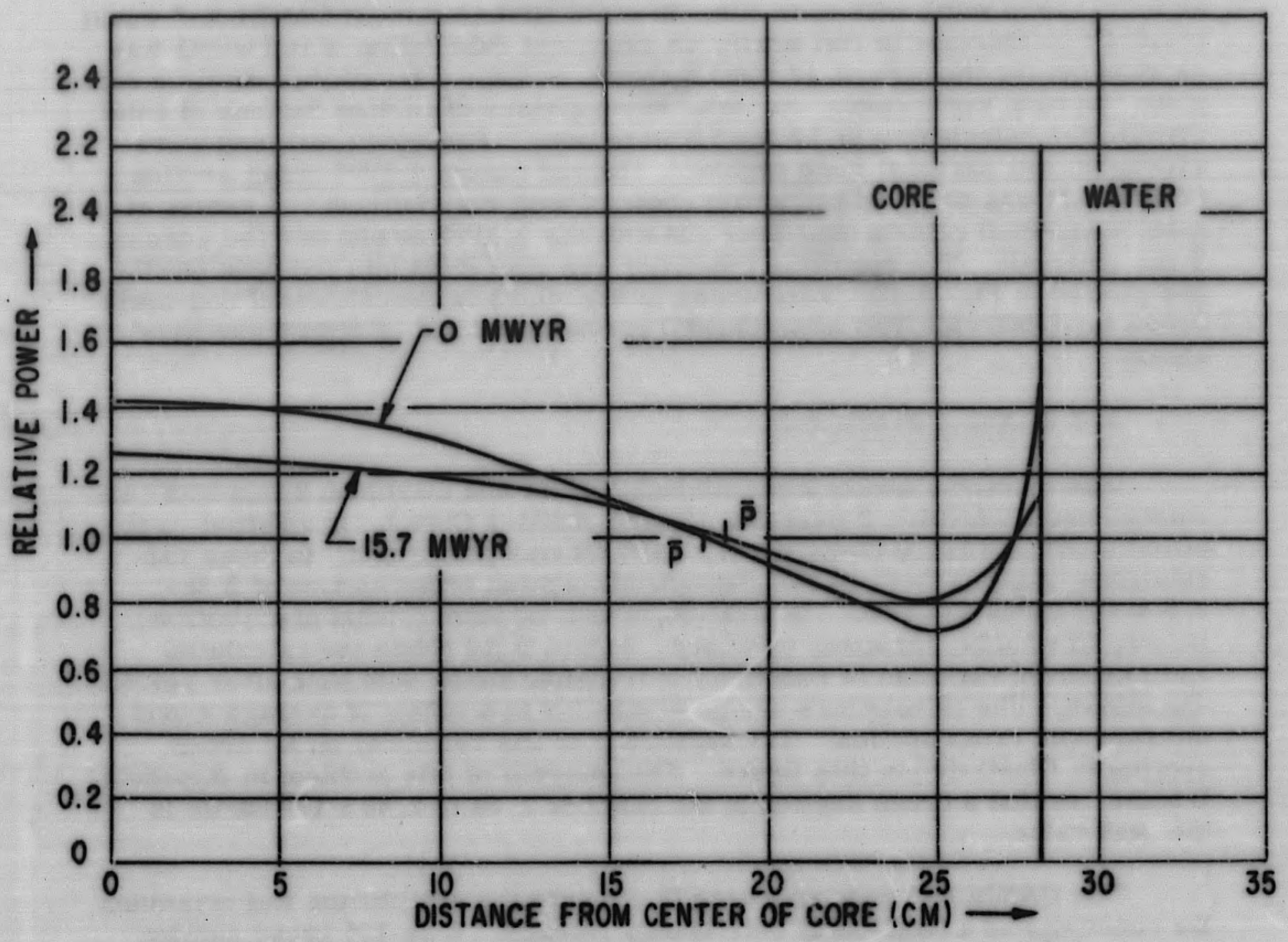

Figure 5.12 SM-1 Radial Power Distribution $-440^{\circ} \mathrm{F}$, Equilibrium Xenon - All Fixed Elements - $\Sigma_{a}$ 


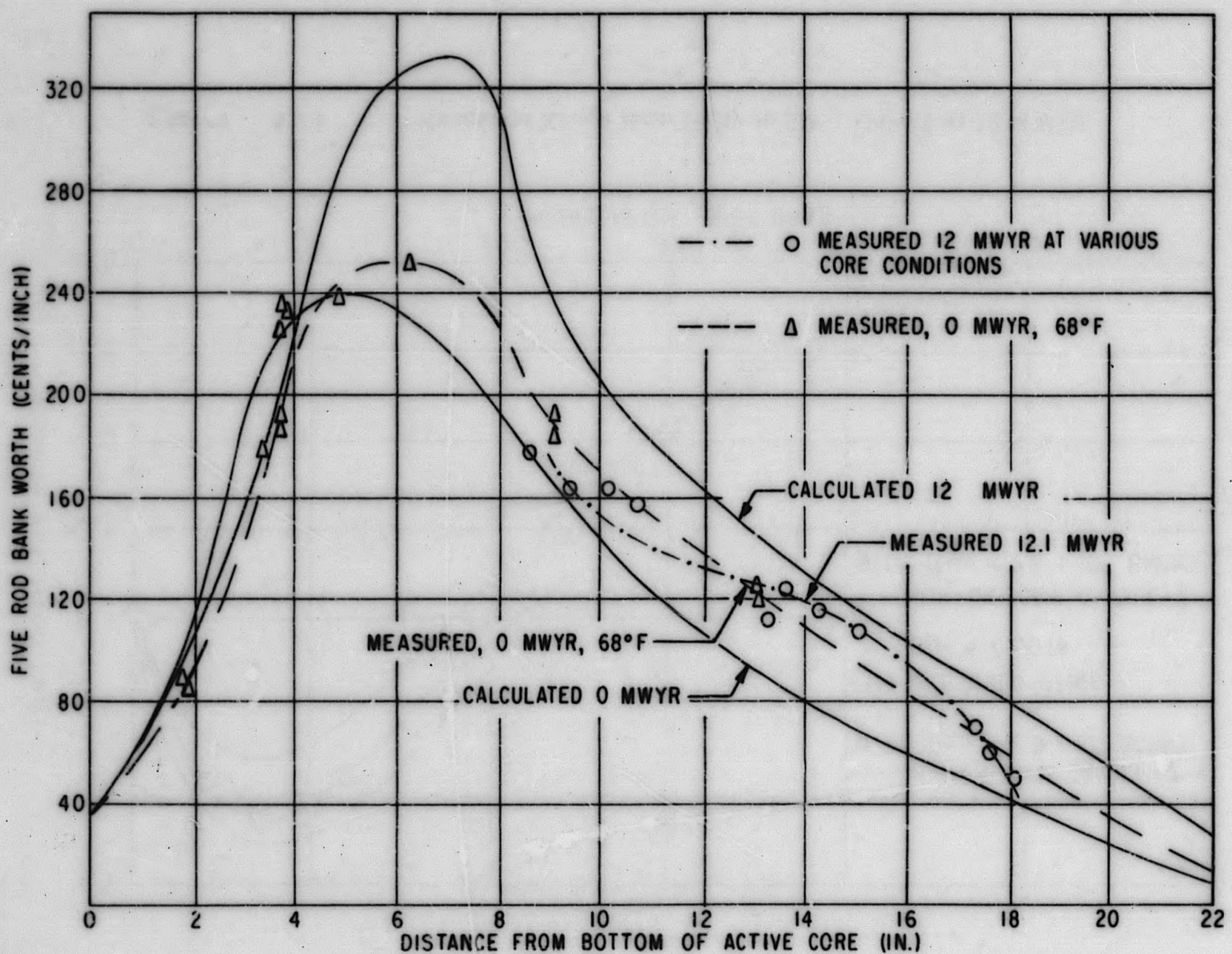

Figure 5.13

SM-1 Five Rod Bank Calibration 
ֻั

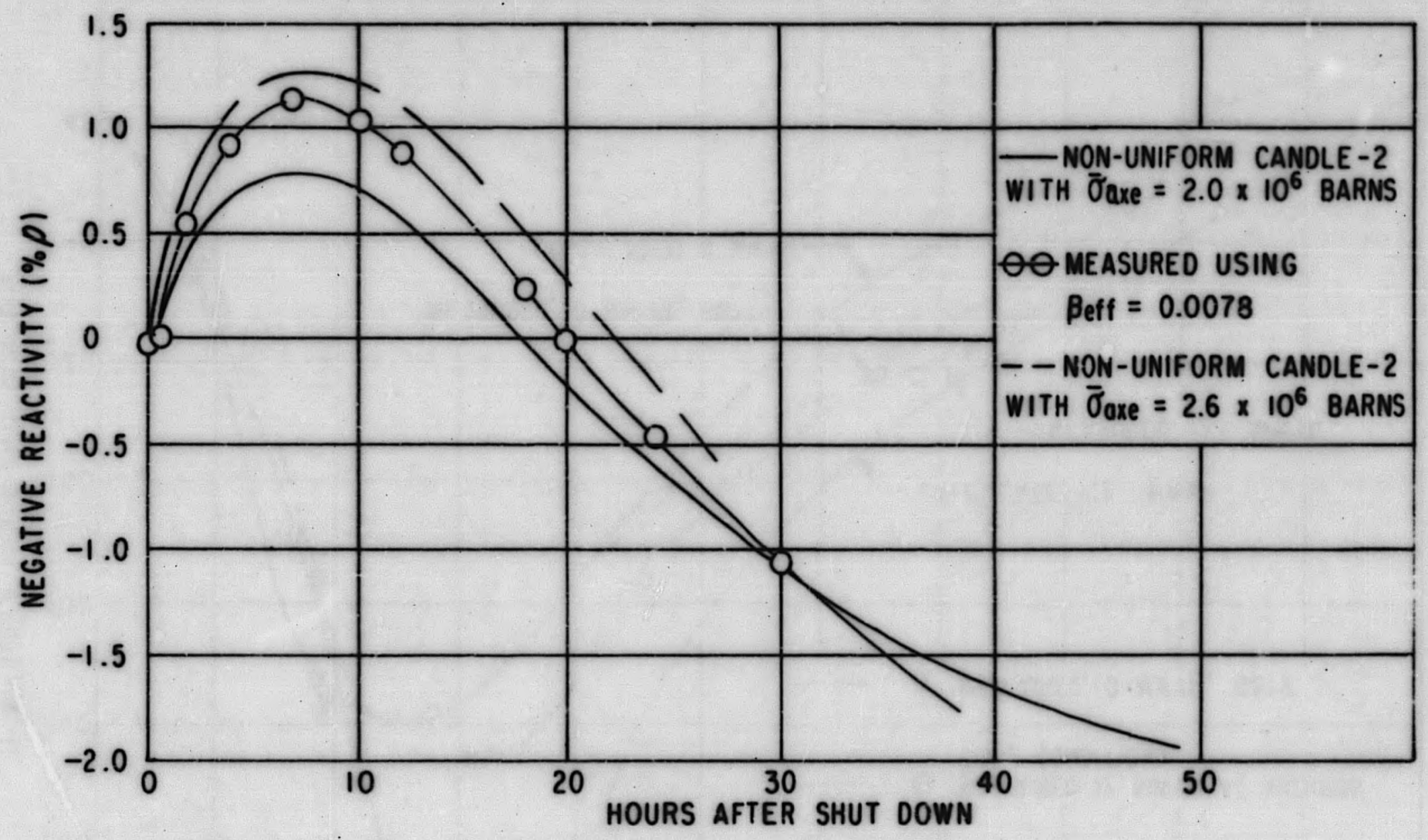

Figure 5.14 Transient Xenon Reactivity in SM-1 Core I at 12 MWYR 


\section{3 ESTIMATE OF CORE CHANGES AT 10.5 MWYR OF CORE LIFE}

At 10.5 MWYR energy release of SM-1 two fuel elements were removed and replaced by two new fuel elements. (7) In addition the original absorber sections employing boron enriched in the B-10 isotope were replaced by absorbers containing Eu $\mathrm{O}_{3}$. This latter change had a negligible effect on bank positions and therefore no change in core life. The element in position 64 is a control rod fuel element. The extension of SM-1 Core I life due to substitution of a new element into positions 64 and 56 was estimated using the CANDLE-2 code.

A geometrical model consisting of a control fuel element surrounded by an annulus of fixed elements reflected by water was employed. A CANDLE-2 burnout calculation was performed in this geometry. The core for an energy release of 10.5 MWYR was then modified by the adjustment of atomic concentrations of fuel and burnable poison to initial values in the control region, and the core burnout repeated. The reactivity variations were then compared yielding a $0.5 \% \rho$ increase and a core lifetime increase of $0.45 \mathrm{MWYR}$. Since the two elements substituted were not in the central positions, the reactivity effect was estimated by $\mathrm{J}_{0}^{2}\left(\mu_{\mathrm{r}}\right)$ weighing of the value obtained for the central element. The difference between fixed and control rod substitution were neglected. The result for new elements in positions 64 and 56 at 10.5 MWYR is $0.4 \%$ increase in core reactivity and a 0.35 MWYR increase in core life. The best estimate of the core life of an unperturbed SM-1 Core I is then 16. $4-0.35$ or 16. 05 MWYR energy release.

At the time of the 10.5 MWYR change a reactivity increase of 0.13 percent was estimated and a lifetime increase estimated of 0.35 MWYR. (7)

\subsubsection{Buildup of U-236 in SM-1 Core I}

Measurements of U-236 buildup in SM-1 Core I are now underway at ORNL on four elements removed from SM-1 Core I, two at 10.5 MWYR and two at end of life (16. 4 MWYR). Using CANDLE-2, the buildup of U-236 in SM-1 Core I has been calculated as a function of core life. A value of 4 barns was used for the thermal absorption cross section of U-236 at $440^{\circ} \mathrm{F}$.

Similar calculations of U-236 buildup are given for pile irradiated U-235 in Reference (8). From Fig. 8.1 of Reference (8) and a thermal nvt of $5.2 \times 10^{20}$ neutrons $/ \mathrm{cm}^{2}$ (for $10.5 \mathrm{MWYR}$ operation of SM-1) the U-235 remaining per initial atom of U-235 is 76 percent. This compares with a CANDLE-2 value of 76. 6 percent. The number of U-236 atoms per initial U-235 atoms is 4.2 percent from Reference (8) and 4. 4 percent from CANDLE-2 at 10.5 MWYR. 


\subsubsection{Conclusions}

1. The substitution of two elements of SM-1 Core I at 10.5 MWYR produced an estimated core life increase of 0.35 MWYR. Therefore the core life of an unperturbed SM-1 Core I would have been 16. 05 MWYR.

2. A CANDLE-2 calculation has been performed to estimate the U-236 buitit up. However lack of experimental measurements prevents evaluation of the results.

\section{4 SUMMARY}

In the present section CANDLE-2 has been used as the basic tool in predicting the core lifetime of SM-1 Core I.

With a reactivity adjustment at $1.4 \mathrm{MWYR}$, to the measured value, the core life was found to be 16. 8 MWYR compared to 16. 4 MWYR measured. U-235 and B-10 axial depletion and power distribution at various burnup levels have been calculated. The reactivity associated with equilibrium xenon was calculated and found in good agreement with experiment.

\subsection{REFERENCES}

1. Weiss, S. H. , "Summary Report of Physics Measurements on SM-1 Core I," APAE-96, February 6, 1962.

2. Gallagher, J. G., "Reactor Analysis for APPR-1," APAE No. 7, May 29, 1956.

3. ORNL-1613, "A Conceptual Design of a Pressurized Water Package Power Reactor." (classified)

4. Williamson, T. G. , et al, "NUB-1: A Non-Uniform Burnout Code for the IBM-650," AP Note 116, Alco Products, Inc. , October 23, 1958.

5. ANL-5800, Reactor Physics Constants, 1958.

6. KAPL-2000-12, Reactor Technology Report No. 15, December 1960.

7. Obrist, C. M. , "SM-1 Reactor Core Inspection at 2/3 Core Life," APAE-55, January 13, 1960.

8. Schuman, R. P., Tromp, R. L. , "Calculation of the Composition of Reactor Irradiated Heavy Nuclides," IDO-16571, December 17, 1959. 
9. Marlowe, O.J. and Ombrellaro, P.A., "CANDLE-A One-Dimensional Few-Group Depletion Code for the IBM-704, Addendum 1 - CANDLE-2," WAPD-TM-53, Addendum 1, October 1957.

10. Oby, P. V., "Modified Two Group Calculations on the IBM-650," APAE-11, August 21, 1956.

11. Rosen, S. S., "Supplement to MUFT-III Code Multigroup Fourier Transform Calculations," AP Note 90, Alco Products, Inc. , December 6, 1957.

12. Williamson, T. G. , Leibson, M. J., Byrne, B. J., "Reactor Analysis APPR-1 Core II, " APAE No. 32, July 15, 1958.

13. Bobe, P. E. , editor "Interim Report of Nuclear Analysis Performed on SM-2 Core and Vessel, September 1, 1958 to December 31, 1959," APAE-65, May 27, 1960.

14. Oby, P. V., "Modified Two Group Multiregion Calculation Using the VALPROD Code for the IBM-650," AP Note 24, August 14, 1957.

15. Fried, B. E., et al, "Flux and Power Distributions for the SM-2 Reference and Critical Experiment Cores," APAE Memo No. 286, June 30, 1961.

16. McElligott, P. E., "Burnout Distribution in SM-1 (APPR-1) Control Rod Elements Fixed Element No. 57 and Absorber Section at 10.5 MWYR," APAE Memo No. 199, June 5, 1959.

17. ORNL-2907, "Army Package Power Reactor Project, Annual Progress Report for Period Ending January 31, 1960."

18. Kemp, S. N. , Moote, F. G., McCool, W. J., "PWR Research and Development Program Test Report - Gamma Scanning Spent SM-1 Core I Elements, Test 318," APAE Memo No. 281, April 6, 1961. 


\section{0 TEMPERATURE COEFFICIENT}

\subsection{BACKGROUND}

An analytical expression for the temperature coefficient of reactivity has been obtained by differentiating the modified two group critical equation with respect to temperature, assuming that all variables except the number density of the moderator are independent of temperature. The justification for this assumption is based on the results of the analysis of SPERT III experimental data as reported in IDO-16586. (i) Although this assumption represents a gross simplification of the physical processes which contribute to the temperature coefficient of a water moderated reactor, the values of temperature coefficient calculated from the equations derived under this assumption agree well with measured values.

\section{2 DERIVATION OF THE ANALYTICAL EXPRESSION FOR TEMPERATURE COEFFICIENT}

The modified two group critical equation is:

$$
\begin{aligned}
& K_{\text {eff }}=k_{\text {th }} L_{\text {th }} L_{f}+K_{f} L_{f} \\
& k_{t h}=P K_{t h} \\
& k_{f}=(1-P) K_{f}
\end{aligned}
$$

where the symbols are defined in Appendix $\mathbf{E}$.

Defining the temperature coefficient as:

$$
\alpha_{T}=\frac{1}{k_{\text {eff }}} \cdot \frac{d_{\text {eff }}}{d T}
$$

and using Equation (1),

$$
\begin{aligned}
& \alpha_{T}=\frac{1}{L_{f}} \frac{d L_{f}}{d T}+\left(\frac{1}{1+\frac{K_{f}}{K_{\text {th }} L_{\text {th }}}}\right) \frac{1}{L_{\text {th }}} \cdot \frac{d L_{\text {th }}}{d T} . \\
& \text { where } \\
& L_{f} \text { is: } \\
& \qquad L_{f}=\frac{1}{1+\tau B^{2}},
\end{aligned}
$$


and

$$
\frac{1}{L_{f}} \frac{d L_{f}}{d T}=-\frac{B^{2}}{1+\tau B^{2}} \frac{d T}{D T}
$$

$L_{t}$ is: $\quad L_{t h}=\frac{1}{1+B^{2} L^{2}}$

and

$$
\frac{1}{L_{\text {th }}} \frac{d L_{\text {th }}}{d T}=-\frac{B^{2}}{1+B^{2} L^{2}} \frac{d L^{2}}{D T}
$$

$$
L^{2} \text { is: } \quad L^{2}=\frac{D}{\sum_{a_{t h}}}=\frac{1}{3 \sum_{t r} \sum_{a_{t h}}} \simeq \frac{1}{3 N^{w} \sigma_{t h} w \sum_{a_{t h}}}
$$

where the superscript, w, denotes water and $\sum_{a_{t h}}$ is assumed independent of $\sum_{a_{\text {th }}}^{w}$

$$
\frac{d L^{2}}{d T} \text { is: } \frac{d L^{2}}{d T}=-L^{2} \frac{1}{N^{W}}+\frac{d N^{W}}{d T}=L^{2} \frac{1}{\rho^{w}} \frac{d \rho w}{d T}
$$

where $\rho^{w}$ is the density of water as a function of temperature (at constant pressure). Assuming that the neutron age in a heterogeneous medium is given by: $:^{(3)}$

$$
\begin{aligned}
& \frac{1}{\sqrt{T}} \approx \frac{V w}{\sqrt{T_{w}}}+\frac{V m}{\sqrt{T}} \\
& \frac{d T}{d T} \text { becomes } \frac{d T}{d T}=T V_{w} \sqrt{\frac{T}{T_{w}}} \frac{1}{T w} \frac{d T_{w}}{d T}
\end{aligned}
$$

where $\mathbf{V} w$ is the volume fraction of water in the core, $7 \mathrm{w}$ is the neutron age in pure water, $T_{m}$ is the neutron age in metal, and $V_{m}$ is volume fraction of metal in the core. In obtaining Eq. (7) from Eq. (6), it is further assumed that $T \mathrm{~m}$ is independent of temperature. $T w$ is given by: 


$$
\tau_{\mathrm{w}}=\int_{E_{\mathrm{th}}}^{E_{0}} \frac{d E}{3 \xi \sum_{s} \sum_{\mathrm{tr}} E} \approx \frac{1}{\left(\mathrm{~N}^{\mathrm{w}}\right)^{2}} \int_{E_{\text {th }}}^{E_{0}} \frac{d E}{3 \sigma_{t r} \xi \sigma_{s}^{w} E}
$$

and ,

$$
\frac{1}{\tau_{w}} \frac{d_{w}}{d T}=-2 \frac{1}{N^{w}} \frac{d N w}{d T} \cdot-2 \alpha
$$

where

$$
\alpha \equiv \frac{1}{\rho^{w}} \frac{d \rho^{w}}{d T}
$$

Substituting (9) and (7) into (3) yields:

$$
\frac{1}{L_{f}} \frac{d L_{f}}{d T}=\frac{2 B^{2} V_{W}}{1+B^{2}} \sqrt{\frac{T}{T_{w}} \alpha}
$$

Substituting (4), (5) and (10) into (2) gives:

$$
\alpha_{T} \approx B^{2} \alpha\left[\frac{2 V_{W} \cdot T}{1+\tau_{B}^{2}} \sqrt{\frac{T}{T_{W}}}+\left(\frac{1}{1+\frac{K_{f}}{K_{t h} L_{t h}}}\right)\left[\frac{L^{2}}{1+B^{2} L^{2}}\right]\right.
$$

The numerical value of the first term in brackets is approximately 80 times the second for the SM-1: therefore, the secend term is neglected and the formula for the temperature coefficient becomes:

$$
\alpha T \approx \frac{2 V_{W}^{\prime} \tau_{B}{ }^{2}}{1+T_{B^{2}}} \sqrt{\frac{T}{T_{w}}} \alpha
$$

\subsection{COMPARISON OF CALCULATED AND EXPERIMENTAL TEMPERATURE COEFFICIENTS}

The 0 MWYR temperature coefficients of the SM-1 and PM-2A as calculated by Eq. (12) are compared to the experimental values in Table 6.1. 
TABLE 6.1

COMPARISON OF CALCULATED AND EXPERIMENTAL

TEMPERATURE COEFFICIENTS

\begin{tabular}{|c|c|c|c|c|}
\hline Core & $\begin{array}{l}\alpha_{\text {Tat }} 68^{\circ} \mathrm{F} \text { Calculated } \\
\text { from Eq. } 12 \text { in } \zeta /{ }^{\circ} \mathrm{F}\end{array}$ & $\begin{array}{l}\alpha_{\mathrm{T} \text { at Oper. Temp. }} * \\
\text { Calc. from Eq. } 12 \\
\text { in } \mathrm{c} / \mathrm{O}_{\mathrm{F}}\end{array}$ & $\begin{array}{l}\text { Exp. Temp. } \\
\text { Coef. } \mathrm{C} /{ }^{\circ} \mathrm{F}\end{array}$ & $\begin{array}{l}\% \text { Erior, Calc. } \\
\text { to Experimental }\end{array}$ \\
\hline \multirow[t]{2}{*}{ SM-1 } & 0.413 & $\longrightarrow$ & 0.448 & $-7.80 \%$ \\
\hline & & 3.86 & 3.25 & $+18.8 \%$ \\
\hline \multirow[t]{2}{*}{ PM-2A } & 0.526 & - & 0.550 & $-4.36 \%$ \\
\hline & & 5.65 & 4.85 & -16.5\% \\
\hline
\end{tabular}

* The operating temperature for the SM-1 is $440^{\circ} \mathrm{F}$ and $510^{\circ} \mathrm{F}$ for the PM-2A.

It should be noted that the experimental values recorded in Table 6.1 were obtained from, the curve resulting from fitting the curve of the bulk coefficient of expansion of water at the appropriate pressure (1000 psi for the SM-1 and 2000 psi for the PM-2A) to the experimental data. (4), (5) These are the solid curves of Fig. 6.1 and 6.2 which are plots of $\frac{\partial}{\partial T}=C\left[\frac{1}{D} \frac{\partial D}{\partial}\right]_{p}$ where $D$ is the density
of water at constant pressure.

Since the values of $\alpha_{T}$ at the low temperature are lower than the experimental values (the converse is true at the high temperature) and since SPERT III data indicates that $\alpha_{\mathrm{T}}$ is directly proportional to $\alpha$, the value of

$$
C \equiv \frac{2 V_{W} \tau_{B}^{2}}{1+\tau_{B}^{2}} \sqrt{\frac{T}{\tau_{w}}}
$$

at $68^{\circ} \mathrm{F}$ was used to calculate $\alpha_{\mathrm{T}}$ at all temperatures of interest. The results of this choice are presented in Fig. 6.1 for the SM-1 and Fig. 6.2 for the PM-2A. The agreement is seen to be good except for PM-2A at high temperature.

$\mathrm{B}^{2}$ for the $68^{\circ} \mathrm{F}$ calculation of Table 6.1 for the SM-1 was obtained from experiment $(6)$ and $T$ and $T$ w' were calculated by MUFT-II, P1-SG vaiues obtained with the MUFT-III stainless steel file as given in APAE-27. (6)

$\mathrm{B}^{2}$ for the $68^{\circ} \mathrm{F}$ and $510^{\circ} \mathrm{F}$ calculation of Table 6.1 for the PM-2A was obtained from the IBM-650 Code, FINK-I (21), and $\tau$ and $T_{\mathrm{W}}$ were calculated by MUFT-III, P1 - SG values obtained with the MUFT-III stainless steel files as given in

APAE-27. 


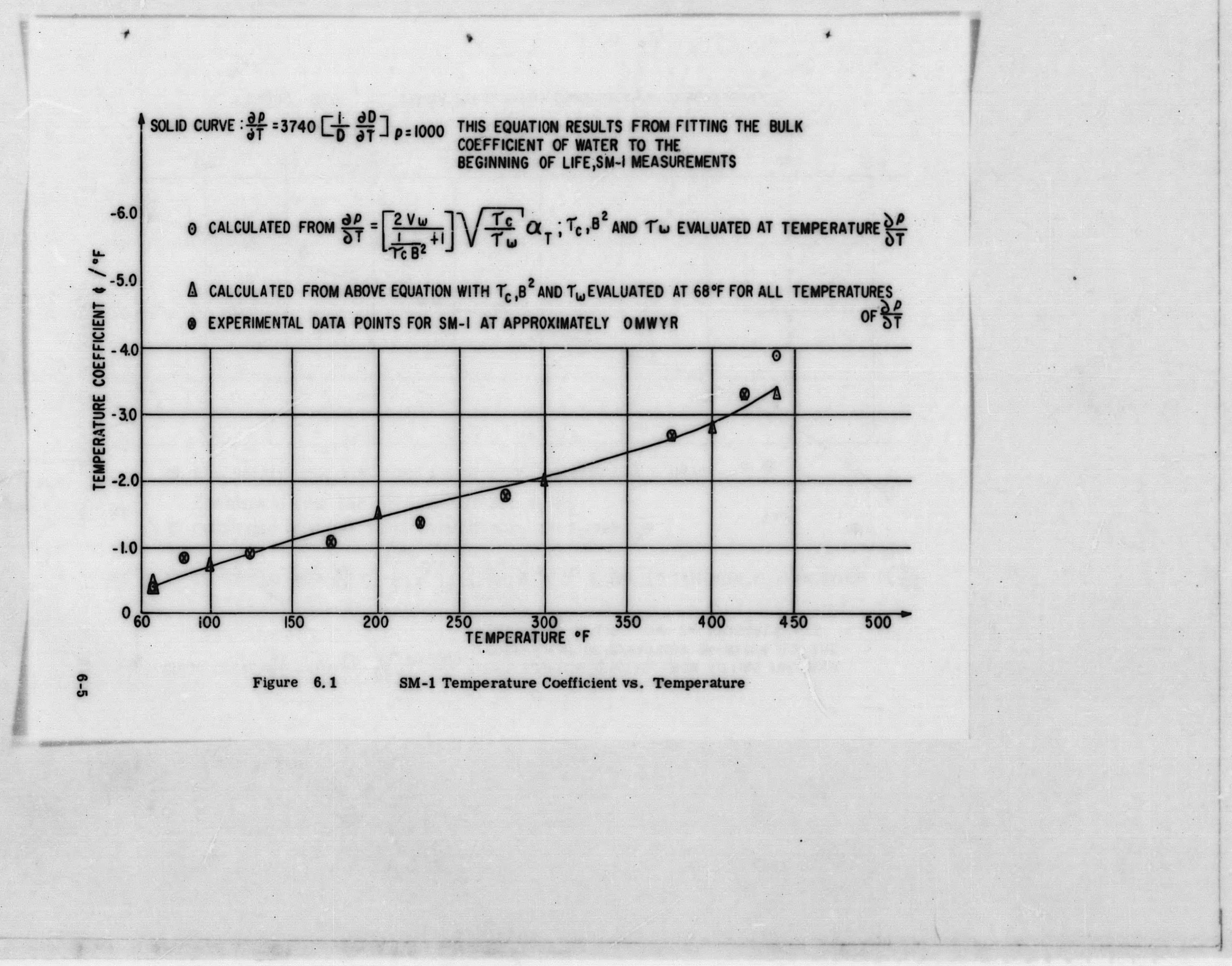




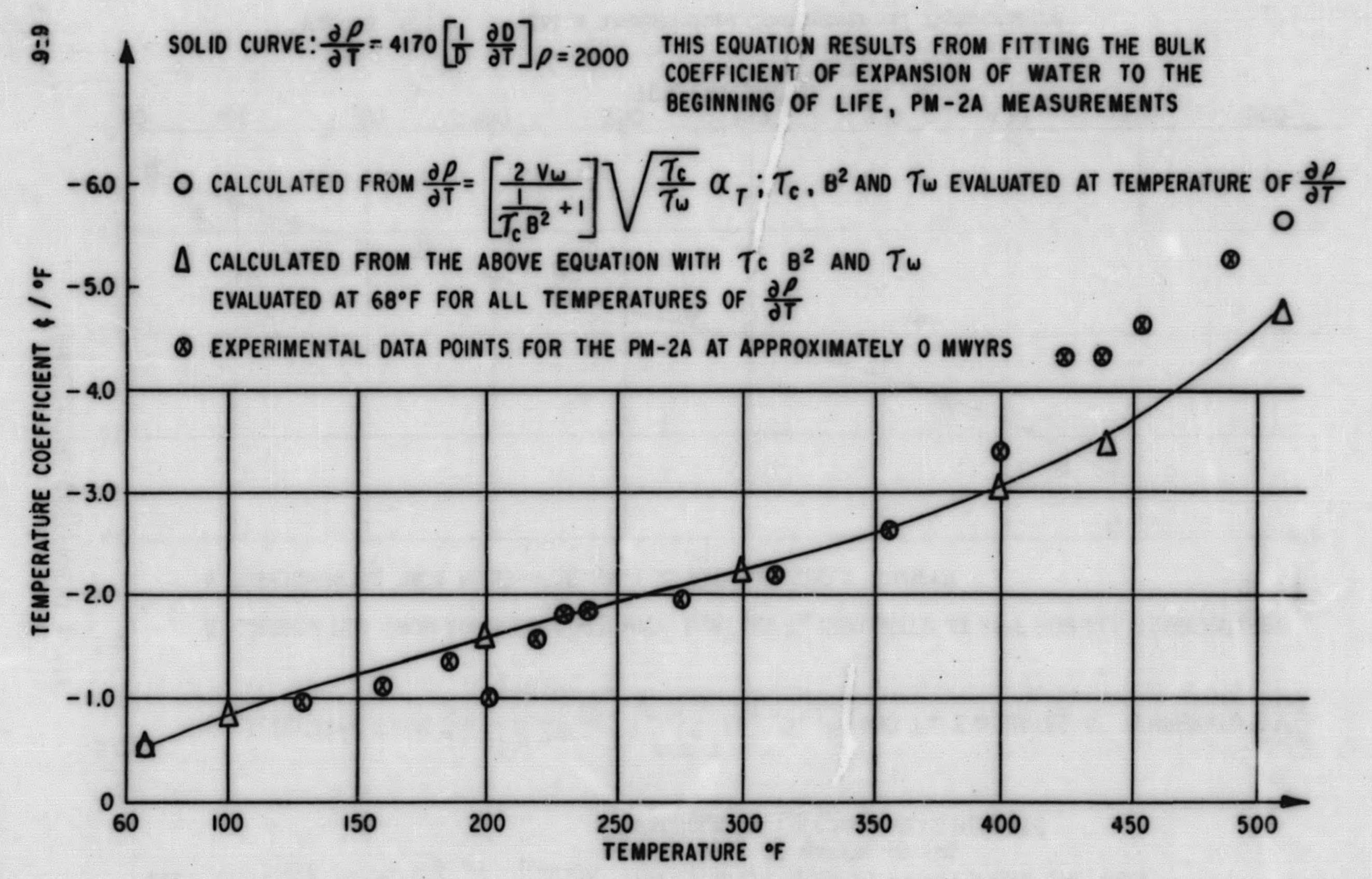

Figure 6.2 PM-2A Temperature Coefficient vs. Temperature 
As a further test of this model, $T$ for the SM-1 was recalculated by MUFTIII using the P-1 slowing down approximation and the revised stainless steel files presented in Appendix $\mathrm{F}$ of this report. ${ }^{*} \mathrm{~B}^{2}$ was calculated at $68^{\circ} \mathrm{F}$ by FINK-I using the fast core and reflector constants obtained from MUFT-III, P-1, revised stainless steel file. The calculated temperature coefficients based on these values (with the value of $\mathrm{C}$ assumed constant at its value at $68^{\circ} \mathrm{F}$ ) are compared with experimental results in Table 6.2. The agreement between calculated and experimental values is seen to be even better than the results based on the P1-SG - slowing down approximation and the previously used stainless steel files.

TABLE 6.2

EXPERIMENTAL AND CALCULATED TEMPERATURE COEFFICIENTS FOR SM-1 CORE I

\begin{tabular}{|c|c|c|c|}
\hline Temp. ${ }^{\circ} \mathrm{F}$ & $\begin{array}{l}\alpha_{\mathrm{T}} \text { Calculated from } \\
\mathrm{Eq} .12 \text { in } \mathrm{C} /{ }^{0} \mathrm{~F}^{*}\end{array}$ & $\begin{array}{l}\alpha_{\mathrm{T}} \text { from Experiment } \\
\text { in } \mathrm{c} /{ }^{\circ} \mathrm{F}\end{array}$ & $\begin{array}{l}\% \text { Error, Calculated } \\
\text { to Experiment }\end{array}$ \\
\hline 68 & 0.428 & 0.448 & $-4.5 \%$ \\
440 & 3.21 & 3.25 & $-1.23 \%$ \\
\hline
\end{tabular}

* $\beta_{\text {eff }}$ was assumed to be .0078.

\subsection{TEMPERATURE COEFFICIENT AS A FUNCTION OF ENERGY RELEASE}

Using values of $T$ calculated as a function of energy release, $\alpha_{\mathrm{T}}$ for the SM-1 Core I was calculated from Eq. (12) of Section 6.1.2. The results are plotted in Fig. 6.3 along with experimental values. The calculated age (from MUFT-III, P-1) is a linear function of energy release. The reflector savings were assumed constant in this calculation.

\subsection{CONCLUSIONS}

1. A reasonable fit of the measured temperature coefficient data vs. temperature can be obtained with the equation $\partial_{\rho} / \partial_{T}-C\left[\frac{1}{D} \frac{\partial D}{\partial T}\right] \rho$
where $D$ is the density of water.

* This method of calculating $T$ is currently considered best since reactivities based on this value of $T$ agree more closely with experiment. For a discussion of this point, refer to Section 3.0. 
के

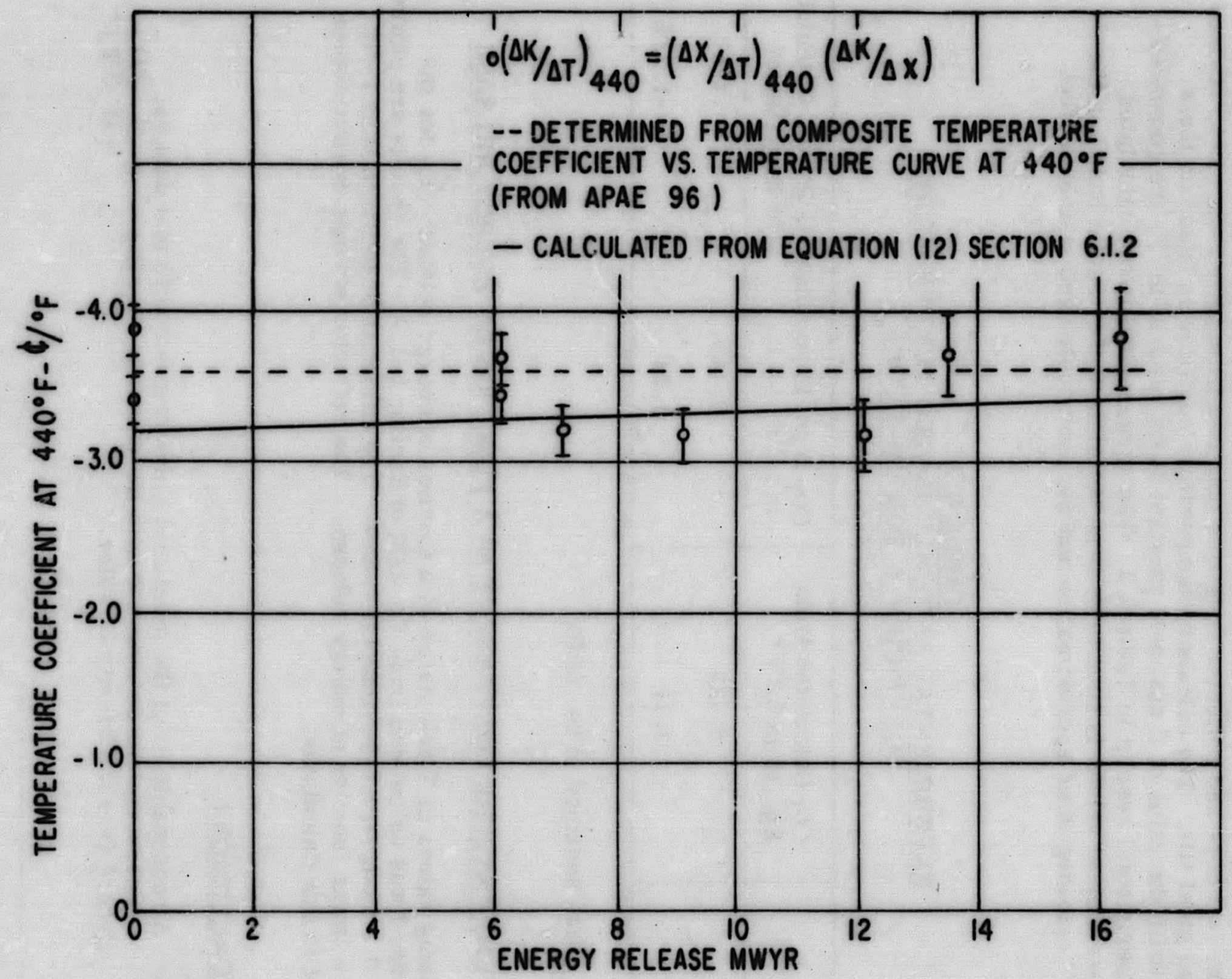

Figure 6.3 Temperature Coefficient at $440^{\circ} \mathrm{F}$ as a Function of Energy Release for the SM-1 
2. A simple equation has been developed for calculation of temperature coefficient that agrees well with experiment.

3. This equation indicates only slight variations of temperature coefficient with burnup.

\section{6 SUMMARY}

A reasonable fit of experimental and calculated temperature coefficient vs. energy release has been obtained. A slight increase of temperature coefficient vs. lifetime is indicated.

\section{7 REFERENCES (6.0)}

1. Schroeder, E. T., et al, "The SPERT III Reactor Nuclear Startup," IDO-16586, 1960.

2. Murray, R. L., "Nuclear Reactor Physics," Prentice Hall, Inc., Englewood Cliffs, N. J., 1957.

3. Kaplan and Chernick, "Uranium Graphite Lattices - Brookhaven Reactors," in Peaceful Use of Atomic Energy, Volume 5, "Physics of Reactor Design," Columbia University Press, 1956.

4. Weiss, S. H. , "Summary Report of Physics Measurements on SM-1 Core I," APAE-96, February 6, 1962.

5. McCool, W.J., "Startup and Initial Testing of the PM-2A Plant," APAE-92, to be issued March 1962.

6. Byrne, B. J., and Oby, P. V., "Analysis of Extended Zero Power Experiments on the Army Package Power Reactor, ZPE-2," APAE No. 27, May 7, 1958.

7. McElligott, P. E., "FINK I; A Two Group, Two Region Calculation on the IBM-650," APAE Memo 121, January 28, 1958. 


\section{0 CONCLUSIONS AND RECOMMENDATIONS}

\section{1 CONCLUSIONS}

1. P-1 slowing down theory utilizing MUFT-IIInuclear data as given in Ap rendix $F$ yielded the best agreement between calculated and measured reactivity for a wide range of cores. The calculated reactivities were within a standard deviation of $0.91 \% \rho$.

2. There are inconsistencies in the agreement of P-1, MUFT-III calculations of reactivity and measurements on minimum size and fully poisoned SM-1 ZPE Core I experiments.

3. The agreement of P-1 and P1-SG slowing down models with both MUFT-III and MUFT-V files with neutron ages of Po-Be neutrons in iron water mixtures is not good.

4. The use of Wigner-Wilkins averaged thermal cross sections rather than hardened Maxwellian cross sections results in a reactivity increase for SM-1 Core I of about $0.2 \% \rho$.

5. There is little difference between reactivity calculated using one-and two-dimensional diffusion theory, provided the substitution effects are properly treated.

6. The calculation ofcritical bank positions at room and operating temperatures can be made utilizing a one-dimensional axial model and homogenized rod cross section and give agreement within 1.4 in. of measurement.

7. A caiculation of the central control rod worth in both a boron stainless steel and a stainless steel poisoned SM-1 Core I indicate good agreement with experiments when utilizing the P-1 MUFT-III fast constants and absorber properties from blackness theory.

8. One-dimensional depletion calculations are applied to SM-1 with difficulty because of the presence of the control rod fuel elements and the problems of selecting an equivalent uniform cross section for the control rod absorbers. The results of the application of CANDLE III to the SM-1 is a core life of 16. 8 MWYR compared with a measured value of 16. 4 MWYR.

9. Calculations indicate that the substitution of two new fuel elements in SM-1 Core 1 at 2/3 life increased the core life by 0.3 MWYR. The best estimate of SM-1 Core I life unmodified is 16.1 MWYR. 
10. A simplified model for calculation of temperature coefficient has been developed and applied to SM-1 with good agreement with the measurements.

11. An anlytical model based on perturbation theory was applied to SM-1 Core I and yielded a good estimate of core life. These parameters such as xenon which are highly dependent on flux distribution were not accurately treated.

12. A calculation of effective delayed neutron fraction for SM-1 Core I indicated a value of 0.0078 based on a value of delayed neutron fraction of 0.0065 . Calculation indicated the effective delay in neutron fraction was not a sensitive function of bank position.

13. Calculations indicated that the xenon cross section for SM-1 Core I is a sensitive function of effective neutron temperature.

\subsection{RECOMMENDATIONS}

1. A concentrated effort should be made to obtain an improved set of basic nuclear cross section data for stainless steel in the energy region from $10 \mathrm{Mev}$ to a few kev. The validity of this set of improved data should be checked against available experimental ages from Po-Be sources and clean critical experiments with high steel-to-water rations.

2. Measurements of the age of fission neutrons in steel-water mixtures are needed to provide a check on slowing down models and nuclear data.

3. Experimental information is needed on the variation of thermal flux and neutron spectrum in the SM type cells. This information can then be used as a basis for determining the validity of various models for calculations of thermal group properties.

4. The inherent difficulties in the application of one-dimensional burnout codes to cores as heterogeneous as the SM-1 Core I indicate the desirability of investigating the application of at least two-dimensional codes such as TURBO to the burnout of SM-1 type cores. The most preferable calculational model would be a three-dimensional model such as DRACO, modified to account explicitly for the presence of moving control rod fuel elements. A computer of the capacity of the Philco-2000 is needed to accurately treat the geometry. 
5. Consideration should be given to programming the series burnup method (1) calculation of core lifetime accounting for non-uniform burnup. The availability of such a code would facilitate parameter studies on core life.

6. A series of clean critical experiments should be performed utilizing actual SM-2 mockup fuel plates in order to have available configurations for checking analytical models.

7. The development of longer-lived replacement cores with higher metal/ water ratios will require an improved treatment of the epithermal effects of fission products.

8. An effort should be made to obtain good agreement between the constants resulting from the fast group coalescing schemes as used in the MUFT codes and coalescing schemes as used in the burnup codes CANDLE and TURBO.

9. More accurate measurements of the fuel (and poison) burnup in the fuel element SM-1 Core I is needed to provide a check of analytical predictions.

(1) Murray, R. L. et al., "Reactor Fuel Cycle Analysis by Series Method," Nuclear Science and Engineering, July 1959. 


\section{APPENDIX A \\ PREDICTION OF SM-1 CORE I BURNUP CHARACT ERISTICS USING SERIES TECHINIQUE}

\section{INTRODUCTION}

Appendix A consists of analytic studies of the behavior of the SM-1 Core I. The reactor physics employed is intended to be of such nature that the maximum physical content is included, compatible with a model that admits hand calculations. The procedure consists of the following steps: (a) to adapt burnup theory to a reactor with control rod bank and to determine the variation of reactivity with time, (b) to employ data on successive "states" of the reactor during its operating life to predict its flux pattern, the xenon poisoning and the temperature coefficient; (c) to develop a theory of the effective delayed neutron fraction that is consistent with the burnup model to permit interpretation of experimental rod calibration. However the burnup theory, while adaptable to hand calculation is quite approximate for higher burnup as the fuel and poison distributions constantly depart from the initial and are constantly substituted with equivalent states. Although the numbers may not be as accurate as in more sophisticated techniques, the physical trends of the core are present. 


\section{A. 1 PREDICTION OF CORE LIFE BY BURNUP THEORY}

\section{A. 1.1 Introduction}

Analytic approximate methods are used to predict the SM-1 core life. The approach is an adaptation of that developed for a reactor controlled by a uniform adjustable poison. * The generalizations effected are as follows.

a. Inclusion of effect of epithermal processes on criticality and on fuel consumption.

b. Account of the reactivity variation due to discrete control bank motion.

c. Distinction between fixed and control fuel elements.

Several necessary simplifying assumptions are made:

a. For purposes of computation the core fluxes are as in a two-region bare equivalent core. Burnup is taken to occur however, only in the actual physical dimensions of the core and rod region.

b. Although the flux amplitude is allowed to change with time as burnup ensues, the initial shape is retained. The total core power is maintained constant in time and the reactor is always critical.

c. Effects of xenon poisoning and long-lived fission product poisoning are superimposed on the basic dynamic response.

d. A modified one-group diffusion theory that is dominated by fast leakage effects is employed.

\section{A. 1. 2 Initial Criticality and Flux Distributions}

Physical arrangement. The essential features of the actual core and the equivalent model for analysis are sketched in Figs. 1a and 1b.

The bare equivalent core has dimension $\mathbf{H}^{\prime}-\mathbf{H}+2 \mathrm{~S}_{2}$ and $\mathbf{R}^{\prime}-\mathbf{R}+\mathbf{S}_{\mathbf{r}}$, where axial and radial reflector savings are employed. The radial flux distribution is automatically a zero order Bessel function $J_{0}\left(j_{0} r / R^{\prime}\right)$. The axial distribution has two parts $\phi(\mathrm{z})$ and $\phi_{\mathbf{r}}(\mathrm{z})$ for the core and rod region respectively.

* Murray, Raymond L. , S. A. Hasnain and A. L. Mowery, Jr. "Reactor Fuel Cycle Analysis by Series Methods," Nuclear Science and Engineering, 6, 18 (1959) 


\section{Two Withdrawn rods}

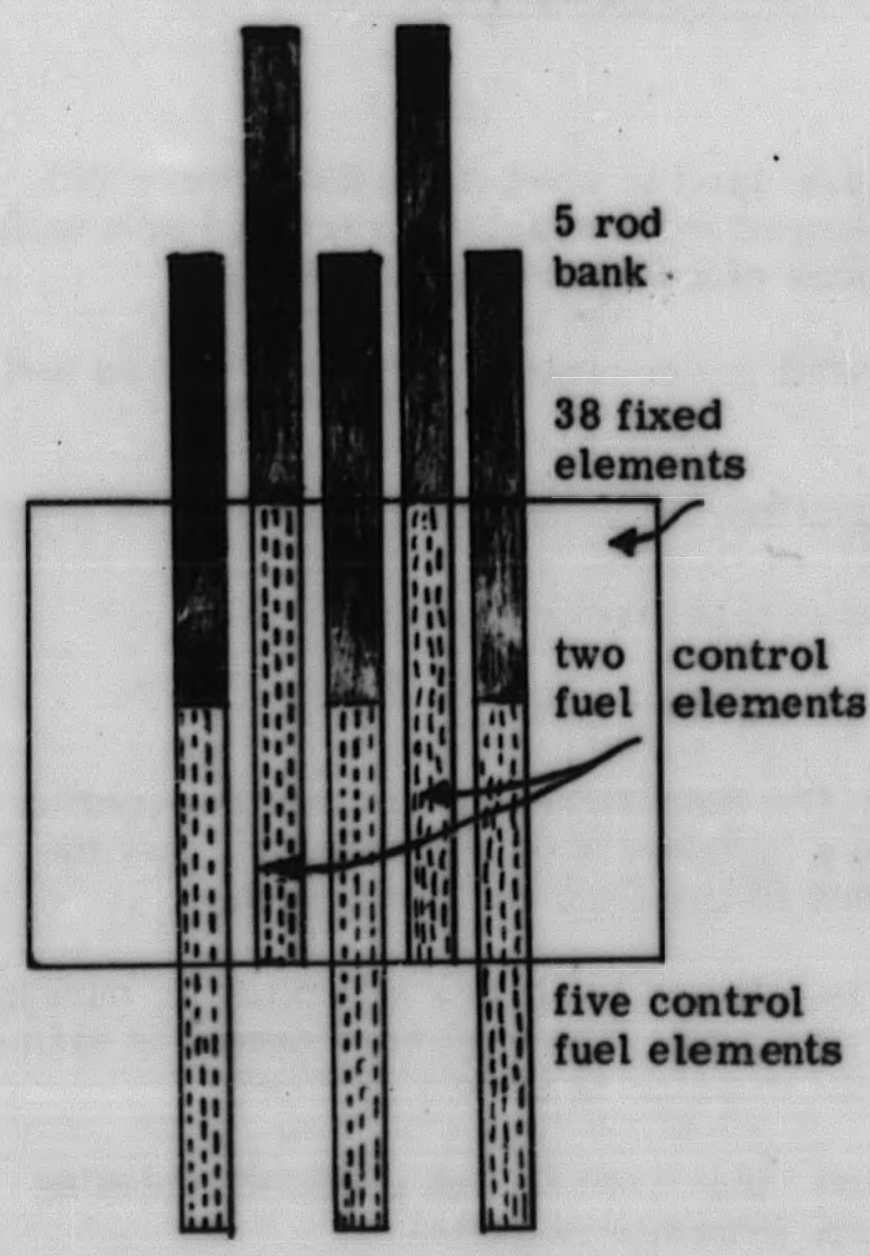

Fig. A. 1a Physical Core

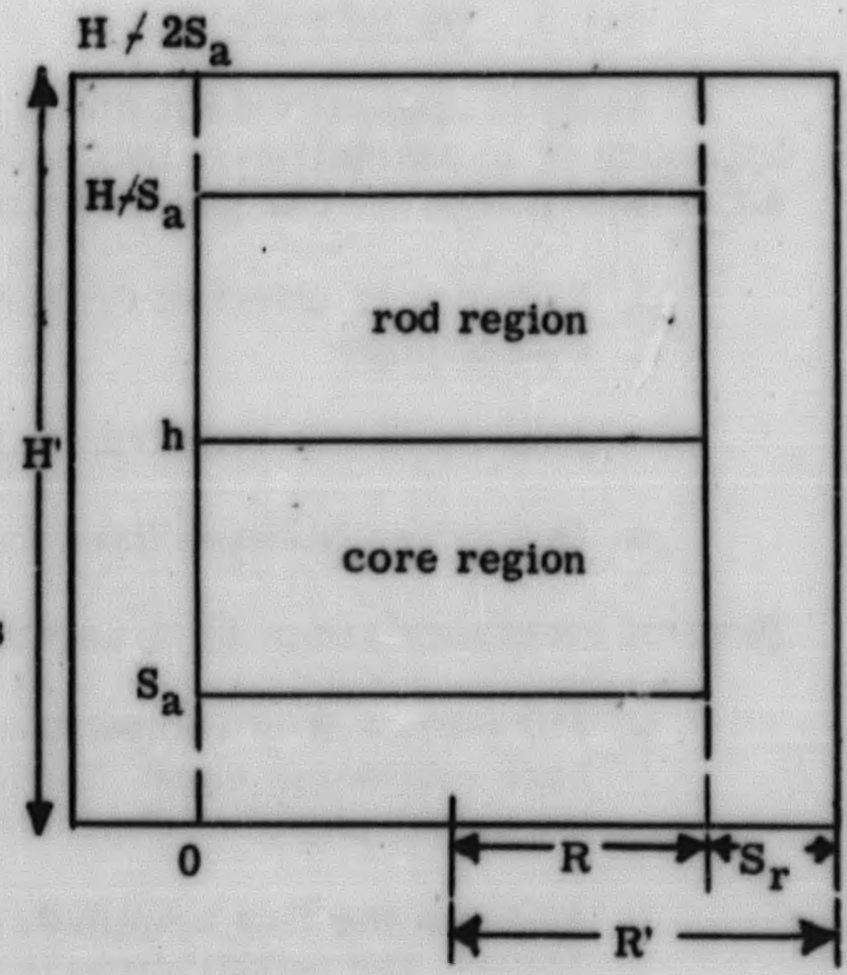

Fig. A. 16 Core Model

Figure A. 1. Physical Arrangement of Core and Core Model

The differential equations of modified two-group theory serve as the starting point for the solution

$$
\begin{aligned}
& \mathrm{D}_{1} \nabla^{2} \phi_{1}-\phi_{1} \sum_{1}+\phi_{2} \sum_{2} \eta^{\mathrm{f}}+\phi_{1} \sum_{1}(1-\mathrm{p}) \eta_{\mathrm{r}_{\mathrm{r}}}=0 \\
& \mathrm{D}_{2} \nabla^{2} \phi_{2}-\phi_{2} \sum_{2}+\mathrm{p} \phi_{1} \sum_{1}=0
\end{aligned}
$$

where the thermal and resonance fission sources appear in the fast group equation. Since the two-group two-region problem is unduly complicated for a situation in which rod motion and burnup talie place, a simpler group model is proposed. It is well known that the thermal leakage for a heavily loaded light water 
moderated reactor is small compared with fast leakage. Thus we may neglect the term $D_{2} \nabla^{2} \phi_{2}$ with little error, giving

$$
p \phi_{1} \Sigma_{1}=\phi_{2} \Sigma_{2}
$$

Substitution in the first equation yields

$$
\left.D_{1} \nabla^{2} \phi_{2}-\sum_{1}\left[1-(1-p) \eta_{r^{f}} r\right)\right] \phi_{2}+\eta_{f} \sum_{2} \phi_{2} p \sum_{1}=0
$$

\section{Letting}

$$
\begin{aligned}
& \frac{D_{1}}{\Sigma_{1}}=\tau \text { and } \mathrm{K}=\eta \mathrm{fp}+(1-\mathrm{p}) \eta_{\mathrm{r}} \mathbf{f} \\
& \nabla^{2} \phi_{2}+\left(\frac{\mathrm{K}-1}{\tau}\right) \phi_{2}=0
\end{aligned}
$$

This new one group model contains the necessary fast and thermal multiplication factors. The only assumption made is that neutrons diffuse very short distances after thermalization.

By virtue of the assumed radial distribution, the axial fluxes in the two regions involve a modified buckling and inverse diffusion length. Let $\mathrm{B}^{2}=$ $(\mathrm{K}-1) / T$ and $\mathrm{B}_{\mathrm{r}}^{2}=\left(\mathrm{K}_{\mathbf{r}}-1\right) / \tau$. Use of the method of separation of variables with $\nabla^{2}=\partial^{2} \partial \mathrm{r}^{2}+1 / \mathrm{r} \partial / \partial_{\mathrm{r}}+\partial^{2} / \partial z^{2}$ yields core and rod equations in what is now the axial dist ribution

$$
\frac{d^{2} \phi_{2}}{d z^{2}}+\bar{B}^{2} \phi_{2}=0
$$

and

$$
\frac{d^{2} \phi_{2 r}}{d z^{2}}-K^{2} \phi_{2 r}=0
$$

where

$$
\begin{aligned}
& \bar{B}^{2}=B^{2}+\left(j_{0} / R^{\prime}\right)^{2} \\
& \bar{K}^{2}=\left(j_{0} / R^{\prime}\right)^{2}-B_{r}^{2}
\end{aligned}
$$

The regions are distinguished by the fact that the subtraction of radial buckling in the rod region places the differential equation in the non-multiplying category.

The solutions of the equations for the two media that satisfy the boundary condition $\phi_{2}(0)=0$ and $\phi_{2} \mathbf{r}\left(\mathrm{H}^{\prime}\right)=0$ are readily seen to be 


$$
\begin{aligned}
& \phi(z)=A \sin B z \\
& \phi_{r}(z)=C \sinh K\left(H^{\prime}-z\right)
\end{aligned}
$$

where the subscript 2 for thermal group has heen suppressed, as have the bars over $B$ and $K$.

Continuity of flux and current at $\mathrm{z}=\mathrm{h}$ with an assumed common thermal diffusion coefficient is invoked, leading to

$$
\begin{aligned}
& A \sin B h=C \sinh K\left(H^{\prime}-h\right) \\
& B A \cos B h=-C K \cosh \left(H^{\prime}-h\right)
\end{aligned}
$$

from which the critical equation is derived

$$
\tan B h=-\frac{B}{K} \tanh \left(H^{\prime}-h\right)
$$

and the constant $\mathrm{C}$ is

$$
C=A \frac{\sin B h}{\sinh K\left(H^{\prime}-h\right)}
$$

\section{A. 1.3 Perturbation Theory}

Consistent adaptation of one group perturbation theory is made. Consider the critical core equation in the form

$$
\nabla^{2} \phi+B_{0}^{2} \phi=0
$$

dr compactly

$$
M \phi=B_{0}^{2} \phi
$$

where

$$
\mathbf{M}=-\nabla^{2} \text { and } \mathrm{B}_{\mathrm{o}}^{2}=\frac{\mathrm{K}-\mathbf{1}}{\mathrm{T}}
$$

Assume that changes in fuel or absorption occur to cause a distributed change in buckling

$$
\Delta B^{2}=\Delta\left(\frac{K-1}{T}\right)=\frac{\Delta K}{T}
$$

There must be made a corresponding uniform buckling change $\delta \mathbf{B}^{2}$ to accommodate this perturbation, giving a new critical equation

$$
M^{\prime} \phi^{\prime}=B^{2} \phi^{\prime}
$$


where $M^{\prime}=-\nabla^{2}+\Delta B^{2}$

Multiplying the differential equation through by the original flux $\phi$ and integrating over the core,

$$
B^{2}=\frac{\int \phi M^{\prime} \phi^{\prime} d V}{\int \phi \phi^{\prime} d V}
$$

The perturbation approximation $\phi \underline{\underline{ } \phi}$ is made, and

$$
B^{2}=B_{0}^{2}+\frac{\int \phi \Delta B^{2} \phi d V}{\int \phi^{2} d V}
$$

or

$$
\delta^{B^{2}}=\frac{\int \Delta B^{2} \phi^{2} d V}{\int \phi^{2} d V}
$$

The correlation between $\delta^{\mathrm{B}^{2}}$ and reactivity $\rho$ can be made through the neutron economy formula

$$
k_{e}=K \mathscr{L}
$$

where $\mathscr{L}$ is the constant non-leakage probability

$$
\mathcal{L}=\frac{1}{1+B^{2} \mathrm{~g} T}
$$

Now $\rho=\frac{\delta^{\mathbf{k}_{\mathbf{e}}}}{\mathbf{k}_{\mathbf{e}}}=\frac{\delta^{\mathbf{K}}}{\mathbf{K}}$

However $\delta \mathrm{B}^{2}=\frac{\delta \mathrm{K}}{T}$ and $\rho=\frac{\tau \delta \mathrm{B}^{2}}{\mathrm{~K}}$

Thus $\rho=\frac{\int \Delta K \phi^{2} d V}{\int K \phi^{2} d V}$

The relation between $\Delta K / K$ and microscopic changes can be deduced. Let $K_{t}=$. $\eta^{\mathrm{f} p}$ and $\mathrm{K}_{\mathrm{f}}=(1-\mathrm{p}) \eta_{\mathbf{r}} \mathrm{f}_{\mathrm{r}}$. Then

$$
\frac{\Delta K}{K}=\frac{\Delta K_{t}}{K}+\frac{\Delta K_{f}}{K}
$$


Assuming negligible change in $\mathrm{p}$, and going to the differential notation, we find for either themal or fast neutrons

$$
\frac{d K_{i}}{K_{i}}=\frac{d \sum_{f i}}{\sum_{f i}}-\frac{d \sum_{a i}}{\sum_{a i}}
$$

Further, since the principal absorbers are uranium (U) and boron (B),

$$
\frac{d \Sigma_{a}}{\Sigma_{a}}=\frac{d \sum_{a U^{+}} d \Sigma_{a B}}{\sum_{a}}=\frac{\sum_{a U}}{\sum_{a}} \frac{d \sum_{a U}}{\sum_{a d}}+\frac{\sum_{a B}}{\sum_{a}} \frac{d \sum_{a B}}{\sum_{a B}}=f_{U} \frac{d N_{U}}{N_{U}}+f_{B} \frac{d N_{B}}{N_{B}}
$$

with $f_{U}$ and $f_{B}$ as the "utilizations" of the two elements. For either region then

$$
\frac{\Delta \mathrm{K}}{\mathrm{K}}=\alpha \frac{\Delta \mathrm{N}_{\mathrm{U}}}{\mathrm{N}_{\mathrm{U}}}-\beta \frac{\Delta \mathrm{N}_{\mathrm{B}}}{\mathrm{N}_{\mathrm{B}}}
$$

where

$$
\begin{aligned}
& \alpha=1-\left(\frac{K_{t} \mathbf{f}_{t}+K_{r} f_{u r}}{K}\right) \\
& \beta=\frac{K_{t} f_{B t}+K_{r} f_{B r}}{K}
\end{aligned}
$$

The "windowshade" method of treating the control bank is employed, in which the rod region is assumed to have a uniform thermal poison $\sum p$. As the bank is moved, there is a local change in absorption $\Delta \Sigma_{\mathrm{a}}=-\sum_{\mathrm{p}}$, giving rise to

$$
\left.\mid \frac{\Delta \mathrm{K}}{\mathrm{K}}\right)_{\mathrm{p}}=+\frac{\mathrm{K}_{\mathrm{t}}}{\mathrm{K}} \cdot \frac{\delta \Sigma_{\mathrm{p}}}{\Sigma_{\mathrm{a}}}
$$

Integration over the volume that rod motion affects is to be made.

\section{A. 1. 4 Burnup Theory}

The rate of consumption of fuel is governed by

$$
\frac{d N_{U}}{d t}=-A_{t}-A_{r}
$$

where the absorption rate of thermals is

$$
A_{t}=\phi_{2} N_{U} \sigma_{a U}
$$


where $\mathrm{g}$ is a self-shielding factor for the fuel plate and that in the resonance region is

$$
A_{r}=\phi_{1} \sum_{1}(1-p) f_{r}
$$

The two absorptions can be expressed entirely in terms of the thermal flux, if we invoke the following relations:

$$
\begin{aligned}
& f_{r}=\frac{N_{U} \sigma a U_{r}}{\sum a r} \\
& p \phi_{1} \Sigma_{1} \simeq \phi_{2} \Sigma_{2}
\end{aligned}
$$

Then

$$
A_{r}=\phi_{2} N_{U}\left[\frac{\sum_{2}(1-p) \sigma_{a U r}}{p \sum_{a r}}\right]
$$

Combining terms, and using an effective uranium absorption cross section

$$
\sigma_{\mathrm{aU}} \mathrm{e}=\sigma_{\mathrm{aU}}+\frac{\sum_{2}(1-\mathrm{p}) \sigma_{\mathrm{aUr}}}{\mathrm{p} \sum_{\mathrm{ar}}}
$$

the fuel burnup equation becomes

$$
\frac{d N_{U}}{d t}=-\phi N_{U} \sigma_{a U^{e}}
$$

The flux is assumed to be separable in space and time

$$
\phi(r, z, t)=c(t) \phi(r)
$$

and letting $u=\int_{0}^{t} c(t) d t$

$$
N_{U}(r, t)=N_{U}^{o} e^{-\phi(\bar{r}) \sigma^{e}} a U^{u}
$$

Similarly the boron atom density is

$$
N_{B}(\bar{r}, t)=N_{B}^{o} e^{-\phi(r) \sigma}{ }_{a B}^{e}
$$

with an analogous effective boron cross section,

$$
\sigma_{a B}^{e}=\sigma_{a B}+\frac{\sum_{2}(1-p) \sigma_{a B r}}{p \sum_{a r}}
$$


The condition on constant fission rate or core power is invoked to obtain a relation between $u$ and time. Reference is made to standard burnup theory* which carries over to yield the expression

$$
t=\frac{1-B_{0}\left(x_{U}\right)}{c_{0} \sigma_{a U}^{e} \phi(r)}
$$

where $c_{o}$ is the initial amplitude of the flux, $\overline{\phi(\mathbf{r})}$ is the spatial average over the core and rod region, $x_{U}=\sigma_{\mathrm{aU}}^{\mathrm{u}}$, and the zero order burnup function is

$$
B_{0}(x)=\int_{V} e^{-\phi(\bar{r}) x} d V
$$

a series expansion of which is

$$
B_{0}(x)=1-\not x+\frac{\phi^{2} x^{2}}{2 !}-\frac{\overline{\phi^{3}} x^{3}}{3 !}+\cdots
$$

\section{A. 1.5 Reactvity Due to Rod Motion}

The position dependent reactivity effect or rod motion through a differential distance $\mathrm{dz}$ when the bank position is $\mathrm{z}$ is

$$
d \rho=\frac{\int \frac{\Delta K}{K} \phi^{2} d V}{\int \phi^{2} d V}
$$

If one assumes in first approximation that the flux is separable in space and time, the time variation cancels out in the above expression, thus

$$
d \rho=\frac{\frac{K_{t}}{K} \sum_{p} d z \phi^{2}(z)}{\sum_{c+r} \sqrt{\phi^{2}(z) d z}}=\frac{K_{t} \sum_{p} \phi^{2}(z) d z}{\sum_{2} K H \overline{\phi^{2}}}
$$

The total reactivity due to removal from initial $z=h$ to any level $z$ is

$$
\rho(x)=\frac{k_{t} \sum_{p} \int_{h}^{z} \phi^{2}(z) d z}{k\left[k \overline{\phi_{c}^{2}}+m \overline{\phi^{2}}\right]}
$$

where $\mathbf{k}=\mathbf{h}=\mathrm{S}_{\mathrm{a}}$ and $\mathrm{m}=\mathrm{H}+\mathbf{2} \mathrm{S}_{\mathrm{a}}-\mathrm{h}$ are the core and bank lengths, and the average square fluxes are over the two regions. The reactivity associated with fuel and boron consumption is computed from

* Murray, et al, ibid.

A-10 


$$
\rho=\frac{\int \frac{\Delta K}{K} \phi^{2} d V}{\int \phi^{2} d V}=\frac{\int\left[\alpha \frac{\Delta N_{U}}{N_{U}}-\beta \frac{\Delta N_{B}}{N_{B}}\right] \phi^{2} d V}{\int \phi^{2} d V}
$$

Now for a given point of the system

$$
\begin{aligned}
& \frac{\Delta N_{U}}{N_{U}} \cong \frac{N_{U}-N_{U}^{o}}{N_{U}^{o}}=-\left[1-e^{-\phi(\bar{r}) \sigma_{a U^{u}}^{e}}\right] \\
& \frac{\Delta N_{B}}{N_{B}} \cong \frac{N_{B}-N_{B}^{o}}{N_{B}^{0}}=-\left[1-e^{-\phi(\bar{r}) \sigma_{a B}^{e}}\right]
\end{aligned}
$$

In this relation for $\rho$, the time amplitude cancels, and integration over the regions of length $\mathrm{k}=\mathrm{h}-\mathrm{S}_{\mathrm{a}}$ and $\mathrm{m}=\mathrm{H}+2 \mathrm{~S}_{\mathrm{a}}-\mathrm{h}$

$$
\begin{aligned}
\rho= & -\left\{\alpha_{c} \phi_{c}^{2} k\left[1-\frac{B_{2}\left(x_{U c}\right)}{\overline{\phi_{c}^{2}}}\right]+\alpha_{r} \bar{\phi}_{r}^{2}\left[1-\frac{B_{2}\left(x_{U r}\right)}{\overline{\phi_{r}^{2}}}\right]\right\} \\
& +\left\{\beta_{c} \bar{\phi}_{c}^{2}\left[1-\frac{B_{2}\left(x_{B c}\right)}{\phi_{c}^{2}}\right]-\beta_{r} \bar{\phi}_{r}^{2} m\left[1-\frac{B_{2}\left(x_{B r}\right)}{\overline{\phi_{r}^{2}}}\right]\right\}
\end{aligned}
$$

where

$$
B_{2}(x)=\frac{1}{V} \int_{V} \phi^{2}(\bar{r}) e^{-\phi(\bar{r}) x} d V
$$

depends on the region (c,r) over which the integration is taken and on the nature of the material being consumed (U, B).

$$
\begin{aligned}
& \text { A series expansion is } \\
& B_{2}(x)=\overline{\phi^{2}}-\overline{\phi^{3}} x+\frac{\overline{\phi^{4}} x^{2}}{2 !}-\frac{\overline{\phi^{5}} x^{3}}{3 !}+\ldots
\end{aligned}
$$

As the formula for $\rho$ is written, the negative sign in front of $\alpha$ correlates with fuel removal and the positive sign with boron removal to increase'multiplication. 


\section{A. 1. 6 Calculation of System Group Constants}

The basic constants chosen were those regularly enployed by Alco Products in its nuclear analysis. ${ }^{*}$ They are tabulated here for reference.

\section{Atoms $/ \mathrm{cm}^{3}$ of core at $440^{\circ} \mathrm{F}$}

\section{Fixed Element $\quad$ Control Fuel Element}

Hydrogen $\left(\times 10^{22}\right)$

4. 4398

4. 2767

Steel $\left(\begin{array}{lll} & 22 \\ & 22\end{array}\right.$

1. 4819

1. 7793

$\mathrm{U}^{235}\left(\mathrm{x} 10^{20}\right)$

4. 2863

3. 4796

$\mathrm{U}^{238}\left(\mathrm{x} \mathrm{10}^{20}\right)$

0. 3151

0.2558

$\mathrm{B}^{10}\left(\mathrm{x} 10^{20}\right)$

0. 07049

0.05722

Microscopic Cross Sections (barns) for $0.0549 \mathrm{ev}$ Distribution

Thermal

Boron

$\mathrm{U}^{235}$ absorption

$\mathrm{U}^{235}$ fission

$\mathrm{Xe}^{135}$

H
2398

385. 5

326. 7

1. $98 \times 10^{6}$

0.1998
Epithermal

84. 68

18. 98

13. 34

Thermal $1+\alpha=1.18$, epithermal $1+\alpha=1.42$

Buckling

$\begin{array}{ll}\text { radial } & 0.004465 \\ \text { axial } & 0.002129 \\ \text { total } & 0.006594\end{array}$

Core dimensions Height

$55.88 \mathrm{~cm}$, extrapolated $68.08 \mathrm{~cm}$ Radius

$28.19 \mathrm{~cm}$, extrapolated $35.99 \mathrm{~cm}$

"Windowshade"cross section $\Sigma_{\mathrm{p}}=0.07756 \mathrm{~cm}^{-1}$

Self-shielding factors - fixed 0.9443, control 0.9061

* Williamson, T. G., Leibson, M. J., and Byrne, B. J., "Reactor Analysis APPR-1 Core II," APAE No. 32, July 15, 1958, and separate communications from Paul E. Bobe. 


\section{Group Constants at $440^{\circ} \mathrm{F}$}

\section{Fixed}

Control

Age, $\tau$

43. 02

43. 05

Fast Diffusion Coefficient, $\mathrm{D}_{1}$

1. 490

1. 440

Thermal Diffusion Coefficient, $\mathrm{D}_{2}$

0. 2571

0.2551

Thermal Multiplication, $\eta^{\mathrm{f}}$

$\begin{array}{ll}1.5705 & 1.4486\end{array}$

Fast Multiplication, $\eta_{\mathbf{r}^{\mathbf{f}}} \mathbf{r}$

1. 3014

1. 1820

Resonance Escape Probability, p

0. 7297

0. 7464

Fast Product $\nu_{\mathbf{r}} \sum_{\mathrm{fr}}$

0. 01219

0.01003

Thermal Product $U \Sigma_{\mathrm{f}}$

0.3242

0.2523

Thermal absorption $\sum_{\mathrm{a}}$

0. 2065

0.1742

(no Xe or control poison)

\section{A. 1. 7 Region Group Constants}

Composite constants for the core and rod bank region were formed by use of importance $\left(\phi^{2}\right)$ weighting. The two regions have the fuel element arrangement sketehed in Fig. 2. The designation $\mathrm{C}$ refers to a control fuel element, $\mathbf{R}$ to a control rod, the remainder are fixed fuel elements.

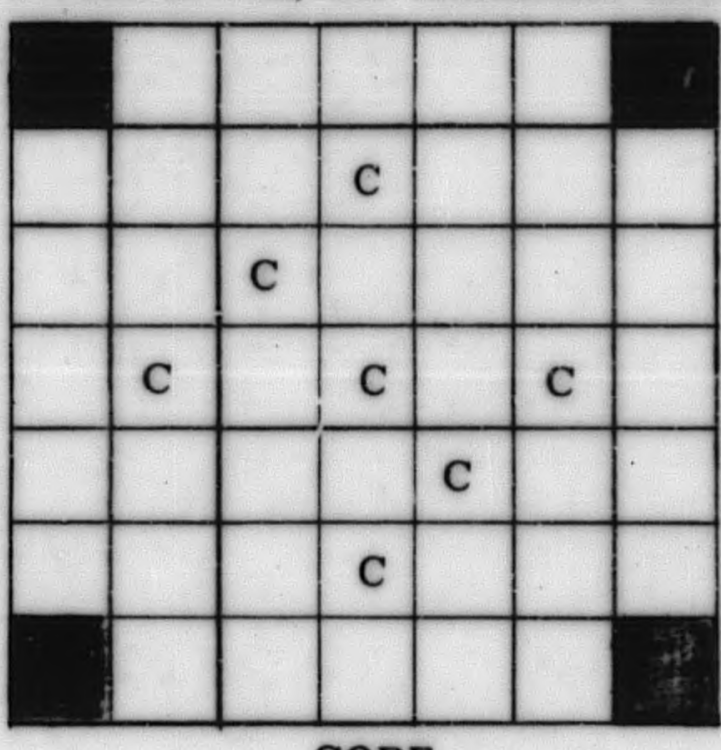

CORE

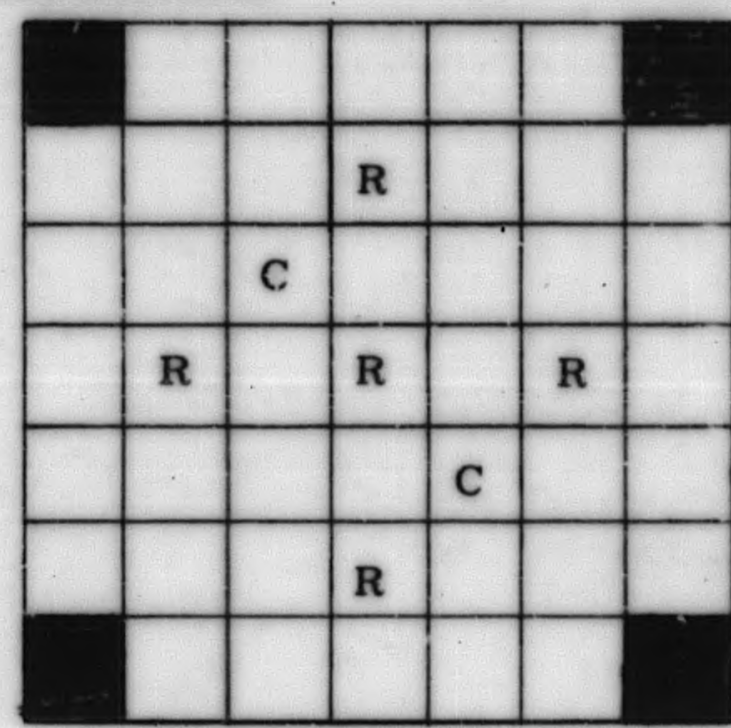

BANK

Figure 2. Fuel, Control Elements, Bank and Rods 
Weighting of the composite multiplication iactor

$$
K=\eta \mathbf{f p}+(1-p) \eta_{\mathbf{r}} \mathbf{r}
$$

was performed with the use of the recipe

$$
\bar{K}=\frac{\sum_{i} N_{i}\left(J_{o}^{2}\right)_{i} K_{i}}{\sum_{i} N_{i}\left(J_{0}^{2}\right)_{i}}
$$

where there appears the appropriate square of the radial Bessel function $\mathrm{J}_{0}$ $\left(j_{0} r / R^{\prime}\right)$, the number of eiements at a characteristic distance from the origin

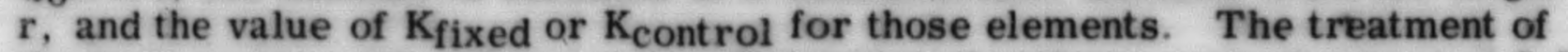
the bank region with reference to substitution of uniform control poison of 0.7756 $\mathrm{cm}^{-1}$ in place of rod effects is somewhat ambiguous. The procedure adopted was to perform the above weighting ignoring rods completely, followed by a thermal multiplication correction due to insertion of control poison in the rod region. The results of all these computations are summarized below.

\section{Core}

\section{$\mathbf{K}$ thermal}

K epithermal

\section{K total}

Fractional absorption
$\mathrm{U}^{235}$, thermal
B 10 , thermal
$\mathrm{U} 235$, epithermal
B10, epithermal
0. 7409
0.0758
0. 8454
0. 0620
0.5428
0.0555
0. 8597
0. 0631

0. 3385

1. 4679
1. 1294

\section{Rod Region}

0. 7811

0. 3467

1. 1278

Effective cross sections for $\mathrm{U}^{235}$ (fission and absorption) and $\mathrm{B}^{10}$ for core and rod region were obtained by the relation

$$
\sigma_{\mathrm{ai}}^{\mathrm{e}}=\left(\sigma_{\mathrm{ai}}\right)_{\mathrm{t}}+\frac{\sum_{2}(1=\mathrm{p})\left(\sigma_{\mathrm{ai}}\right)_{\mathrm{r}}}{\mathrm{p} \sum_{\mathrm{ar}}}
$$

where subscripts $i$ refer to either element, $t$ to thermal and $\mathbf{r}$ to resonance. Weightings according flux and volume were then applied to form the composite cross sections for fuel and control elements of the core and bank regions:

The results are:

$\begin{array}{lcccc}\sigma_{\mathrm{f}}^{\mathrm{e}}\left(\mathrm{U}^{235}\right) & \text { Fixed } & \text { Control } & \text { Core } & \text { Bank } \\ \sigma_{\mathrm{a}}^{\mathrm{e}}\left(\mathrm{U}^{235}\right) & 417.4 & 389.0 & 411.5 & 415.3 \\ \sigma_{\mathrm{a}}^{\mathrm{e}}\left(\mathrm{B}^{10}\right) & 518.9 & 481.7 & 511.1 & 516.1 \\ \mathrm{~A}-14 & 2941 & 2764 & 2904 & 2928\end{array}$


For purposes of establishing average flux from the fixed $10 \mathrm{Mw}$ power level, fission rate $F=3.24 \times 10^{17}$ fissions/sec, atom densities of uranium were computed, using flux and volume weightings. The results are:

\begin{tabular}{|c|c|c|c|c|}
\hline & Fixed & Control & Core & Bank \\
\hline $\begin{array}{l}\mathrm{N}^{\mathrm{O}}\left(\mathrm{U}^{235}\right) \\
\left.\text { (units of } 10^{20}\right)\end{array}$ & 4. 826 & 3. 480 & 4. 118 & 3 \\
\hline
\end{tabular}

Then, the amplitude of the flux $c_{0}$, is obtained from

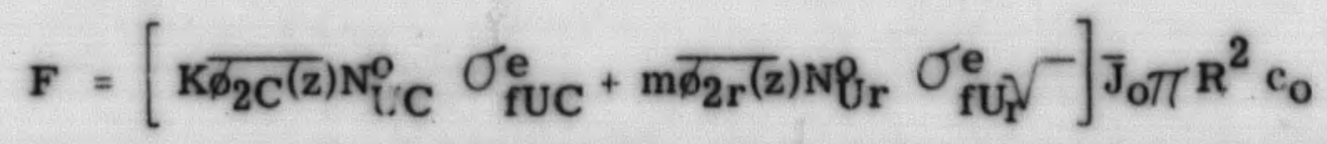

where $\mathrm{k}$ and $\mathrm{m}$ are the heights of the core and bank regions, $17.02 \mathrm{~cm}$ and $38.86 \mathrm{~cm}$, respectively. The core radius is $R=28.19 \mathrm{~cm}$, and averages over initial axial fluxes are: ccre 0.9057 , bank 0.3964 . The radial average flux $\bar{J}_{0}$ is 0.6174 for both regions. The amplitude was found to be $4.276 \times 10^{13} / \mathrm{cm}^{2}-\mathrm{sec}$.

\section{A. 1.8 Initial Criticality and Flux Calculations}

The basic relations employed were

$$
\begin{aligned}
& \tan \overline{B h}=-\frac{\bar{B}}{\bar{K}} \tanh \left(H^{\prime}-h\right) \bar{K} \\
& \mathbf{z}_{\mathbf{C}}(\mathrm{z})=\sin \bar{B} z \\
& \mathbf{z}_{\mathbf{r}}(\mathbf{z})=\frac{\sin \overline{\mathrm{B}} \mathrm{sinh} \bar{K}\left(\mathrm{H}^{\prime}-\mathrm{z}\right)}{\sinh \bar{K}\left(\mathrm{H}^{\prime}-\mathrm{h}\right)}=\frac{\mathrm{C}}{\mathrm{A}} \sinh \bar{K}\left(\mathrm{H}^{\prime}-\mathrm{z}\right)
\end{aligned}
$$

With $T=43.03 \mathrm{~cm}^{2}$ taken as common for both regions, and $\left(\mathrm{j}_{0} / \mathrm{R}^{\prime}\right)^{2}=0.004465$, one finds

$$
\bar{B}=0.008006, \quad \bar{\eta}=0.003867
$$

The known critical bank position without $\mathrm{Xe}^{135}$ poisoning was $6.70 \mathrm{in}$. (17.02 cm) out. In order to reproduce this result for the beginning of core life, different deflector savings were chosen $\mathrm{S}_{\mathrm{a}}=8.60 \mathrm{~cm}$, at the bottom and $\mathrm{S}_{\mathrm{a}}=3.60 \mathrm{~cm}$ at the top. These are qualitatively different since the addition of reflector at the top has relatively little effect on criticality.

\section{A. 1.9 Summary}

A geometrical model for the representation of SM-1 Core I has been adapted to account for reactivity changes due to material burnup and rod motion. Realizing the smallness of the term $\mathrm{D}_{2} \nabla^{2} \sigma_{2}$ the two group modified theory equations reduce to a one group. Use of perturbation techniques and series burnup method lead to the calculation of critical bank position vs energy release. 


\section{A. 2 FLUX. DISTRIBUTION AND ROD BANK CALIBRATION}

\section{A. 2.1 Rod Bank Position}

The general behavior of the reactor system with time is complex in that rod motion is accompanied by variable local flux changes and accumulated fuel consumption, which in turn affects the necessary rate of rod withdrawal to maintain criticality. In order to estimate these effects, a series of reactor states corresponding to different bank positions was chosen, and criticality and flux calculations performed for each. In lieu of inclusion of fuel pattern changes, a uniform variation in the number of neutrons per fission, $\nu$, was made. By trail and error methods the ratio $V_{/} V_{0}$ was determined for each selected bank position. The basic criticality equations were solved, using

$$
\mathrm{B}_{\mathrm{C}}^{2}=\frac{\frac{V_{0}}{V_{\mathrm{O}}} \mathbf{K}_{\mathrm{C}}^{0}-1}{T} \quad \text { and } \mathrm{B}_{\mathrm{r}}^{2}=\frac{\frac{V_{0}}{V_{\mathrm{r}}} \mathbf{K}^{0}-1}{T}
$$

and the previously stated equations. The important results are listed blow.

\begin{tabular}{|c|c|c|c|c|c|}
\hline $\mathrm{h}(\mathrm{cm})$ & Bank Position(In. ) & Critical $U / \nu_{0}$ & $\overline{\mathrm{B}}$ & $\bar{K}$ & $\mathrm{C} / \mathrm{A}$ \\
\hline 25. 62 & 6. 70 & 1. 000 & 0. 0801 & 0.0387 & 0.3568 \\
\hline & 8. 43 & 0.966 & 0.0726 & 0.0481 & 0.2700 \\
\hline 36 & 10.79 & 0.934 & 0. 0645 & 0.0568 & 0.2427 \\
\hline 42 & 13.15 & 0.910 & 0.0579 & 0.0620 & 0. 2693 \\
\hline 48 & 15.51 & 0.894 & 0.0527 & 0.0653 & 0. 3339 \\
\hline 54 & 27. 87 & 0.883 & 0.0491 & 0.0679 & 0.4248 \\
\hline & 20. 24 & 0.876 & 0. 0469 & 0.0690 & 0.5484 \\
\hline 64. 48 & 22.00 & 0.874 & 0.0462 & 0.0694 & 0.6169 \\
\hline
\end{tabular}

According to perturbation theory the reactivity $\rho$ is related to changes in $\nu$ by

$$
\rho=\frac{\Delta \nu}{\nu}=\frac{\nu_{0}-\nu}{\nu_{0}}=1-\frac{\nu}{\nu_{0}}
$$

A plot of system reactivity as a function of rod bank position is shown in Fig.

A. 3.

The detailed axial flux distributions for these states were obtained, using

$$
\begin{aligned}
& \mathrm{Z}_{\mathrm{c}}(\mathrm{z})=\sin \overline{\mathrm{B}} \mathrm{z} \\
& \mathrm{Z}_{\mathbf{r}}(\mathrm{z})=\frac{\mathrm{C}}{\mathrm{A}} \sin \bar{K}\left(\mathrm{H}^{\prime}-\mathrm{z}\right)
\end{aligned}
$$

and the constints listed above. Figure A. 4 shows a plot of these results. The shift is in accord with physical expectations. 
With these savings, the critical value of $h=17.02+S_{2}=25.62 \mathrm{~cm}$ was obtained, thence the flux distribution, as shown in Fig. A. 5. The peaking in the core region and the depression in the bank region are evident.

Flux averages for the two regions are readily obtained by integration. Now the core averages may be translated into a form where the tables of $\overline{\sigma^{n}} *$ are useful.

$\overline{Z_{c}^{n}}=\frac{1}{h-S_{a}} \int_{S_{a}}^{h}(\sin \bar{B} z)^{n} d z=\frac{1}{h-S_{a}}\left[\int_{S_{a}}^{Z_{\max }}(\sin \bar{B} z)^{n} d z+z_{\max }^{h}(\sin \bar{B} z)^{n} d z\right]$

This may be rewritten

$$
\overline{\phi_{c}^{n}}=\frac{\delta_{1}}{\delta_{1}+\delta_{2}} \overline{\phi_{1}^{n}}+\frac{\delta_{2}}{\delta_{1}+\delta_{2}} \overline{\phi_{2}^{n}}
$$

where $\delta_{1}=\mathrm{z}_{\max } /\left(\mathrm{h}-\mathrm{s}_{\mathrm{a}}\right), \delta_{2}=\left(\mathrm{h}-\mathrm{z}_{\max }\right) /\left(\mathrm{h}-\mathrm{s}_{\mathrm{a}}\right)$ and $\overline{\phi_{1}^{\mathrm{n}}}$ and $\overline{\phi_{2}^{\mathrm{n}}}$ are the tabulated averages corresponding to the given $\delta_{1}$ and $\delta_{2}$, for slabs.

The rod region average must be performed in detail

$$
\overline{z_{r}^{n}}=\frac{\left(\frac{C}{A}\right)^{n} \int_{h}^{H^{\prime}-S_{a}^{\prime}}\left[\sinh \bar{K}\left(H^{\prime}-z\right)\right]^{n} d z}{H^{\prime}-S_{a}^{\prime}-h}
$$

By a change in variables, this becomes

$$
\overline{z_{r}^{n}}=B_{n} \int_{b}^{a} \sinh ^{n^{n}} d x
$$

where

$$
\begin{aligned}
& B_{n}=(C / A)^{n} \frac{1}{(a-b)} \\
& a=\bar{K}\left(S_{a}^{\prime}\right)=1.6419 \\
& b=K\left(H^{\prime}-h\right)=0.1392
\end{aligned}
$$

The recursion integration relation is used

$$
I_{n}=\int \sinh ^{n} x d x=\frac{1}{n} \sinh ^{n-1} x \cosh x-\frac{n-1}{n} \int \sinh ^{n-2} x d x
$$

* Raymond L. Murray and Lawrance A. Mink, Tables of $\overline{\rho^{\bar{n}}}$ for Reactor Slabs, Cylinders and Spheres $n=1$ to $\underline{n}=20$. 


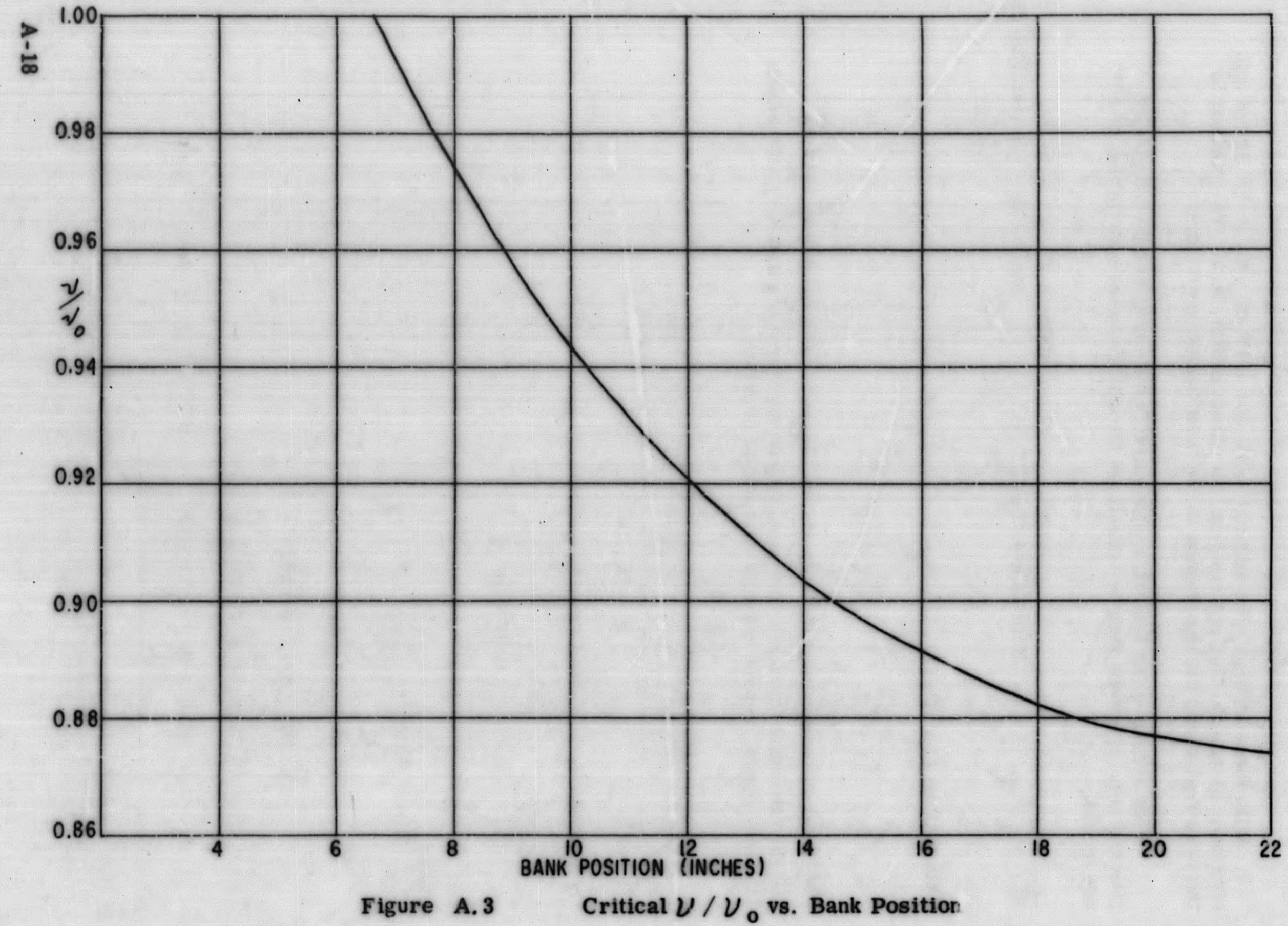




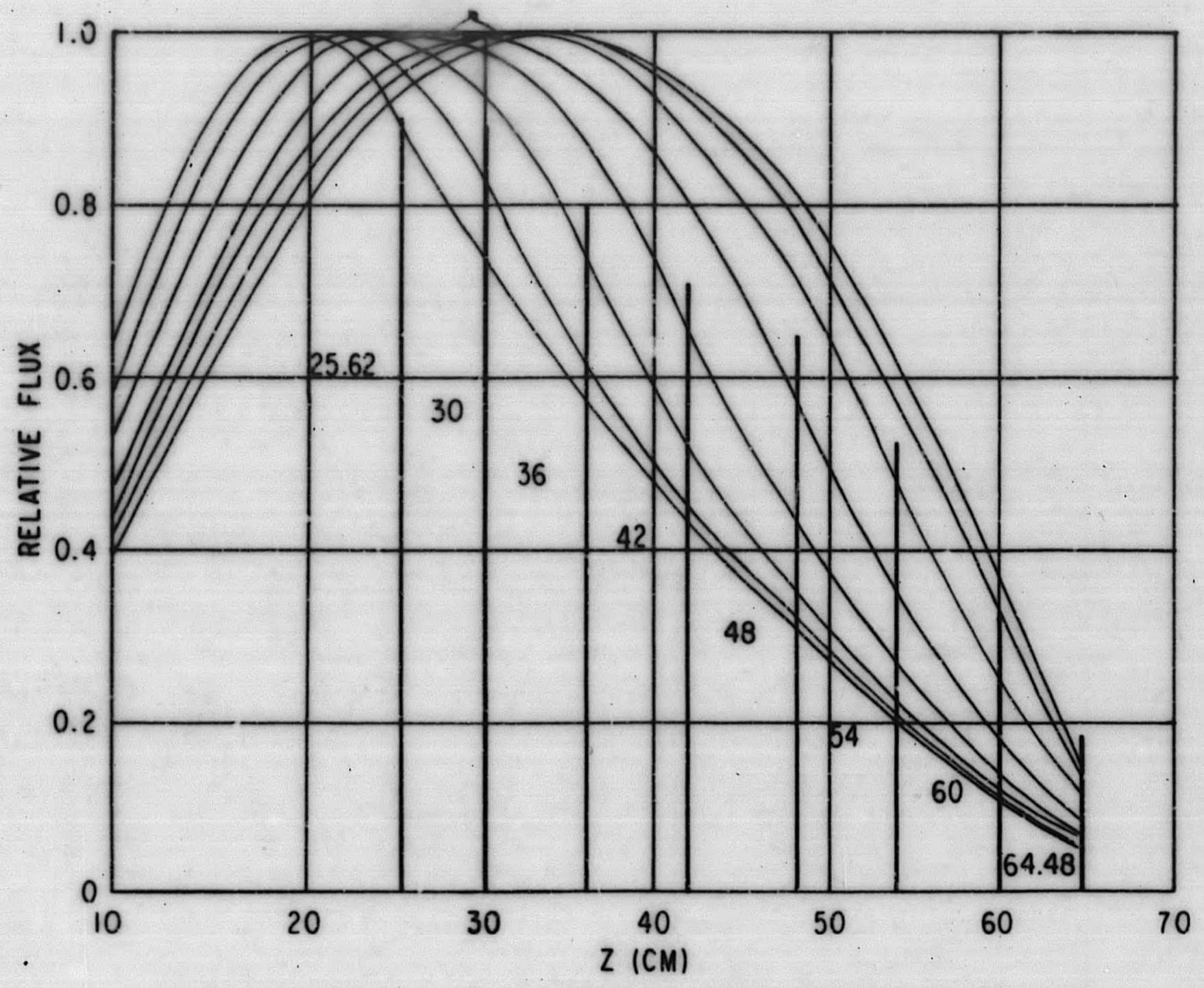

Figure A.4 Flux Distribution as a Function of $\nu / \nu_{0}$ 
ì

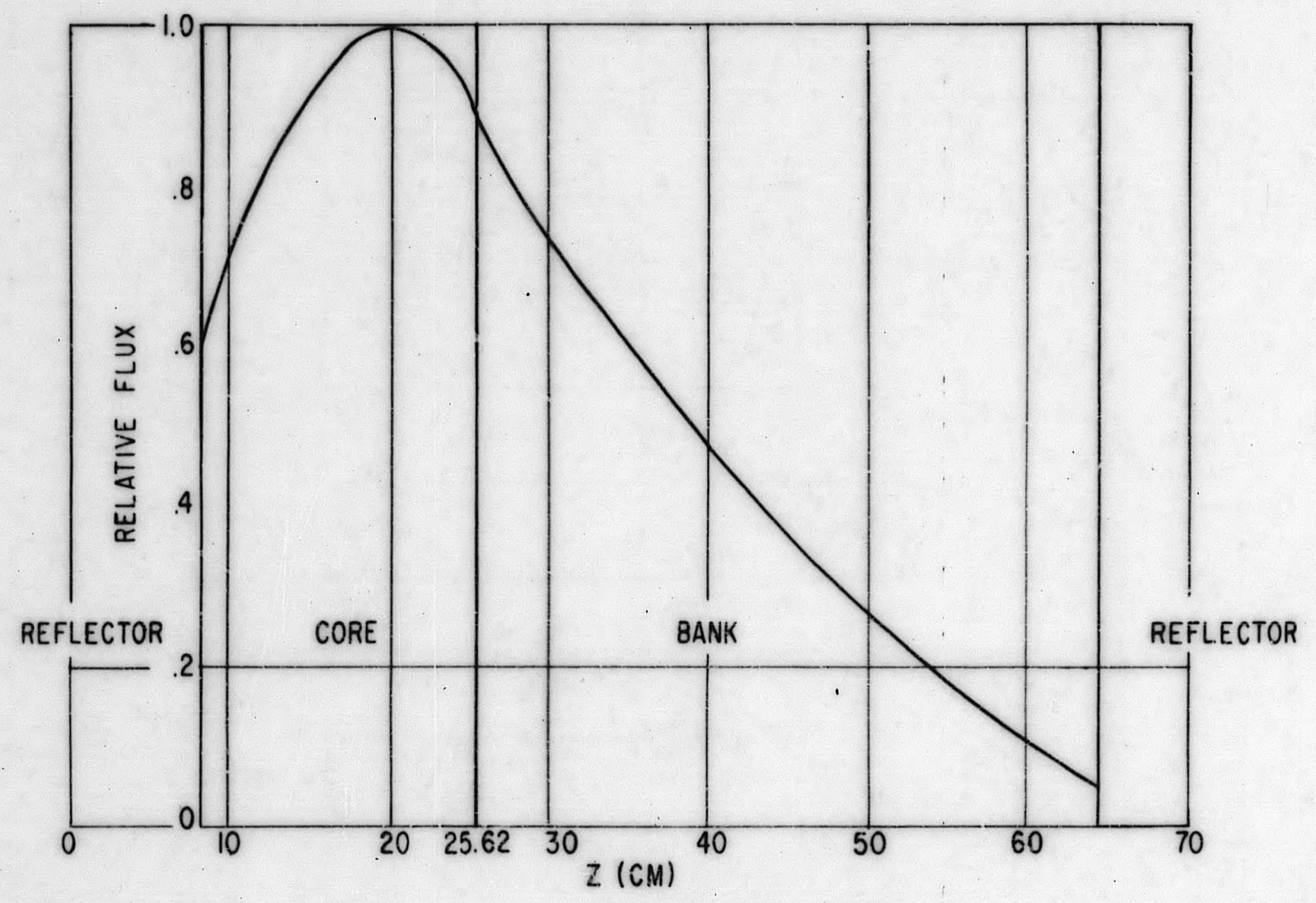

Figure A. 5 Initial Flux Distribution 
with starting expressions

$$
\begin{aligned}
& I_{1}=\cosh x \\
& I_{2}=\frac{1}{2}(\sinh x \cosh x-x)
\end{aligned}
$$

The average values for various $n$, for the axial flux and for the complete flux are

\begin{tabular}{|c|c|c|c|c|}
\hline $\mathbf{n}$ & $\overline{\mathrm{z}_{\mathrm{c}}^{\mathrm{n}}(\mathrm{z})}$ & $\overline{\mathrm{z}_{\mathrm{r}}^{\mathrm{n}}(\mathrm{z})}$ & $\overline{\phi_{c}^{n}(r, z)}$ & $\phi_{r}^{n}(r, z)$ \\
\hline & 0.9057 & 0.3964 & 0.5592 & 0.2447 \\
\hline 2 & 0.8302 & 0. 2126 & 0.3512 & 0. 08993 \\
\hline & 0.7665 & 0.1329 & 0.2408 & 0.04176 \\
\hline & 0.7152 & 0.0906 & 0.1771 & 0.02243 \\
\hline & 0.6754 & 0.0652 & 0.1375 & 0.01327 \\
\hline & 0.6391 & 0.0485 & 0.1104 & 0. 00838 \\
\hline & 0.6078 & 0.037 .1 & 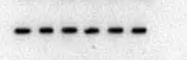 & - n- \\
\hline & 0.5805 & 0.0289 &.---- & \\
\hline
\end{tabular}
tabulated below.

\section{A. 2.2 Variation of Core Reactivity with Fuel Consumption}

The burnup theory described in an earlier section was applied to compute the core reactivity as a function of operating time. In the evaluation of the burnup functions for boron, it was necessary to force a series expansion of the form

$$
B_{2}(x)=\frac{\overline{\phi^{3}}}{\overline{\phi^{2}}} \times\left[e^{-\frac{\phi^{4} x}{2 \phi^{3}}}+a x^{2} e^{-\frac{b}{a} x}\right]
$$

where

$$
a=\frac{\overline{\phi^{5}}}{3 ! \phi^{3}}-\frac{1}{2 !}\left(\frac{\overline{\phi^{4}}}{\overline{2 \phi^{3}}}\right)^{2} b=\frac{\overline{\phi^{6}}}{\overline{4 \phi^{3}}}-\frac{1}{3 !}\left(\frac{\overline{\phi^{4}}}{2 \phi^{3}}\right)^{3}
$$

The effect of fission product poisons other than xenon-135 was incorporated by inserting a correction of the form

$$
1-\frac{\sigma_{\text {aFP }}}{\sigma_{\text {aU }}}
$$

as a multiplier of $\mathrm{f}_{\mathrm{U}}$ in the coefficient $\alpha$. The relation between the reduced flux-time variable $u$ and the number of megawatt years was computed. The results are listed on the following page. 


\begin{tabular}{lll}
$u$ & MWYR & \multicolumn{1}{c}{$-\rho$} \\
\cline { 3 - 3 } 0.0 & 0 & 0 \\
0.25 & 2.235 & 0.0004 \\
0.50 & 4.322 & 0.0076 \\
0.75 & 6.278 & 0.0186 \\
1.00 & 8.106 & 0.0316 \\
1.25 & 9.813 & 0.0453 \\
1.50 & 11.31 & 0.0598 \\
1.75 & 12.88 & 0.0707 \\
2.00 & 14.26 & 0.0820 \\
2.25 & 15.54 & 0.0923 \\
2.50 & 16.73 & 0.1011
\end{tabular}

A plot is given in Fig. A. 6.

In the performance of the perturbation theory estimate of rod reactivity, proper cognizance should be taken of flux changes during operation. For rod motion near the start of the cycle, the end of the bank moves in the initial highly distorted flux pattern, while at the end, it moves in a more symmetric flux. Evaluations of $\rho(z)$ were performed using the expression

$$
\rho(z)=\frac{K_{t}}{K} \frac{\sum_{p}}{\sum_{a}}\left[\int_{h}^{z} \phi^{2}(z) d z / \int_{\text {core }} \phi^{2}(z) d z\right]
$$

but with the two types of fluxes. The use of this relation both at the end of the cycle and at the beginning is valid in that the reduced factor $v_{/} \nu_{0}$ is common to numerator and denominator. In terms of rod calibration, using the initial flux gives correct $\rho$ at early times but underestimates the worth toward the end of the cycle. The converse is true for the use of the final flux. To give an approximate realistic value, the average of the two calculations was taken as listed on Page A-24. 


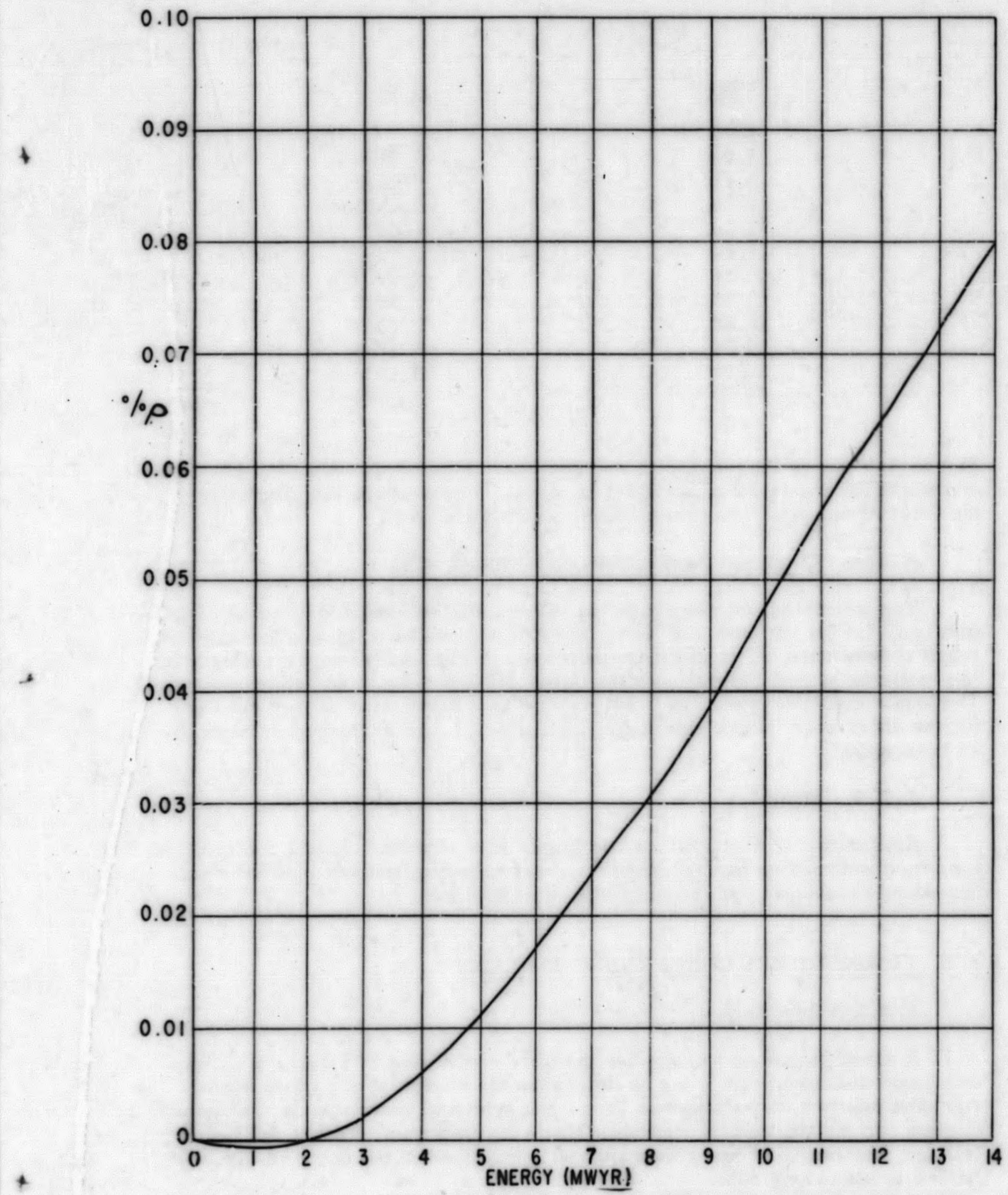

Figure A. 6 Burnout Reactivity of U-235, B-10 Fission Products 


\begin{tabular}{rl}
$\mathrm{z}$ (in.) & $\overline{\bar{\rho}(\mathrm{z})}$ \\
\hline 6.70 & 0 \\
7.64 & 0.0133 \\
9.21 & 0.0336 \\
10.79 & $0.05 \mathrm{T5}$ \\
12.36 & 0.0671 \\
13.94 & 0.0795 \\
15.51 & 0.0903 \\
17.09 & 0.0979 \\
18.66 & 0.1027 \\
20.24 & 0.1055 \\
21.81 & 0.1064 \\
22.00 & 0.1064
\end{tabular}

Figure A. 7 shows the trend with rod position. For comparison, the integrated rod worth as measured in the SM-1 is shown. Considering the simplicity of the theory employed, the agreement is suprisingly good.

\section{A. 2. 3 Combined Bank and Burnout Reactivities}

The predicted rod bank removal pattern may be deduced by combining the data on $\rho(z)$ for the bank and $\rho$ for the fuel burnout as a function of megawatt years of operation. Two plots are predicted in Fig. A. 8, one for each of the two methods or rod calibration calculation, for the case of no xenon poisoning. The experimentally measured bank position as a function of energy release for the SM-1 core is also shown for comparison. The agreement is seen to be reasonable.

\section{A. 2.4 Summary}

Application of perturbation techniques in a stepwise control rod motion, combined with series burnup calculation gave good agreement between measured and calculated control rod position vs lifetime.

\section{A. 3 TEMPERATURE COEFFICIENT ANALYSIS}

\section{A. 3.1 Introduction}

A simplified theory of the temperature coefficient of reactivity $\alpha$ was developed and applied in order to determine the variation of $\alpha$ with control rod bank position during reactor life. The principal innovation is the specific account for the two reative regions. Since the dominant effect is due to fast leakage, the modified one-group approach employed in the basic burnup calculations is again applicable. 


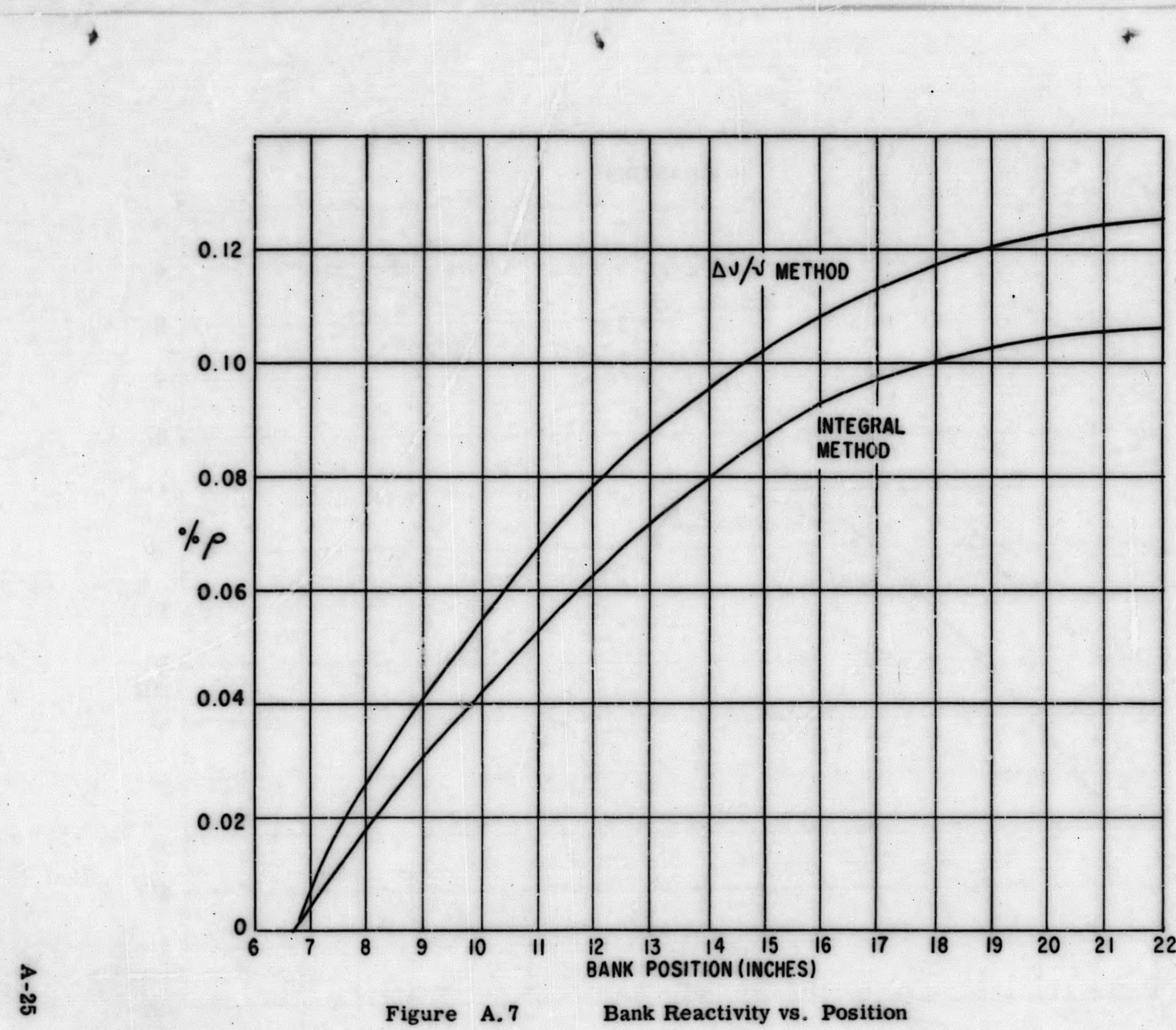





\section{A. 3.2 Theory}

During the course of operation, the system remains essentially critical with rod bank motion balancing the fuel-boron consumption. The series of criticality states characterized by reduced numbers of neutrons per fission $\nu$ can serve as points of departure for finding the temperature coefficient. A change in temperature causes a change in moderator-coolant density with negligible effect on metal structure. Define the temperature coefficient as

$$
\alpha=\frac{1}{V} \frac{d U}{d T}
$$

where the change in $\nu$ is that required to balance the effect of change in moderator density, retaining a critical state. The latter is given by

$$
\tan \bar{B} h=-\frac{\bar{B}}{K} \tanh R\left(H^{\prime}-h\right)
$$

where

$$
\begin{aligned}
& \overline{\mathrm{B}}^{2}=\frac{\frac{V_{\mathrm{O}}}{\mathrm{K}} \mathrm{K}_{\mathrm{C}}^{\mathrm{O}}-1}{\tau}-\left(\frac{\mathrm{j}_{\mathrm{O}}}{\mathrm{R}^{\prime}}\right)^{2} \\
& \mathrm{~K}^{2}=\left(\frac{\mathrm{j}_{0}}{\mathrm{R}^{\prime}}\right)^{2}\left[\frac{\frac{V}{V_{0}} \mathrm{~K}_{\mathrm{r}}^{0}-1}{\tau}\right]
\end{aligned}
$$

Differentiating the criticality condition and rearranging gives

$$
d \bar{B} \mathbf{F}=-d \bar{K} G
$$

where

$$
\begin{aligned}
& F=\bar{K} h\left(1+\tan ^{2} \bar{B} h\right)+\tanh \bar{K} \lambda \\
& G=\bar{B} \lambda\left(1-\tanh ^{2} \bar{K} \lambda\right)+\tan \bar{B} h
\end{aligned}
$$

with $\mathbf{H}^{\prime}-\mathrm{h}=\lambda$

Now

and

$$
d \bar{B}=\frac{1}{2 \bar{B} T}\left[K_{C}\left(\frac{d \nu}{\nu}+\frac{d K_{C}^{0}}{K_{C}^{0}}\right)-\left(K_{C}-1\right) \frac{d T}{T}\right]
$$

$$
d \bar{K}=-\frac{1}{2 \bar{K} T}\left[\mathbf{K}_{\mathbf{r}}\left(\frac{\mathrm{d} V}{V}+\frac{\mathrm{dK}_{\mathbf{r}}^{\mathrm{o}}}{\mathrm{K}_{\mathrm{r}}^{\mathrm{o}}}\right)-\left(\mathrm{K}_{\mathbf{r}}-1\right) \frac{\mathrm{d} T}{T}\right]
$$


Inserting,

$\frac{d \nu}{U}=\frac{d \tau}{T}\left[\bar{K} F\left(K_{C}-1\right)-\bar{B} G\left(K_{r}-1\right)\right]-\left[\bar{K} F_{C} \frac{d K_{C}^{0}}{K_{C}^{0}}-\bar{B} G K_{r} \frac{d K_{r}^{0}}{K_{r}^{0}}\right]$

There remains the evaluation of the effects on $T, K_{C}^{0}$ and $K_{r}^{0}$. By invoking the assumption that the composite age of a heterogeneous medium may be written

$$
\frac{1}{\sqrt{T}} \cong \frac{v_{w}}{\sqrt{T_{w}}}+\frac{v_{m}}{\sqrt{T_{m}}}
$$

where subscripts refer to water and metal, and v's are volume fractions. One deduces that

$$
\frac{d T}{\tau}=-2 v_{w} \frac{d N_{w}}{N_{w}} \sqrt{\frac{T}{T_{w}}}
$$

with water molecule number density $\mathrm{N}_{w}$. The quantity

$$
\frac{1}{\mathrm{~N}_{\mathrm{w}}} \quad \frac{\mathrm{dN}_{\mathrm{w}}}{\mathrm{dT}}
$$

is the temperature coeificient of expansion of water, labeled $\alpha_{\mathrm{T}}$. It has the same absolute vaiue as $\frac{1}{\bar{\rho}} \frac{\mathrm{d} \rho}{\mathrm{dT}}$. Also, using

$$
K=K_{t}+K_{r}
$$

with $K_{\mathrm{t}}=\eta$ fp and $K_{r}=(1-p) \eta_{r} f_{r}$, the fractional change in $K$ for a process that is predominantly thermal is

$$
\frac{d K}{K}=\frac{K_{t}}{K} \frac{d f}{f}=-\frac{K_{t}}{K} \frac{d \sum_{a}}{\sum_{a}}=-\frac{K_{t}}{K} \quad f_{w} \quad \frac{d_{w}}{N_{w}}
$$

Here $f_{w}$ is the "utilization" of water. Combining we find

$$
\frac{\alpha}{\alpha_{T}}=\frac{-2 v_{w} \sqrt{\frac{T}{T_{w}}}\left[\left(K_{C}-1\right)-\frac{\bar{B}}{\bar{K}} \frac{G}{F}\left(K_{r}-1\right)\right]+\frac{\nu}{U_{0}}\left[K_{t C}^{0} f_{w C}-\frac{\bar{B} G}{\bar{K} \mathbf{F}} K_{t r}^{o} f_{w r}\right]}{K_{C}-\frac{\bar{B}}{\bar{K}} \frac{G}{\bar{F}} K_{r}}
$$

This is the working formula. 


\section{A. 3. 3 Calc 'ations}

The variation of specific volume and density of saturated water in the vicinity of the operating temperature was obtained from the Nuclear Engineering Handbook, pages $9-10$ as follows:
$\underline{T}\left(^{0} \mathbf{F}\right)$
$\underline{\mathrm{ft}^{3} / \mathrm{lb}}$
$\mathrm{cm}^{3} / \mathrm{gm}$
$\mathrm{gm} / \mathrm{cm}^{3}$
430
0.01910
1. 1924
0. 8386
440
0.01926
1. 2024
0.8317
450
0.01940
1. 2111
0. 8257

The quantity $\left|\alpha_{T}\right|=\frac{1}{\rho} \frac{d \rho}{d T}$ was found to be $7.78 \times 10^{-4} /{ }^{\circ} F$. Other data
needed are:

$$
\begin{aligned}
& f_{w}(\text { core })=0.04452 \\
& f_{w}(\text { bank })=0.03149 \\
& \tau=43.03 \mathrm{~cm}^{2} \\
& T_{w}=47.50 \mathrm{~cm}^{2} \\
& v_{w}=0.792, v_{m}=0.198
\end{aligned}
$$

The value of $\alpha / \alpha_{\mathrm{T}}$ was determined for four states, corresponding to the bank at its initial position, full out, and two intermediate locations. Tabulated results are as follows:
$\frac{h(\mathrm{~cm})}{25.62}$
$v_{1} \nu_{0}$

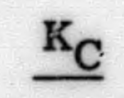
$\underline{\mathbf{r}}$
$\underline{\mathbf{G} / \mathbf{F}}$
$\alpha / \alpha_{\mathrm{T}}$
$\alpha \underline{{ }^{0} \mathrm{~F}}$
C/ ${ }^{\circ} \mathrm{F}$
36
1. 000
1. 4679
$1.1278-0.2596$
0. 3491
2. $72 \times 10^{-4}$
3. 49
0. 934
1. 3710
1. 0534
$-0.1621$
0. 3232
2. $51 \times 10^{-4}$
3. 22
54
0. 883
1. 2962
0. 9958
$-0.0410$
0. 2916
2. $27 \times 10^{-4}$
2. 91
64. 48
0. 874
1. 2829
0. 9857
$+0.0016$
0. 2872
2. $23 \times 10^{-4}$
2. 86

The last column is hased on the assumption of an effective delayed neutron fraction of $(1.20)(0.0065)=0.0078$. It is notable that there is only a slight variation of temperature coefficient with core life, being a downward trend. The theoretical results are compared with the experimental observations on SM-1 in Fig. A. 9. Within the accuracy of measurement and the limitations of the theory, the agreement is good. 


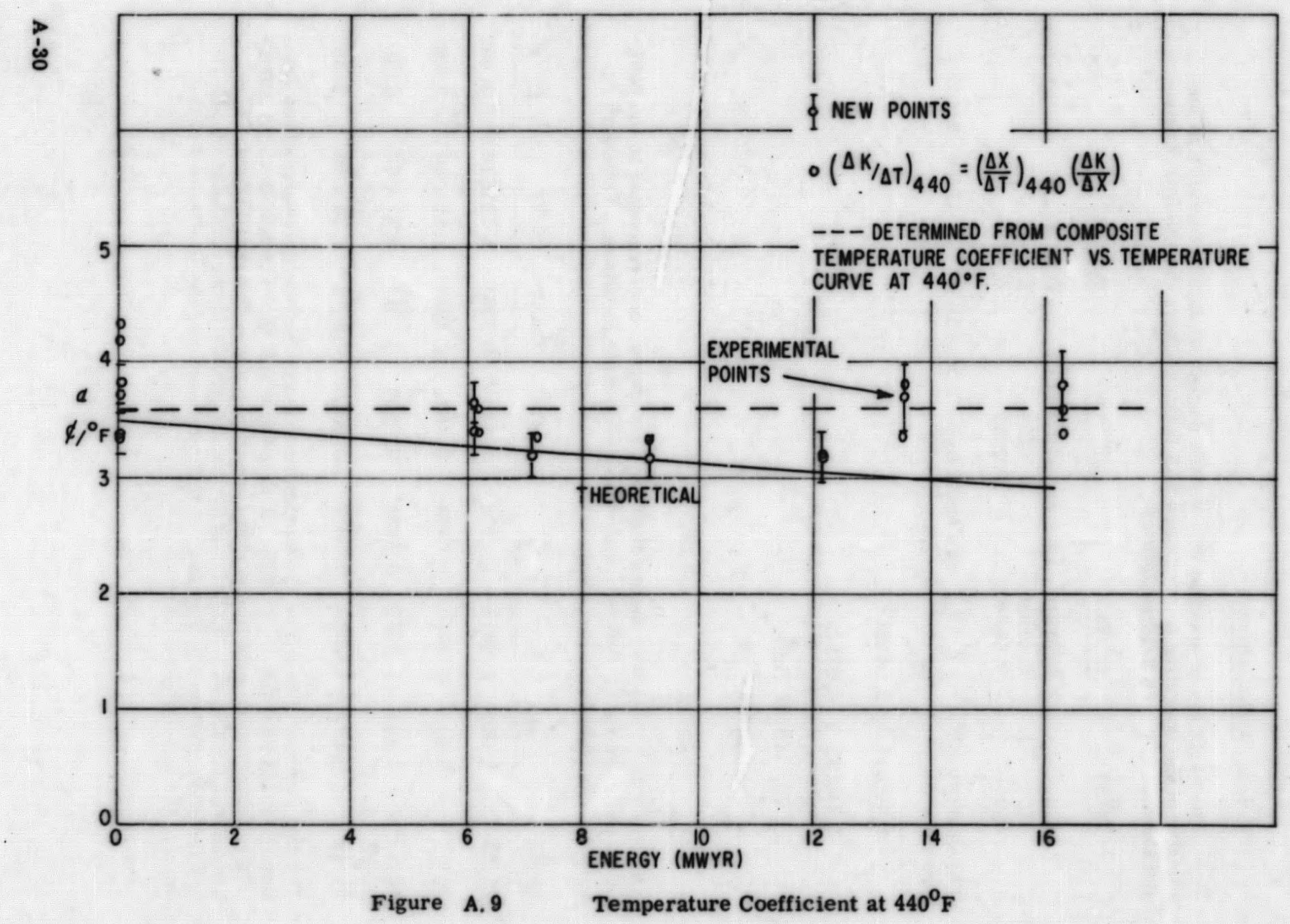

A 


\section{A. 3. 4 Summary}

While it is very difficult to account explicitly for all parameters contributing to the change of the temperature coefficient vs energy release, it is possibie to considerably simplify the calculations by disregarding thermal leakage.

Use of the one group modified theory gave a temperature coefficient slightly decreasing with energy release.

The difference of the results of Sec. A. 3 with Sec. 6.0 is attributed to the approximations made.

\section{A. 4 STEADY STATE XENON POISONING}

\section{A. 4.1 Introduction}

An adaptation of the burnup theory is made to account for the reactivity due to xenon poisoning. . It can be assumed that the cycle life of the reactor is far greater than the half-life of the isotopes $\mathrm{I}^{135}$ and $\mathrm{Xe} \mathrm{e}^{135}$, such that essential equilibrium is maintained even though fuel is being consumed.

\section{A. 4. 2 Analysis}

The steady state local poisoning due to $\mathrm{Xe}^{135}$ is readily written

$$
\Sigma_{\mathrm{ax}}(\bar{r}, \mathrm{t})=\frac{\sum_{\mathrm{f}}(\mathrm{r}, \mathrm{t})}{\lambda_{\mathrm{xe}}}
$$

The reactivity of the system is of the form

$$
\rho=\frac{\int \frac{\delta \mathrm{K}}{\mathrm{K}} \phi^{2}(\overline{\mathrm{r}}, \mathrm{t})}{\int \phi^{2}(\overline{\mathrm{r}}, \mathrm{t}) \mathrm{dV}}
$$

where

$$
\mathbf{K}=\eta^{\mathrm{fp}}+(1-\mathbf{p}) \eta_{\mathbf{r}} \mathbf{r}
$$

Now for a thermal poison

$$
\frac{\delta \mathrm{K}_{\mathrm{t}}}{\mathrm{K}_{\mathrm{t}}}=-\frac{\overline{\delta \Sigma_{\mathrm{a}}}}{\Sigma_{\mathrm{a}}} \text { or } \delta \mathrm{K}_{\mathrm{t}}=-\frac{\delta \Sigma_{\mathrm{a}}}{\sum_{\mathrm{a}}} \mathrm{K}_{\mathrm{t}}
$$




$$
\begin{aligned}
& \text { Substituting } \\
& \text { or } \quad \rho=\frac{-\int \frac{\delta \sum_{a}}{\sum_{a}} \frac{k_{t}}{K} \phi^{2} d V}{\int \frac{\frac{\sum_{f}}{\sum_{a}} \frac{k_{t}}{K} \phi^{2}(\bar{r}, t) d V}{1+\frac{\lambda x e}{\sigma_{x e} \phi(\bar{r}, t)}}}
\end{aligned}
$$

Letting the quotient $\lambda_{\mathrm{xe}} / \sigma_{\mathrm{xe}}$ be defined by $\phi_{1}$, a polynomial expanșion can be made

$$
\frac{1}{1+\frac{\phi_{1}}{\sigma}}=\sum_{n=0}^{m}(-1)^{n}\left(\phi_{1} / \phi\right)^{n}+\text { remainder }
$$

To three terms, this is

$$
1-\frac{\phi_{1}}{\phi}+\left(\frac{\phi_{1}}{\phi}\right)^{2}
$$

with a remainder of

$$
-\frac{\left(\frac{\phi_{1}}{\phi}\right)^{3}}{1+\frac{\phi_{1}}{\phi}}
$$

Now let $\phi(\bar{r}, t)=C(t) \phi(\bar{r})$, where $C(t)$ is the time dependent amplitude, with initial value $C_{0}={ }_{C}{ }^{-}$the central initial flux. Then invoking the burnup function

$$
B \lambda=\frac{1}{v} \int \phi^{\lambda}(\bar{r}) e^{-\phi(\bar{r}) x} d V
$$


the reactivity becomes

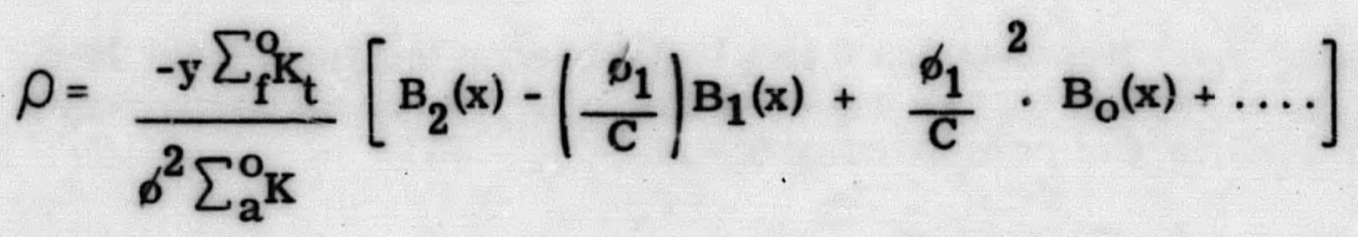

where

$$
\mathrm{x}=\sigma_{\mathrm{aU}} \mathrm{u}
$$

Noting that

$$
\frac{1}{C}=\frac{B_{1}(x)}{\phi_{C}^{\overline{\phi(r)}}}
$$

the final working formula to three terms for a given region is

$$
\rho=\frac{-y \sum_{f}^{0} K_{t}}{\phi^{2} \sum_{a}^{0} K}\left[B_{2}(x)-\left(\frac{\phi_{1}}{\phi_{C}^{\bar{\phi}}}\right) B_{1}^{2}(x)+\left(\frac{\phi_{1}}{\phi_{C}^{\sigma}}\right)^{2} B_{1}^{2}(x) B_{0}(x)-\ldots .\right]
$$

Exponential approximations to the burnup functions may be used.

$$
\begin{array}{ll}
\mathrm{B}_{0}=\mathrm{e}^{-\phi_{e} 0^{\mathrm{x}}} & \phi_{\mathrm{e} 0}=\bar{\phi} \\
\mathrm{B}_{1}=\overline{\phi e}^{-\phi_{e} \mathrm{x}} & \phi_{\mathrm{e} 1}=\overline{\phi^{2}} / \bar{\phi} \\
\mathrm{B}_{2}=\bar{\phi}^{2} \mathrm{e}^{-\phi_{\mathrm{e} 2} \mathrm{x}} & \phi_{\mathrm{e} 2}=\overline{\phi^{3}} / \overline{\phi^{2}}
\end{array}
$$

Some of the functions are available from previous calculations of the burnup.

An investigation of the contribution of the correction due to all other terms in the series was made. Rigorously, the remainder is of the form

$$
\frac{1}{V} \int \frac{\phi^{2}(\bar{r})\left[\frac{\phi_{1}}{\phi_{C^{\sigma}(\bar{r})}}\right]^{3}}{1+\frac{\phi_{1}}{\phi_{C} \phi(\bar{r})}}=\left(\frac{\phi_{1}}{\phi_{c}}\right)^{3} \frac{1}{V} \int \frac{\frac{1}{\phi(\bar{r})} d V}{1+\frac{\phi_{1}}{\phi_{C} \phi(\bar{r})}}
$$

A-33 


$$
=\left(\frac{\phi_{1}}{\phi_{C}}\right)^{3} \frac{1}{V} \int \frac{\phi(\bar{r}) d V}{\phi_{(\bar{r})+\left(\phi_{1} / \phi_{C}\right)}}
$$

The coefficient of $\left(\phi_{1} / \phi_{C}\right)^{3}$ lies between 0 and 1 , and hence the remainder lies between $p$ and $\left(\phi_{1} / \phi_{C}\right)^{3}$, which will be negligible if $\phi_{1} / \phi_{C}$ is considerably less than 1 , as it is $(0.249)$ for the reactor considered.

The composite reactivity for a two region core is

$$
\rho=\frac{\int_{C} \frac{\delta K}{K} \phi^{2} d V+\int_{r} \frac{\delta K}{K} \phi^{2} d V}{\int_{\mathbf{r}} \phi^{2} d V}+\int_{\phi^{2} d V}
$$

which may be rearranged to

$$
\rho=\frac{\rho \mathbf{c}^{\phi^{2}} \mathrm{c}^{\mathrm{k}}+\rho \mathrm{r}^{\overline{\phi^{2}}} \mathbf{r}^{\mathrm{m}}}{\bar{\phi}_{\mathrm{c}}^{\mathrm{k}}+\overline{\phi^{2} \mathrm{~m}}}
$$

The values for $\rho$ for each region $i$ are weighted by the average square of the flux and the volume of that region

$$
\rho_{i}=\int_{i} \frac{\delta K}{K} \phi^{2} d V / \int \phi^{2} d V
$$

\section{A. 4. 3 Constants for $\mathrm{Xe}^{135}$ Calculations}

Basic data used are listed:

Absorption cross section of $\mathrm{Xe},\left(\sigma_{\mathrm{a}}\right)_{\mathrm{xe}}=1.98 \times 10^{6} \mathrm{barns}$ Yield of $\mathrm{Xe}+\mathrm{I}, \mathrm{y}=0.064$

Decay Constant $\lambda_{\mathrm{xe}}=2.11 \times 10^{-5} \mathrm{sec}^{-1}$

$\phi_{1}=\lambda_{\mathrm{xe}} /\left(\sigma_{\mathrm{a}}\right)_{\mathrm{xe}}=1.066 \times 10^{13} / \mathrm{cm}^{2}-\mathrm{sec}$

Fission cross section of $U^{235}=\mathbf{4 1 1 . 5}$ barns (core), 415.3 (bank)

Initial central flux, $C_{0}=\phi_{C}=4.276 \times 10^{13} / \mathrm{cm}^{2}-\mathrm{sec}$ 
$K_{t}=1.1294$ (core), 0.7811 (bank)

$\mathrm{K}=1.4679$ (core), 1.1278 (bank)

$\sum_{\mathrm{a}}=0.2758$ (core), 0.2809 (bank)

Region lengths $\mathrm{k}=17.02 \mathrm{~cm}, \mathrm{~m}=38.86 \mathrm{~cm}$

Average flux squares $\overline{\phi_{C}^{2}}=0.3512, \overline{\phi_{r}^{2}}=0.08993$

Flux averages from earlier calculations were employed to determine the following variation of equilibrium xenon reactivity with operating time.

u
0.25
0.50
0.75
1.00
1.25
1.50
1.75
2.00
2.25
2.50

W(MWYR)

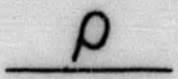

0.25

0

0.0242

2. 235

0.0222

4. 322

0.0205

0.75

6. 278

0.0189

8. 106

9. 813

0.0174

1.25

11. 31

0.0162

1.50

12. 88

0.0150

14. 26

0.0140

15. 54

16. 73

0.0131

0.0123

0.0115

\section{A. 4. 4 Combined Burnup, Fission Product and Xe Reactivity}

The total negative reactivity due to $U^{235}$ consumption, boron burnup, fission product poison, and $\mathrm{Xe}^{135}$ poison was obtained by addition. The results are listed in the table beiow, and plotted in terms of rod bank position in Fig. A. 10. The trends developed by theory agree rather well with the experimentally observed results on SM-1.

\begin{tabular}{cccc} 
W (MWYR) & $\rho_{\text {Total }}$ & W (MWYR) & \\
\cline { 1 - 2 } & 0.024 & 8 & \\
\hline 0 & 0.022 & 9 & 0.048 \\
1 & 0.022 & 10 & 0.055 \\
2 & 0.024 & 11 & 0.062 \\
3 & 0.026 & 12 & 0.070 \\
4 & 0.030 & 13 & 0.078 \\
5 & 0.035 & 14 & 0.081 \\
6 & 0.041 & 16 & 0.093 \\
7 & & & 0.100 \\
& & & 0.108
\end{tabular}


\&े

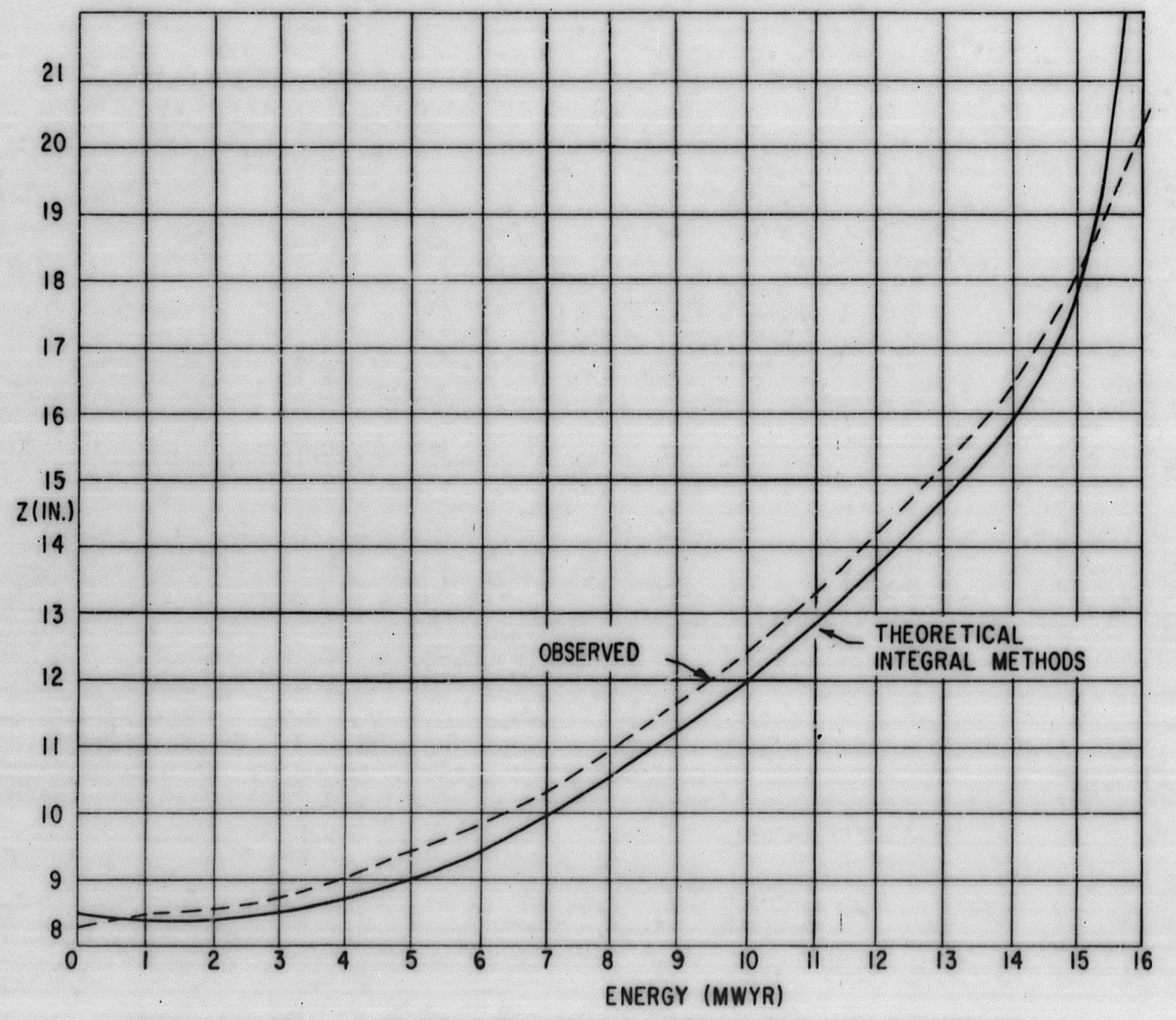

Figure A.10 Critical Bank Position During Core Life Equilibrium Xenon 


\section{A. 4. 5 Summary}

Using perturbation techniques in conjunction with the series burnup, the reactivity due to equilibrium xenon has been evaluated vs energy release of the core.

This combined with the results of Sec. A. 2 gives an estimate of the control rod bank position vs energy release and therefore lifetime. It can be seen that the lifetime is $15.8 \mathrm{MWYR}$ vs 16.05 experimental for the unperturbed core.

\section{A. 5 EFFECTIVE DELAYED NEUTRON FRACTION AS A FUNCTION OF BANK POSITION}

\section{A. 5.1 Introduction}

Calculations of the effective delayed neutron fraction $\beta$ e by two group analytic methods are very laborious, even for simple geometrical shapes such as the reflected sphere or a two-region bare cylinder. A simple method is developed and applied to the SM-1, under conditions of operation with banked control rods. A modified one-group approach is employed, in which advantage is taken of the short thermal diffusion length.

\section{A. 5.2 Critical Conditions}

The reactor core is taken to be a cylinder with side reflector replaced by a radial savings $R^{\prime}=R+S_{r}$, and end reflector replaced by bottom savings $S_{a}$ and top savings $\mathrm{S}_{\mathrm{a}}$. With origin at the bottom, the core extends from $\mathrm{z}=\mathrm{S}_{\mathrm{a}}$ to $z=h$, at which point the bank begins, extending to $z=H^{\prime}-S_{a}^{\prime}$ where $\mathbf{H}^{\prime}=\mathbf{H}$ $+\mathrm{S}_{\mathrm{a}}+\mathrm{S}_{\mathrm{a}}$. The two regions are similar except for the differences in rod follower fuel elements and the equivalent control poison in the rod region. The critical conditions and axial flux distributions are

$$
\begin{aligned}
& \tan \bar{B} h=-\frac{\bar{B}}{\bar{K}} \tanh \bar{K}\left(H^{\prime}-\mathrm{h}\right) \\
& \mathrm{z}_{2 C^{(}}(\mathrm{z})=A \sin \bar{B} \mathrm{z} \\
& \mathrm{z}_{2 \mathbf{r}}(\mathrm{z})=C \sinh \bar{K}\left(H^{\prime}-\mathrm{z}\right)
\end{aligned}
$$

where

$$
\mathrm{C} / \mathrm{A}=\frac{\sin \overline{\mathrm{B} h}}{\sinh \bar{K}\left(\mathrm{H}^{\prime}-\mathrm{h}\right)}
$$


and

$$
\begin{aligned}
& \bar{B}^{2}=\frac{\left(K_{C}-1\right)+\left(j_{O} / R^{\prime}\right)^{2}}{T} \\
& K^{2}=\left(j_{0} / R^{\prime}\right)^{2}-\frac{\left(K_{r}-1\right)}{T} \\
& K=\eta^{f p}+(1-p) \eta r^{f} r
\end{aligned}
$$

\section{A. 5.3 Effective $\beta$ Analysis} are

The general two-group equations for delayed neutron fluxes in a given region

$$
\begin{aligned}
& \mathrm{D}_{1 \mathrm{~d}} \nabla^{2} \phi_{1 \mathrm{~d}}-\phi_{1 \mathrm{~d}} \sum_{1 \mathrm{~d}}+\left[\phi_{2} \sum_{2} \eta^{\mathrm{f}}+\phi_{1} \sum_{1}(1-\mathrm{p}) \eta_{\mathrm{r}} \mathrm{f}_{\mathrm{r}}\right] \beta=0 \\
& \mathrm{D}_{2} \nabla^{2} \phi_{2 d}-\phi_{2 d} \sum_{2 d}+P_{d} \phi_{1 d} \sum_{1 d}=0
\end{aligned}
$$

where one compositęgroup of neutrons of fraction $\beta$ is assumed to have slowing properties $D_{1 d}$ and $\sum_{1 d}$, related by $T=D_{1 d} / \sum_{1 d}$. Since the thermal diffusion length is short compared with the age, we may write $\phi_{1} \Sigma_{1 \mathrm{p}} \cong \phi_{2} \Sigma_{2}$ and $\phi_{1 d} \Sigma_{1 \mathrm{~d}} \mathrm{p}_{\mathrm{d}}$ $\approx \sigma_{2} \Sigma_{2}$. Insertion and simplification yields the inhomogeneous equation

$$
\tau_{\mathrm{o}} \nabla^{2} \phi_{2 d}-\phi_{2 d}=-\phi_{2} \mathrm{~K} \beta
$$

where the termal flux $\phi_{2}$ is known functionally. Extraction of the radial buckling yields

$$
\frac{d^{2} z_{2 d}}{d z^{2}}-K_{1 d}^{2} z_{2 d}=-\frac{K \beta z_{2}}{T_{d}}
$$

where

$$
K_{1 \mathrm{~d}}^{2}=\frac{1}{\tau_{\mathrm{d}}}+\left(\mathrm{j}_{\mathrm{o}} / \mathbf{R}^{\prime}\right)^{2}
$$

The complementary functions are $\sinh \bar{K}_{1 d^{2}}$ and $\sinh \bar{K}_{1 \mathrm{~d}}\left(\mathrm{H}^{\prime}-\mathrm{z}\right)$ for the two regions, and the particular integrals readily obtained by operator methods. The result is

$$
\begin{aligned}
& \mathrm{Z}_{2 \mathrm{dc}}=\mathrm{E} \sinh K_{1 d^{\mathrm{z}}+\mathrm{GA} \sin \overline{\mathrm{B}} \mathrm{z}} \\
& \mathrm{z}_{2 \mathrm{dr}}=\mathrm{F} \sinh K_{1 \mathrm{~d}}\left(\mathrm{H}^{\prime}-\mathrm{z}\right)+\mathrm{HC \operatorname {sinh }} K\left(\mathrm{H}^{\prime}-\mathrm{z}\right)
\end{aligned}
$$


where

$$
\begin{aligned}
& \mathbf{G}=\frac{\mathbf{K}_{\mathrm{c}} \beta}{\tau_{\mathbf{d}}\left(\bar{R}_{1 \mathrm{~d}}^{2}+\bar{B}^{2}\right)}=\frac{\mathbf{K}_{\mathbf{c}} \beta}{1+\mathrm{B}^{2} \tau_{d}} \\
& \mathbf{H}=\frac{\mathbf{K}_{\mathrm{r}} \beta}{\mathbf{d}\left(\bar{K}_{1 \mathrm{~d}}^{2}-\bar{K}^{2}\right)}=\frac{\mathrm{K}_{\mathrm{r}} \beta}{1-\bar{K}^{2} \tau_{d}}
\end{aligned}
$$

with $\mathbf{E}$ and $\mathbf{F}$ as arbitrary constants.

Abbreviating,

$$
\begin{aligned}
& \mathrm{V}=\sinh \bar{K}_{1 \mathrm{~d}^{\mathrm{z}}} \\
& \mathrm{W}=\sinh \bar{K}_{1 \mathrm{~d}}\left(\mathrm{H}^{\prime}-\mathrm{z}\right) \\
& \mathrm{T}=\sin \overline{\mathrm{Bz}} \\
& \mathrm{U}=\sinh \bar{K}\left(\mathrm{H}^{\prime}-\mathrm{z}\right) \\
& \mathrm{z}_{2 \mathrm{dc}}=\mathrm{EV}+\mathrm{GAT} \\
& \mathrm{z}_{2 \mathrm{dr}}=\mathrm{FW}+\mathrm{HCU}
\end{aligned}
$$

The effective $\beta$ is defined as

$$
\beta_{\text {eff }}=\frac{\int \phi_{2 d d V}}{\int \phi_{2} d V}=\frac{c^{\int} z_{2 d c} d V+\int_{r} z_{2 d r d V}}{\int_{c}^{z_{2 c} d V}+\int_{r}^{z_{2 r} d V}}
$$

Letting $\int \mathrm{TdV}=\widetilde{\mathbf{T}}$ and similarly for other terms,

$$
\beta_{\text {eff }}=\frac{E \tilde{V}+F \tilde{W}+\mathbf{G A} \tilde{\mathbf{T}}+\mathbf{H C U}}{\mathbf{A} \tilde{\mathbf{T}}+\mathbf{C U}}
$$

The necessary integrals are

$$
\widetilde{\mathbf{T}}=\int_{\mathrm{Sa}}^{\mathrm{h}} \sin \overline{\mathrm{B}} \mathrm{zdz}=\frac{\cos \overline{\mathrm{B}} \mathrm{S}_{\mathrm{a}}-\cos \overline{\mathrm{B}} \mathrm{h}}{\overline{\mathrm{B}}}
$$




$$
\begin{aligned}
& \widetilde{\mathrm{U}}=\int_{\mathrm{h}}^{\mathrm{H}^{\prime}-\mathrm{S}_{\mathbf{a}}^{\prime}} \sinh \bar{K}\left(\mathrm{H}^{\prime}-\mathrm{z}\right) \mathrm{dz}=\frac{\cosh \bar{K}\left(\mathrm{H}^{\prime}-\mathrm{h}\right)-\cosh ^{-} \mathrm{S}_{\mathbf{a}}^{\prime}}{\bar{K}}
\end{aligned}
$$

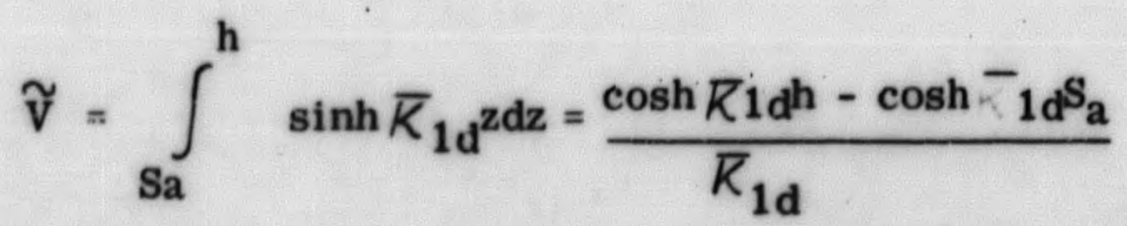

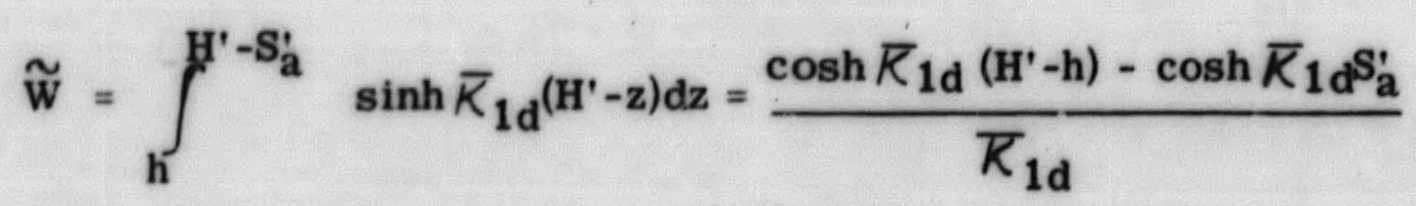

The arbitrary constants are obtained by equating flux and current at $\mathrm{z}=\mathrm{h}$. The results are listed without proof.

$$
\begin{aligned}
& E=\frac{\left.H C\left(\left[U^{\prime}\right]_{W}-\mathbf{U}^{\prime}\right)-G A[T]_{W}-\left[\mathbf{T}^{\prime}\right]\right)}{\left[V^{(w-v)}\right.}
\end{aligned}
$$

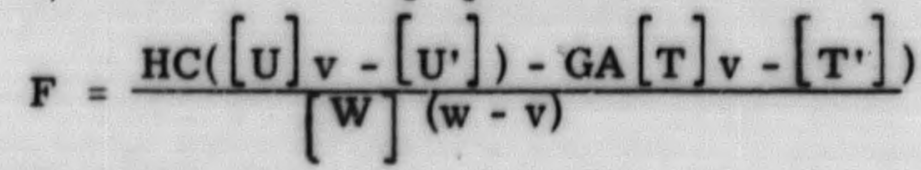

where all quantities are evaluated at $h$, and

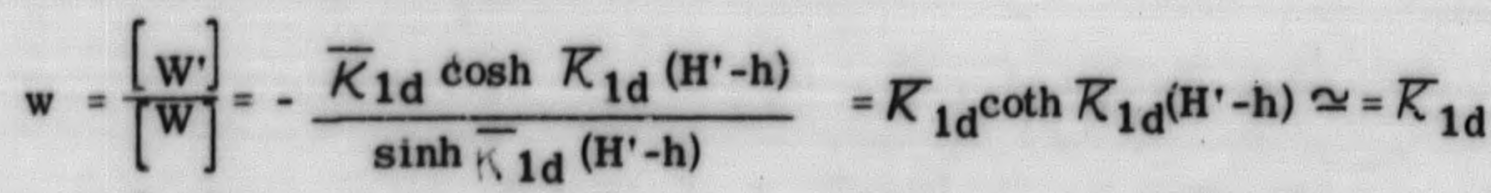

$$
\begin{aligned}
& \mathrm{v}=\frac{\left[\mathrm{v}^{\prime}\right]}{[\mathrm{V}]}=R_{1 \mathrm{~d}} \frac{\cosh K_{1 \mathrm{~d}^{\mathrm{h}}}}{\sinh \bar{K}_{1 \mathrm{~d}^{\mathrm{h}}}}=R_{1 \mathrm{~d}} \operatorname{coth} R_{1 \mathrm{~d}} \mathrm{~h} \simeq K_{1 \mathrm{~d}}
\end{aligned}
$$

For rod bank positions over most of the range, $\widetilde{v}_{\simeq} \frac{\cosh K_{1 \mathrm{~d}}}{\bar{K}_{1 \mathrm{~d}}}=\frac{[\mathrm{v}]}{\bar{K}_{1 \mathrm{~d}}}$ $\widetilde{w} \simeq \frac{\cosh K_{1 d}\left(H^{\prime}-h\right)}{\bar{K}_{1 d}}=\frac{w}{\bar{K}_{1 d}}$. Also, w $-v=-2 K_{1 d}$ and $w+v=0$.

Thus

$$
E \tilde{V}+F \tilde{W} \simeq \frac{H C[U \cdot]-G A\left[T^{\prime}\right]}{R_{1 d}^{2}}
$$




$$
\text { where } \begin{aligned}
{\left[\mathbf{U}^{\prime}\right] } & =-\bar{K} \cosh \bar{K}\left(\mathrm{H}^{\prime}-\mathrm{h}\right) \\
& {[\mathrm{T}]=\overline{\mathrm{B}} \cos \overline{\mathrm{B}} \mathrm{h} }
\end{aligned}
$$

\section{A. 5.4 Calculations}

A set of critical states for the core hot, with no xenon, at various rod bank positions was achieved by varying the effective number of neutrons per fission $\nu$, and applying the basic critical conditions. A summary of the pertinent values follows.

\begin{tabular}{|c|c|c|c|c|}
\hline$(\mathrm{cm})$ & $\overline{\mathbf{B}}$ & $R$ & $\mathbf{K}_{\mathbf{c}}$ & $\mathbf{K}_{\mathbf{r}}$ \\
\hline 25.62 & 0.0801 & 0.0387 & 1. 4679 & 1.1278 \\
\hline 30 & 0.0726 & 0.0481 & 1. 4180 & 1. 0895 \\
\hline 36 & 0.0665 & 0.0568 & 1. 3710 & 1. 0534 \\
\hline 42 & 0.0579 & 0.0620 & 1. 3358 & 1. 0263 \\
\hline 48 & 0.0527 & 0.0653 & 1. 3123 & 1. 0083 \\
\hline 54 & 0.0491 & 0.0679 & 1. 2962 & 0. 9958 \\
\hline & 0.0469 & 0.0690 & 1. 2859 & 0.9880 \\
\hline 64.48 (out) & 0.0462 & 0.0694 & 1. 2829 & 0.9857 \\
\hline
\end{tabular}

Bank Position*

* With full in position at $8.60 \mathrm{~cm}$.

Application of the effective $\beta$ formulas was then made using these group constants:

$$
\begin{aligned}
T_{d} & =10.52 \mathrm{~cm}^{2} \\
\bar{K}_{1 d} & =0.3155 \mathrm{~cm}^{-1}
\end{aligned}
$$

The results are listed on the following page, and plotted in Fig. A. 11 on an expanded scale in termsi of $\left(\beta_{\text {eff }} / \beta\right)-1$. The $\beta_{\text {eff }}$ values have been obtained for delayed neutron fraction $\beta=$.0065*.

* See Keepin, G. R., Wimett, T. F., and Ziegler R. K. , "Delayed Neutrons from Fissionable Isotopes of Uranium, Plutonium and Thorium,"

Nm. Energy G. , No. 1/2, 1, (1957). 


\section{Bank Position (In. )}

6. 70

8. 43

10. 79

13. 15

15. 51

17. 87

20. 24

22. 00

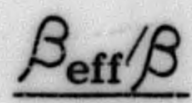

1. 208

1. 203

1. 199

1. 195

1. 194

1. 196

1. 199

1. 202 $\beta_{\text {eff }}$

.007852

.007820

.007794

.007768

.007761

.007774

.007794

.007813

It will be noted that the variation is regular, but small over the large range of rod motion. The minimum appears to be quite real. The average value of $\beta_{\text {eff }} / \beta$ has been taken as 1.200 elsewhere in this report yiêlding a $\bar{\beta}_{\text {eff }}=.0078$. Detailed examination of the calculations reveals that the first two terms in the numerator of $\beta_{\text {eff }}$ are very small, and that a good approximation is

$$
\beta_{\text {eff }}=\frac{\mathbf{G A} \widetilde{T}+\mathbf{H C U}}{\mathbf{A T}+\mathbf{C U}}
$$

or

$$
\beta_{\text {eff } / \beta}=\frac{\frac{k_{c}}{1+B^{2} \tau_{d}} \tilde{\phi}_{c}+\frac{k_{r}}{1-K^{2} \tau_{d}} \tilde{\phi}_{r}}{\tilde{\phi}_{c}+\tilde{\phi}_{r}} .
$$

where $\bar{\phi}_{\mathrm{c}}$ and $\widetilde{\phi}_{\mathrm{r}}$ are the integrals of the flux over the core and rod region respectively. Qualitatively, the approximate relation is a total-fluxweighted effective multiplication factor for delayed neutrons. Beyond this, no detalled physical explanation of the formula has been attermpted.

\section{A. 5.5 Summary}

A simplified theory is used to account for the preferential neutron leakage and therefore the effective delayed neutron fraction. Advantage is also taken of the short thermal diffusion length to simplify the two grpup modified equations.

Using the results of the previous sections of this Appendix, $\beta_{\text {eff }}$ has been found to vary between 0.00783 to 0.00776 , the minimum occurring at about 13.5 MWYR. 


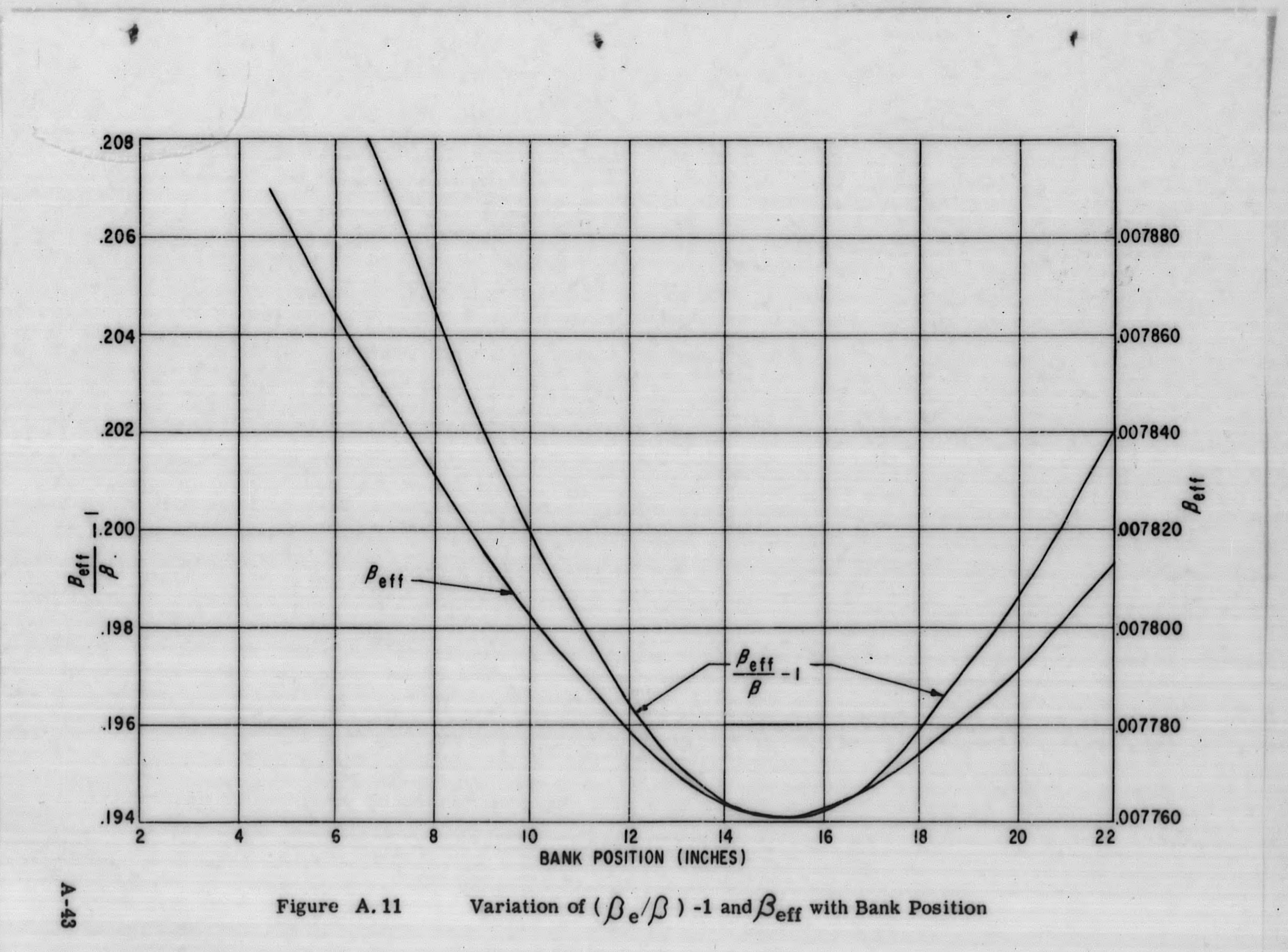





\section{APPENDIX B}

\section{CANDLE-2 INPUT FOR AXIAL SM-1 CORE I-440}

To understand the following CANDLE-2 input listing, it is necessary to obtain copies of WAPD-TM-53(1) and WAPD-TM-53 Add. 1. (2) AP Note 268(3) will also be of assistance.

Table B.1 shows the numbering system for the elements as used at Alco.

TABLE B. 1

\section{ALCO ELEMENT NUMBERS FOR THE CANDLE-2 IBM-704 CODE}

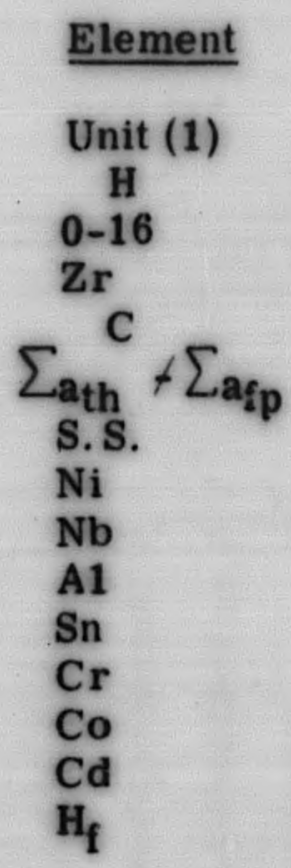

\begin{tabular}{c} 
Number \\
\hline 0 \\
1 \\
2 \\
3 \\
4 \\
5 \\
6 \\
7 \\
8 \\
9 \\
10 \\
11 \\
12 \\
13 \\
14
\end{tabular}

Element

$\mathrm{Mn}_{55}$

Li

In

U-235

$\mathrm{U}-236$

U-238

Pu-239

$\mathrm{Pu}-240$

$\mathrm{Pu}-241$

Pm-149

I-135

Sm-149

$\mathrm{Xe}-135$

Fission Products

B-10
Number

15

16

17

18

19

20

21

22

23

24

25

26

27

28

29

30

\section{REFERENCES}

1. O. J. Marlowe, P. A. Ombrellaro, "Candle-A One Dimensional Few-Group Depletion Code for the IBM-704," WAPD-TM-53, May, 1957.

2. O. J Marlowe, P. A. Ombrellaro, "Candle-A One Dimensional Few-Group Depletion Code for the IBM-704, Addendum 1, Candle-2," WAPD-TM-53 Add. 1, October, 1957.

3. H. N. Lerman, "Candle Input and Output Instructions for the Depletion Code Candle-2," AP Note 268, Alco Products, Inc., June 10, 1960. 
$160998048000-1-161-1647500600000626161-18003-1608805612800000534800$ 3652206500006513642000060000 4800000 5600000 6600000 760000 8650197353006000000 9600000 . 10800000

116514000000080

136.538030345080000000

148533256236860000000

5211579000

6542281118960000000000 6522811189006 8

660000085525261606181616

1682864467269860000000000

198000000008

51125556808

68085112555680\&5112555680800000000006

216 007459900006574599000055745990000857459900006574599000085745990000 $23657459900008574599000065745990000 \$ 57459900008574599000085745990000$ 2485810000008581000000085810000000858100000008581000000085810000000 25658100000008581000000085810000000858100000006581000000085810000000 266497756000064977560000849775600006000000 \&

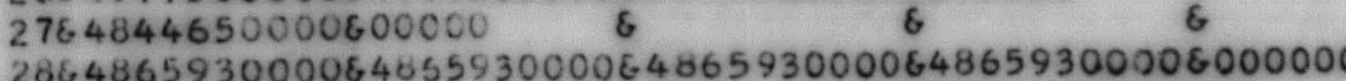
$298511000000065110000000 \$ 511000000065110000000600$

308511000000060 \&

6

8

8

5338553843

31618060000000

3264955806667649

336260800000000
3484927903333649231195006492311950064927903333600000000008

35656263800000000

36848857300008488573000080000 \&

3786628360000000000

उ8\&4914818770\&49148187706000000000 \&

3981862836000000000

4084742863160647428631606000000000 \&

4162682638000000000
4264343588770843435887708000000000 \&

( 6

8

8

6

680000000000

8

$\S$ 


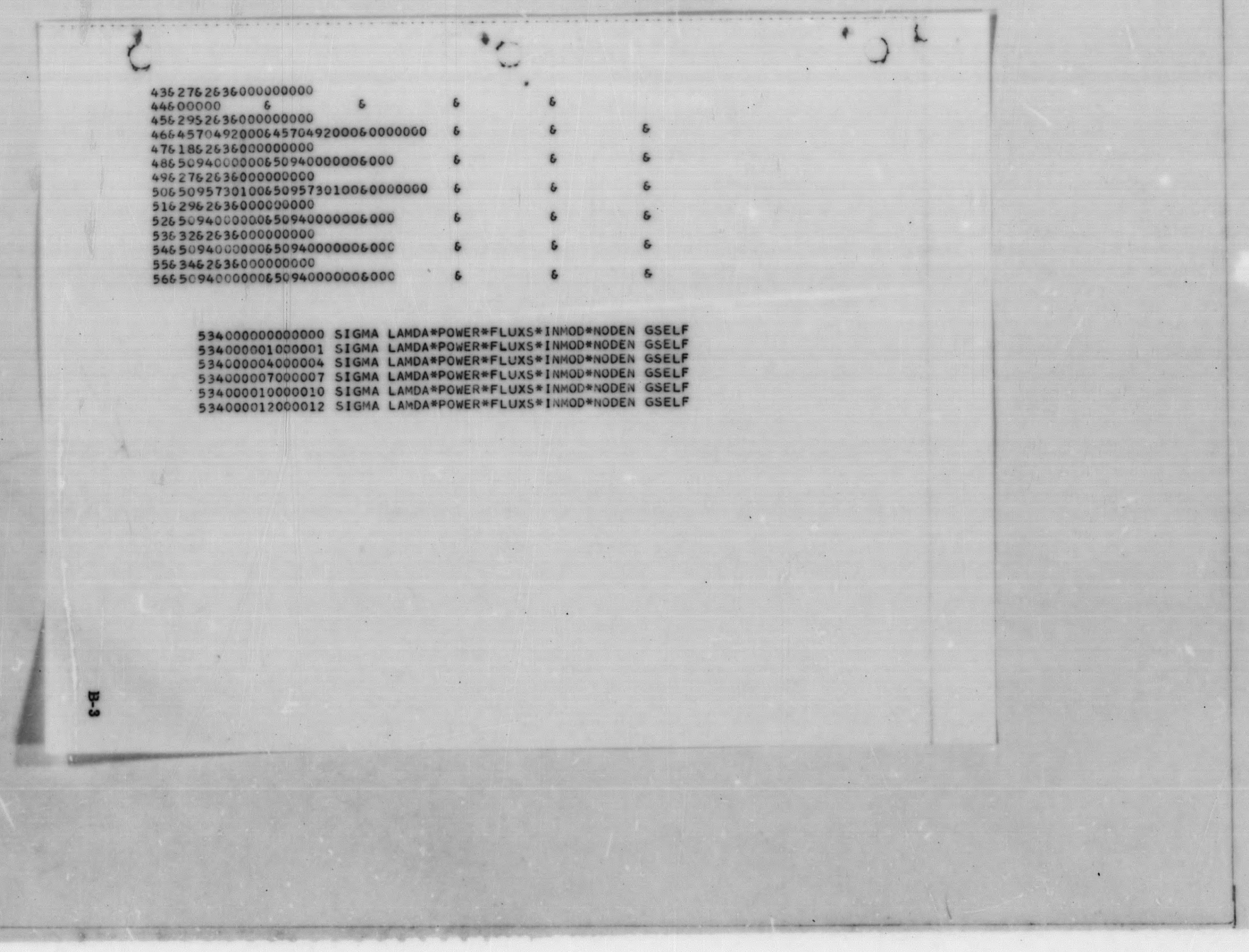




\section{APPENDIX C}




\section{APPENDIX C.}

\section{REFERENCE PARAMETERS FOR SM-1 CORE I}

During the course of the analysis performed under Subtask 2.3 of the PWR Support Program, slightly revised estimates of material contents and geometrical parameters became available; in addition, with the completion of the BOBCAT, IBM-650 code, (I) a more detailed analysis of the core composition and nuclear properties was feasible. Accordingly, the BOBCAT code was utilized to compute the atomic composition and nuclear parameters for the SM-1 Core I elements at start of life. The fast parameters were calculated by the MUFT-III code, using the cross sectional files listed in Appendix F, for both the P-1 and P1-SG slowing down approximations. For the cold $\left(68^{\circ} \mathrm{F}\right)$ and hot $\left(440^{\circ} \mathrm{F}\right)$ operating cores, with a system pressure of 1200 psia, 59 and 58 energy groups were used, respectively. The thermal parameters were computed by the $\mathbf{P}_{3}$ theory codes (2), (3) presently used for the stationary and control rod fuel elements. The microscopic cross sections needed as input to the $\mathbf{P}_{3}$ theory codes have been averaged over a hardened Maxwell-Boltzmann neutron distribution. The effective hardened neutron energies for the cold $\left(68^{\circ} \mathrm{F}\right)$ and hot $\left(4400^{\circ}\right) \mathrm{SM}-1$ Core I at $0 \mathrm{MWYR}$ are $0.0331 \mathrm{ev}$ and $0.0549 \mathrm{ev}$, respectively.

The reference modified two group nuclear parameters, as calculated by the methods described above, are listed in the tables on the following pages; aiso included are the best estimates of geometrical and material data. Comparison of these parameters to various others reported earlier in this report will reveal minor deviations; however, checks were made to verify that the effects of the revised parameters are negligible upon the analysis reported in the preceding chapters. To be even more accurate, it is recommended that the parameters listed in this appendix be utilized for future calculations. 
Geometrical - Core

Core configuration

Cell size, in.

Active core height, in.

Equivalent diameter, in.

Number of cells

Control rod cells

Stationary element cells

Material Composition - Core

Fuel

Burnable Poison

Stainless Steel

Cladding and Side. Plates

Fuel Matric

Absorber Material

Approximate Densities of Pure Materials

$\mathrm{UO}_{2}, \mathrm{gms} / \mathrm{cm}^{3}$

$\mathrm{B}_{4} \mathrm{C}, \mathrm{gms} / \mathrm{cm}^{3}$

Stainless Steel

304 L

302 B
7 × 7 (Corners Missing)

2. $9375 \times 2.9375$

21. 75

22.2

45

7

38

Highly enriched $\mathrm{U}_{2}$

Natural boron in $\mathrm{B}_{4} \mathrm{C}$

304 L.

302 B

Originally $\mathrm{B}_{4} \mathrm{C}$, later changed to $\mathrm{Eu}_{2} \mathrm{O}_{3}$

10.9

2. 535

7. 90

7. 56

C-2 
Geometrical - Elements

Fixed Element

Number in core

Number of fuel plates

Fuel Plates

Active length, in.

Dead edge, in.

Active width, in.

Clad thickness, in.

Active thickness, in.
38

18

21. 75

0.117

2. 54

0.005

0.0195
Control Fuel Element

7

16

21. 75

0.117

2. 318

0.005

0.0195

Side Plates

Thickness, in. Width, in.

Groove depth, in.

0.05

0.05

2. 863

2. 619

0.025

0.025

Control Rod Basket

Outer width, in.

Thickness, in.

no-

3. 781

0.05

\section{Material Composition}

$\mathrm{UO}_{2}$ per fuel plate, $\mathrm{gm}$

$\mathrm{U}$ per fuel plate, $\mathrm{gm}$

35. 092

32. 014

30. 751

28. 054

U-235 per fuel plate, gm

28. 62

26. 11

$\mathrm{B}_{4} \mathrm{C}$ per fuel plate, $\mathrm{gm}$

B per fuel piate, gm

B-10 per fuel plate, gm

$\mathrm{w} / \mathrm{O} \mathrm{UO}_{2}$ in fuel matri., \%

0.1439

0.1313

0.1092

0.0997

0.0200

0.0183

25. 9601

25. 9522

$w / o B_{4} C$ in fuel matrix, \%

0.1065

0.1065

$w / o$ SS in fuel matrix, \%

73. 9334

73. 9413

w/o $\mathrm{B}$ in fuel matrix, \%

0.0808

0.0808 
w/o B-10 in fuel matrix, \%

w/o U in fuel matrix, \%

w/o U-235 in fuel matrix, \%

a/o U-235 in fuel matrix, \%

a/o B in fuel matrix, \%

a/o B-10 in fuel matrix, \%

U-235 per fuel element, gm

B-10 per fuel element, gm

Stainless Steel per fuel element, gm

Mass of $\mathrm{H}_{2} \mathrm{O}$ per fuel element, gm

$$
\begin{array}{r}
68^{\circ} \mathrm{F}, 1200 \text { psia } \\
440^{\circ} \mathrm{F}, 1200 \text { psia }
\end{array}
$$

Total U-235 in the core, $\mathrm{kg}$

Total B-10 in the core, gm

\section{Volumes - Elements}

Total element volume, in. ${ }^{3}$ Dead region, in Active region, in. 3

Water in active region, in. 3

SS in active region, in. 3 .

Water in dead region, in. 3

SS in dead region, in. 3

Metal to water volume ratio
0.0148

22. 7488

21.1723

5. 6181

0.4662

0.0923

515.16

0.36054

4200.36

2456. 77

2051.93

2369.33

1978. 90

417. 76

5024. 79
22.5

15. 748
22. 7419

21. 1659

5. 6162

0.4662

0.0923

0.29248

187. 6787

25. 3965

162. 2822

132. 9471

23. 8400

16. 7793

8. 6172

0.253
187. 6787

56. 0356

131. 6431

107. 8465

19. 3400

36. 5513

19.4843

0.300 
TABLE C. 2

ATOMIC NUMBER DENSITIES * FOR SM-1 CORE I ELEMENTS

(0 MWYR, 1200 psia)

Number Densities (atoms $/ \mathrm{cm}^{3}$ )*

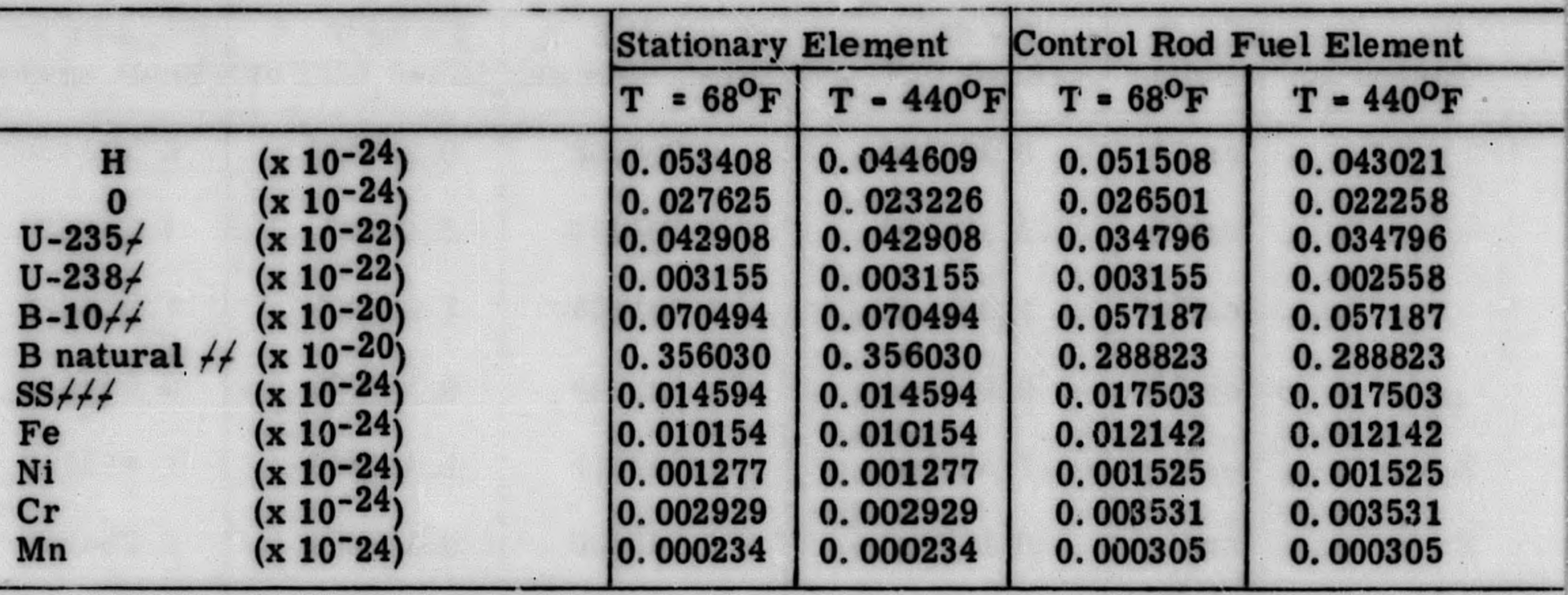

* Atomic number densities are given as atoms per $\mathrm{cm}^{3}$ of fuel element.

t Based upon $87.63 \mathrm{w} / \mathrm{o} \mathrm{U}$ in $\mathrm{UO}_{2}$ and $93.07 \mathrm{w} / \mathrm{o} \mathrm{U-235}$ in $\mathrm{U}$.

tf Based upon $75.9 \mathrm{w} / \mathrm{o} \mathrm{B}$ in $\mathrm{B}_{4} \mathrm{C}$ and $19.8 \mathrm{a} / \mathrm{o} \mathrm{B-10}$ in $\mathrm{B}$.

The boron densities listed reflect a $22.4 \%$ average fabrication loss.

th Stainless steel assumed to be composed only of $\mathrm{Fe}, \mathrm{Ni}, \mathrm{Cr}$ and $\mathrm{Mn}$. 
TABLE C. 3

THERMAL PARAMETERS * FOR SM-1 CORE I ELEMENTS

(0 MWYR, 1200 psia)

\begin{tabular}{|c|c|c|c|c|c|}
\hline \multirow[b]{2}{*}{ Parameter } & \multirow[b]{2}{*}{ Units } & \multicolumn{2}{|c|}{ Stationary Element } & \multicolumn{2}{|c|}{ Control Rod Fuel Element } \\
\hline & & $\begin{array}{c}T-68^{\circ} \mathrm{F} \\
(\text { En-0.0331 ev })\end{array}$ & $\begin{array}{l}T=440^{\circ} \mathrm{F} \\
(\text { En=0.0549 ev })\end{array}$ & $\begin{array}{c}T=68^{\circ} \mathrm{F} \\
(E n=0.0331 \mathrm{ev})\end{array}$ & $\begin{array}{l}T-440^{\circ} \mathrm{F} \\
(\mathrm{En}=0.0549 \mathrm{ev})\end{array}$ \\
\hline$\sum_{\mathrm{a}}^{* *}$ & $\mathrm{~cm}^{-1}$ & 0.266078 & 0.205902 & 0.221898 & 0.173456 \\
\hline$\Sigma_{s}$ & $\mathrm{~cm}^{-1}$ & 2. 100701 & 1. 540316 & 2. 048670 & 1. 516377 \\
\hline$\sum_{\text {tr }}$ & $\mathrm{cm}^{-1}$ & 1.961792 & 1. 351166 & 1. 884407 & 1.308841 \\
\hline$v \sum_{\mathrm{f}}$ & $\mathrm{cm}^{-1}$ & 0.415949 & 0.323948 & 0.317678 & 0.251908 \\
\hline $\mathbf{K}_{t}$ & $\cdots$ & 1.563258 & 1. 573311 & 1.431640 & 1.452290 \\
\hline D & $\mathrm{cm}$ & 0.169913 & 0.246700 & 0.176890 & 0.254678 \\
\hline$L^{2}$. & $\mathrm{cm}^{2}$ & 0.638581 & 1.198146 & 0. 797170 & 1. 468261 \\
\hline$\sum_{a}^{x e} t$ & $\mathrm{~cm}^{-1}$ & $-\cdots$ & .006975 & - & - \\
\hline$g^{\prime}+t$ & -- & 0.910110 & 0.942506 & - - - & ------ \\
\hline
\end{tabular}

Caculated by the $\mathbf{P}_{3}$ theory codes (2),(3) using microscopic cross section averaged over a hardened Maxwell-Boltzmann energy distribution $\left(E_{n}\right)$.

** Does not include $\sum_{\mathrm{a}}{ }^{\mathrm{xe}}$

f Calculated using parameters given in this report and methods described in APAE No. 65, (4) at a power level of $10 \mathrm{Mwt}$ for the entire core.

If Average flux in fuel plate divided by average flux in fuel element. 
TABLE C. 4

FAST PARAMETERS* OF COLD CLEAN SM-1 CORE I ELEMENTS

(o MWYR, T $=68^{\circ} \mathrm{F}, 1200 \mathrm{psia}$ )

$\left(B=0.0845 \mathrm{~cm}^{-1}\right)$

\begin{tabular}{|c|c|c|c|c|c|c|}
\hline \multirow[t]{2}{*}{ Parameter } & \multirow[t]{2}{*}{ Units } & \multicolumn{3}{|c|}{ Stationary Element } & \multicolumn{2}{|c|}{ Control Rod Fuel Element } \\
\hline & & P-1 Model f & P-1 SG & Model $/ t$ & P-1 Model $f$ & P-1SG Model $t \not$ \\
\hline$\tau$ & $\mathrm{cm}^{2}$ & 30.310198 & \multicolumn{2}{|c|}{34.247459} & 30.912692 & 34.672212 \\
\hline$\sum_{t}=D / T$ & $\mathrm{~cm}^{-1}$ & 0.040765 & \multicolumn{2}{|c|}{0.041181} & 0.039466 & 0.039837 \\
\hline D & $\mathbf{c m}$ & 1.235593 & \multicolumn{2}{|c|}{1.410353} & 1.220002 & 1.381242 \\
\hline$\Sigma_{a}$ & $\mathrm{~cm}^{-1}$ & 0.010168 & \multicolumn{2}{|c|}{0.010238} & 0.009182 & 0.009237 \\
\hline$\nu \sum_{f}$ & $\mathrm{~cm}^{-1}$ & 0.013213 & \multicolumn{2}{|c|}{0.013340} & 0.010882 & 0.010979 \\
\hline $\mathbf{K}_{\mathbf{f}}$ & $\cdots$ & 1.299538 & \multicolumn{2}{|c|}{ 1. 302989} & 1. 185177 & 1.188564 \\
\hline $\mathbf{p}$ & $\cdots$ & 0.750579 & \multicolumn{2}{|c|}{0.751386} & 0.767350 & 0.768125 \\
\hline
\end{tabular}

* Computed by the MUFT-III code, using files listed in Appendix $\underline{F}$, for cold clean core (59 energy groups).

4 Computed by use of P-1 slowing down approximation.

If Computed by use of P-1 SG slowing down approximation. 
TABLE C. 5

FAST PARAMETERS* OF HOT CLEAN SM-1 CORE I ELEMENTS

(0 MWYR, $\mathrm{T}=440^{\circ} \mathrm{F}, 1200 \mathrm{psia}$ )

$\left(B^{2}=.006594 \mathrm{~cm}^{-2}\right)$

\begin{tabular}{|c|c|c|c|c|c|}
\hline \multirow[t]{2}{*}{ Parameter } & \multirow[t]{2}{*}{ Units } & \multicolumn{2}{|c|}{ Stationary Element } & \multicolumn{2}{|c|}{ Control Rod Fuel Element } \\
\hline & & P-1 Model $f$ & P1-SG : Model \&t & P-1 Model 4 & P1-SG . Model At \\
\hline$\tau$ & $\mathrm{cm}^{2}$ & 41.190926 & 46. 021892 & 41. 728927 & 46. 295430 \\
\hline$\Sigma_{T}=\mathrm{D} / T$ & $\mathrm{~cm}^{-1}$ & 0.034501 & 0.034901 & 0.033428 & 0.033781 \\
\hline D & cm & 1.421115 & 1. 606221 & 1.393915 & 1. 563902 \\
\hline$\sum_{a}$ & $\mathrm{~cm}^{-1}$ & 0.009285 & 0.009360 & 0.008413 & 0.008471 \\
\hline$\nu \Sigma_{f}$ & $\mathrm{~cm}^{-1}$ & 0.012012 & 0.012142 & 0.009902 & 0.010000 \\
\hline $\mathbf{K}_{\mathbf{f}}$ & & 1.293656 & 1.297238 & 1.177021 & 1.180550 \\
\hline $\mathbf{p}$ & $\ldots$ & 0.730866 & 0.731819 & 0.748323 & 0.749236 \\
\hline
\end{tabular}

* Computed by the MUFT-III, using files listed in Appendix F for hot clean core (58 energy groups)

f Computed by use of P-1 slowing down approximation.

tf Computed by use of P-1 SG slowing down approximation

C-8 
TABLE C. 6

XENON PARAMETERS FOR SM-1 CORE I*, 0 MWYR

$\left(T=440^{\circ} F, E_{n}=0.0549 \mathrm{ev}\right)$

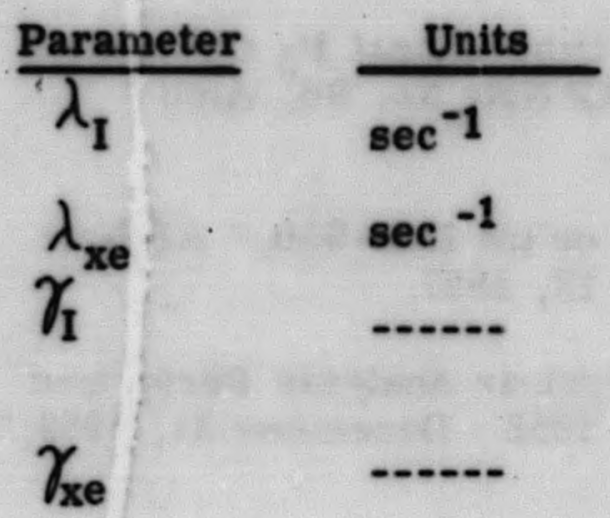

Description

fission/watt

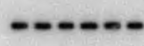

-......

watts

$\mathrm{cm}^{3}$

$\mathrm{cm}^{2}$

$\mathrm{cm}^{-1}$

$\beta$
Decay constant of iodine

Decay constant of xenon

Fractional fission yield of iodine

Fractional fission yield of xenon

Fissions per watt per second

Value

2. $89 \times 10^{-5}$

$2.09 \times 10^{-5}$

0.060

0.0029

$3.2175 \times 10^{10}$

1.13

Non-uniform distribution

factor

Self-shielding factor

.942506

Thermal power

Active core volume

$1 \times 10^{7}$

$1.3999 \times 10^{5}$

Xenon thermal absorption cross section

$2.5 \times 10^{-18}$

Macroscopic fission cross section of core

.13169

Fraction of thermal fissions

.82439

* Refer to APAE No. 65, Appendix A. (4) 


\section{REFERENCES (APPENDIX C)}

1. Bobe, P. E. and Caton, R. L., "BOBCAT (Program \#56) Code Preparation Analysis on the IBM-650," APAE Memo No. 289, August 9, 1961.

2. Byrne, B. J., and Caton, R. L., "Two-Dimensional $\mathbf{P}_{3}$ Calculation for APPR Type Fixed Fuel Elements," AP Note No. 96, Alco Products, Inc. February 14, 1958.

3. Caton, R. L. et al. "P-3 Approximation on the IBM-650," AP Note No. 85, Alco Products, Inc., November 13, 1957.

4. Bobe P. E. editor, "Interim Report of Nuclear Analysis Performed on SM-2 Core and Vessel, September 1, 1958 - December 31, 1959," APAE No. 65, May 27, 1960. 


\section{APPENDLX D \\ DISCUSSION OF Xe CROSS-SECTION \\ AND NON-UNTIORM XE FACTOR}

Since the calculations in Section 5.0 were performed, there has been evidence that the $\mathrm{Xe}$ cross-section used is rather low. Following Westcott's formulation(i) i.e.

$$
\bar{\sigma}=\frac{\sqrt{\pi}}{2} \sqrt{\frac{T_{0}}{T}} \hat{\sigma}
$$

$$
\text { where } \hat{\sigma}=\sigma_{0}(\mathrm{~g}+\mathrm{rs}) \text { and } \sigma_{0}=\sigma(.0253 \mathrm{ev})
$$

$g$ is the non $1 / v$ factor and $r s$ accounts for the epithermal region. Values of O have been measured by crystal spectrometer (Bernstein) and fast chopper (Smith) and given as function of T ${ }^{\circ} \mathbf{K}$ Fig. 1. For the SM-1 core at $440^{\circ} \mathrm{F}$ we get:

Hence:

$$
T_{n} / T_{o}=1+A \frac{\sum a_{\text {th }}}{\xi \sum_{s}}=1.284^{(2)}
$$

$$
\begin{aligned}
& \bar{\sigma}=2.99 \frac{10^{6}}{1.128} \sqrt{\frac{1}{1.284}}=2.34 \times 10^{6} \text { barns (Bernstein) } \\
& \bar{\sigma}=3.23 \frac{10^{6}}{1.128} \sqrt{\frac{1}{1.284}}=2.60 \times 10^{6} \text { barns (Smith) }
\end{aligned}
$$

The strong dependence of $\hat{\sigma}$ on $T$ implies that the energy distribution of the neutron flux in the neighborhood of Xe must be accurately known for an accurate estimate of the Xe cross-section. Calculated Wigner-Wilkins spectra*(3) show a strong decrease of $\bar{\sigma}$ upon U-235 content in a homogeneous mixture, as can be seen in Fig. D. 2 for $440^{\circ} \mathrm{F}$. It is therefore necessary to assign an "effective" U-235 atom content as well as geometry. This problem however, cannot successfully be solved by diffusion techniques.

The effect of the non-uniform distribution of Xe poison on reactivity can be expressed in terms of the non-uniform factor $\alpha$ defined in such a way that $\alpha \delta \sum \mathrm{a}$ would give the amount of change in uniform absorption that will result in the same change in reactivity. 


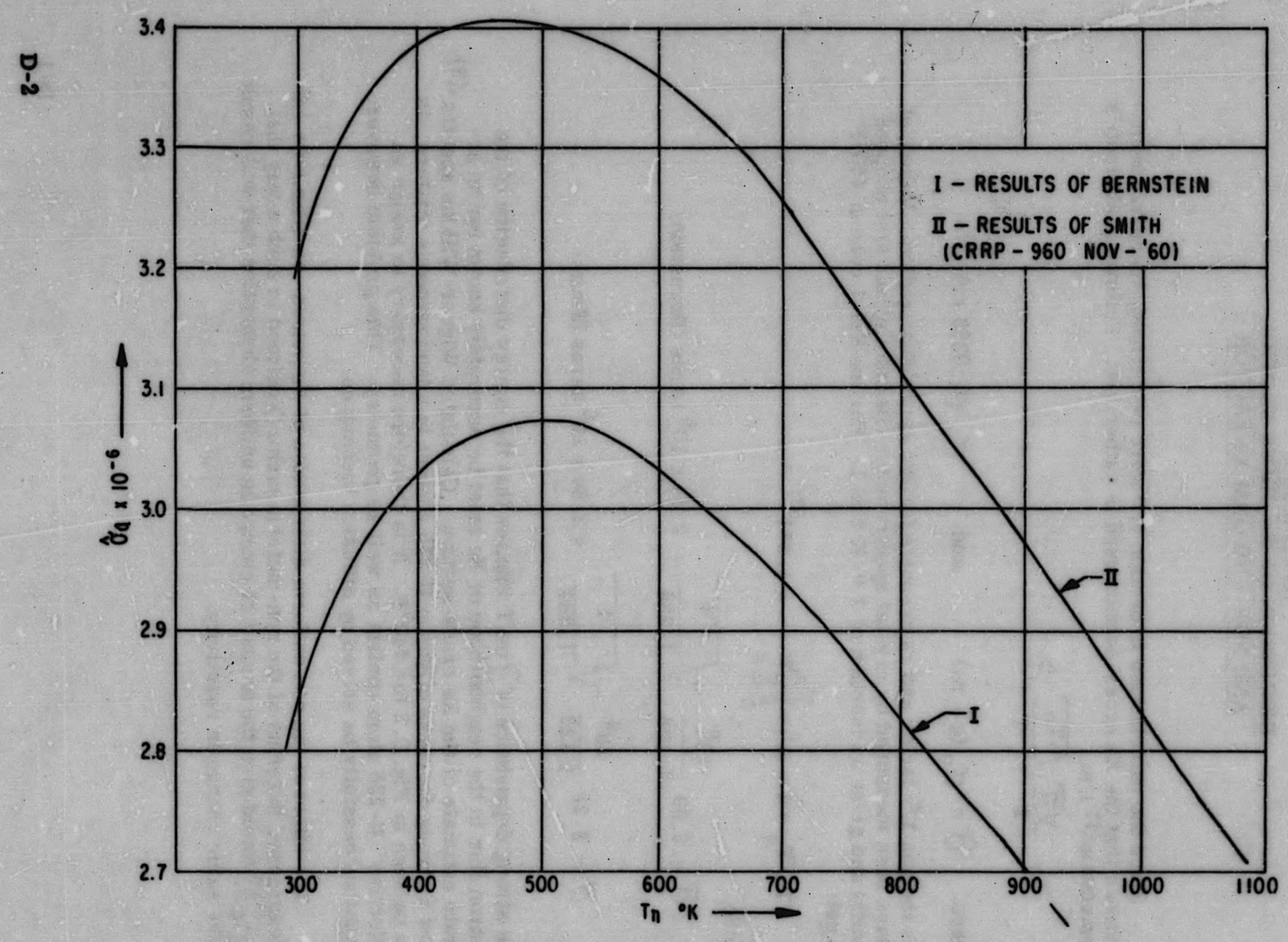
Figure D.1 Effective Xe-135 Cross Section $\hat{\sigma}_{a}$ vs. Effective Neutron
Temperature $T_{n} o_{K}$

4

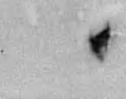




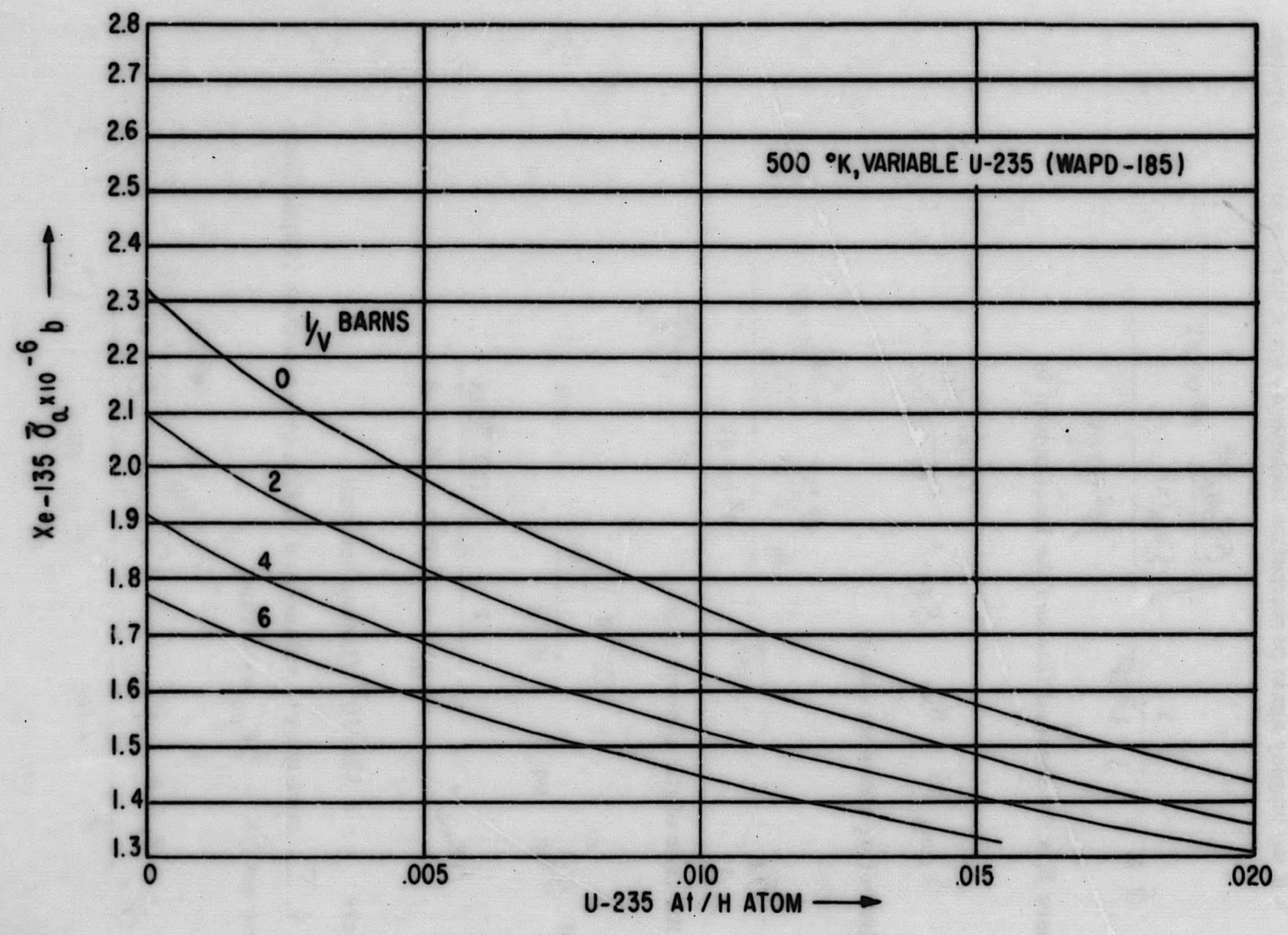

Figure D. 2 Average Xe-135 Absorption vs. U-235/H Atom Ratio 
If we employ again perturbation techniques for a bare equivalent system:

$$
\delta K=-\frac{1}{1+L^{2} B^{2}} \frac{\int \frac{\delta \sum a_{t h}(x)}{\sum a_{t h}(x)} d^{2}(x) d V}{\int \phi^{2}(x) d V}
$$

where $\emptyset$ is the thermal flux and the local poison is:

$$
\delta \sum_{\mathrm{ath}_{\mathrm{th}}}(\mathrm{x})=\mathrm{N}_{\mathrm{xe}} \cdot \delta_{\mathrm{xe}}=\frac{\mathrm{Y} \emptyset(\mathrm{x}) \sum_{\mathrm{f}_{\mathrm{th}}}}{\phi_{1}+\phi(\mathrm{x})}
$$

Substituting above we obtain:

$$
\delta \mathrm{K}=-\frac{1}{1+L^{2} B^{2}} \frac{\frac{\phi^{3}(x)}{\phi_{1}+\phi(x)} \frac{\sum_{f_{t h}}}{\sum^{a_{t h}}} d V}{\int \phi^{2}(x) d V}
$$

In the case of the uniform flux

$$
\bar{\emptyset}=\frac{c p}{V \sum f_{\text {th }}}
$$

and

$$
\begin{aligned}
& \delta \sum_{a}^{\mathrm{xe}}=\frac{\alpha^{\mathrm{Y} \bar{\varnothing}} \sum_{\mathrm{f}_{\text {th }}}}{\emptyset+\bar{\varnothing}} \quad \text { and } \\
& \delta \mathrm{K}_{\mathrm{eq}}=-\frac{1}{\sum_{\mathrm{a}_{\mathrm{th}}}\left(1+\mathrm{L}^{2} \mathrm{~B}^{2}\right)} \frac{\alpha \mathrm{Y} \overline{\overline{\mathrm{f}}_{\mathrm{th}}}}{\phi_{1}+\bar{\phi}}
\end{aligned}
$$

where $c=3.121 \times 10^{10}$ fission $/ \mathrm{sec}$ watt

$P, v, \sum_{f}$, core power, volume and fission cross-section respectively. If we set $\delta \mathbf{K}=\delta \mathbf{K}_{\text {eq }}$ we obtain:

$$
\alpha=\frac{\phi_{1}+\bar{\phi}}{\bar{\phi}} \frac{\sum_{a_{\text {th }}}}{\sum_{f_{\text {th }}}} \frac{\int \frac{\sum_{\mathrm{f}_{\text {th }}}(x)}{\sum_{a_{\text {th }}}(x)} \frac{\phi^{3}(x)}{\phi_{1}+\phi(x)} d V}{\int \phi^{2}(x) d v}
$$

D-4 
In the case of no burnup

$$
\sum_{f_{\text {th }}}(x) \cdot \sum_{a_{\text {th }}}(x)=\text { const. }
$$

therefore:

$$
\alpha=\frac{\emptyset_{1}+\bar{\emptyset}}{\varnothing} \quad \frac{\int \frac{\phi^{3}(x)}{\phi_{1}+\phi(x)} d V}{\int \phi^{2}(x) d v}
$$

Numerical integration over the thermal flux distribution at $\mathbf{0}$ MWYR (obtained from multiregion calculation and close to the experimental) leads to the values of $\alpha_{\text {rad }}=1.0421$ and $\alpha_{a x}=1.088$ then the overall $\alpha=\alpha_{\text {rad }} \alpha_{\text {ax }}=1.134$.

At an appreciable burnup where $\sum_{f_{\text {th }}}(x)$ and $\sum_{\text {ath }}(x)$ can no longer be considered as constants the former expression for $\alpha$ must be used where $\sum_{a_{t h}}$ and $\sum f_{t h}$ must be flux and volume weighted.

Let us now use one group flux distribution to evaluate $\alpha$ i.e., if

$\emptyset(r)=J_{0}\left(\frac{j_{0} r}{R^{\prime}}\right)$ and

$\emptyset(\mathrm{z})=\mathrm{Asin} \mathrm{B} \mathrm{z}$ for the core region and

$\emptyset_{\mathrm{r}}(\mathrm{z})=\mathrm{C} \sinh \mathrm{K}\left(\mathrm{H}^{\prime}-\mathrm{z}\right)$

Then we obtain $\alpha=1.477$

This indicates the dependence of reactivity due to xenon poisoning upon the flux distribution. At high burnup however the representation of the flux as it has been done in Section A. 1 is obviously on approximation, then the disagreement between calculated and experimental values should not be surprising.

\section{SUMMARY}

Perturbation techniques were employed to evaluate the non-uniform distribution factor for xenon in SM-1 Core $I$ at 0 MWYR.

It has been found that the xenon concentration due to an average power must be multiplied by 1.134 to give the reactivity effect due to the non-uniform distribution of xenon. An evaluation of the xenon microscopic absorption cross section based on the latest data leads to the value of $\sigma_{a}^{x_{e}}=2.34-2.60 \times 10^{6}$
barns. 


\section{REFERENCES}

1. Westcott, C. H., "Effective Cross Section Values for Well Moderated Thermal Reactor Spectra," CRRP-960, November 1960.

2. Bobe, P. E., editor, "Interim Report of Nuclear Analysis Performed on SM-2 Core and Vessel, September 1, 1959 - December 31, 1959," APAE No. 65, May 29, 1960.

3. Amster, H. T., "A Compendium of Thermal Neutron Cross Sections Averaged Over the Spectra of Wigner and Wilkins," WAPD-185, January 1958.

D-6 
APPENDIX E 


\section{APPENDIX E. NOMENCLATURE}

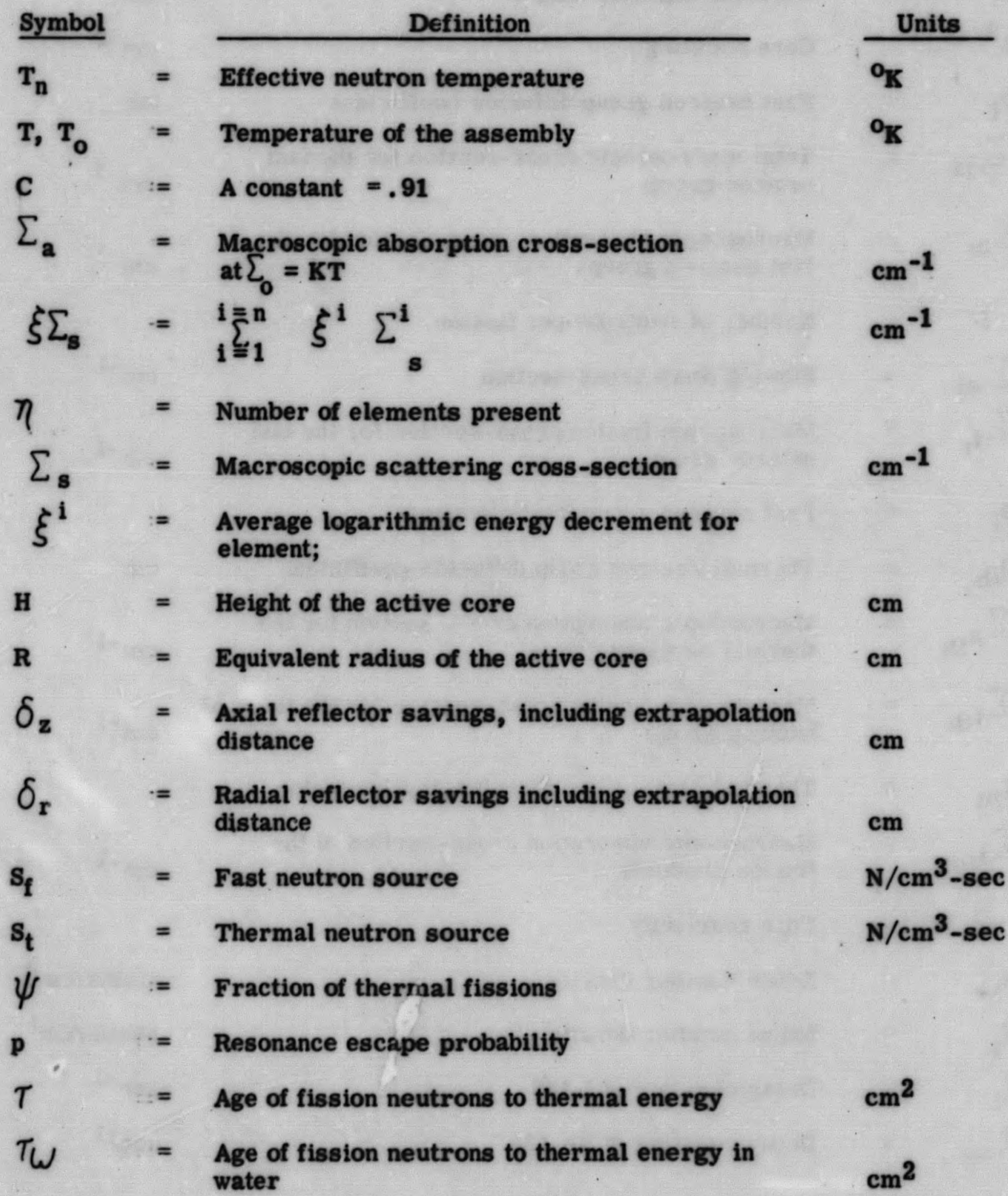




\begin{tabular}{|c|c|c|c|}
\hline Symbol & & Definition & Units \\
\hline $\mathbf{L}$ & $=$ & Thermal diffusion length & cm \\
\hline$B^{2}$ & $=$ & Core buckling & $\mathrm{cm}^{-2}$ \\
\hline$D_{\mathbf{f}}$ & $=$ & Fast neutron group diffusion coefficient & cm \\
\hline $\mathrm{Tf}$ & $=$ & $\begin{array}{l}\text { Total macroscopic cross-section for the fast } \\
\text { neutron group }\end{array}$ & $\mathrm{cm}^{-1}$ \\
\hline & $=$ & $\begin{array}{l}\text { Macrascopic absorption cross-section for the } \\
\text { fast neutron group }\end{array}$ & $\mathrm{cm}^{-1}$ \\
\hline$\nu$ & $=$ & Number of neutrons per fission & \\
\hline & $=$ & Slowing down cross-section & $\mathrm{cm}^{-1}$ \\
\hline$\sum_{f_{f}}$ & $=$ & $\begin{array}{l}\text { Macroscopic fission cross-section for the fast } \\
\text { neutron group }\end{array}$ & $\mathrm{cm}^{-1}$ \\
\hline $\mathbf{K}_{\mathrm{f}}$ & $=$ & Fast neutron group multiplication & \\
\hline $\mathbf{D}_{\text {th }}$ & $=$ & Thermal neutron group diffusion coefficient & cm \\
\hline$\sum_{a_{\text {th }}}$ & $=$ & $\begin{array}{l}\text { Macroscopic absorption cross-section for the } \\
\text { thermal neuttron group }\end{array}$ & $\mathrm{cm}^{-1}$ \\
\hline $\mathrm{L}_{\mathrm{fth}_{\mathrm{th}}}$ & $=$ & $\begin{array}{l}\text { Macroscopic fission cross-section for the thermal } \\
\text { neutron group }\end{array}$ & $\mathrm{cm}^{-1}$ \\
\hline th & $=$ & Thermal neutron group multiplication factor & \\
\hline$\sum_{a_{f p}}$ & $=$ & $\begin{array}{l}\text { Macroscopic absorption cross-section of the } \\
\text { fission products }\end{array}$ & $\mathrm{cm}^{-1}$ \\
\hline$\rho$ & $=$ & Core reactivity & \\
\hline $\mathrm{N}_{\mathrm{xe}}$ & $=$ & Xenon number density & atoms $/ \mathrm{cm}^{3}$ \\
\hline $\mathrm{N}_{1}$ & $=$ & Iodine number density & atoms $/ \mathrm{cm}^{3}$ \\
\hline$\lambda_{1}$ & $=$ & Decay constant of I-135 & $\sec ^{-1}$ \\
\hline$\lambda_{\mathrm{xe}}$ & $=$ & Decay constant of $\mathrm{Xe}-135$ & $\sec ^{-1}$ \\
\hline
\end{tabular}




\begin{tabular}{|c|c|c|c|}
\hline Symbol & & Definition & Units \\
\hline $\mathbf{Y}_{\mathbf{I}}$ & $=$ & Fission fractional yield of I-135 & \\
\hline $\mathbf{Y}_{\mathbf{x e}}$ & $=$ & Fission fraction yield of $\mathrm{Xe}-135$ & \\
\hline$\emptyset$ & & Thermal neutron flux & $\mathrm{N} / \mathrm{cm}^{2}$-sec \\
\hline$\beta$ & $=$ & $\begin{array}{l}\text { Ratio of thermal fissions to total } \\
\text { fissions }\end{array}$ & \\
\hline$\phi_{\mathrm{f}}$ & $=$ & Fast neutron flux & $\mathrm{N} / \mathrm{cm}^{2}-\mathrm{sec}$ \\
\hline $\mathbf{L}_{\mathbf{f}}$ & $=$ & Fast neutron leakage & \\
\hline $\mathbf{L}_{\text {th }}$ & $=$ & Thermal neutron leakage & \\
\hline $\mathbf{K}_{\text {eff }}$ & $=$ & Effective neutron multiplication & \\
\hline$\alpha_{\mathbf{T}}$ & $=$ & Temperature coefficient & $0_{F}^{-1}$ \\
\hline B & $=$ & Fuel burnup fraction ( $B=0$ at start of life) & \\
\hline $\mathbf{v}$ & & Core volume & $\mathrm{cm}^{3}$ \\
\hline $\bar{\sigma}_{a}^{x e}$ & $=$ & $\begin{array}{l}\text { Average xenon thermal absorption cross- } \\
\text { section }\end{array}$ & barns \\
\hline$\delta$ & $=$ & Fissions /watt-sec & \\
\hline$\alpha$ & $=$ & Xenon non-uniform distribution factor & \\
\hline $\mathbf{P}_{\mathbf{M w}}$ & $=$ & Reactor power in megawatts & \\
\hline$g^{\prime}(B)$ & $=$ & $\begin{array}{l}\text { Average flux in fuel plate divided by the average } \\
\text { flux in the entire fuel element }\end{array}$ & \\
\hline
\end{tabular}




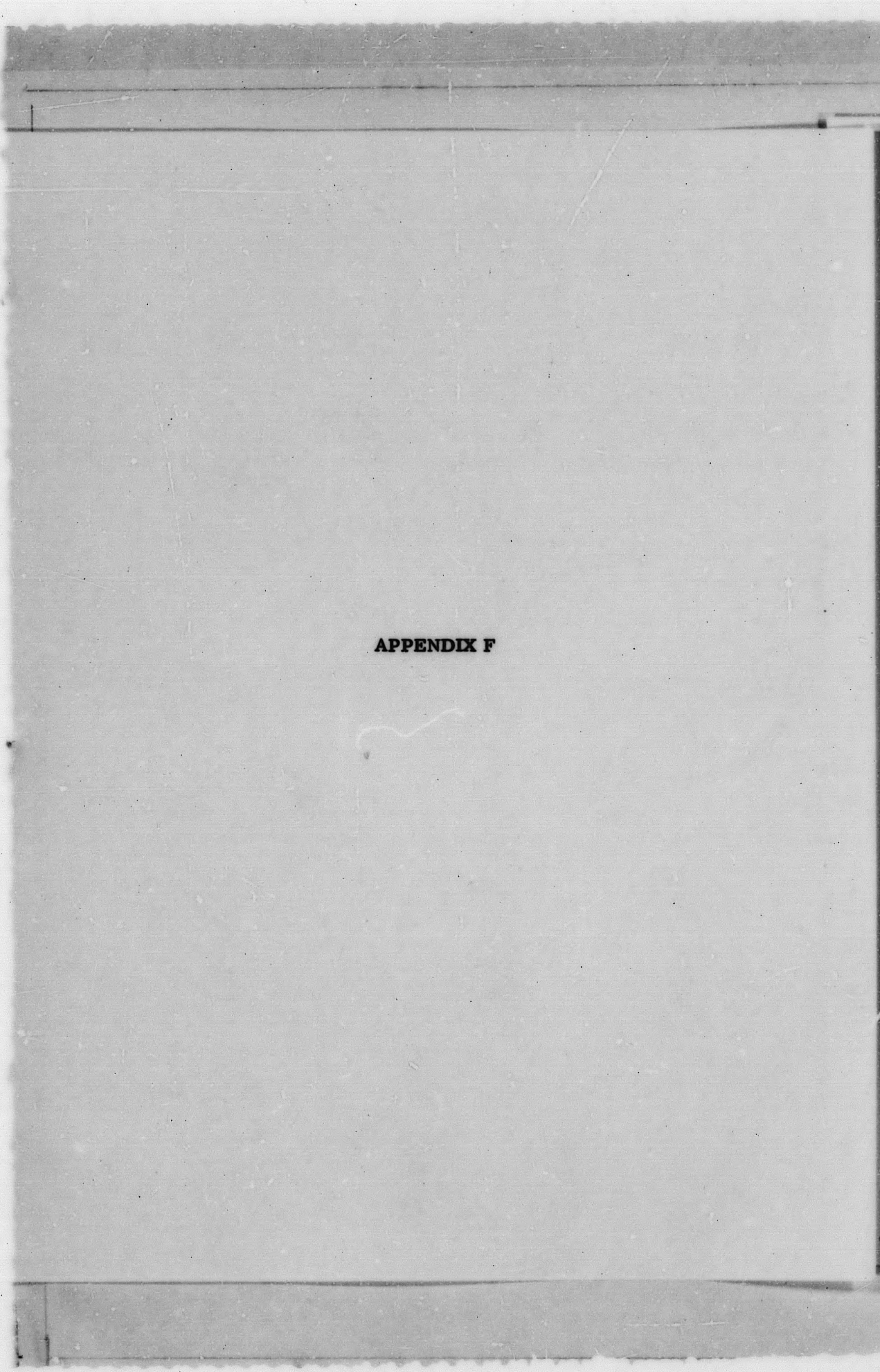




\section{APPENDIX F}

\section{THE MUFT-III CROSS SECTION FILES}

An evaluation of the agreement between calculated and experimental nuclear quantities using MUFF-III cross section files was made in Section 3. 0.

The inelastic scattering matrix in iron has been determined by using known cross sections for the $\left(n, n^{\prime}, \gamma\right)$ reaction to various levels from the threshold at $0.85 \mathrm{Mev}$ to about $4 \mathrm{Mev}$. At higher incident neutron energies the slowing down distributions have been determined by using more recent values of the "Nuclear temperature."(1)

The behavior of neutrons scattered elastically is described by means of $\mu_{0}$. the average cosine of the angle between the direction of the incident and scattered neutron and $\xi$, the average loss in the logarithmic energy decrement. In order to account for anisotropic scattering events in the center of mass system, the elastic slowing down distributions of scattered neutrons have been determined by using known angular distributions.

The total cross section curve for iron indicates that there are unresolved resonances between 0.008 to $10 \mathrm{Mev}$. These are mainly scattering, since there are no sharp peaks. However, the measured resonance integral for iron, 2.1 barns, is higher than the value 1.26 barns to be expected if the iron cross section followed a $1 / 2$ behavior. and (3).

The MUFT-III energy-lethargy group structure is given in references (2)

\section{REFERENCES}

1. Rosen, L., and Stewart, L., "The Determination of Nuclear Temperatures by Means of the Evaporation Model," LA-1560, August 18, 1953.

2. Bobe, P.E., editor, "Interim Report of Nuclear Analysis Performed on SM-2 Core and Vessel, September 1, 1958, December 31, 1959," APAE No. 65, May 27, 1960.

3. Byrne, B. J., and Oby, P. V., "Analysis of Extended Zero Power Experiments on the Army Package Power Reactor - ZPE-2," APAE No. 27, May 7, 1958. 
7 FILE NO 01 HYOROGEN

\begin{tabular}{|c|c|c|c|c|c|c|c|c|}
\hline GROUF & $\bar{\mu}$ & $\bar{\xi}$ & $\bar{\sigma}_{s \times 10}=-1$ & $\bar{\sigma}_{c}^{s}$ & $\bar{\sigma}_{1 m}$ & 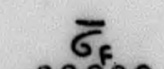 & & $\Delta u$ \\
\hline $\begin{array}{l}1 \\
2\end{array}$ & $\begin{array}{l}.6656666 \\
.6666666\end{array}$ & $\begin{array}{l}0.0 C 00000 \\
0.000000\end{array}$ & $\begin{array}{l}.102500 \\
.126250\end{array}$ & $\begin{array}{l}.0000 \\
.0000\end{array}$ & .000 & .00000 & $\begin{array}{l}.0000 \\
.0000\end{array}$ & $\begin{array}{r}.25000 \\
.25000\end{array}$ \\
\hline 3 & .6666666 & 0.000000 & .154250 & .0000 & .000 & .00000 & .0000 & .25000 \\
\hline 4 & .666666 & 0.000000 & .183250 & .0000 & .000 & .00000 & .0000 & .25000 \\
\hline 5 & .666666 & 0.000000 & .216500 & .0000 & .000 & .00000 & .0000 & .25000 \\
\hline 6 & .666666 & 0.000000 & .253500 & .0000 & .000 & .00000 & .0000 & .25000 \\
\hline 7 & .666666 & 0.000000 & .293250 & .0000 & .000 & .00000 & .0000 & .25000 \\
\hline 8 & .666666 & 0.000000 & .337250 & .0000 & .000 & .00000 & .0000 & .25000 \\
\hline 9 & .666666 & 0.000000 & .387000 & .0000 & .000 & .00000 & .0000 & .25000 \\
\hline 10 & . 666666 & 0.000000 & .443500 & .0000 & .000 & .00000 & .0000 & .25000 \\
\hline 11 & .666666 & 0.000000 & .506500 & .0000 & .000 & .00000 & .0000 & .25000 \\
\hline 12 & .666666 & 0.000000 & .575000 & .0000 & .000 & .00000 & .0000 & .25000 \\
\hline 13 & .666666 & 0.000000 & .652500 & .0000 & .000 & .00000 & .0000 & .25000 \\
\hline 14 & . 666666 & 0.000000 & .737500 & .0000 & .000 & .00000 & .0000 & .25000 \\
\hline 15 & .666666 & 0.000000 & . 827500 & .0000 & .000 & .00000 & .0000 & .25000 \\
\hline 16 & .666666 & 0.000000 & .928000 & .0000 & .000 & .00000 & .0000 & .25000 \\
\hline 17 & .666666 & 0.000000 & 1.040500 & .0000 & .000 & .00000 & .0000 & .25000 \\
\hline 18 & . 666666 & 0.000000 & 1.155000 & .0000 & .000 & .00000 & .0000 & .25000 \\
\hline 19 & .666666 & 0.000000 & 1.275000 & .0000 & .000 & .00000 & .0000 & .25000 \\
\hline 20 & .666666 & 0.000000 & 1.395000 & .0000 & .000 & .00000 & .0000 & .25000 \\
\hline 21 & .666666 & 0.000000 & 1.537500 & .0000 & .000 & .00000 & .0000 & - 50000 \\
\hline 22 & .666666 & 0.000000 & 1.725000 & .0000 & .000 & .00000 & .0000 & - 50000 \\
\hline 23 & .666666 & 0.000000 & 1.900000 & .0000 & .000 & .00000 & .0000 & .50000 \\
\hline 24 & .666666 & 0.000000 & 1.987500 & .0000 & .000 & .00000 & .0000 & .50000 \\
\hline 25 & . 666666 & 0.000000 & 2.000000 & .0000 & .000 & .00000 & .0000 & .50000 \\
\hline 26 & .666666 & 0.000000 & 2.005000 & .0000 & .000 & .00000 & .0000 & .50000 \\
\hline 27 & .666666 & 0.000000 & 2.015000 & .0000 & .000 & .00000 & .0000 & .50000 \\
\hline 28 & .666666 & 0.000000 & 2.035000 & .0000 & .000 & .00000 & .0000 & .50000 \\
\hline 29 & .666666 & 0.000000 & 2.050000 & $.000 \mathrm{C}$ & .000 & .00000 & .0000 & .50000 \\
\hline 30 & .666666 & 0.000000 & 2.050000 & .0000 & .000 & .00000 & .0000 & .50000 \\
\hline 31 & .666666 & 0.000000 & 2.050000 & .0000 & .000 & .00000 & .0000 & - 50000 \\
\hline 32 & .666666 & 0.000000 & 2.050000 & .0000 & .000 & .00000 & .0000 & .50000 \\
\hline 33 & . 666666 & 0.000000 & 2.050000 & .0000 & .000 & .00000 & .0000 & .25000 \\
\hline 34 & . 666666 & 0.0000 & 2.050000 & .0000 & .000 & .00000 & .0000 & .25000 \\
\hline 35 & .666666 & $0.6 \cup 0000$ & 2.050000 & .0000 & .000 & .00000 & .0000 & .25000 \\
\hline 36 & . 666666 & 0.000000 & 2.050000 & .0000 & .000 & .00000 & .0 .000 & .25000 \\
\hline 37 & . 666666 & 0.000000 & 2.050000 & .0000 & .000 & .00000 & $.0000^{\circ}$ & .25000 \\
\hline 38 & .666666 & 0.000000 & 2.050000 & .0000 & .000 & .00000 & .0000 & .25000 \\
\hline 39 & .6666666 & 0.000000 & 2.050000 & .0000 & .000 & .00000 & .0000 & .25000 \\
\hline 40 & .666666 & 0.000000 & 2.050000 & .0000 & .000 & .00000 & .0000 & .25000 \\
\hline
\end{tabular}




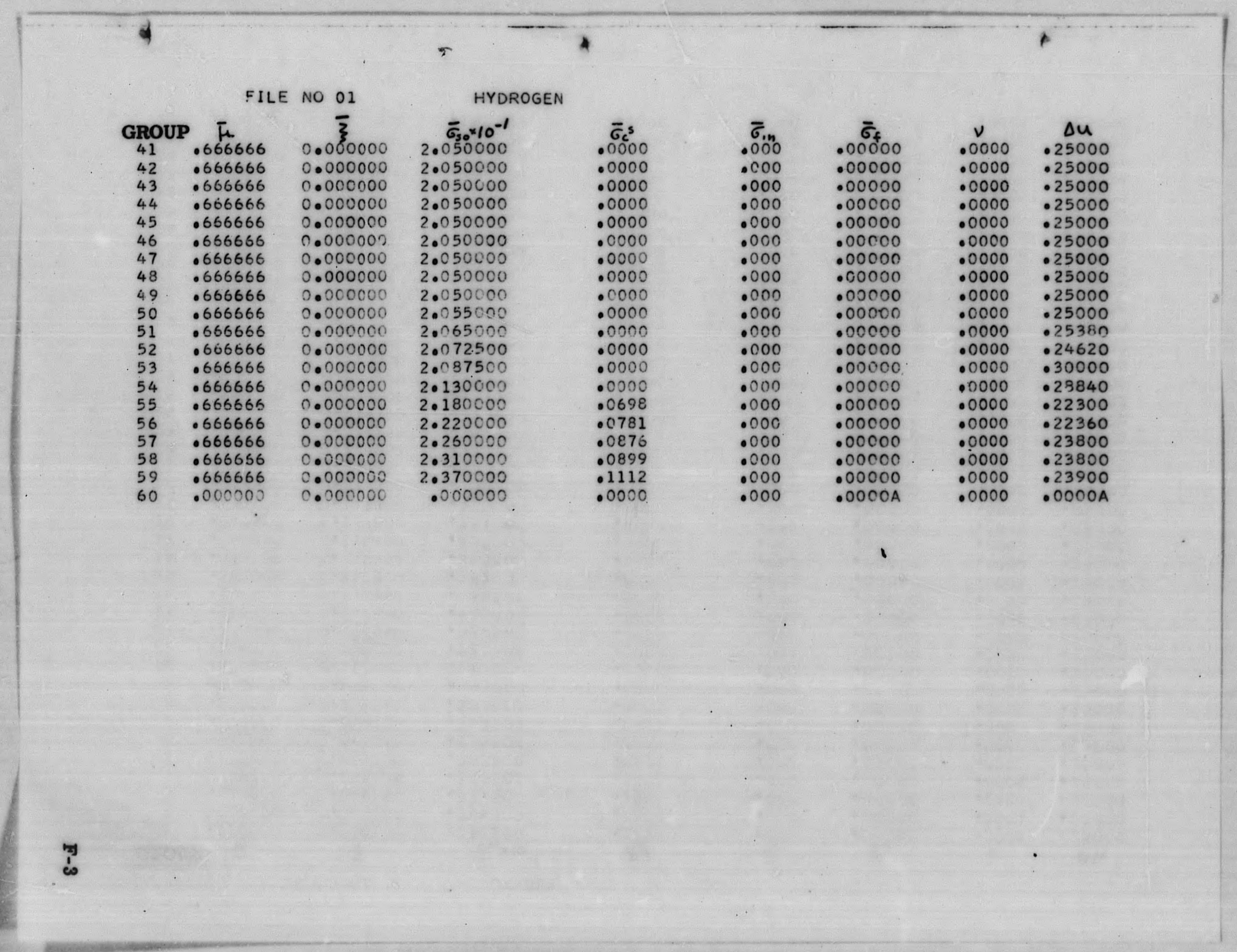




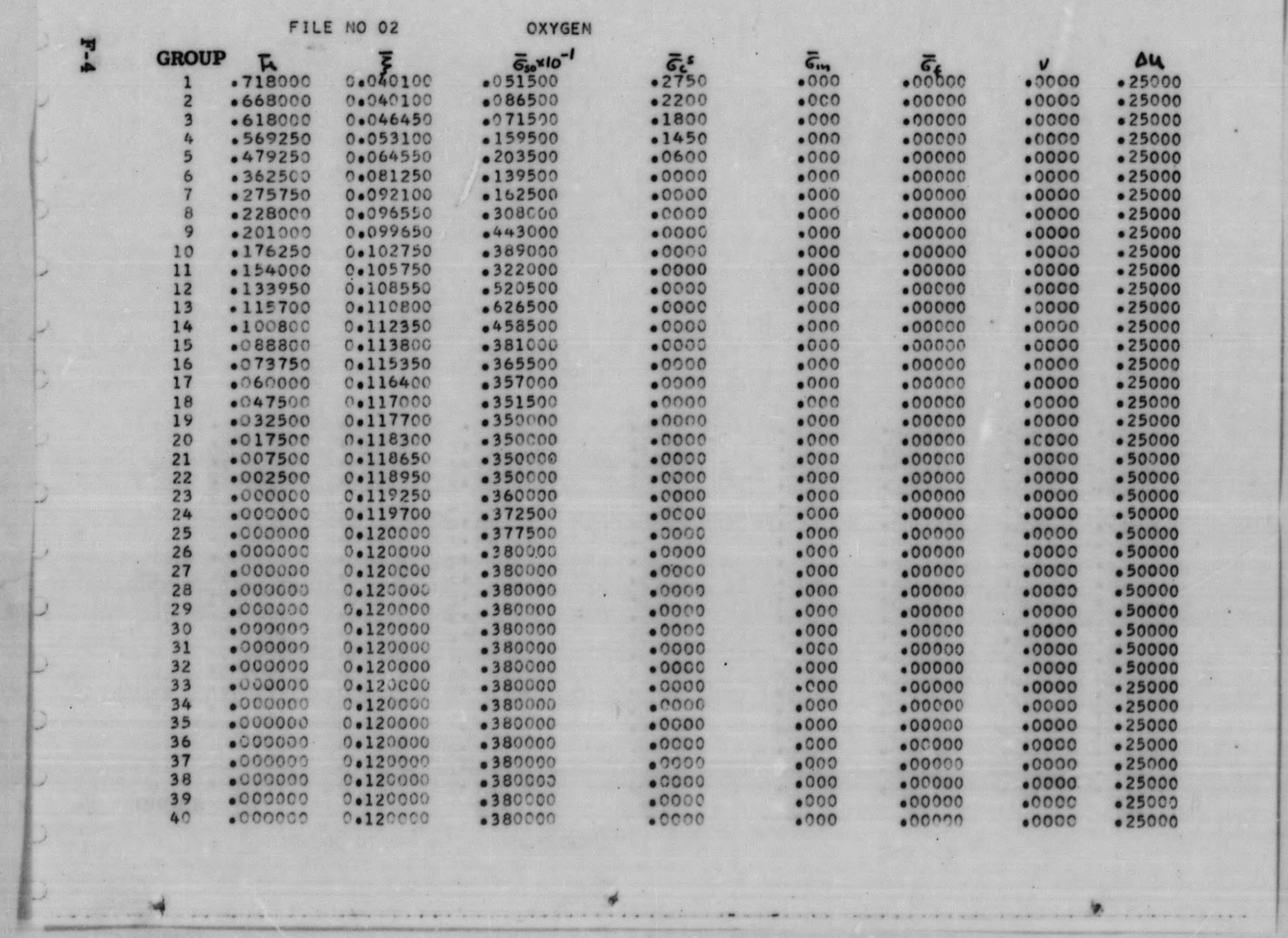




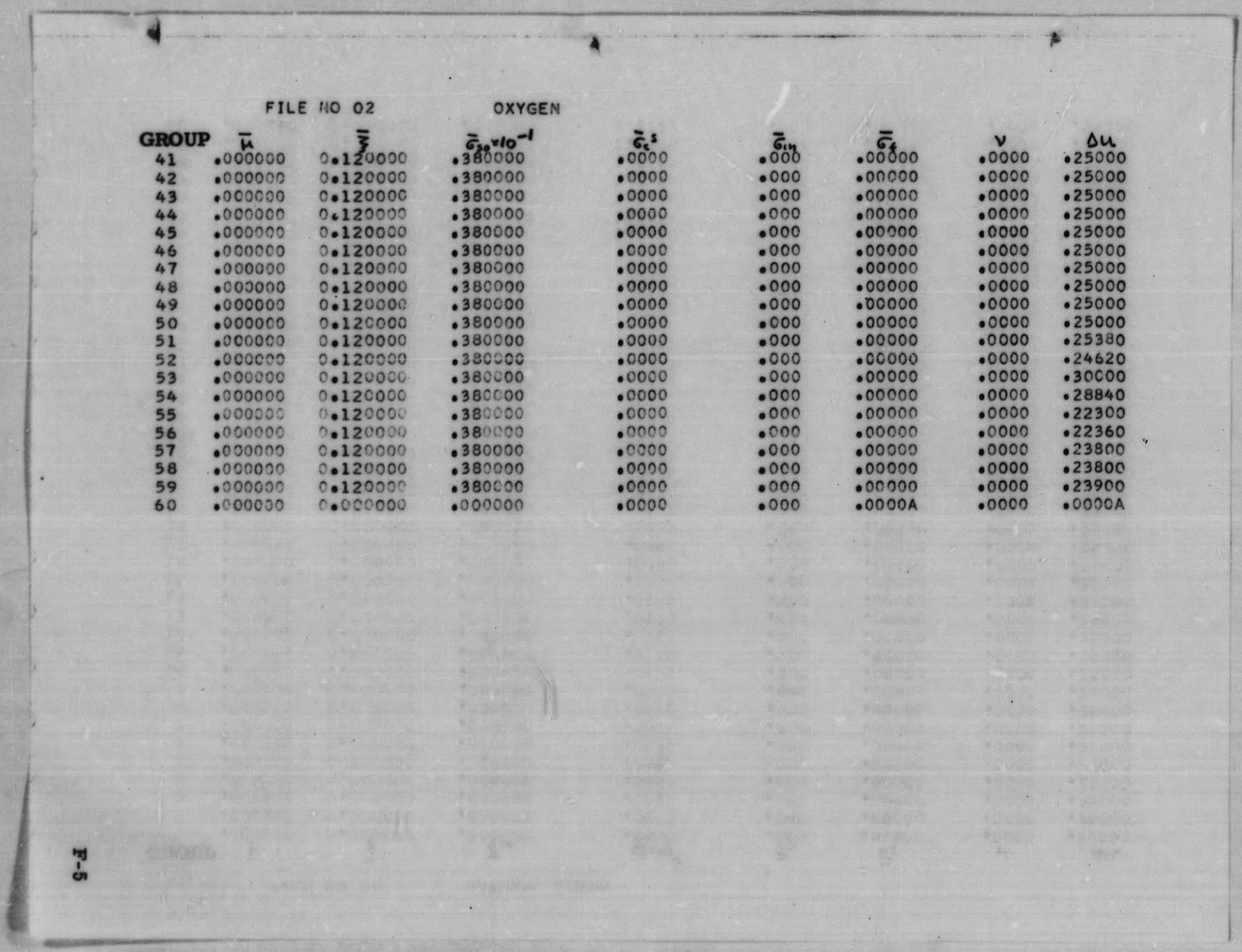


FILE NO ${ }_{4}$ NATURAL BORON

!. GROUP

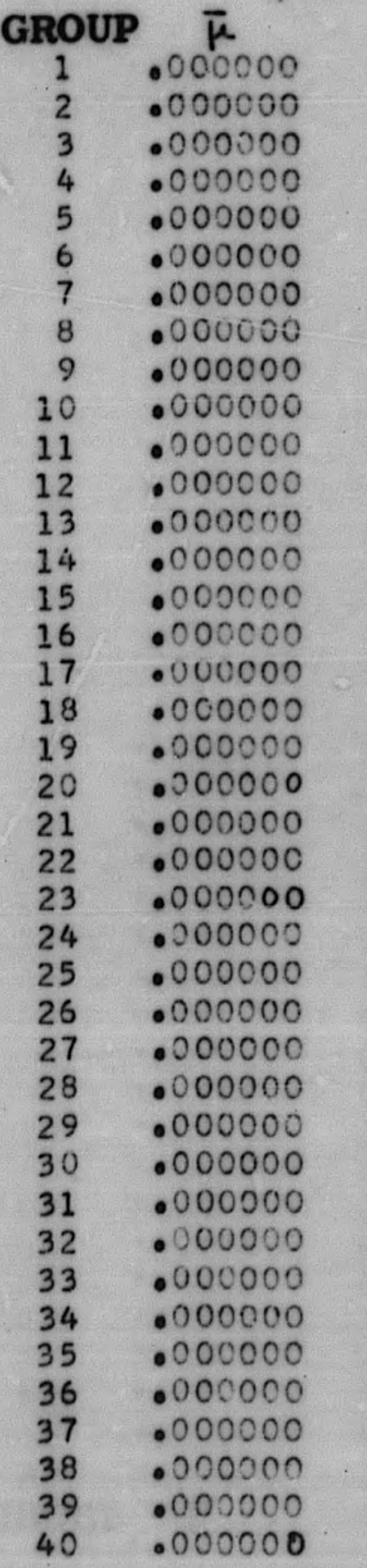

0.000000

0.000900

0.0000000
0.000000
0.000000

0.000000
0.000000

0.0000000

0.000000

0.000000

0.000000

0.000020

0.000000

0.000000

0.000000

.00000

.

$.00000 \mathrm{C}$

0.000000

.000000

0.000000

0.000000

0.000000

0.000000

0.000000

0.000000

0.000000

0.000000

0.000000

0.000000

0.000000

0.000000

0.000000
0.000000

0.000000

0.000000

0.000000
$.00 \overline{\sigma_{3}} 0$

.000000

.000000

.000000

.000000

.000000

.000000

.000000

- 0000

- 00000

- 000000

.000000

.000000

.000000

.0000000

.000000

.000000

.005000

.0000000

.000000

.000000

.000000

.020000

.000000

.000000

.000000

- 000050

- 00000

.000000

.000000

.000000

.000000

.000000 $\overline{6} 5 \times 10^{-1}$

.0005

.0051

.0058

.0066

.0074

.0084

.0096

.0109

.0123

.0139

.0158

.0179

.0203

.0261

.0261

.0296
.0335

.0335
.0382

.0382

.0431

.0516

.0663

.1095

.1405

.1816

.2333

.2333
.2979

.3822

.4902

.6300

.8090

.9813

1.1128

1.2616

1.4294

1.6190

1.6190
1.8345
2.0786
2.03547

2.0786
2.3547
$.0 \bar{\sigma}_{4}$

.00000

.00000

.00000

.00000

.00000

.000000

.00000

.00000

.00000

.000000

.00000

.00000

.00000

.00000

.00000

.00000

.00000

.00000

.00000

.00000

.00000

.00000

.00000

.00000

.00000

.00000

.00000

.00000

.00000

.00000

.00000

.00000

.00000

.00000

.00000

.00000
.0000

$.0000 \quad .25000$

.25000

.25000

$.0000 \quad .25000$

$.0000 \quad .25000$

.25000

$.0000 \quad 25000$

$.0000 \quad .25000$

$.0000 \quad .25000$

$.0000 \quad .25000$

$.0000 \quad .25000$

$.0000 \quad .50000$

$.0000 \quad .50000$

$.0000 \quad .50000$

$.0000 \quad .50000$

$.00000 \quad .50000$

$.0000 \quad .50000$

$.0000 \quad .50000$

$.0000 \quad .50000$

$.0000 \quad .25000$

$.0000 \quad .25000$

$.0000 \quad .25000$

$.0000 \quad .25000$

$.0000 \quad .25000$

.0000
.0000
.250000 


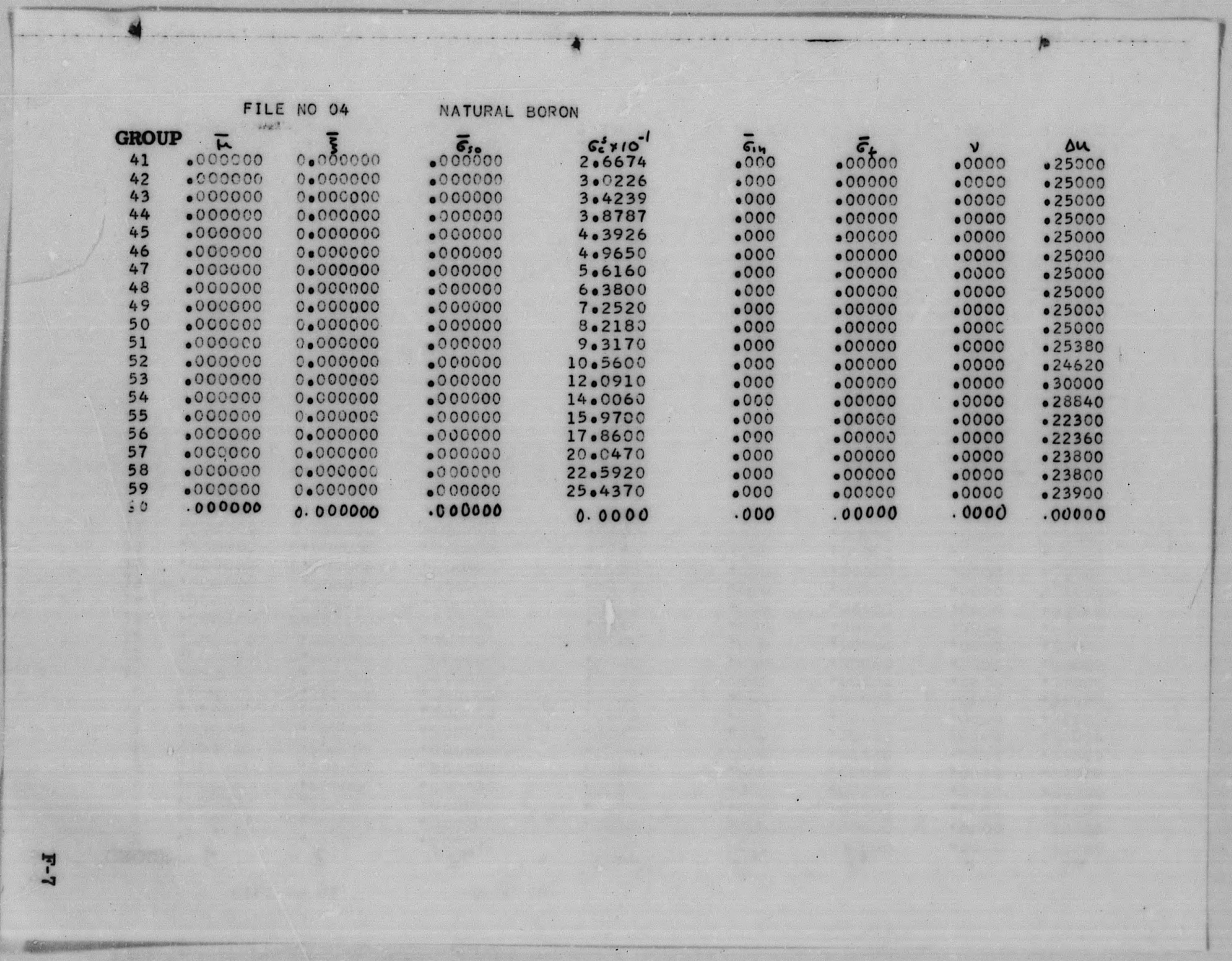


70 FILE NO 05 BORON 10

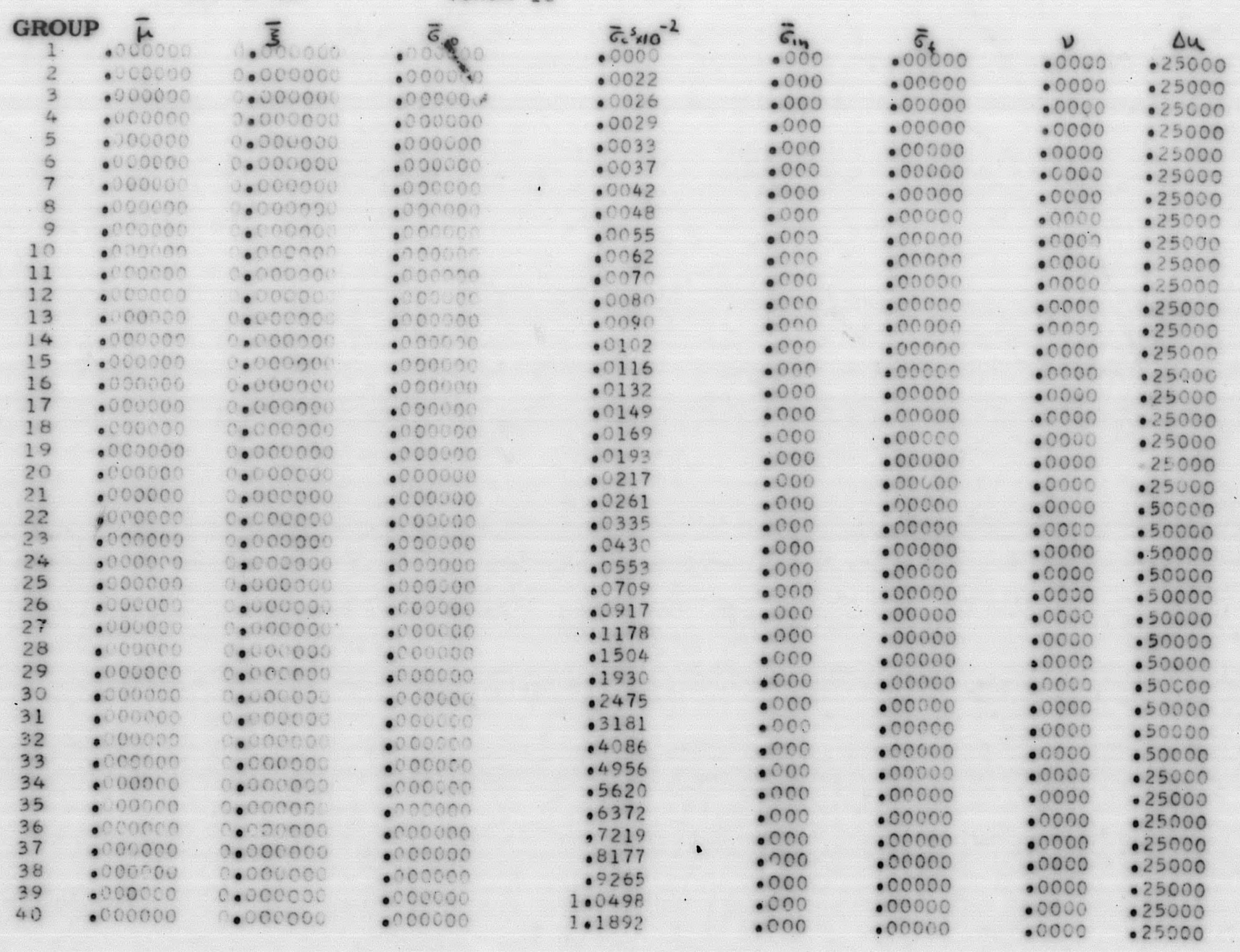




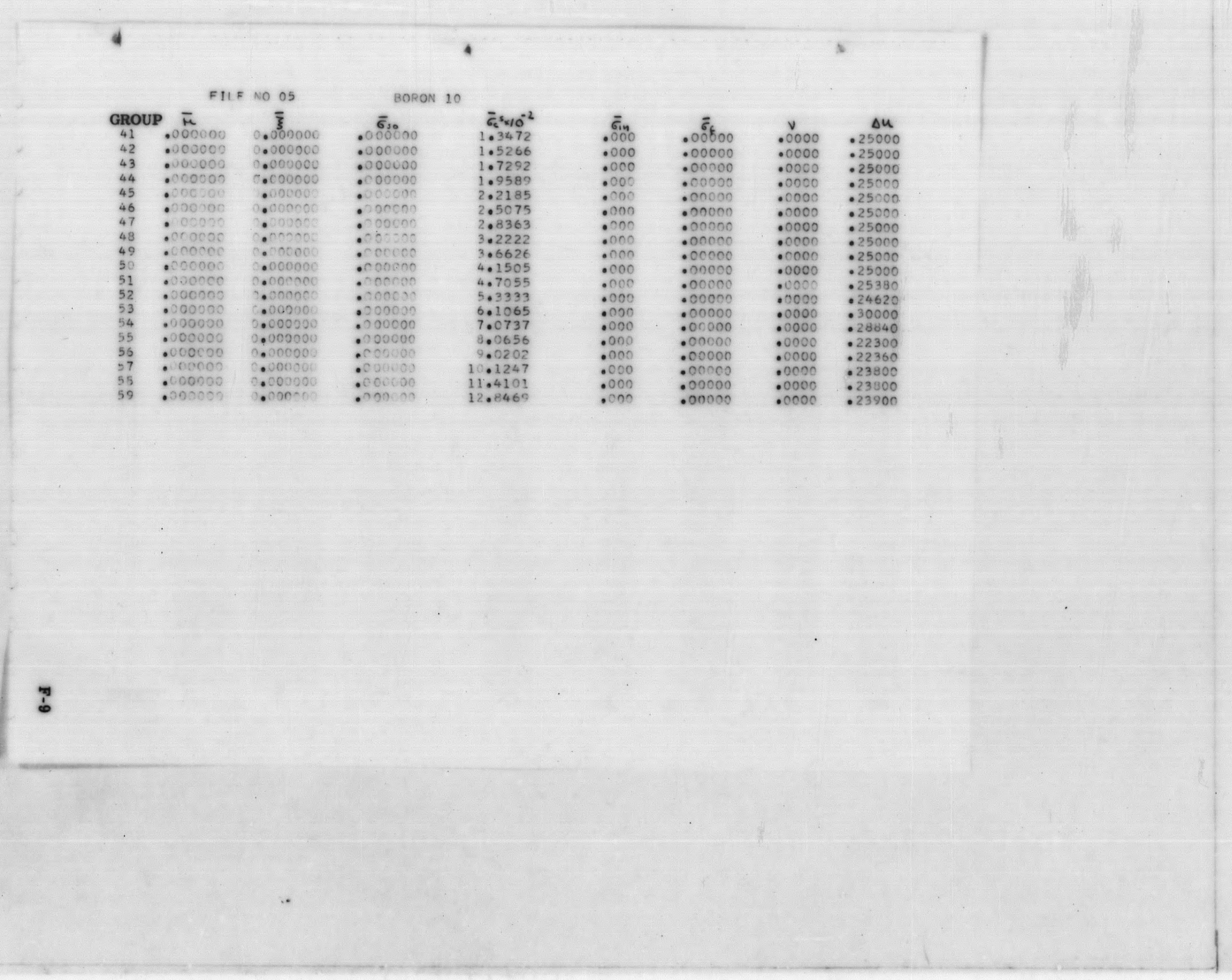




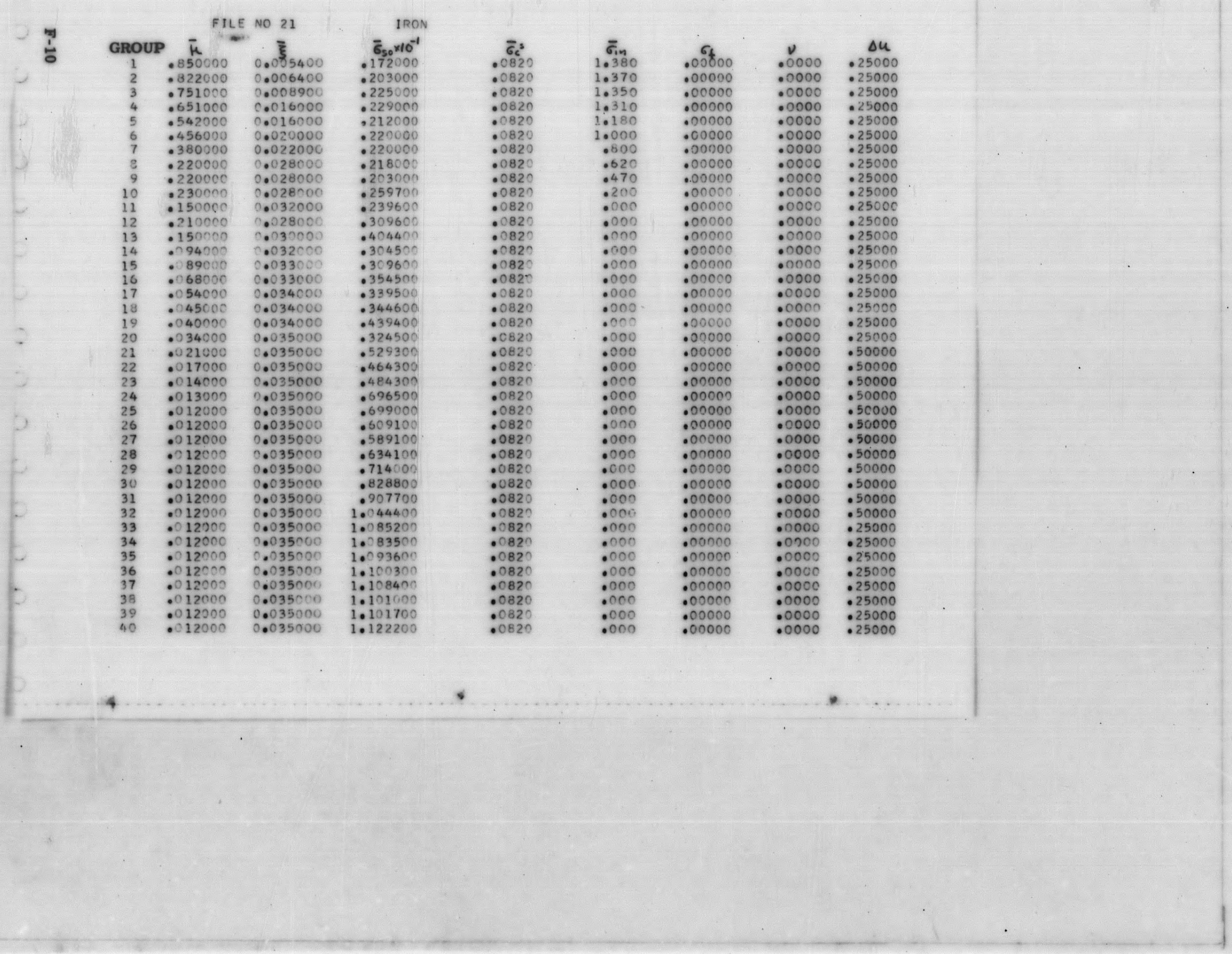




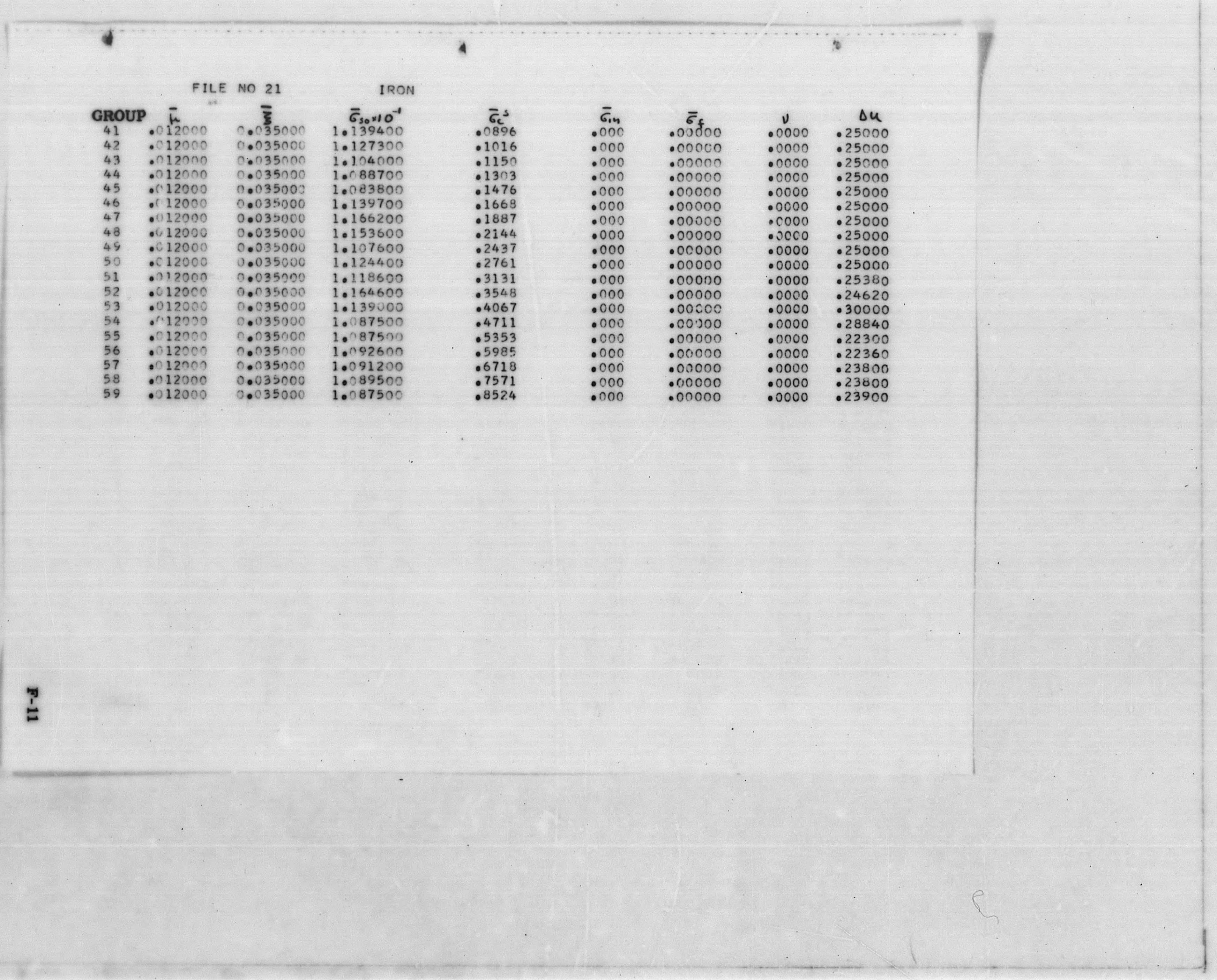




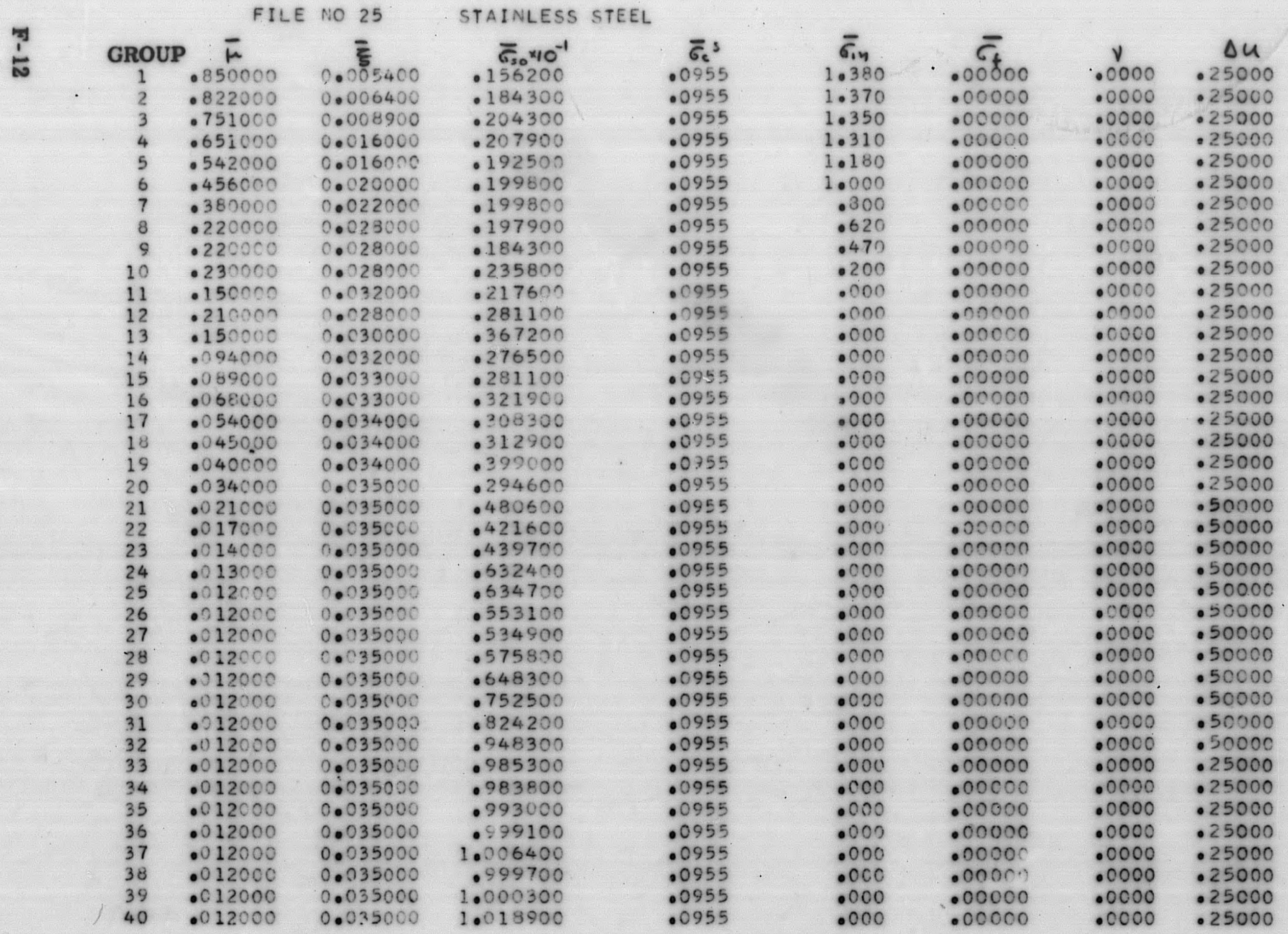

$4 \ldots \ldots \ldots+\ldots \ldots$ 
4

\begin{tabular}{|c|c|c|}
\hline \multicolumn{3}{|c|}{ FILE NO 25} \\
\hline GROUP & & $\bar{\xi}$ \\
\hline 41 & .012000 & 0.035 \\
\hline 42 & .012000 & 0.0350 \\
\hline 43 & .012000 & I \\
\hline 44 & .012000 & \\
\hline 45 & .012000 & 50 \\
\hline 46 & .012000 & \\
\hline 47 & .012000 & \\
\hline 48 & .012000 & \\
\hline 49 & .012000 & \\
\hline 50 & - 012000 & \\
\hline 51. & - 12000 & \\
\hline 52. & . 012000 & 0.0350 \\
\hline 53 & . 012000 & \\
\hline 54 & - 12000 & \\
\hline 55 & - 12000 & \\
\hline 56 & - 12000 & \\
\hline 57 & . 012000 & \\
\hline 58 & - 12000 & \\
\hline 59 & . 12000 & \\
\hline 60 & & \\
\hline
\end{tabular}

STAINLESS STEEL

$\overline{6}_{s 0} \times 10^{-1}$

1.034600

1.023600

. 988500

.984500

.034800

1.47400

1. 05700

1.020900

1. 15700

1.057405

. 034200

-987400

- 987400

-992100

-990800

.987400

$\because 987400$

$\begin{array}{cc}\bar{\sigma}_{c}^{s} & \bar{\sigma}_{\text {in }} \\ .1044 & .000 \\ .11184 & .000 \\ .1340 & .000 \\ .1518 & .000 \\ .1720 & .000 \\ .1943 & .000 \\ .2199 & .000 \\ .2498 & .000 \\ .2839 & .000 \\ .3217 & .000 \\ .3648 & .000 \\ .4134 & .000 \\ .4738 & .000 \\ .5499 & .000 \\ .6237 & .000 \\ .6973 & .000 \\ .7827 & .000 \\ .8821 & : 000 \\ .9931 & : 000 \\ .0000 & .000\end{array}$

$\bar{\sigma}_{f}$

$\nu$
.0000

.25000

$.00000 \quad .0000 \quad .25000$

$.00000 \quad .0000 \cdot .25000$

$.00000 \quad .0000 \quad .25000$

$.00000 \quad .0000 \quad .25000$

$.00000 \quad .0000 \quad .25000$

$.00000 \quad .0000 \quad .25000$

$.00000 \quad .0000 \quad .25000$

$.00000 \quad .0000 \quad .25000$

$.00000 \quad .0000 \quad .25000$

$.00000 \quad .0000 \quad .25380$

$.00000 \quad .0000 \quad .24620$

$.00000 \quad .0000 \quad .30000$

$.00000 \quad .0000 \quad .28840$

$.00000 \quad .0000 \quad .22300$

$\begin{array}{lll}.00000 & .0000 \quad .22360\end{array}$

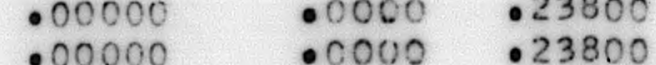

$.00000 \quad .0000 \quad .23900$ 


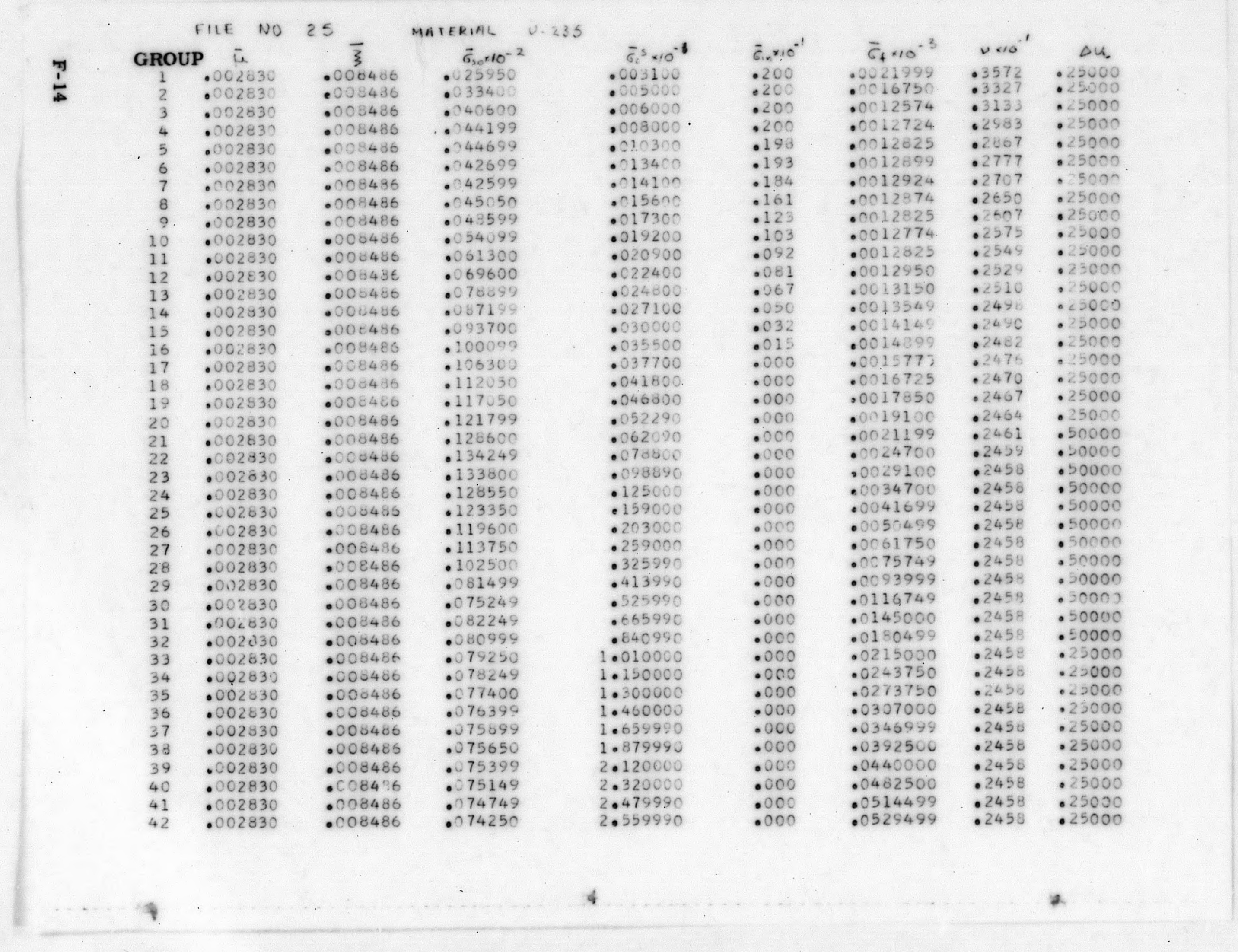




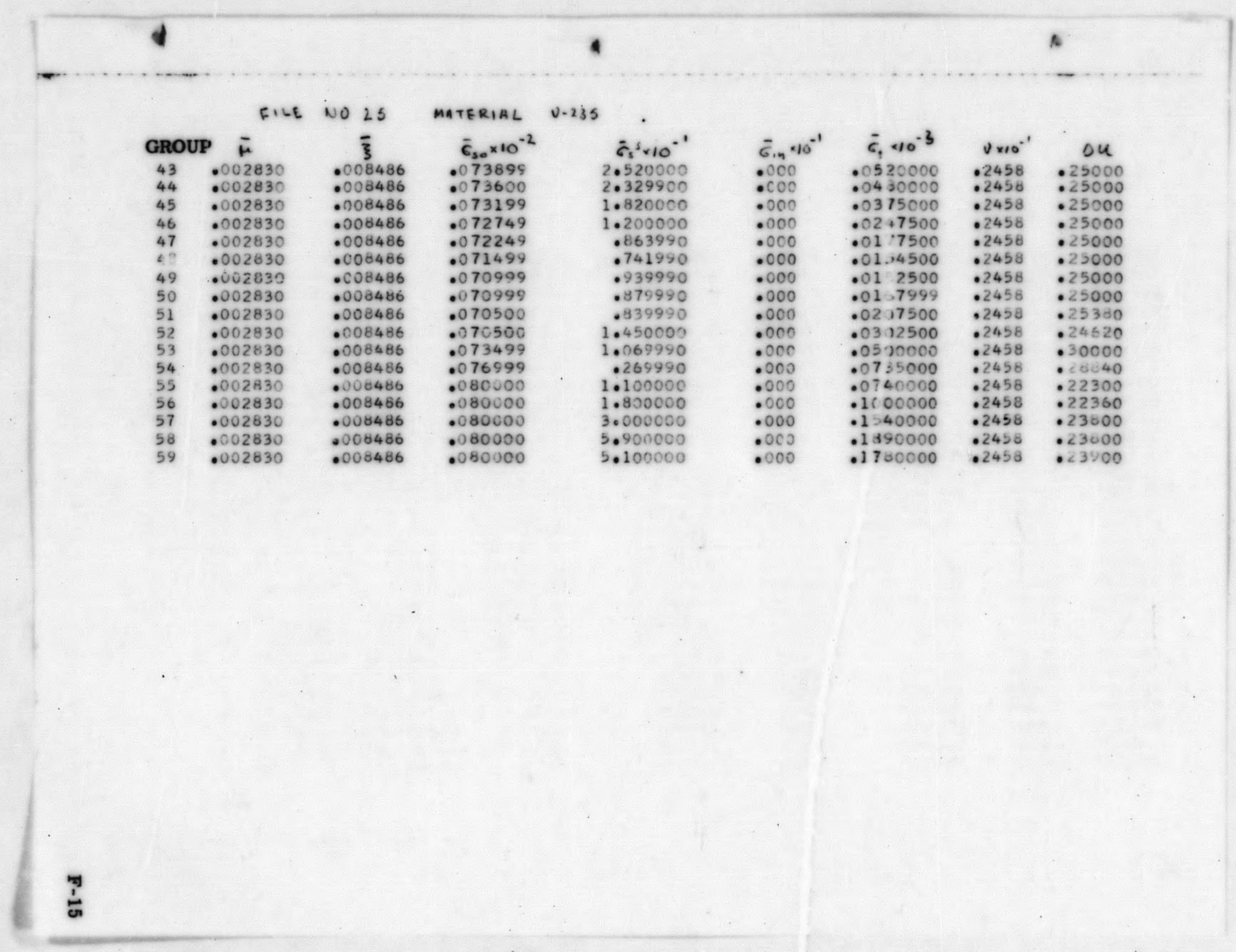




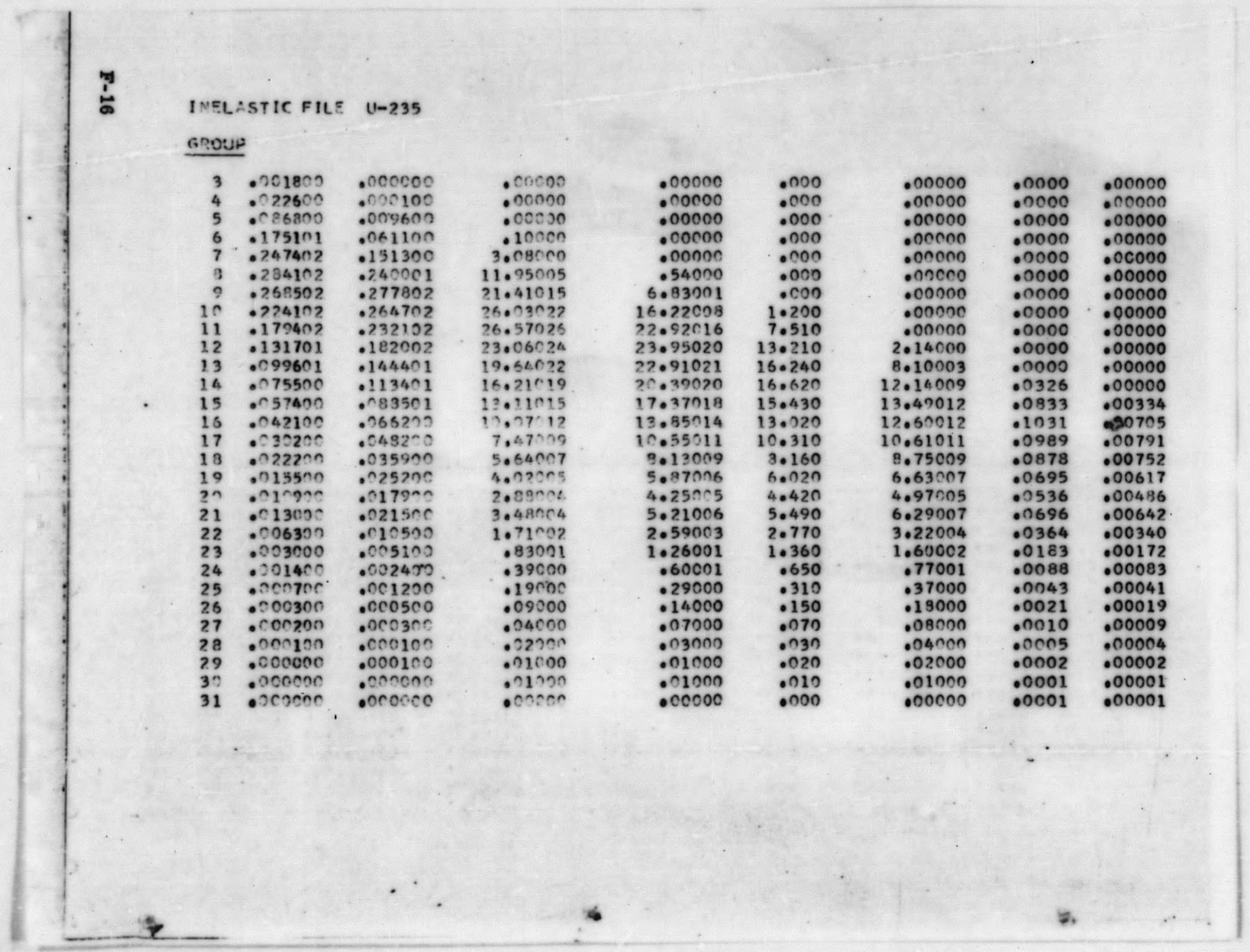




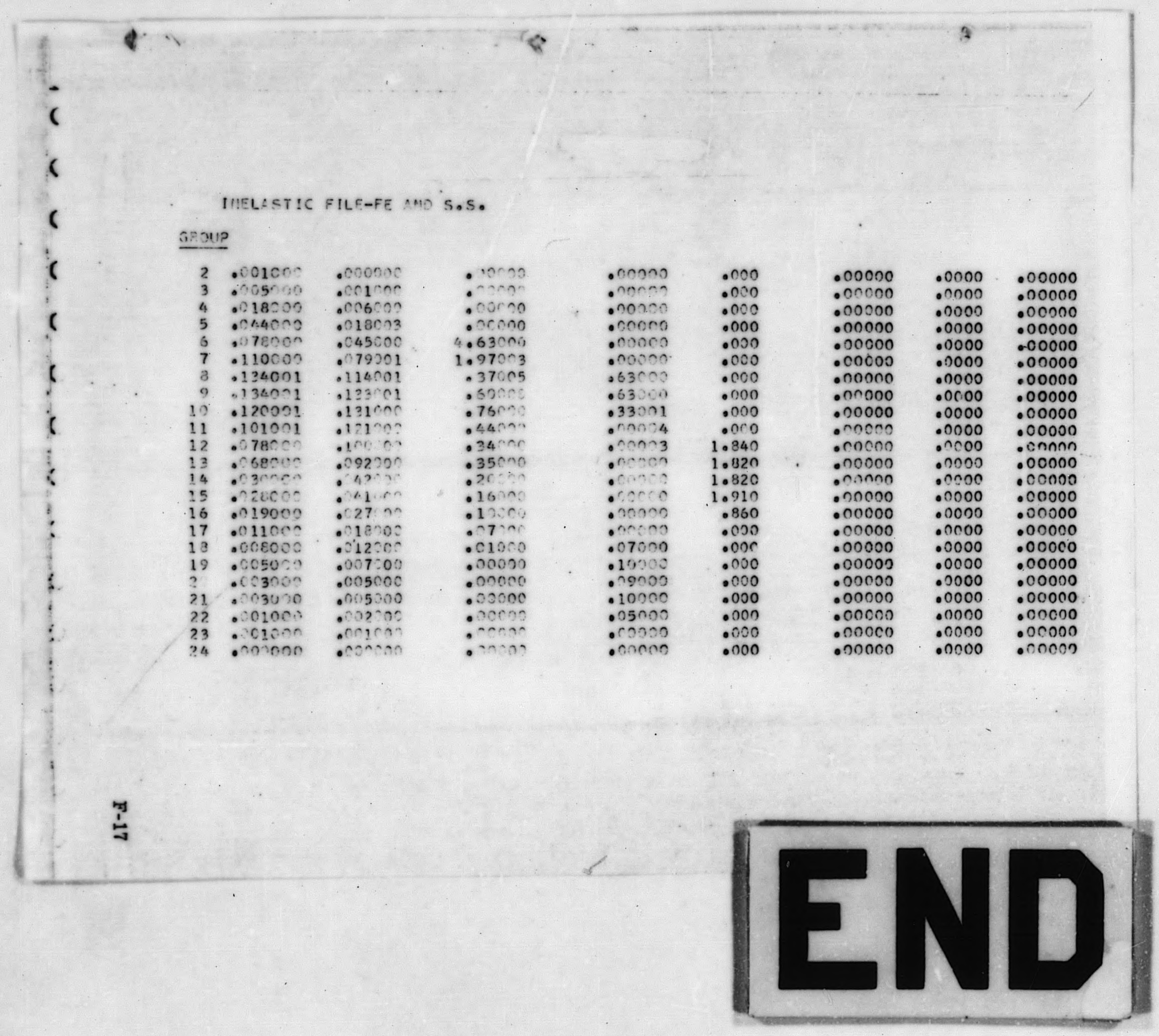

